DAVID FERNANDES NEVES OLIVEIRA

INTERPRETABILIDADE DE MODELOS DE APRENDIZADO PROFUNDO APLICADOS AO DIAGNÓSTICO E PROGNÓSTICO NÃO SUPERVISIONADO DE FALHAS

São Paulo 


\title{
INTERPRETABILIDADE DE MODELOS DE APRENDIZADO PROFUNDO APLICADOS AO DIAGNÓSTICO E PROGNÓSTICO NÃO SUPERVISIONADO DE FALHAS
}

\section{Versão Revisada}

\author{
Dissertação apresentada à Escola \\ Politécnica da Universidade de São Paulo \\ para obtenção do título de Mestre em \\ Ciências \\ Área de Concentração: \\ Engenharia de Computação
}

Orientador:

Prof. Dr. Jorge Rady de Almeida Junior. 
Autorizo a reprodução e divulgação total ou parcial deste trabalho, por qualquer meio convencional ou eletrônico, para fins de estudo e pesquisa, desde que citada a fonte.

Este exemplar foi revisado e corrigido em relação à versão original, sob responsabilidade única do autor e com a anuência de seu orientador.

São Paulo, de de

Assinatura do autor:

Assinatura do orientador:

Catalogação-na-publicação

Oliveira, David F. N

NTERPRETABILIDADE DE MODELOS DE APRENDIZADO

PROFUNDO APLICADOS AO DIAGNÓSTICO E PROGNÓSTICO NÃO SUPERVISIONADO DE FALHAS / D. F. N. Oliveira -- versão corr. -- São Paulo, 2020.

$161 \mathrm{p}$.

Dissertação (Mestrado) - Escola Politécnica da Universidade de São Paulo. Departamento de Engenharia de Computação e Sistemas Digitais.

1.confiabilidade 2.aprendizado de máquina 3.diagnóstico 4.prognóstico 5.manutenção baseada em condição I.Universidade de São Paulo. Escola Politécnica. Departamento de Engenharia de Computação e Sistemas Digitais II.t. 
Dedico este trabalho à Marinalva Rita Fernandes Neves, in memoriam. 


\section{AGRADECIMENTOS}

Gostaria de agradecer:

- À Deus

- Á minha amada mãe Marinalva, a quem é para mim o grande exemplo de integridade, generosidade, dedicação e sabedoria.

- Ao meu querido irmão Daniel, a quem tenho grande admiração. Obrigado por todo apoio e parceria incondicional

- Aos grandes amigos que a vida me deu: Luiz Ricardo Claus, Pedro Fagundes, Felipe Vilarinho, Marcus Eloi, Raphael Marques e Thaís Maia

- Ao professor Jorge Rady, a quem tenho grande admiração. Sou muito grato por me aceitar como seu aluno, bem como pela valiosa mentoria e paciência durante toda essa jornada.

- Aos professores Paulo Cugnasca e João Batista, pelo grande apoio e serem sempre tão solícitos.

- À VALE S.A, pelo suporte financeiro e institucional que viabilizou esta pesquisa - Acordo de Cooperação Científica e Tecnológica no 4600043577.

- Aos pesquisadores Lúcio Vismari, Alexandre Nascimento e Macílio Ferreira pelas valiosas horas de discussões, que contribuíram significativamente para este trabalho.

- À toda a equipe do Grupo de Análise e Segurança (GAS) pelo ótimo convívio. 
"Anunciai-nos as coisas que ainda hão de vir, para que saibamos que sois deuses ..."

(Isaías 41:23) 


\section{RESUMO}

O diagnóstico de falhas representa uma tarefa importante de equipes de manutenção operacional, tendo como foco a tarefa de identificar as causas de problemas em equipamentos que possam levar a desvios no comportamento esperado, bem como à redução da eficiência prevista. A aplicação de técnicas de detecção e diagnóstico associadas a métodos preditivos, comumente conhecida por prognóstico, possibilita um planejamento mais preciso e adequado para tratar eventos inesperados que possam colocar em risco o funcionamento do sistema sob estudo. Por meio de uma identificação antecipada e detalhada de possíveis causas e ameaças, as equipes de manutenção podem se mobilizar de forma mais apropriada, planejada e assertiva, para tratar situações indesejadas, antes que elas realmente ocorram, favorecendo uma maior confiabilidade do sistema e, consequentemente, evitando interrupções inesperadas do serviço, reduzindo a possibilidade de perdas materiais e humanas. Diversas técnicas têm sido sugeridas na literatura para endereçar questões sobre prognósticos de falhas, com grande destaque para os métodos baseados em deep learning. Tais métodos são considerados como possuindo características denominadas "caixa-preta", por não proverem meios que expliquem os resultados obtidos, dificultando a adoção de decisões embasadas e confiáveis. Dessa forma, esta pesquisa propõe um método não supervisionado para diagnóstico e prognóstico de falhas, tendo como base técnicas de deep learning, que propiciem meios para atestar e contribuir para robustez dos resultados obtidos, promovendo maior confiança e assertividade na previsão e identificação de possíveis problemas. No estudo de caso são consideradas medições físicas reais de parâmetros de rodas e rolamentos de vagões ferroviários de transporte de carga pesada, capturadas a partir de múltiplos sensores de via acopladas em pontos específicos de uma estrada de ferro no Brasil. São propostos meios que enderecem restrições na modelagem com dados e que atestem a razoabilidade das predições realizadas.

Palavras-chave: prognóstico, diagnóstico, confiabilidade, manutenção baseada em condição, aprendizado de máquina 


\begin{abstract}
Failure diagnosis represents an important task for operational maintenance teams, focusing on the task of identifying the causes of equipment problems that can lead to deviations in expected behavior, as well as reducing expected efficiency. The application of detection and diagnostic techniques associated with predictive methods, commonly known as prognosis, enables a more accurate and adequate planning to deal with unexpected events that may put the system under study at risk. Through an early and detailed identification of possible causes and threats, maintenance teams can mobilize themselves in a more appropriate, planned and assertive manner, to deal with unwanted situations, before they actually occur, favoring greater system reliability and, consequently, avoiding unexpected service interruptions, reducing the possibility of material and human losses. Several techniques have been suggested in the literature to address questions about failure prognosis, with great emphasis on methods based on deep learning. Such methods are considered to have characteristics called "black box", as they do not provide the means to explain the results obtained, making it difficult to adopt informed and reliable decisions. Thus, this research proposes an unsupervised method for the diagnosis and prognosis of failures, based on deep learning techniques, which provide means to attest and contribute to the robustness of the results obtained, promoting greater confidence and assertiveness in the prediction and identification of possible problems. In the case study, real physical measurements of parameters of wheels and bearings of railroad cars carrying heavy loads are considered, captured from multiple track sensors coupled at specific points in a Brazilian railroad. Means are proposed that address restrictions in modeling with data and that attest to the reasonableness of the predictions made.
\end{abstract}

Keyword: prognosis, diagnosis, reliability, condition-based maintenance, machine learning 


\section{LISTA DE FIGURAS}

FIGURA 1 - DEMANDA MUNDIAL EM OPERAÇÕES FERROVIÁRIAS 18

FIGURA 2 - CUSTOS ATRELADOS A UM TREM DURANTE SEU CICLO DE VIDA 19

Figura 3 - EXeMPLo de Rede MLP E VISÃo de UM PERCEPTRON 30

FIGURA 4 - ARQUITETURA PADRÃO DE UMA REDE AUTOENCODER 32

FIGURA 5 - FORMATOS DE ENTRADAS E SAÍDAS EM REDES RECORRENTES. 33

FIGURA 6 - FUNÇÃO DE ATIVAÇÃO DE REDES RNN 34

FIGURA 7- FORMATOS DE ENTRADAS E SAÍDAS EM REDES RECORRENTES. 35

FIGURA 8- REDE LSTM 36

FIGURA 9 - REDE LSTM-AE TREINADA PARA RECONSTRUIR SÉRIES TEMPORAIS. 37

FIGURA 10 - REDE LSTM-AE TREINADA PARA PREDIÇÃO DE COMPORTAMENTOS FUTUROS 38

FIGURA 11 - INTERPRETAÇÃo POR RANQUEAMENTO DE PARÂMETROS (A) E REGIÕES DA $\operatorname{IMAGEM}(B)$. 43

FIGURA 12 - TAXONOMIA DE NÍVEIS DE AVALIAÇÃO PARA INTERPRETABILIDADE ....... 46

FIGURA 13-ESTADOS E EVENTOS EM UM SISTEMA (VISÃO DE LAPRIE).................. 50

FIGURA 14 - Estados E EVENTOS DE UM SISTEMA (VISÃo DE ISERMANN)............... 51

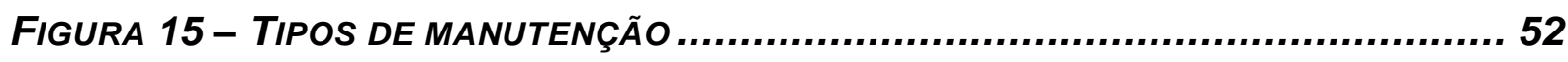

FIGURA 16 - PROCESSO DE MANUTENÇÃO BASEADA EM CONDIÇÃO ....................... 55

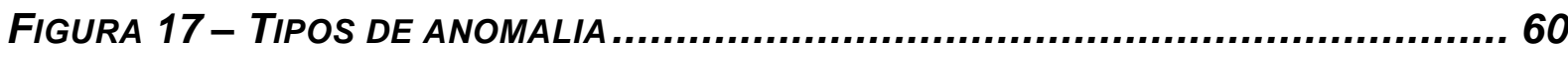

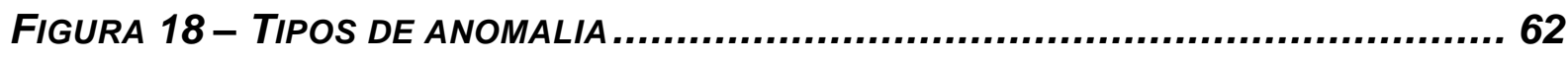


FIGURA 19 - EXEMPLO DE DETECÇÃO USANDO ISOLATION FOREST 63

FIGURA 20 - MÉTODO GENÉRICO DE DETECÇÃo BASEADA RECONSTRUÇÃO 64

FIGURA 21 - MATRIX DE CONFUSÃO. 65

FIGURA 22 - TIPOS DE DIAGNÓSTICO. 67

Figura 23 - Formação de Clusters de FalHa 70

Figura 24-Metodologia 83

FIGURA 25 - ETAPAS DE PREPARAÇÃO DOS DADOS 84

FIGURA 26 - DIAGRAMA DE SISTEMA GENÉRICO DE DETECÇÃO DE FALHAS EQUIPADO СOM $R X P$. 86

FIGURA 27 - PASSOS PARA TREINAR REDE LSTM-AE PARA PREVISÃO DE FALHAS FUTURAS 90

Figura 28 - Estrada de FERRo Vitória À Minas (EFVM) 95

FIGURA 29 - PAINEL DE CONTROLE DO CCO - EFVM 96

Figura 30 - Estrutura dE UM VAGÃo. 100

FIGURA 31 - ROLAMENTO COM ROLETE CONNICO 102

FIGURA 32 - GEOMETRIA DO PERFIL DE UMA RODA DE VAGÃO 103

FIGURA 33 - ETAPAS DE PREPARAÇÃO DOS DADOS 106

FIGURA 34 - EXEMPLO dE CODIFICAÇÃO DE DADOS CATEGÓRICOS PARA CAMPOS NUMÉRICOS 107

FIGURA 35 - HISTOGRAMA DOS ERROS RESIDUAIS SOBRE AMOSTRA DE TESTE. 115

FIGURA 36 - AMOSTRA DE ERROS RESIDUAIS SOBRE TESTE 116 
FIGURA 37 - DADOS REDUZIDOS POR UM ENCODER COM SAÍDA DE 2 DIMENSÕES.....117

FIGURA 38 - INTERPRETAÇÃO DE RESULTADOS SOBRE A AMOSTRA 295 120

FIGURA 39 - REGIÕES DE ANÁLISE SOBRE FALSOS NEGATIVOS E VERDADEIROS POSITIVOS 122

FIGURA 40 - VARIÂNCIA DAS INTERPRETAÇÕES SOBRE TESTES REPETIDOS SOBRE A REGIÃO 1 DOS VERDADEIROS POSITIVOS 124

FIGURA 41 - VISUALIZAÇÃO DE AMOSTRAS COM DIMENSÃO REDUZIDA 125

FIGURA 42 - VISUALIZAÇÃO DE AMOSTRAS COM DIMENSÃO REDUZIDA 126

FIGURA 43 - VARIÂNCIA DAS INTERPRETAÇÕES SOBRE TESTES REPETIDOS EM DIFERENTES FAIXAS DE RESIDUAIS 127

FIGURA 44 - ANÁLISE DE RELEVÂNCIA DE PARÂMETROS SOBRE FALSOS POSITIVOS.129

Figura 45 - Percentual de amostras com parÂMEtro maIS RELEVANTE NÃo AUXILIAR. 130

FIGURA 46 - ANÁLISE dE RELEVÂNCIA DE PARÂMETROS SOBRE FALSOS NEGATIVOS 131

Figura 47 - PESO ATRIBUído SOBRE O PARÂMETRO MAIS RELEVANTE. 132

FIGURA 48 - PADRÕES DE MEDIÇÕES SOBRE A SÉRIE TEMPORAL EM DIFERENTES SITUAÇÕES 139

FIGURA 49 - PADRÕES DE VARIÂNCIA DA RELEVÂNCIA OBTIDOS PELO RXP SOBRE AS ESTIMATIVAS. 141

FIGURA 50 - MÉdIA DE PESO do PARÂMETRO MAIS RELEVANTE OBTIDO PELO RXP SOBRE OS GRUPOS DE CONTROLE. 142 


\section{LISTA DE TABELAS}

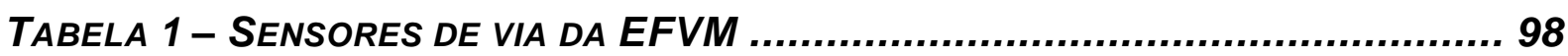

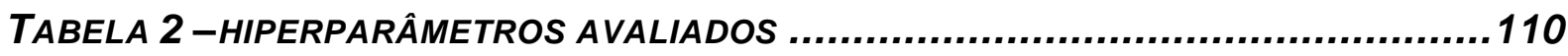

TABELA 3 - SUMÁRIO DOS IMPACTOS DOS HIPERPARÂMETROS ............................112

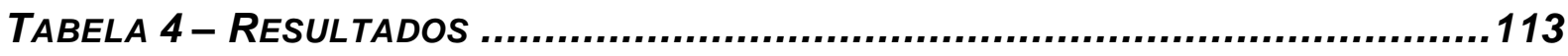

TABELA 5 - RESULTADOS EXPERIMENTAIS (RXP, SHAP1, SHAP2 E SHAP3) ......121

TABELA 6 - DESEMPENHO SOBRE REGIÕES RESIDUAIS DIFERENTES EM EVENTOS DE FALHA. 123

TABELA 7 - MODELOS DE DETECÇÃO USADOS PARA AVALIAR GANHO DE DESEMPENHO COM RXP 133

TABELA 8 - GANHO DE DESEMPENHO EM DETECÇÃO USANDO RXP 134

TABELA 9-CONJUNTOS DE DADOS DE TREINAMENTOS PARA PREDIÇÃO DE FALHAS.136

TABELA 10 - RESULTADOS DE PREDIÇÕES DE FALHAS SOBRE OS DIFERENTES AMOSTRAGENS. 137

TABELA 11 - RESULTADOS EXPERIMENTAIS RXP SOBRE AS PREDIÇÕES DE FALHAS 140 


\section{LISTA DE ABREVIATURAS E SIGLAS}

$\begin{array}{ll}\text { AE } & \text { Autoencoder } \\ \text { BTT } & \text { Backpropagation Through Time } \\ \text { DBN } & \text { Deep Belief Networks } \\ \text { DBSCAN } & \text { Density Based Spatial Clustering } \\ \text { DR } & \text { Dimensionality Reduction } \\ \text { HBW } & \text { Hot-Box and Wheel } \\ \text { HMM } & \text { Hidden Markov Model } \\ \text { LIME } & \text { Local Interpretable Model-agnostic Explanations } \\ \text { LSTM } & \text { Long Short-Term Memory } \\ \text { LSTM-AE } & \text { Long Short-Term Memory Autoencoder } \\ \text { MLP } & \text { Multi-Layer Perceptron } \\ \text { PCA } & \text { Principal Component Analysis } \\ \text { PHM } & \text { Proportional Hazards model } \\ \text { RB } & \text { Acoustic Bearing Detector } \\ \text { RBM } & \text { Restricted Boltzmann Machines } \\ \text { RUL } & \text { Remaining Useful Lifetime } \\ \text { SAE } & \text { Stacked Autoencoder } \\ \text { SDA } & \text { Stacked Denoising Autoencoder } \\ \text { SHAP } & \text { Shapley Addictive Explanations } \\ \text { SOM } & \text { Self-Organizing Maps } \\ \text { SVM } & \text { Support Vector Machines } \\ \text { VAE } & \text { Variational Autoencoder } \\ \text { WILD } & \text { Wheel Impact Load Detector } \\ \text { WSP } & \text { Wheelset Profile } \\ \text { XAI } & \text { Explanatory Artificial Intelligence } \\ & \end{array}$


1.1 MOTIVAÇÃO

1.1.1. Considerações sobre a Complexidade do Sistema .21

1.1.2. Considerações sobre a Disponibilidade de Anotações .22

1.1.3. Considerações sobre a Interpretabilidade dos Modelos .24

1.2 OBJETIVOS

1.3 JUSTIFICATIVA .26

1.4 ESTRUTURA DO TRABALHO .27

2 FUNDAMENTAÇÃO TEÓRICA .28

2.1 TÓPICOS SOBRE DEEP LEARNING .28

2.1.1 Definições Básicas .28

2.1.2 Redes Feedforward 29

2.1.3 Redes Recorrentes 32

2.2 INTERPRETABILIDADE DE MODELOS DE APRENDIZADO DE MÁQUINA .38

2.2.1 Conceitos e Atributos de Interpretabilidade 39

2.2.2 Tipos e Escopo de Técnicas 40

2.2.2.1 LIME 43

2.2.2.2 SHAP .44 
2.2.3 Formas de Avaliação da Interpretabilidade

2.3 CONCEITOS BÁSICOS DE DEPENDENDABILIDADE E MANUTENÇÃO BASEADAS EM CONDIÇÃO.

2.3.1 Dependabilidade e Confiabilidade ............................................. 48

2.3.2 Falha, Defeito e Disfunção ........................................................... 49

2.3.3 Manutenção Baseada em Condição............................................52

2.3.4 Etapas do Processo de Manutenção baseada em Condição ....54

2.3.5 Detecção de Falhas 59

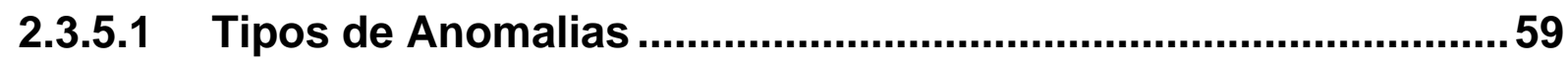

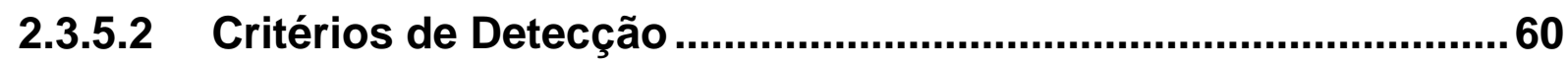

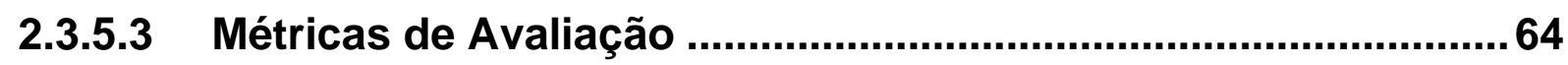

2.3.6 Diagnóstico de Falhas .............................................................6

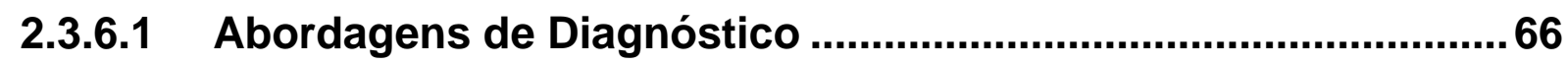

2.3.6.2 Diagnóstico Não Supervisionado..............................................68

2.3.6.3 Considerações sobre o Diagnóstico via Interpretabilidade de Modelos.

2.3.7 Prognóstico de Falhas 71

2.3.7.1 Abordagens de Prognóstico ....................................................72

2.3.7.2 Prognóstico Não Supervisionado ............................................74

2.3.7.3 Considerações sobre o Prognóstico via Interpretabilidade de Modelos. 
3 TRABALHOS RELACIONADOS.

4 MODELO DE DIAGNÓSTICO E PROGNÓSTICO NÃO SUPERVISIONADO UTILIZANDO MÉTODO RXP .80

4.1 CONSIDERAÇÕES INICIAIS. .80

4.2 METODOLOGIA 82

4.2.1 Detecção/Diagnóstico de Falhas Presentes .84

4.2.1.1 Detecção .84

4.2.1.2 Diagnóstico - Método RXP .85

4.2.2 Prognóstico de Falhas Futuras 89

4.2.2.1 Previsão de Falhas Futuras .89

4.2.2.2 Interpretabilidade de Falhas Futuras .92

5 ESTUDO DE CASO .94

5.1 CONSIDERAÇÕES INICIAIS .94

5.2 FONTES DE DADOS .96

5.3 PARÂMETROS PARA RETENÇÃO DOS VAGÕES .98

5.4 CARACTERÍSTICAS DO VAGÃO, RODA E ROLAMENTO .99

5.4.1 Rolamento 101

5.4.2 Roda 103

6 EXPERIMENTOS E ANÁLISES DE RESULTADOS .105

6.1 INFRAESTRUTURA E TECNOLOGIAS UTILIZADAS 105 
6.2 PREPARAÇÃO DOS DADOS

6.3 EXPERIMENTOS

6.3.1 Detecção de Falhas: Avaliação de Capacidade de Detecção de Falhas Presentes 109

6.3.2 Diagnóstico: Avaliação de Capacidade do RXP 118

6.3.2.1 Avaliação de Desempenho de Interpretabilidade 118

6.3.2.2 Análise das Interpretações 125

6.3.2.3 Avaliação de Ganho de Desempenho sobre Detecção usando Interpretabilidade 132

6.3.3 Prognóstico: Avaliação de Capacidade sobre Falhas Futuras134

6.3.3.1 Avaliação de Capacidade de Detecção. 135

6.3.3.2 Análise das Interpretações e Ganho de Desempenho Preditivo CONSIDERAÇÕES FINAIS .144

7.1 CONTRIBUIÇÕES E LIMITAÇÕES 


\section{INTRODUÇÃO}

Este capítulo apresenta breves conceitos sobre o prognóstico não supervisionado de falhas e contextualiza a pesquisa, apresentando os objetivos, motivação e justificativas que guiam o trabalho, bem como a organização dos capítulos desta dissertação.

\subsection{MOTIVAÇÃO}

Sistemas ferroviários são considerados um meio de transporte seguro, que proporciona grande capacidade de vazão logística (transporte de um grande volume de produtos, principalmente quando comparado com o transporte por malha rodoviária). No período entre 2004 e 2016 houve um crescimento relativo considerável na demanda em operações ferroviárias no mundo, com aumento de 4,5\% na quantidade de linhas férreas disponíveis, 17\% em transporte de cargas e 54\% no transporte de passageiros (UIC, 2017). Esses números mostram que a demanda, no período especificado, cresceu em ritmo mais acelerado do que a infraestrutura de malha férrea existente, necessitando que o sistema opere de forma cada vez mais eficiente para atender ao aumento do tráfego, sem impacto na qualidade do serviço entregue. A Figura 1 apresenta a demanda mundial atendida por sistemas de transportes ferroviários no ano de 2017, considerando número de passageiros, quilômetros percorridos e toneladas de cargas transportadas.

Falhas em composições ferroviárias que levem a paradas inesperadas podem comprometer a eficiência de toda a cadeia logística, impactando desde composições subsequentes (ou em sentido oposto em vias singelas) até a operação portuária, devido ao atraso no descarregamento da carga ferroviária. Para que as operações ferroviárias de grande porte estejam aptas a atender às demandas crescentes, exigese infraestrutura e práticas robustas de manutenção, de modo que se garanta a disponibilidade e eficiência para o sistema como um todo.

As atividades de manutenção englobam uma gama extensa de atividades que, normalmente, consomem grandes recursos financeiros. De acordo com a Community of European Railway and Infrastructure Companies (EIM; EFRTC; CER, 2012), os 
países europeus investiram, em 2012, entre 15 e 20 bilhões de euros em atividades de manutenção em operações ferroviárias.

\section{FIGURA 1 - DEMANDA MUNDIAL EM OPERAÇÕES FERROVIÁRIAS}
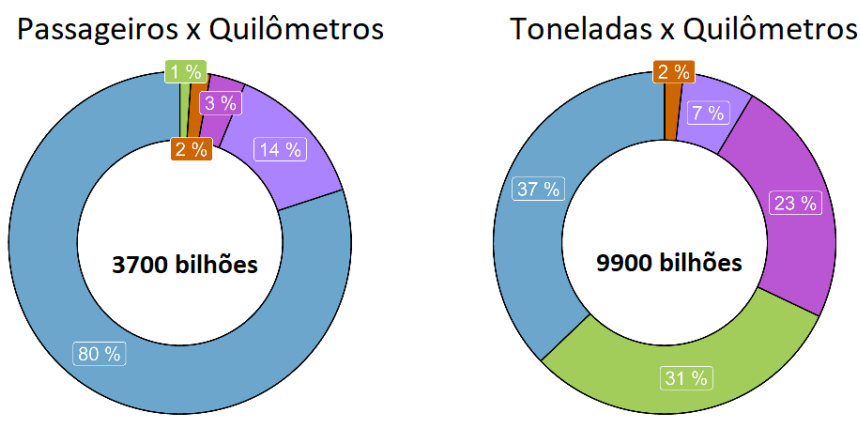

Extensão (Quilômetros)

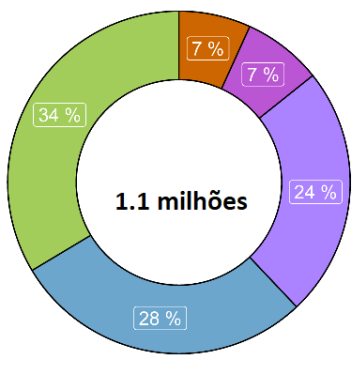

Transporte Ferroviávio Global

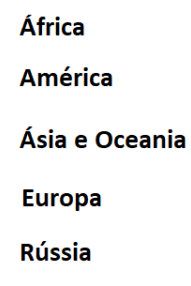

FONTE: ADAPTADO DE (UIC, 2017)

Como pode ser visto na Figura 2, o investimento em manutenção representa um dos aspectos mais onerosos sobre o total de investimentos de uma ferrovia, atingindo $30 \%$ do seu valor total (CONNOR, 2019). É um aspecto inerente dessa área conviver com o conflito entre conseguir realizar as tarefas de manutenção e a execução do serviço de transporte (LIDÉN, 2015), de modo que haja mínimo impacto, principalmente quando se trata de operações de grande porte, nas quais o tráfego é intenso e a demanda sobre os trens e ocupação das vias é praticamente constante.

Abordagens tradicionais de manutenção que atuam de modo reativo (após manifestação do problema) ou baseadas em regras estáticas (períodos ou cargas operacionais fixas), podem fazer com que os sistemas sofram em decorrência de eventos e falhas inesperadas, levando a paradas e possíveis acidentes. Novos formatos de manutenção seguindo modos proativos sugerem ações planejadas baseadas no estado atual do equipamento, além possibilitar previsões sobre possíveis falhas e vida útil operacional restante. 
Hashemian (2011) destaca que em indústrias tradicionais, baseadas em regras fixas de manutenção, verifica-se que, do total de equipamentos inspecionados, cerca de $30 \%$ apresentam problemas que exijam manutenção, enquanto que, em usinas nucleares, normalmente baseadas no monitoramento da condição e técnicas preditivas, esse número se reduz para apenas $10 \%$ do total. A baixa incidência de problemas na operação em usinas nucleares sugere que o monitoramento contínuo e o planejamento baseado nas condições previstas podem reduzir problemas operacionais também em outras indústrias (HASHEMIAN; BEAN, 2011).

FIGURA 2 - CUSTOS ATRELADOS A UM TREM DURANTE SEU CICLO DE VIDA

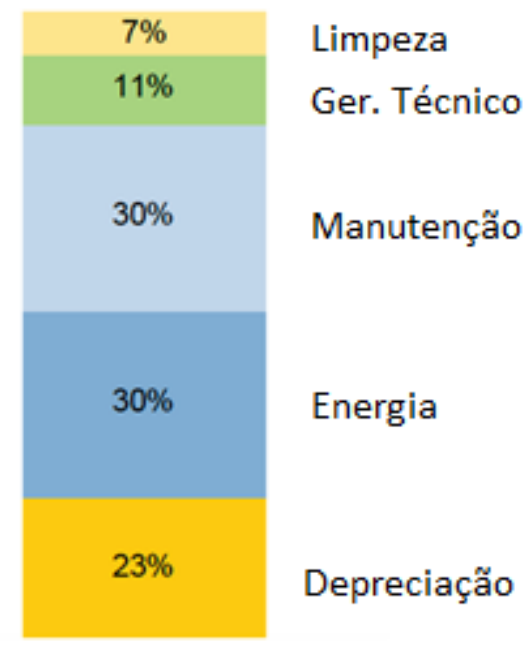

FONTE: ADAPTADO DE (CONNOR, 2019)

Equipamentos e peças mecânicas são projetados para resistirem a perturbações comuns inerentes à operação, como por exemplo, vibrações, sobreaquecimento, aumento de pressão ou condições ambientais adversas. Com o objetivo de manter a estabilidade operacional e prolongar a vida útil do equipamento, as atividades de manutenção são responsáveis por garantir que os equipamentos operem dentro das condições normais esperadas, o que inclui o tratamento e controle sobre equipamentos que apresentem comportamento anômalo ou que se desviem das faixas operacionais aceitáveis. A alteração do comportamento percebida pode advir de condições de degradação de seus componentes ou por condições ambientais/operacionais (por exemplo, inclinação, umidade, velocidade, rotações por minuto) ao qual são submetidos. 
Considerando que práticas de manutenção puramente baseadas em tempos fixos não captam a situação do equipamento entre os marcos de manutenção préestabelecidos, tal estratégia permite que equipamentos continuem a operar em situação anormal, trazendo a possibilidade de perda de desempenho e maior risco de ocorrência de falhas, interrupções inesperadas e possíveis acidentes (JARDINE; LIN; BANJEVIC, 2006). Essas práticas comumente, definem os tempos das tarefas com base em modelos estocásticos de degradação que aproximem um comportamento padrão do equipamento durante a sua vida útil. Essa abordagem, baseada em tempos fixos, não depende de dados históricos do equipamento avaliado, mas da escolha de um modelo adequado (as mais comumente aplicadas são a Weibull, Gamma e Lognormal) e sua parametrização, fundamentada no conhecimento empírico e especialista que se aproxime de um comportamento padrão estimado.

A ineficiência de práticas de manutenção baseadas em períodos fixos foi evidenciada em um estudo realizado pelo grupo SKF (HASHEMIAN; BEAN, 2011), no qual a variação da vida útil de peças foi avaliada. Por meio de testes controlados de stress, 30 rolamentos idênticos e em condições de desgaste similares foram colocados em operação até a sua inutilização. Nesse estudo houve uma alta dispersão sobre o tempo médio até a falha, situando-se entre 15 e 300 horas, indicando que regras fixas podem ser pouco confiáveis e imprecisas. A partir de tal estudo, entende-se que operações reais de manutenções em situações similares de baixa visibilidade quanto à situação real de cada equipamento, podem sofrer tanto de falhas precoces (como um rolamento que falhou em 15 horas), quanto haver 0 desperdício de equipamentos em estado ótimo de saúde, por intermédio de reposições desnecessárias.

De acordo com Stern et al. (2017), a aplicação de um processo de manutenção com base no real estado de funcionamento dos equipamentos poderia reduzir em até $15 \%$ os custos operacionais totais. Esse ganho torna-se viável devido à visibilidade mais clara que uma estratégia baseada na condição real do material pode prover ao processo de manutenção: as equipes atuam assertivamente e em tempo hábil sobre o problema, já que o estado do equipamento é avaliado em tempo real, e considerando os sintomas encontrados, é feito um diagnóstico conhecido sobre as possíveis causas. 
Uma atuação bem planejada e assertiva sobre formas de manutenção, possibilita um melhor aproveitamento do equipamento, mitigando o mau funcionamento que pode levar a uma degradação acelerada, além de garantir que o desempenho esperado seja mantido por mais tempo (SHIN; JUN, 2015). Adicionalmente, essa estratégia permite reduzir, não somente desperdícios financeiros, como também acidentes que possam levar, inclusive, a perdas humanas.

Com os avanços recentes da inteligência artificial, a implementação de estratégias de manutenção baseadas na condição do equipamento aplicadas às tarefas de detecção, diagnóstico e prognóstico de falhas tem sido sugerida, de forma crescente, na literatura (JARDINE; LIN; BANJEVIC, 2006; SHIN; JUN, 2015; KIM; CHOI; AN, 2016; KHAN; YAIRI, 2018). Entretanto, questões como a complexidade do sistema a ser modelado, a disponibilidade de anotações sobre as observações, e interpretabilidade sobre os resultados obtidos são alguns dos desafios que devem ser ponderados, conforme descrito a seguir.

\subsubsection{Considerações sobre a Complexidade do Sistema}

À medida que aumenta a complexidade do sistema a ser modelado, normalmente, também aumenta a complexidade do modelo desse sistema. Sendo assim, se maiores quantidades de dados forem disponibilizadas, as taxas de erros tendem a ser reduzidas (KHAN; YAIRI, 2018). A complexidade está diretamente relacionada ao número de parâmetros necessários na modelagem, e ao tamanho do espaço de possibilidades que cada atributo e a resposta esperada podem assumir. Sistemas de maior complexidade tendem a necessitar de volumes maiores de dados, de modo que seja possível alcançar resultados mais estáveis e com boa capacidade de generalizar e extrapolar sobre observações até então não vistas.

Métodos tradicionais para predição de séries temporais como ARIMA (BOX; JENKINS; REINSEL, 2008), VAR (LÜTKEPOHL, 2005) e similares possuem a vantagem de necessitar de um baixo volume de dados para serem modelados, porém com baixa capacidade de representar comportamentos não lineares e aleatórios. Adicionalmente, a modelagem de problemas tende a ser exponencialmente mais difícil à medida que cresce 0 número de parâmetros (DOMINGOS, 2012). Consequentemente, esses métodos tendem a não escalar adequadamente. 
Alternativas mais elaboradas como redes neurais, SVM e Random Forests são apresentados como opções mais eficientes, entretanto exigindo maiores quantidades de dados para treinamento. Com o advento do aprendizado profundo (deep learning) e a sua capacidade superior de aprender e generalizar comportamentos complexos e não lineares, novos métodos foram propostos, transformando-se em estado-da-arte em diversas aplicações (LECUN; BENGIO; HINTON, 2015), tais como visão computacional e reconhecimento de fala.

As técnicas mencionadas acima apresentam grande capacidade de interpolação (BÉLISLE et al., 2015), ou seja, aproximar e generalizar resultados sobre padrões e faixas de valores que estejam contidos dos limites vistos sobre os dados de treinamento. Por outro lado, esses métodos sofrem ao modelar problemas que exigem extrapolação (KAUWE et al., 2020), significando que situações que exijam o aprendizado padrões sobre os dados além das faixas de valores conhecidos em treinamento, tendem a falhar. Visto que a predição de falha visa estimar comportamentos futuros que possam se desviar de um comportamento normal, essa tarefa é potencialmente desafiadora. Desse modo, entende-se que modelos eficientes para predições de falhas devem generalizar adequadamente sobre padrões supostamente conhecidos (interpolação), e na medida do possível, abstrair sobre possíveis situações diferentes (extrapolação) que possam colocar o sistema em risco.

Dado o enorme potencial do deep learning, esta pesquisa visa explorar essa técnica, como base para propor e implementar métodos eficientes de detecção e previsão de eventos de falha.

\subsubsection{Considerações sobre a Disponibilidade de Anotações}

As anotações (ou comumente designadas como variáveis de saída) referem-se às informações dos objetivos das predições. Em treinamentos de modelos supervisionados, o processo de otimização busca convergir iterativamente os resultados obtidos para esses respectivos valores de saída.

A disponibilidade dessas anotações sobre o estado do equipamento define, fundamentalmente, o tipo de modelo que pode ser aplicado. Como vantagem, o uso de métricas tradicionais como acurácia, precisão e sensibilidade podem ser aplicadas 
objetivamente, dado que os resultados são comparados às anotações. Apesar da capacidade superior apresentada pelos métodos supervisionados (MICENKOVÁ; MCWILLIAMS; ASSENT, 2014), esse formato exige que os dados de treinamento contenham disponíveis informações do que precisa ser claramente predito, podendo resultar em esforços excessivos e custos operacionais adicionais para obter e manter tais informações. Adicionalmente, métodos supervisionados têm a presunção de que todos os possíveis erros são conhecidos e classificados corretamente, o que em determinadas aplicações não é possível, já que anomalias são eventos raros e podem se manifestar espontaneamente, em novas formas (GOLDSTEIN; UCHIDA, 2016).

Em casos em que apenas uma parcela dos dados de treinamento possuem anotações, os métodos semi-supervisionados sugerem um treinamento similar ao modo supervisionado, porém utilizando apenas registros de equipamentos supostamente "normais", também conhecido como "classificador de uma classe" (GOLDSTEIN; UCHIDA, 2016). A ideia é que o modelo seja especializado em um padrão aproximado de entrada, e consequentemente observações anômalas sejam identificadas. Esse formato é consideravelmente mais simples, já que registros de falhas são eventos proporcionalmente "raros" e de difícil obtenção para um treinamento adequado.

Em conjuntos de dados sem anotações sobre as variáveis de saída, os métodos não supervisionados são capazes de detectar padrões e similaridades entre as observações com base em propriedades intrínsecas extraídas dos dados (GOLDSTEIN; UCHIDA, 2016). Desse modo, essas técnicas são capazes de reconhecer e agrupar observações em diferentes estados e comportamentos de forma autônoma. As métricas de avaliação para os métodos não supervisionados baseiamse nos próprios dados, considerando a qualidade dos agrupamentos formados, como distância interna/externa entre os grupos, grau de pureza (homogeneidade) das observações dentro dos grupos e capacidade de criação de grupo de anomalias ("Rag Bags”). Amigó (2008) descreve, em maiores detalhes, a respeito de métricas para métodos não supervisionados.

Apesar da flexibilidade e maior independência do conhecimento de domínio oferecida nesse formato, a incerteza e subjetivismo sobre resultados obtidos por meio dos métodos não supervisionados é um desafio típico nessas abordagens, já que não 
há uma definição precisa de fronteiras entre observações normais ou anômalas (CHALAPATHY; CHAWLA, 2019).

O método proposto nesta pesquisa fundamenta-se em abordagens não supervisionadas para as tarefas de detecção, diagnóstico e inferência do estado de vida útil de componentes, promovendo flexibilidade e independência sobre domínio de aplicação. Propõe-se a avaliação de desempenho com o uso de métricas tradicionais (precisão e sensibilidade), com base em regras operacionais de segurança, para detecção de falhas.

\subsubsection{Considerações sobre a Interpretabilidade dos Modelos}

A interpretabilidade sobre modelos refere-se à capacidade de entendimento sobre como classificadores e métodos preditivos alcançam seus resultados. Essa necessidade surge do fato de não somente considerar o desempenho sobre métricas pré-estabelecidas (como, por exemplo, precisão e acurácia), mas saber se o modelo treinado trabalha fundamentado em parâmetros razoáveis em relação ao resultado obtido.

Em aplicações críticas, a constatação que um determinado modelo preditivo obteve uma predição (mesmo que dentro do esperado), fundamentado em premissas irracionais que expliquem essa resposta (ou seja, ponderação de relevâncias dos parâmetros que não sejam razoáveis com relação ao conhecimento especialista), poderia reduzir a sua credibilidade e invalidá-lo. Portanto, um modelo com resultados coerentes em relação ao grau de importância sobre os atributos promove confiança, já que demonstra que o modelo foi capaz de capturar, e entregar resultados robustos com base em fenômenos previamente conhecidos por profissionais especialistas, em relação aos parâmetros de entrada.

O segundo ponto de interesse quanto à interpretabilidade está no ganho de informação adquirido pela interpretação dos resultados obtidos, ou seja, a explicação de como o modelo obteve sua resposta pode ser usada para auxiliar em um tratamento assertivo sobre o evento analisado (ou seja, como diagnóstico), ou induzir ao entendimento de determinados fenômenos até então desconhecidos. 
O balanço entre capacidade de generalização de problemas e interpretabilidade é um conflito inerente na escolha de técnicas de aprendizado de máquina (DOSHIVELEZ; KIM, 2017). Técnicas mais simples como regressão linear ou árvores de decisão são nativamente intuitivas quanto aos seus respectivos processos de decisão. No primeiro caso, os métodos geram funções polinomiais que descrevem os pesos atribuídos sobre cada parâmetro. Por sua vez, a árvore de decisão gera a sua estrutura de ramos e folhas embasada em regras encadeadas de decisão, sendo os parâmetros mais próximos à raiz os mais significativos sobre determinadas respostas.

Em cenários com uma grande quantidade de parâmetros, a intuição da interpretabilidade tende a ser diminuída sobre esses modelos, dificultando um apontamento mais assertivo sobre o resultado (DOMINGOS, 2012). Sob outra perspectiva, devido às suas estruturas arquiteturais complexas, métodos mais robustos como redes neurais e SVM funcionam como "caixas-pretas", ou seja, sem qualquer modo nativo que explique com o resultado foi alcançado. Com o intuito de suprir essa limitação, novos tipos de modelos com foco em interpretabilidade foram criados para auxiliar na explicação das predições, sendo os mais conhecidos o LIME (RIBEIRO; GUESTRIN, 2016) e o SHAP (LUNDBERG; LEE, 2017).

O uso de técnicas de interpretabilidade tem sido discutido na literatura com foco em validação de métodos caixa-preta (como o deep learning), e na aplicação para atender a requisitos regulatórios em domínios como na área financeira e de saúde (ELSHAWI et al., 2019; MURDOCH et al., 2019). Tal recurso caracteriza o uso da interpretabilidade como um artifício para redução da incerteza (ou ganho de confiança) sobre modelos de diagnóstico e prognósticos, visto que se torna viável a avaliação se os resultados foram obtidos baseados em uma combinação de parâmetros, que seja razoável e compreensível ao ser humano.

Esta pesquisa propõe o uso de métodos de interpretabilidade como meio para prover intuição quanto às classificações obtidas sobre a detecção e previsão de falhas, resultando em uma abordagem para identificar (diagnóstico) as fontes das falhas encontradas. Adicionalmente, a pesquisa desenvolve um método próprio de interpretabilidade que apresenta grande desempenho e velocidade sobre as explicações fornecidas, sendo também aplicado como um meio automatizado para complementar e calibrar a classificação de falha. 


\section{$1.2 \quad$ OBJETIVOS}

Esta pesquisa tem como objetivo geral contribuir para a área de aprendizado de máquina aplicada à engenharia de confiabilidade de sistemas, tendo como foco geral propor um método de diagnóstico e prognóstico não supervisionado de falhas, que permita a obtenção de interpretações sobre os resultados obtidos, possibilitando a promoção de confiança e assertividade no tratamento de problemas:

As etapas para se atingir esse objetivo geral incluem:

a) Avaliar o potencial do uso de técnicas não supervisionadas de deep learning sobre detecção e predição de eventos raros de falhas baseado em dados de operação industrial real.

b) Aplicar técnicas de interpretabilidade como estratégia para viabilizar o diagnóstico sobre resultados de métodos de detecção e previsão de falhas.

c) Propor um novo método de interpretabilidade que possa ser associado a métodos de detecção não supervisionada baseados na reconstrução da entrada.

d) Desenvolvimento de protótipos que atendam as tarefas de detecção, diagnóstico e prognóstico. No caso do prognóstico, o mecanismo de identificação da falha deve aproveitar e adaptar as abordagens sugeridas sobre detecção e diagnóstico e estendê-los sobre as estimativas comportamentais futuras

\section{$1.3 \quad$ JUSTIFICATIVA}

As justificativas desta pesquisa fundamentam-se nos seguintes pontos:

a) Métodos não supervisionados são flexíveis e independentes do domínio do problema. $\mathrm{O}$ ajuste de métricas de validação baseadas em regras operacionais pode balizar a capacidade do método em encontrar eventos de falhas que violem as regras operacionais, e ao mesmo avaliar registros falso-positivos, que podem indicar estado incipientes ou novos padrões de falhas.

b) A interpretabilidade de modelos está se tornando requisito regulatório em determinadas aplicações críticas, como no mercado financeiro e na área de saúde (ELSHAWI et al., 2019; MURDOCH et al., 2019). O uso dela promove 
credibilidade ao constatar que o classificador gera respostas bem fundamentas, bem como geração de conhecimento ao prover informações sobre a causa de eventos ocorridos. Entende-se que $\mathrm{o}$ acoplamento de técnicas de interpretabilidade é um diferencial nesta pesquisa, ao promover automação e praticidade sobre o diagnóstico de falhas, que é um aspecto da manutenção baseada em condição que comumente exige grande conhecimento especialista.

c) Visto que os resultados das interpretações representam um conjunto de dados completamente novo (mesmo conjunto de parâmetros, porém contendo os pesos de relevância), poderiam ser associados por técnicas de reconhecimento de padrões, com intuito de fornecer um novo meio para explorar modos de falha.

\subsection{ESTRUTURA DO TRABALHO}

Este trabalho está organizado do seguinte modo:

- O capítulo 2 reúne a fundamentação teórica, contendo os conceitos sobre deep learning e interpretabilidade de modelos, importantes para o entendimento da pesquisa.

- O capítulo 3 apresenta uma seleção de trabalhos relacionados, que de alguma forma aplicam recursos relevantes a esta pesquisa.

- O capítulo 4 apresenta o estudo de caso, que é usado como base para a avaliação das hipóteses formuladas.

- O capítulo 5 descreve as questões de pesquisa, metodologia aplicada na pesquisa, e métodos desenvolvidos.

- O capítulo 6 detalha os experimentos realizados e contém análises sobre os resultados obtidos

- O capítulo 7 apresenta considerações finais quanto à pesquisa de mestrado, sumarizando as contribuições alcançadas e algumas sugestões de trabalhos futuros. 
Esse capítulo apresenta aspectos teóricos relativos aos temas de deep learning e interpretabilidade, básicos para o entendimento da proposta central desta dissertação. Portanto, a forma de apresentação desses temas é:

- A seção 2.1 apresenta o modo de funcionamento de algumas das técnicas não supervisionadas de deep learning consideradas para exploração nesta pesquisa;

- A seção 2.2 descreve conceitos básicos e algumas das técnicas de interpretabilidade para modelos caixa-preta, que podem ser aplicáveis para modelos de deep learning;

- Em seguida, na seção 2.3 são apresentados conceitos básicos de dependabilidade, terminologia sobre estados e eventos que ameaçam 0 funcionamento de um sistema (ou seja, falha, defeito e disfunção), e esquema básico de um gerenciamento de manutenção baseado em condição;

- Nas seções 2.4, 2.5 e 2.6 são apresentados conceitos e tipos gerais de técnicas de detecção, diagnóstico e prognóstico de falhas, respectivamente.

\section{$2.1 \quad$ TÓPICOS SOBRE DEEP LEARNING}

Esta seção apresenta aspectos teóricos e justificativas sobre a escolha das técnicas de deep learning consideradas nesta pesquisa, abrangendo conceitos básicos sobre redes neurais artificiais (redes feedforward, com foco específico sobre Autoencoders), e redes neurais recorrentes (com maiores detalhes sobre redes LongShort Term Memory - LSTM).

\subsubsection{Definições Básicas}

Deep learning consiste em técnicas baseadas em redes neurais artificiais com múltiplas camadas, que permitem 0 aprendizado de representações e relacionamentos complexos e não lineares entre os parâmetros de entrada e a saída esperada. Tal forma de representação vem sendo considerada estado da arte em diversos domínios, como no reconhecimento de fala, tradução, visão computacional e 
descoberta de drogas para criação de novos remédios (LECUN; BENGIO; HINTON, 2015).

As redes neurais são compostas por neurônios, que são unidades básicas que realizam cálculos simples, e interagem com outros neurônios sob diferentes formas e organizações. Entre as diferentes arquiteturas, dois padrões gerais podem ser destacados: (i.) as redes feedforward, formadas por conexões acíclicas entre neurônios de uma mesma camada, geralmente voltadas para problemas supervisionados de classificação e regressão; (ii.) as redes recorrentes, possuindo conexões cíclicas entre os neurônios, aplicando processamento de predições sobre dados sequenciais.

\subsubsection{Redes Feedforward}

As redes feedforward são caracterizadas pela organização dos neurônios em camadas, nas quais os neurônios de uma mesma camada não se conectam, mas apenas aos neurônios da camada seguinte em seu estado de ativação (ou estado “forward'), ou da camada anterior durante o seu aprendizado pela atualização de pesos (estado “backward”), sendo a rede Multi-Layer Perceptron (MLP) é um dos tipos de rede feedforward mais utilizada, comumente aplicada em problemas de classificação e regressão.

A Figura 3 apresenta um exemplo de rede MLP contendo uma camada, e a estrutura básica de funcionamento de um Perceptron (modelo básico contendo um neurônio). O neurônio representa uma unidade básica de cálculo, equivalendo à soma ponderada das entradas com a aplicação de uma função de ativação (transformação). A saída de um neurônio serve de entrada para todos os neurônios da camada seguinte, processo esse que se repete até a saída da rede MLP, representando assim a operação da rede no estado forward. Na figura 3, está representada apenas uma camada intermediária, que recebe a denominação de camada escondida.

A função de ativação (ou transformação conforme a figura 3) tem como caraterística básica a não linearidade e ser monotonicamente crescente, como, por exemplo, as funções sigmoide (limitada entre 0 e 1), tangente hiperbólica (limitada entre -1 e 1) ou ReLU (limitada entre 0 e $\infty$ ). Esse comportamento representa o estado 
de excitação do neurônio, conforme o peso da entrada, o que possibilita que uma MLP consiga modelar funções complexas. Ao estar com pesos ajustados e com funções de ativação adequadas, o MLP pode aproximar praticamente qualquer função matemática (CYBENKO, 1989; HORNIK; STINCHCOMBE; WHITE, 1989).

Figura 3 - EXemplo de REDE MLP E VISÃo de UM PERCEPTRON

(a) Rede MLP com 1 camada escondida

(b) Perceptron
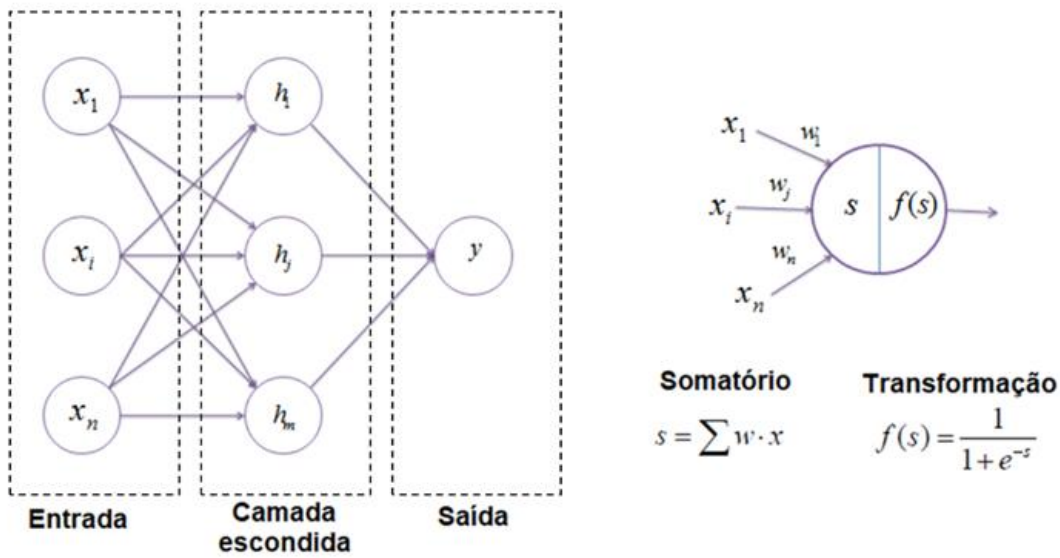

FONTE: ADAPTADO DE (SAED SAYAD, 2019)

Durante o treinamento, o resultado da saída calculada da rede é comparado com a saída real desejada, por meio de uma função de cálculo de erro. Por meio do método iterativo backpropagation, os parâmetros da rede são reajustados a partir da saída da rede e "propagados" em direção à primeira camada, representando a operação da rede em estado de aprendizado (backward) (Rumelhart \& Hinton, 1986).

O método de otimização de parâmetros usados no backpropagation é normalmente feito por meio do algoritmo do gradiente descendente, que se baseia no cálculo de derivadas parciais sobre a função que calcula o erro residual entre as saídas esperada e a obtida (normalmente erro quadrático médio). Uma pequena alteração no peso de uma camada inicial gera efeitos encadeados para as camadas subsequentes durante uma predição. O gradiente calculado sobre cada neurônio define o efeito propagado das camadas anteriores que gera o desvio em relação ao resultado esperado. Esse valor é propagado para as respectivas camadas anteriores, e é usado como fator de ajuste sobre os pesos para aproximação do resultado esperado. (LECUN; BENGIO; HINTON, 2015). 
O gradiente descendente procura seguir para a direção que reduz o erro, procurando convergir para regiões onde o valor da derivada sobre a função do erro seja 0 , indicando que é uma zona de erro mínimo local. Adicionalmente, é definida uma taxa de otimização, que define a velocidade de atualização a cada backward.

Dentre os tipos de rede feedforward, destaca-se o autoenconder, que é uma rede treinada para reproduzir um conjunto de valores de entrada em sua saída, passando pelas fases de encoder (compressão) e decoder (descompressão). Essa arquitetura permite que o autoencoder seja usado para tarefas de redução de dimensionalidade (DR), aprendizado de parâmetros (pela transformação não linear gerada pelas compressões do encoder), e para o aprendizado de modelos generativos. O autoencoder aprende aspectos intrínsecos a partir dos dados, criando um espaço latente dimensional reduzido que descarta ruídos e dados não são representativos, como correlações e informações redundantes (MAKHZANI; FREY; GOODFELLOW, 2014).

Assim como já descrito sobre as redes feedforward, as entradas multidimensionais são processadas por neurônios, passando por uma sequência de funções não lineares ao longo das camadas, combinando as entradas e gerando representações densas, ricas em camadas ocultas. Os dados compactados são então usados para reconstruir as informações na camada de saída. A Figura 4 apresenta um exemplo de autoencoder contendo 3 camadas escondidas, no qual o encoder e o decoder possuem 1 camada escondida, e o coding layer representando ao mesmo tempo a saída do encoder e a entrada do decoder.

Como destacado na seção 2.3.5, o autoencoder (e outras arquiteturas derivadas dele) é um dos principais representantes dos modelos de deep learning em problemas de detecção de anomalias não supervisionadas, apresentando resultados consideravelmente superiores em relação a outros tipos de técnicas (CHALAPATHY; CHAWLA, 2019). Desse modo, esta pesquisa considera o AE como base para experimentação sobre problemas de classificação binária para detecção de anomalias. 


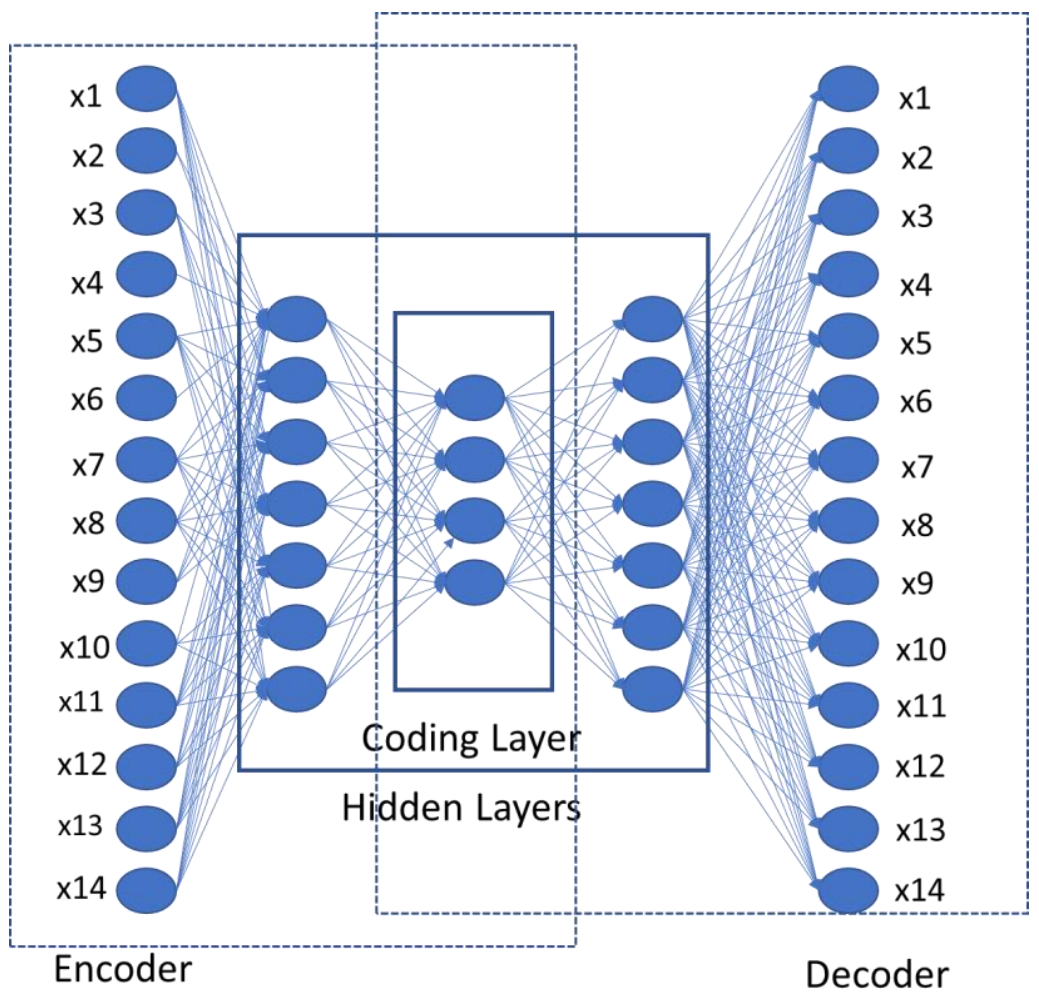

FONTE: AUTOR

\subsubsection{Redes Recorrentes}

Em contraste com as redes feedforward, em redes recorrentes, os neurônios estão arranjados em ligações que permitem a retroalimentação, e armazenam vetores de estados em diferentes momentos no tempo (lapsos temporais) (LECUN; BENGIO; HINTON, 2015). Devido a essa característica de reter dados sobre o passado, essa rede é amplamente aplicada em análises de previsões sobre dados sequenciais, como exemplo em processamento de linguagem natural (NLP), de reconhecimento de fala, traduções ou análise de sentimentos.

Uma rede recorrente é preparada para trabalhar com séries temporais de dados, podendo se ser treinada e exposta a diferentes contextos de entradas e saídas, conforme mostrado na Figura 5:

- "One to One" é o cenário mais simples, onde uma entrada gera uma saída (similar a uma rede feedforward, sem uso de memória); 
- "One to many" refere-se a uma entrada que mapeia uma sequência de informações ordenadas na saída, como, por exemplo, a descrição do que acontece em uma imagem ("image captioning");

- "Many to One" se refere à interpretação de uma sequência ordenada de entradas que podem gerar uma informação única de saída, como a interpretação de frames de um vídeo classifica o gênero do conteúdo, ou a análise de sentimentos para classificar um documento baseada na sequência de palavras contidas;

- "Many to Many" (ou "sequence to sequence") compreende o processamento de múltiplas entradas em sequência e múltiplas saídas ordenadas, como descrição de um vídeo em tempo real ou tradução simultânea (significando que o número de dados de entrada não é necessariamente igual aos de saída).

\section{FIGURA 5 - FORMATOS DE ENTRADAS E SAÍDAS EM REDES RECORRENTES}

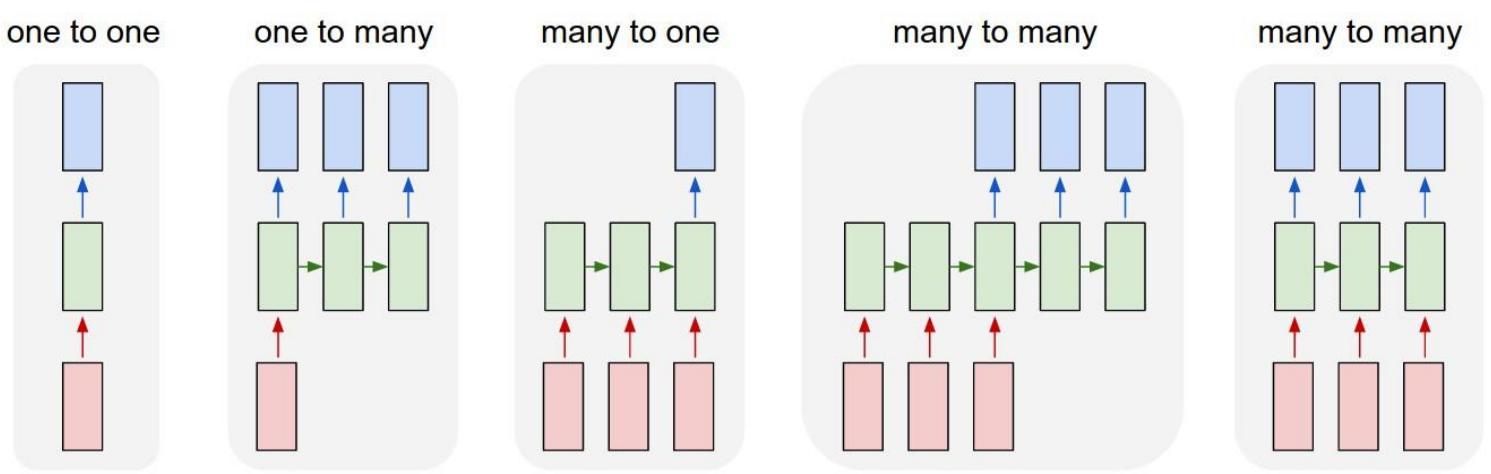

FONTE: ADAPTADO DE (LI F.; JOHNSON J.; YEUNG S., 2017)

A Figura 6 exemplifica o controle de estados armazenados sobre lapsos anteriores. Ao realizar uma predição, para entrada $x_{t}$ no tempo $t$, são gerados dois valores de saída:

- ativação $\left(h_{t}\right)$, que é resultado da soma ponderada da entrada com pesos $W_{x h}$, somados ao estado anterior $h_{t-1}$ com pesos $W_{h h}$, e aplicado a uma função de ativação (sigmoide, tangente hiperbólica, entre outras); 
- predição $(y)$, que corresponde ao resultado obtido da ativação $\left(h_{t}\right)$ com pesos padrões $\left(W_{h y}\right)$, também aplicada a uma função de ativação. Em $t+1, h_{t}$ será usado como lembrança do tempo $t$.

- Note que os pesos $W_{x h}, W_{h h}$ e $W_{h y}$ representam matrizes bidimensionais com tamanhos referenciais ao tamanho do lapso temporal memorizado, e as dimensões da entrada e saída.

FIGURA 6 - FUNÇÃO DE ATIVAÇÃO DE REDES RNN

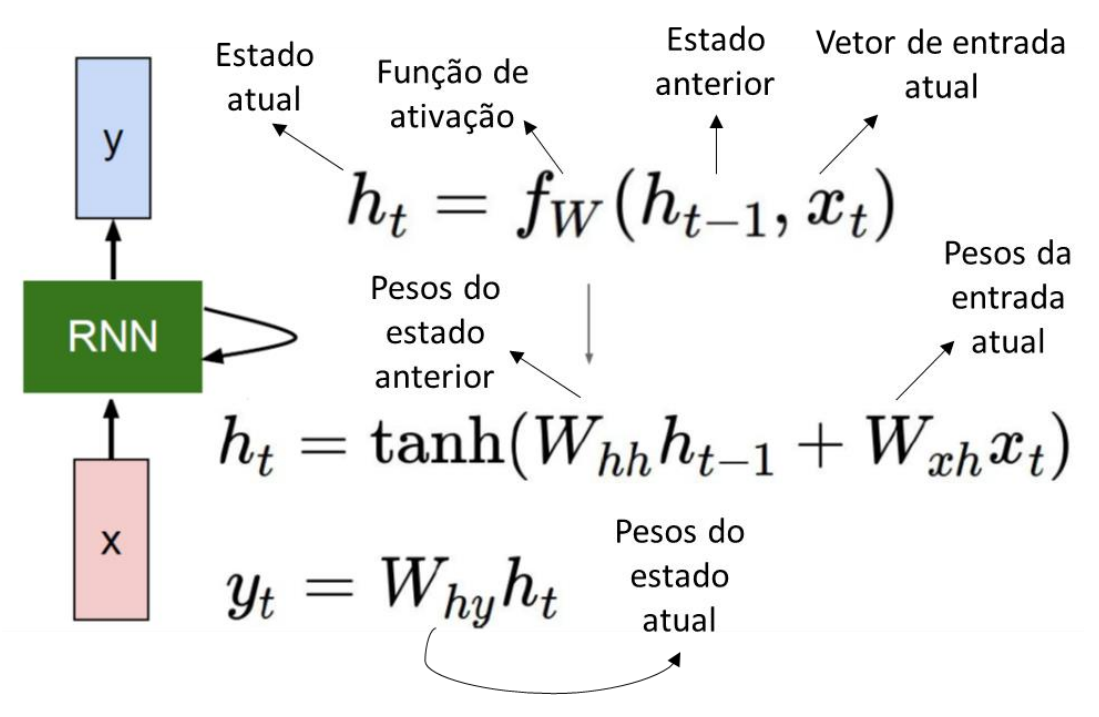

FONTE: ADAPTADO DE (LI F.; JOHNSON J.; YEUNG S., 2017)

Abstraindo-se as unidades que representam diferentes lapsos temporais como diferentes propagações entre camadas em uma rede feedforward, entende-se que o ajuste pelo backpropagation pode ser aplicado em uma rede recorrente. Assim como o backpropagation nas redes feedforward, a função de otimização adequada para as redes recorrentes é conhecida por backpropagation through time (BTT), realizando o ajuste de peso dos parâmetros ao longo das sequências, por meio da função de erro acumulada em toda a sequência, e realizando o cálculo de derivadas parciais sobre os pesos, entradas, ativações e viés.

A Figura 7 exemplifica a propagação de gradientes ao longo da sequência: Durante 0 uso da rede, um neurônio $s_{t}$ processa a entrada $x_{t}$ considerando os resultados obtidos do neurônio $s_{t-1}$, gerando a saída $E_{t}$ e impactos no processamento do neurônio $s_{t+1}$. Desse modo, durante o treinamento dessa rede, além de existir a propagação de gradientes para as camadas anteriores $\left(\partial E_{t} / \partial s_{t}\right.$, como em uma rede 
feedforward), é também calculado o gradiente dos lapsos da própria sequência $\left(\partial s_{t} / \partial s_{t-1}\right)$.

A arquitetura clássica de uma rede recorrente conforme apresentada sofre de problemas sistêmicos quanto ao treinamento sobre sequências que não sejam consideravelmente curtas. A propagação de gradientes ao longo da sequência tende a sofrer de explosão (sobre pesos acima de 1) ou anulação ("vanishing", sobre pesos entre 0 e 1) dos gradientes, causando instabilidade para convergência sobre mínimos locais (BENGIO; SIMARD; FRASCONI, 1994; MARCUS, 2018).

FIGURA 7- FORMATOS DE ENTRADAS E SAÍDAS EM REDES RECORRENTES

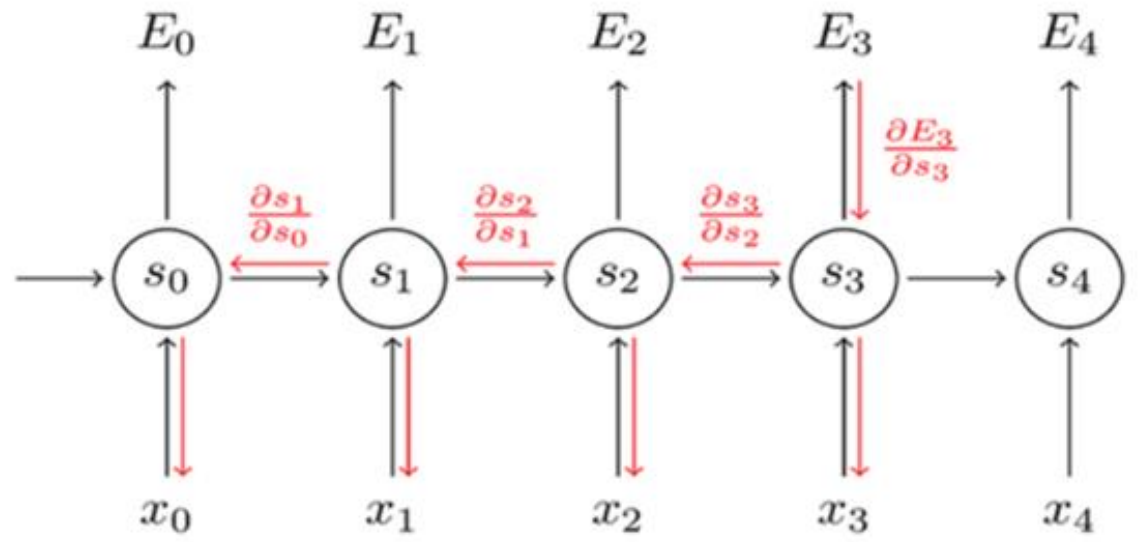

FONTE: EXTRAIDO DE (LI F.; JOHNSON J.; YEUNG S., 2017)

Dessa forma, Com o objetivo de atender ao problema de propagação de gradientes em sequências longas, algumas arquiteturas foram sugeridas, com grande destaque para a Long-Short Term Memory (LSTM) (HOCHREITER; SCHMIDHUBER, 1997) e suas variantes.

A Figura 8 exemplifica uma unidade de processamento de sequência de uma rede LSTM padrão. Pelos controles de inclusão e exclusão sobre os lapsos temporais anteriores e lapsos atuais, a LSTM permite o aprendizado de sequências longas, mitigando o problema de gradientes. Para cada um dos controles, existem pesos e vieses específicos. 


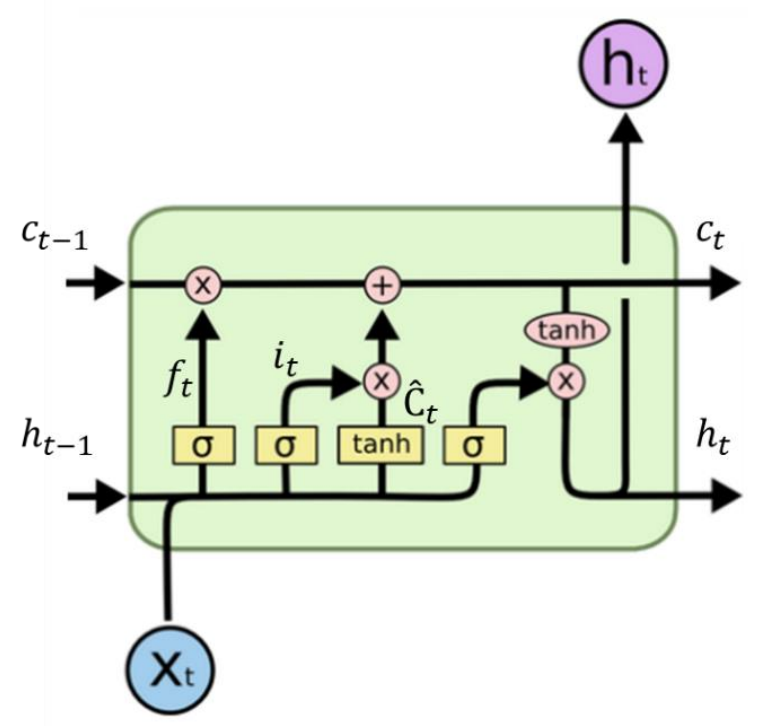

FONTE: ADAPTADO DE (OLAH, 2015)

A LSTM mantém a memória de estado anterior $c_{t-1}$ sobre as unidades anteriores, e tem a capacidade atualizar as informações por meio do conceito de portões ("gates"), sendo eles:

- $f_{t}$ ("forget", ou esquecer) que define quando descartar as lembranças das unidades anteriores;

- $i_{t}$ ("input", ou entrada), o quanto de informação nova (do tempo $t$ ) deve ser x;

- $\quad h_{t}$ ("output", ou saída), a ativação da saída baseada na combinação da saída anterior $h_{t-1}$ com a entrada atual $x_{t}$ e o estado atual $c_{t}$.

- O estado atual $c_{t}$ é gerado pela combinação do $f_{t}, i_{t}$, a saída anterior $h_{t-1}$ e entrada atual $x_{t}$.

Já as redes Long-Short Term Memory Autoencoder (LSTM-AE) são um tipo de rede LSTM que seguem a arquitetura Encoder-Decoder, sendo preparada para processar múltiplas entradas e saídas ("Many-to-Many"), sendo utilizado em diversos problemas como processamento de linguagem natural (tradução e sumarização), processamento de fala. Essa rede pode ser usada tanto para predição de comportamentos futuros, quanto para um comportamento similar ao autoencoder comum, no qual o objetivo da rede é reproduzir a saída igual à entrada, porém preparada para receber sequências de dados, como realizado com a LSTM. 
Consequentemente, essa rede ser treinada para aprender representações de parâmetros sobre entradas no formato séries temporais multidimensionais.

A Figura 9 apresenta um exemplo de rede LSTM-AE reproduzindo uma entrada de sequência de dados com 3 lapsos temporais ( $\mathrm{t} 1$, $\mathrm{t} 2$ e t3), contendo três parâmetros (P1, P2 e P3). Note que nesse caso a entrada e a saída possuem valores aproximados (conforme exemplificado nas tabelas de entrada e saída). Após o dado codificado ser em uma única dimensão (pelo "Coding layer"), ele é novamente expandido ao seu formato original pelo decoder (tanto em número de parâmetros quando lapsos temporais). Assim como no AE tradicional, em certas aplicações, o dado gerado pelo encoder (com 1 lapso temporal) pode ser usado como estratégia de redução de dimensionalidade e ser usado entrada para outros modelos.

FIGURA 9- REDE LSTM-AE TREINADA PARA RECONSTRUIR SÉRIES TEMPORAIS

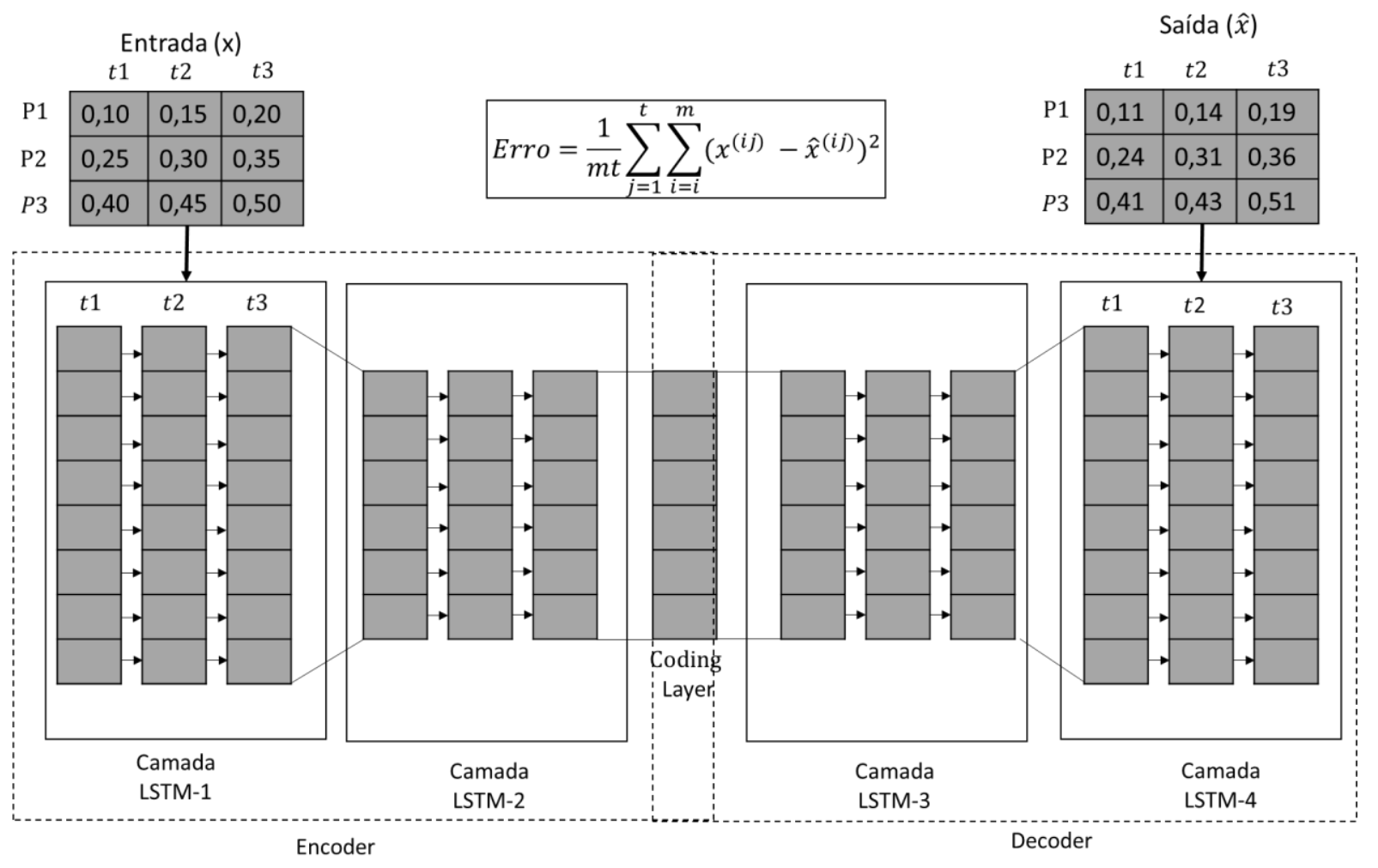

FONTE: AUTOR

A Figura 10 apresenta um exemplo de rede LSTM-AE treinada para realizar predições da sequência de dados sobre 3 lapsos temporais passados (t1, t2 e t3), contendo três parâmetros (P1, P2 e P3), resultando nas predições dos lapsos temporais futuros (t4 e t5). Nesse caso, a sequência não precisa ter os mesmos 
parâmetros da entrada ou exatamente o mesmo número de lapsos temporais da entrada (porém, quanto mais lapsos futuros a serem preditos, tende a trazer maior imprecisão).

FIGURA 10 - REDE LSTM-AE TREINADA PARA PREDIÇÃO DE COMPORTAMENTOS FUTUROS

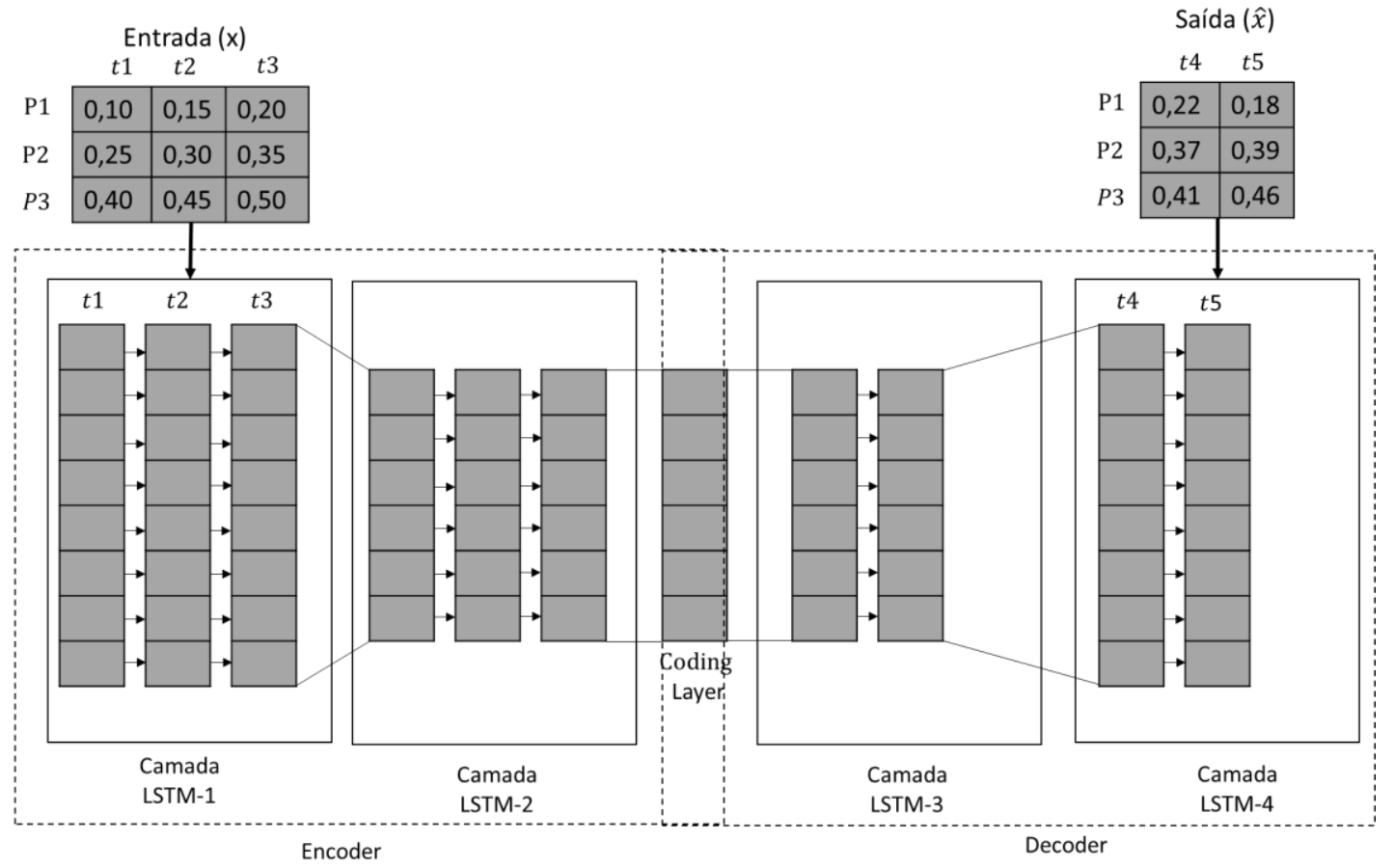

FONTE: AUTOR

A rede LSTM (e suas variantes) são consideradas estado-da-arte para atender a problemas envolvendo sequências temporais em domínios diversos (GREFF et al., 2017). A arquitetura LSTM-AE em especial permite que as dimensões temporais da entrada e saída sejam alteradas em qualquer camada dentro nós internos da rede ("coding layer"), flexibilizando o desenho da rede conforme a necessidade do problema a ser tratado. Portanto, esta pesquisa considera o uso adaptado da rede LSTM-AE para suprir as experimentações para predição de falhas futuras.

\subsection{INTERPRETABILIDADE DE MODELOS DE APRENDIZADO DE MÁQUINA}

Esta seção apresenta conceitos, abordagens gerais e modos de avaliação sobre interpretabilidade de modelos de aprendizado de máquina, descrição dos conceitos e atributos sobre interpretabilidade, detalhamento das técnicas mais conhecidas de 
interpretabilidade (SHAP e LIME), e uma breve explicação sobre meios para avaliar o nível de interpretabilidade provido.

\subsubsection{Conceitos e Atributos de Interpretabilidade}

Com as recentes evoluções e o grande potencial já demonstrado para tratar problemas complexos, as técnicas de aprendizado de máquina estão sendo gradualmente adotadas para resolver tarefas em diferentes domínios de problemas. A adoção em sistemas autônomos ou como apoio na ação em domínios críticos, traz a necessidade de conhecer, racionar e justificar como a tomada de decisão foi realizada pelo modelo, trazendo implicitamente confiança sobre as predições realizadas (CHAKRABORTY et al., 2017). Tal característica é considerada como uma subárea em pesquisas em aprendizado de máquina, e referida como inteligência artificial explanatória (XAI) (DARPA, 2016), ou interpretabilidade (ou ainda explicabilidade).

O conceito preciso de interpretabilidade varia entre os autores, no qual parte deles usa o termo explicabilidade como termo sinônimo (DARPA, 2016) ou como um atributo relacionado (GILPIN et al., 2019). Esta pesquisa adota a interpretabilidade como a habilidade explicar ou apresentar, de modo compreensível ao ser humano, quais fatores foram relevantes para resultados obtidos por um modelo. A compreensão pode variar quanto ao nível de abstração, não se restringindo à ponderação de parâmetros e funcionamento do modelo, mas também pode, eventualmente, considerar com conhecimento a priori sobre o problema (CHAKRABORTY et al., 2017).

Adicionalmente, alguns autores consideram a combinação de alguns atributos de interpretabilidade como a explicabilidade, equidade, responsabilidade e estabilidade, conforme descrito a seguir.

A explicabilidade (ou relevância) (GILPIN et al., 2019; MURDOCH et al., 2019), é um objetivo de interpretabilidade, definida pelo tipo e grau de completude de uma explicação fornecida, considerando o público alvo. Portanto, a qualidade de uma mesma explicação muda se o público for diferente, como por exemplo entre usuários especialistas no domínio do problema (pois esperam explicações detalhadas sobre a predição), ou leigos no assunto. Já a causalidade refere-se à capacidade de encontrar 
relações e interações de dependências entre parâmetros (LIPTON, 2018), provendo explicações sobre relacionamentos e hierarquias. Tais associações não necessariamente refletem causalidade (DOMINGOS, 2012; LIPTON, 2018), mas podem fornecer novas visões até então não percebidas.

Visto que por intermédio da transparência provida pela interpretabilidade, promove-se ganho de confiança (e implicitamente ganho de conhecimento), Chakraborty (2017) define outros desafios que devem ser levados em consideração, dependendo do problema aplicado, como a equidade ("fairness") e a responsabilidade ("accountability").

A equidade (ou justiça) refere-se a questões éticas e regulatórias que possam ser violadas, devido a um viés discriminatório em que o modelo tenha se baseado, como por exemplo, um modelo autônomo de aprovação de crédito imobiliário, que pondera a tomada de decisão sobre a raça ou sexo do indivíduo, prejudicando sumariamente certos grupos sociais, quanto ao desfavorecimento em oportunidades sobre condições justas e igualitárias.

A responsabilidade é a capacidade de inspecionar se a tomada de decisão de um modelo foi realizada de modo confiável (baseado em premissas coerentes), do ponto de vista regulatório. Considerando que muitas tarefas e decisões que antes eram tomadas por humanos agora são delegadas aos modelos, esse atributo promove um meio formal de esclarecer possíveis conflitos.

A estabilidade refere-se à robustez das interpretações sobre diferentes padrões de observações, ou seja, a capacidade do método não sofrer perturbações e manter interpretações coerentes mesmo em observações fora do padrão (MURDOCH et al., 2019). Portanto, esse atributo está intimamente ligado à promoção e manutenção de credibilidade do método preditivo avaliado.

\subsubsection{Tipos e Escopo de Técnicas}

O conflito entre obter níveis satisfatórios de acurácia sobre o modelo preditivo e a transparência sobre os seus resultados, é uma questão comum na seleção das técnicas. Por exemplo, modelos contendo combinações lineares (como a regressão linear e logística) e árvores de decisão possuem estruturas mais simplificadas, 
facilitando o entendimento sobre o peso de cada parâmetro em predições. Tais métodos são considerados como modelos "caixa-branca".

Por outro lado, em problemas mais complexos, envolvendo grande número de parâmetros, outros métodos são necessários, de modo a obter resultados satisfatórios. Entretanto, a alta capacidade de acurácia desses modelos é compensada pela natureza "caixa-preta", não fornecendo qualquer meio nativo de obter interpretabilidade sobre o modelo. Dentre os métodos caixa-preta, destacam-se os métodos de deep learning.

Sobre esses dois tipos de métodos, a interpretabilidade pode ser realizada por meio de recursos nativos providos pelo próprio método preditivo (nativo, ou baseado no modelo), geralmente voltado aos modelos caixa-branca, ou por técnicas e modelos externos (conhecida na literatura por post-hoc) como opção para endereçar a limitação dos modelos caixa-preta (DOSHI-VELEZ; KIM, 2017). Vale notar que, enquanto a capacidade de interpretabilidade nativa interfere na acurácia do modelo preditivo, visto que a interpretação acontece durante a predição (exigindo ajustes que podem gerar impactos sobre a predição ou interpretação), os métodos post-hoc realizam a interpretação sobre os resultados já obtidos, portanto, trabalhando de forma desacoplada.

Sob outra perspectiva, a interpretabilidade pode ser realizada em um escopo local ou global. O escopo local refere-se ao comportamento do modelo sobre o resultado obtido em uma observação específica ao simular o funcionamento do modelo caixapreta sobre amostras de observações similares. Já no escopo global procura-se o entendimento do comportamento geral esperado pelo modelo. Normalmente, o cenário de avaliação de interpretabilidade no escopo local é mais simples e factível de ser obtido, visto que se trata de um caso específico e mais restrito que foi aprendido pelo modelo mais complexo, enquanto no escopo global o interpretador deve se basear em todos os cenários esperados.

Apesar dos métodos de deep learning não proverem meios claros de interpretabilidade, algumas alternativas são sugeridas, como: (i.) a captura de padrões comportamentais do modelo (sobre padrões de ativação dos neurônios e análise de gradientes) (SHRIKUMAR; GREENSIDE; KUNDAJE, 2017), e consequentemente 
sugestões de arquiteturas que organizem o comportamento das variáveis latentes geradas durante as ativações neuronais; (ii.) modelos de arquitetura auto explicativas, preparados e treinados para fornecerem explicações, geralmente com base em anotações de especialistas direcionadas de modo supervisionado sobre padrões de parâmetros importantes identificados (GILPIN et al., 2019).

Dentre as técnicas auto explicativas, destacam-se os modelos que usam Attention (GILPIN et al., 2019), sendo mais aplicadas em problemas de visão computacional (redes neurais convolucionais), e principalmente processamento e predição de séries temporais longas (redes LTSTM). Esse mecanismo inclui um conjunto adicional de pesos e neurônios, que indicam a influência (ou "atenção") dos parâmetros da entrada para geração sobre cada parâmetro da saída. Pela avaliação do comportamento de alta ativação dos mecanismos de Attention, é possível inferir quais os parâmetros da entrada foram mais relevantes para a geração de um resultado particular na saída (que no caso, pode ser região de uma imagem, ou períodos específicos em séries temporais).

No que diz respeito aos métodos post-hoc, diferentes abordagens têm sido sugeridas na literatura para prover meios compreensíveis de explicar as respostas dos modelos. Essas abordagens podem ser categorizadas por métodos que destacam os parâmetros mais importantes por ranqueamento ou por regiões mais importantes por visualização (no caso de imagens).

Essas duas abordagens, são geralmente implementadas pela: (i.) perturbação sobre a entrada, alterando aleatoriamente valores dos atributos, para avaliar o impacto no desempenho, ou seja, atributos importantes vão causar grande impacto no desempenho do modelo; (ii.) geração de modelos agnósticos (caixa-branca) que aproximem o comportamento do modelo caixa-preta, como no caso do LIME (RIBEIRO; GUESTRIN, 2016), que gera um modelo caixa-branca (como uma regressão linear) de fácil compreensão, ou SHAP (LUNDBERG; LEE, 2017), que define a influência quantitativa dos parâmetros baseada na teoria de jogos cooperativos, no qual a importância é distribuída de modo justo pela a sua respectiva contribuição individual sobre a resposta obtida. 
Esta pesquisa visa a exploração experimental sobre métodos post-hoc com objetivo de ranqueamento dos parâmetros mais importantes, com foco específico sobre o LIME (RIBEIRO; GUESTRIN, 2016) e SHAP (LUNDBERG; LEE, 2017), por gerarem interpretações intuitivas, e serem agnósticos no que se refere à arquitetura do modelo preditivo investigado.

\subsubsection{LIME}

Ribeiro (2016) propôs o LIME como um método agnóstico de interpretabilidade de métodos caixa-preta por aproximação local que se destaca pela sua simplicidade conceitual. A ideia se baseia no treinamento de um modelo caixa-branca (como uma regressão linear ou logística), utilizando uma amostragem de observações geradas pelo LIME, baseada em observações similares, aplicando pequenas perturbações sobre os parâmetros. A otimização do método caixa-branca visa a aproximação máxima quanto à resposta do modelo-caixa preta sobre a observação em questão.

A Figura 11 demonstra a versatilidade do LIME sobre diferentes tipos de entradas e diferentes possibilidades de resposta. No exemplo (a), é mostrado um ranqueamento de parâmetros importantes para apoiar avaliação de médicos em diagnóstico de doenças sobre dados tabulares.

\section{FIGURA 11 - INTERPRETAÇÃO POR RANQUEAMENTO DE PARÂMETROS (A) E REGIÕES DA IMAGEM (B)}

a) Ranqueamento de parâmetros

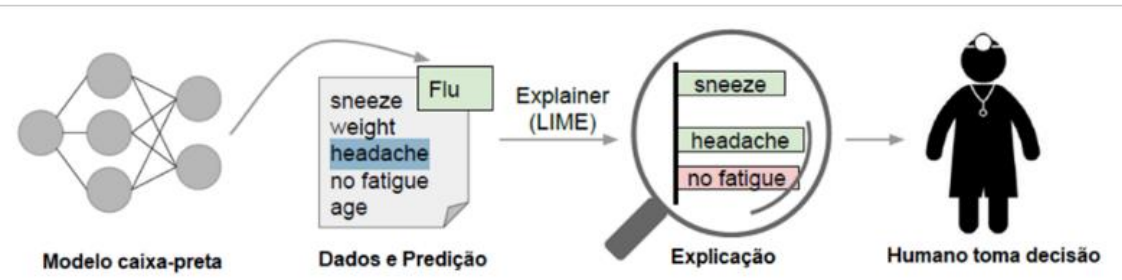

b) Diversas interpretações sobre uma mesma imagem
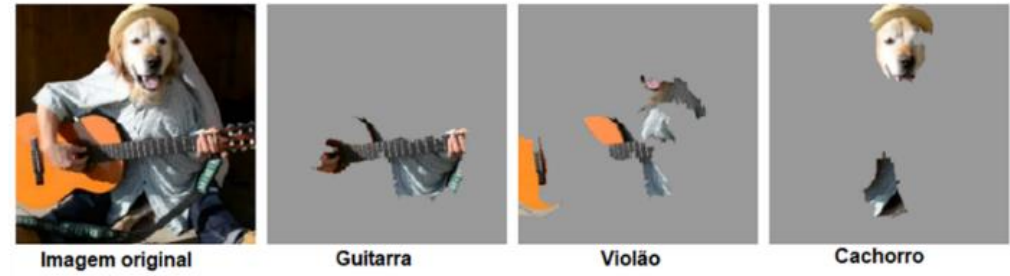

FONTE: ADAPTADO DE (RIBEIRO; GUESTRIN, 2016) 
A partir de um resultado obtido de um modelo caixa-preta indicando gripe, o LIME indicou quais os sintomas (representados pelos parâmetros) que mais impactaram tanto positivamente (dor de cabeça) ou negativamente (a falta de fadiga) no resultado. No exemplo (b), são mostradas múltiplas interpretações de uma mesma imagem, a partir da imagem original, o LIME evidenciou corretamente as regiões da imagem (transformando as partes não relevantes em cinza) referentes a uma guitarra elétrica, um violão, ou um cachorro, respectivamente.

\subsubsection{SHAP}

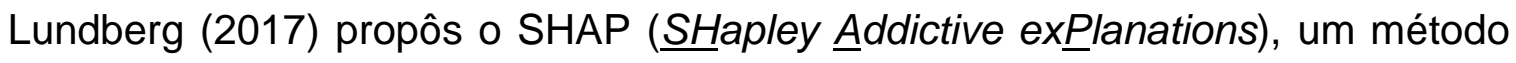
de interpretabilidade inspirado em Shapley Values (SHAPLEY, 1953), um conceito de solução sobre teoria de jogos cooperativos, no qual vários participantes (jogadores) atuam com um objetivo comum a ser alcançado, são recompensados de modo justo em relação à sua contribuição sobre jogo.

Entende-se que a contribuição de cada jogador é variável, dependendo da coalização considerada. Pela verificação de cada uma das possíveis permutações, cria-se uma distribuição única de contribuição média de todos os participantes do jogo. O Shapley Value obtido corresponde à contribuição marginal de cada parâmetro, obtido de forma justa em relação à importância de todos os parâmetros.

Abstraindo esses conceitos para o contexto de interpretabilidade, cada parâmetro pode ser considerado como um jogador, no qual o objetivo do jogo é acertar a predição, e a recompensa de um jogador (parâmetro) é a diferença entre o resultado alcançado entre coalizações de jogadores (grupos de parâmetros) com e sem a colaboração, com o objetivo de minimizar a diferença com a predição real (pelo modelo caixa-preta).

Lundberg (2017) levanta três propriedades importantes que são coerentes a respeito do Shapley Values, e sugere que ponderação de importância entre parâmetros de uma forma justa, que são respeitadas pelo método SHAP (e não consideradas pelo LIME):

a) Propriedade 1 (Acurácia Local): Assim como o LIME, esse método tem objetivo de aproximação local sobre o comportamento de um método caixa- 
preta a respeito de uma observação específica, gerando uma explicação pela combinação aditiva.

b) Propriedade 2 (Falta de Importância, ou "missingness"): Em uma visão simplificada da entrada dimensional reduzida, a falta de importância indica a ausência de um parâmetro sem afetar a resposta esperada.

c) Propriedade 3 (Consistência): Denota que se o modelo caixa-branca é atualizado de modo que a contribuição de um parâmetro aumenta ou se mantém igual, independente dos outros parâmetros, o seu valor não deve ser reduzido.

Visto que problemas com entradas de dados com um número extenso de parâmetros podem levar a um custo computacional elevado sobre as permutações de coalizações, o SHAP sugere uma forma otimizada para o cálculo de parâmetros importantes por meio da média condicional do modelo original de Shapley Values. $O$ autor sugere que a premissa de independência e linearidade entre os parâmetros simplifica a complexidade computacional, pela redução de casos a serem avaliados (ou seja, a avaliação de coalizões de parâmetros não são avaliadas em ordens diferentes, apenas a inclusão de novos parâmetros), e demonstra que uma função caixa-branca pode ser aproximada de uma forma mais eficiente.

\subsubsection{Formas de Avaliação da Interpretabilidade}

Murdoch (2019) define que, além das formas tradicionais de avaliação aplicadas aos métodos preditivos (como acurácia, precisão e sensibilidade, e denominadas genericamente por acurácia preditiva), a acurácia descritiva avalia a qualidade das explicações em fornecer interpretações adequadas deve ser também avaliada. Tanto a acurácia preditiva, quanto a descritiva deve ser ponderada na escolha do método preditivo a ser aplicado, levando em conta a necessidade de desempenho sobre as predições e a facilidade de interpretar os resultados obtidos.

Apesar do valor funcional e científico da acurácia descritiva, não existe consenso quanto ao modo de avaliação mais apropriado (DU; LIU; HU, 2019; GILPIN et al., 2019; MURDOCH et al., 2019). Conforme a Figura 12, a definição feita por Doshi (2017) e adaptada por Murdoch (2019), a interpretabilidade pode ser categorizada em 
diferentes níveis de complexidade (aplicação, humano, ou funcional), o que impacta diretamente na avaliação de desempenho, dado o grau de subjetividade da tarefa.

A avaliação em nível de aplicação envolve a participação integral de especialistas na geração de avaliações elaboradas sobre tarefas complexas, exigindo especialistas no domínio do problema. Como exemplos desse cenário, tem-se o caso sistemas de diagnósticos de pacientes que devem passar por avaliação de médicos para avaliar a precisão dos resultados em cenários altamente subjetivos, como por exemplo, análise de radiografias para diagnosticar câncer precocemente, no qual existem poucos indícios sobre a existência da doença.

FIGURA 12 - TAXONOMIA DE NÍVEIS DE AVALIAÇÃo PARA INTERPRETABILIDADE

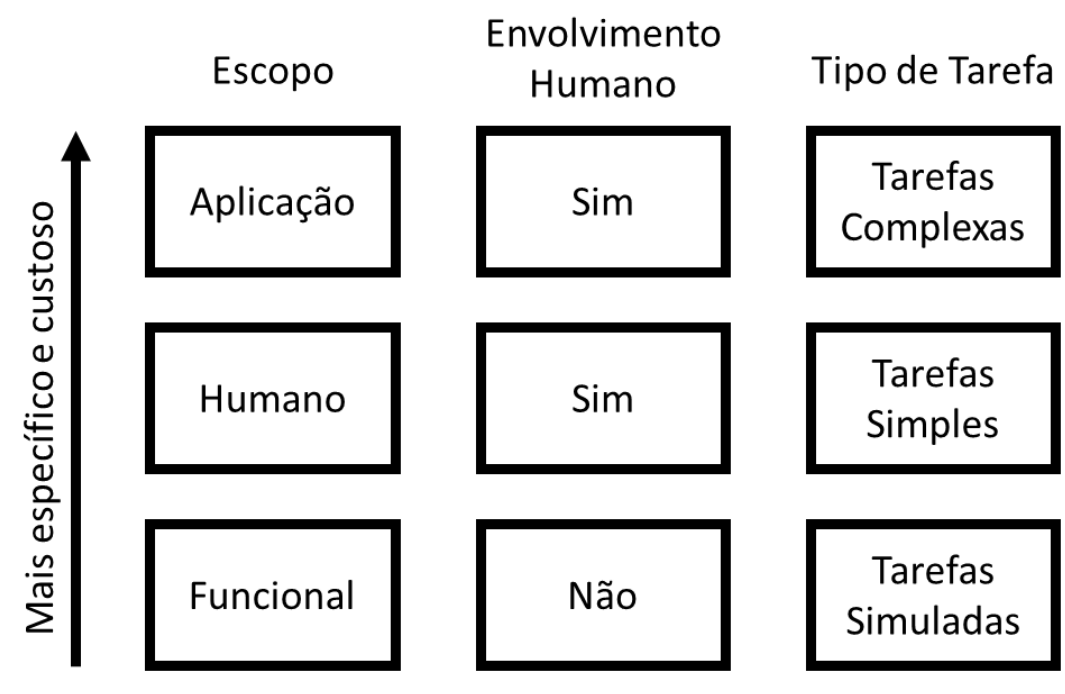

FONTE: ADAPTADO DE (DOSHI-VELEZ; KIM, 2017)

A avaliação em nível humano usa métricas para avaliação por especialistas em tarefas mais simples (menor subjetividade), quando houver limitações quanto à disponibilidade ou acessibilidade sobre uma avaliação profunda. Nesse caso, podese exemplificar com cenários de identificação de falhas em sistemas críticos, no qual equipamentos estão operando com certo desvio em relação ao comportamento esperado (como sobreaquecimento ou ruído excessivo no caso de sistemas mecânicos).

A avaliação em nível funcional segue uma abordagem sem intervenção humana, na qual tarefas simplificadas com resultados previamente conhecidos são usadas como prova formal da capacidade de interpretabilidade. Nesse caso, o nível de 
subjetividade é mínimo, onde as tarefas a serem executadas normalmente não causariam conflitos de interpretação. Como exemplos para esse cenário, pode-se citar situações nas quais devem-se identificar desvios mais grosseiros de comportamento em relação ao esperado, como em sistemas mecânicos (sobreaquecimento acima das especificações do fornecedor), saúde de pacientes (pressão sanguínea elevada, podendo levar ao infarto do indivíduo), ou análises de fraudes financeiras (transações financeiras milionárias recorrentes em períodos específicos sobre contas de pessoas físicas de classe média).

O nível de qualidade das explicações tende a ser consideravelmente superior com o apoio humano, porém tornando a modelagem e treinamento do modelo mais custosa, pela exigência de dedicação e controle sobre todos os possíveis casos de resposta. Visto que as avaliações em nível humano e aplicação dependem da validação humana, entende-se que ambas as abordagens são abstrações que dependem de anotações, e consequentemente são abstrações de treinamentos supervisionados.

Como o objetivo desta pesquisa é explorar métodos não supervisionados, propõese o uso de métodos de interpretabilidade com método de avaliação em nível funcional, devido à necessidade de se explorar abordagens sem intervenção humana e menor subjetividade.

\subsection{CONCEITOS BÁSICOS DE DEPENDENDABILIDADE E MANUTENÇÃO BASEADAS EM CONDIÇÃO}

Esta seção descreve as tarefas gerais relacionadas à análise sobre falhas. Inicialmente são apresentados conceitos relacionados, como a definição de sistemas e propriedades fundamentais como dependabilidade e confiabilidade; conceituação de falha para sistemas mecânicos; apresentação de conceitos básicos de manutenção e aspectos sobre a manutenção baseada em condição; e conceitos e abordagens de análise de falhas (detecção, diagnóstico e prognóstico, respectivamente), com foco em técnicas não supervisionadas. 


\subsubsection{Dependabilidade e Confiabilidade}

A operação de equipamentos e maquinários está sujeita a perturbações e ameaças que podem comprometer o seu funcionamento. Essas ameaças podem surgir de forma aleatória, desde a degradação de peças que compõem esses equipamentos, seu modo de utilização, ou sua iteração com agentes externos.

O desafio de avaliar e mitigar riscos que ameaçam um sistema é explorada pela engenharia de confiabilidade, que define a dependabilidade como um conjunto de atributos importantes para mensurar a resiliência de um sistema sobre possíveis adversidades. Laprie (2004) define a dependabilidade como a capacidade que um sistema possui em prover o corretamente um serviço, de forma confiável, ou ainda ser capaz de evitar perturbações no serviço acima de uma faixa aceitável.

A dependabilidade define características relevantes sobre um sistema como a confiabilidade (probabilidade de não ocorrer problemas que afetem o serviço), continuidade (percentual de tempo que o serviço se mantém disponível), segurançacrítica (não ocorrência de acidentes que ameacem vidas e o ambiente), integridade (não ocorrência de alterações impróprias no sistema) e manutenibilidade (habilidade de um sistema ser restaurado).

Dentre os atributos listados, a confiabilidade trata sobre risco e previsão de falhas. A confiabilidade é a propriedade que mede a probabilidade de um sistema manter-se ativo e capaz de entregar determinada função (serviço), em determinadas condições, durante um período de tempo definido, dado que estava correto no momento inicial (SMITH, 2011). A confiabilidade lida com a incerteza e os riscos que comprometem a disponibilidade do sistema e está atrelada à estimativa de sua vida útil restante. $\mathrm{O}$ risco é a grandeza oposta, ou seja, a probabilidade de um sistema ter sua funcionalidade esperada alterada, representada pela igualdade $R(t)=1-C(t)$ (SMITH, 2011), onde $C$ representa a confiabilidade do sistema em dado momento $t$, e $R$ o risco atrelado.

Smith (2011) sugere que a melhoria da confiabilidade pode ser favorecida desde o projeto e manufatura (no caso de sistemas físicos) do sistema, indo até sua operação. Durante a fase de projeto, definições de arquitetura podem favorecer a 
resiliência do sistema em diversos aspectos, que podem favorecer tanto a escalabilidade, quanto a resiliência.

Um exemplo de crescimento de confiabilidade pela arquitetura de um sistema é representado por meio do emprego de estruturas redundantes, as quais visam proporcionar alta disponibilidade e maior tolerância a falhas. Tal propriedade pode ser alcançada pela prevenção de interrupções inesperadas, principalmente por meio do uso de componentes redundantes, os quais podem assumir a operação do sistema no caso de falhas na estrutura principal. A manufatura pode favorecer o crescimento da confiabilidade pela implantação de processos de produção e controle de qualidade bem definidos, e a capacitação sobre as equipes de operação, visando ainda mitigar riscos causados por falhas humanas.

A fase de operação pode favorecer a confiabilidade por meio de estratégias de manutenção combinadas a métodos eficientes de análise de falhas, com o intuito de atuar assertivamente na detecção, diagnóstico e previsão de eventos que ameacem o serviço entregue. Portanto, a antecipação e atuação preventiva sobre possíveis ameaças visa reduzir a incidência de eventos que possam causar riscos.

\subsubsection{Falha, Defeito e Disfunção}

As definições encontradas na literatura são divergentes em alguns pontos. Esta pesquisa considerou dois autores, Laprie (2004) e Isermann (2011), que apresentam as suas visões de maneira distinta e ao mesmo tempo robustas. Basicamente, as ameaças que podem perturbar a confiabilidade de um sistema são definidas como falha ("fault"), defeito ("error" ou "malfunction") e disfunção ("failure”).

Laprie (2004) define disfunção como um evento que provoca um desvio em relação ao comportamento previsto nas especificações do sistema, o que se considera como uma indisponibilidade do serviço ou ainda como a prestação incorreta de um serviço. A disfunção é o tipo de ameaça que externaliza o problema de um sistema ao ambiente e outros sistemas ligados a ele. Laprie, adicionalmente define disfunções parciais, em casos de degradação avançada, que comprometem o desempenho do serviço entregue. 
Quando ocorre uma disfunção em um sistema, composto por vários componentes interligados, entende-se que ao menos um desses componentes está operando fora do comportamento normal. Esse desvio pode ser chamado de defeito, sendo considerado um estado do sistema que pode, ou não, evoluir para uma disfunção. A causa de um defeito é chamada de falha, que pode estar ativa se o defeito existe ou inativa (ou dormente), caso contrário. A Figura 13 descreve o comportamento dos estados de um sistema após o aparecimento de uma falha. Uma falha pode existir e se manifestar de modo intermitente, estando inativa em certas situações (falha dormente).

FIGURA 13-estados E EVENTOS EM UM SISTEMA (VISÃo DE LAPRIE)

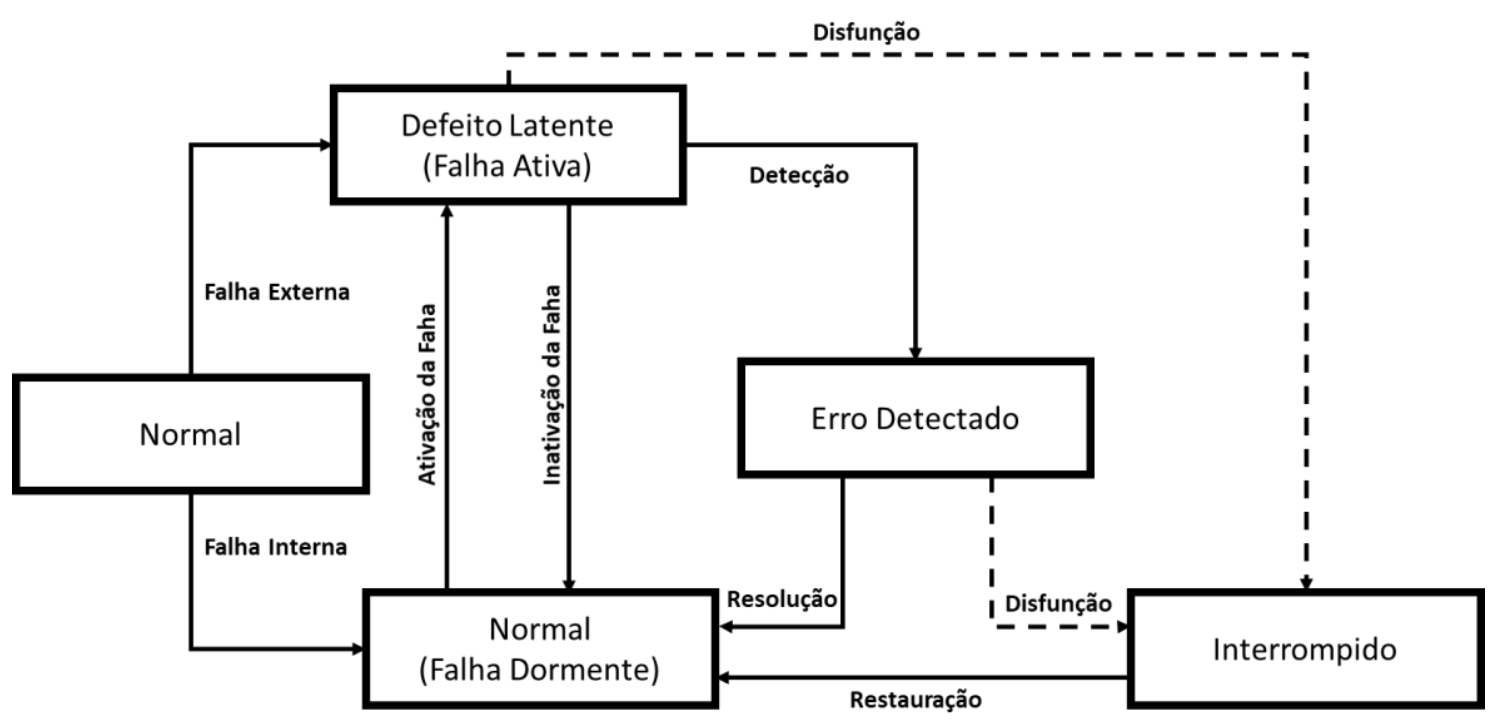

FONTE: ADAPTADO DE (TROGER; FEINBUBE; WERNER, 2015)

Quando a falha é ativada pode evoluir e causar defeitos na operação. Um defeito pode existir em um grau incipiente e passar despercebido pelos sistemas de detecção (defeito latente), podendo também evoluir para uma disfunção, levando à interrupção do serviço provido.

Por outro lado, Isermann (2011) define falha como um estado de desvio comportamental do serviço entregue fora da especificação tolerável, causando condições anormais que podem (ou não) levar à redução ou perda de capacidade de alguma funcionalidade esperada. Isermann complementa que uma falha pode evoluir abruptamente ou gradativamente, e pode iniciar uma disfunção ou defeito. O defeito é um evento de desvio intermitente no provimento do serviço, significando a 
interrupção temporária de uma funcionalidade esperada. O defeito é causado por uma ou mais falhas. A disfunção é um evento de interrupção permanente da habilidade do sistema para prover um serviço conforme as especificações.

Dadas as visões expostas, esta dissertação adota os conceitos de Isermann, pois a sua visão quanto a falha reflete um estado comportamental, e indica que deve ser avaliado detalhadamente por meio de métodos de diagnósticos e prognósticos, visando identificar a fonte do evento. Essa abordagem converge apropriadamente com o uso da nomenclatura adotada na literatura, que comumente usa as tarefas de detecção e diagnóstico de forma distinta (JARDINE; LIN; BANJEVIC, 2006; SHIN; JUN, 2015; CHALAPATHY; CHAWLA, 2019). A visão de Laprie sugere a falha como a causa do desvio, e entende-se que indica implicitamente que a falha se constitui em um desvio já categorizado.

Conforme a Figura 14, Isermann sugere que um sistema pode assumir três estados: normal, falha e interrompido. Um sistema em estado normal é aquele que funciona de acordo com as especificações, e ao ultrapassar determinada faixa aceitável em seu comportamento vai para o estado em falha. Em situações extremas, a disfunção de algum componente pode levar à interrupção permanente do sistema, causando a transição do estado de falha para o estado interrompido. Em situações menos graves, a falha pode apresentar situações intermitentes de comportamento que causem interrupções momentâneas do serviço (defeito). Nesses casos, o estado normal do sistema pode ser restaurado, considerando a existência de mecanismos de proteção.

FIGURA 14 - ESTADOS E EVENTOS DE UM SISTEMA (VISÃo DE ISERMANN)

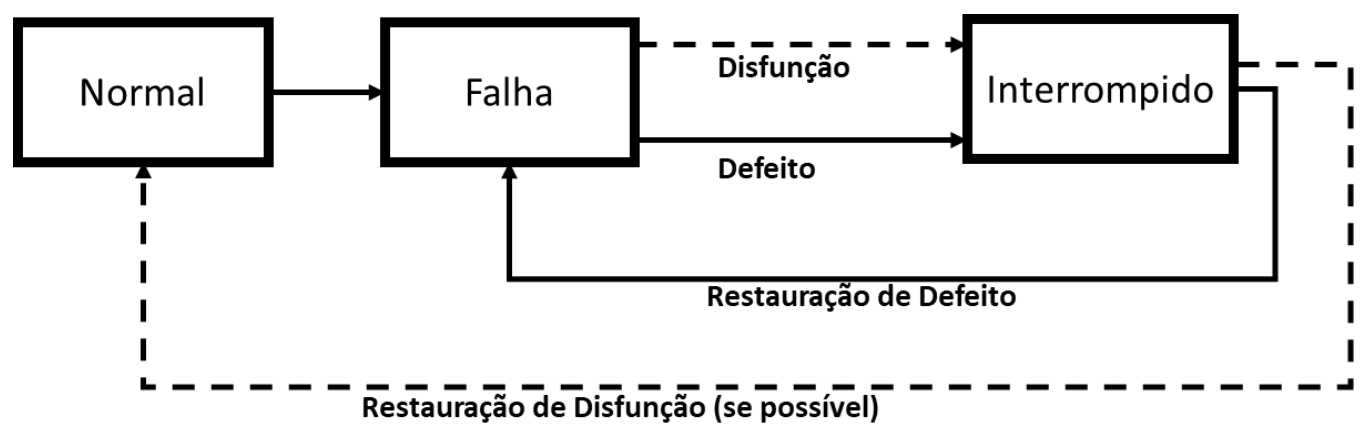

FONTE: AUTOR 


\subsubsection{Manutenção Baseada em Condição}

A atividade de manutenção é responsável por manter e restaurar componentes de um sistema ao estado que funcionem da maneira planejada (RODRIGUES; LAVORATO, 2016), garantindo que o sistema opere continuamente, mantendo os níveis originais de segurança e confiabilidade requeridos (KINNISON; SIDDIQUI, 2013). Também conhecida por "manutenção, reparos e inspeção", essa atividade é responsável por gerir o ciclo de vida do maquinário e engloba as tarefas de monitoramento, reconfiguração, inspeção, reparos e reposição de peças e equipamentos. Baseando-se nas definições de Mobley (2002), pode-se classificar os procedimentos de manutenção em corretiva e preventiva, conforme ilustrado na Figura 15.

FIGURA 15 - TIPOS DE MANUTENÇÃO

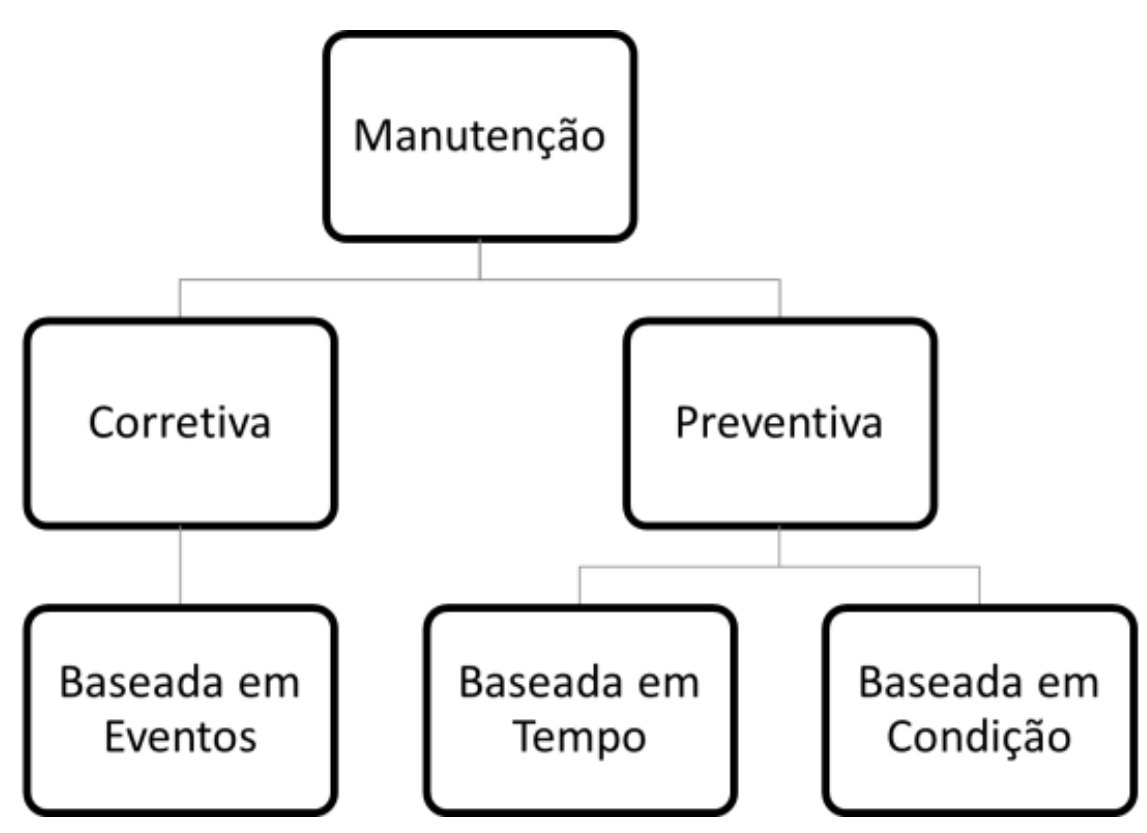

FONTE: ADAPTADO DE (MOBLEY, 2002)

Na manutenção corretiva, a equipe de manutenção atua de forma reativa, ou seja, após o problema ter se manifestado. Esse formato é limitado quanto à capacidade de planejamento prévio de atividades, colocando em risco a eficiência operacional devido à possibilidade de ocorrência de interrupções inesperadas do sistema e, consequentemente, indisponibilidade da prestação de serviço. 
Com o intuito de mitigar o contexto, eventualmente arriscado admitido pela manutenção corretiva, a manutenção preventiva introduz o conceito proativo de atuações antes da manifestação de possíveis problemas. Essa prática contribui para redução de custos por falhas e interrupções operacionais inesperadas (USHER; KAMAL; SYED, 1998), e tem como objetivo padrão a prevenção do acontecimento de falhas e disfunções. Adaptando os conceitos propostos por Mobley (2002) à ISO 13372 (2012), que define a terminologia padrão sobre monitoramento de condição, a manutenção preventiva pode seguir uma abordagem (i) periódica (baseada em tempos fixos de atuação) ou (ii) baseada na condição real do equipamento.

A manutenção periódica assume a ideia de que o comportamento da manifestação das falhas é previsível no tempo, e propõe um planejamento fixo, realizando reparos, ajustes e reposições de componentes degradados em períodos constantes durante toda a sua vida útil. A frequência da atuação das tarefas de manutenção é comumente definida por recomendações sugeridas pelo fornecedor do equipamento, ou adaptações feitas baseadas no conhecimento empírico de especialistas. As recomendações do fornecedor podem não ser ótimas, pois são definidas com base em estudos e testes genéricos que nem sempre reproduzem todos os possíveis cenários operacionais, no que se refere à intensidade de uso e condições ambientais (TAM; CHAN; PRICE, 2006). Consequentemente, com o objetivo de garantir a confiabilidade operacional do equipamento em qualquer cenário de utilização, as especificações sugerem períodos de utilização mais conservadores, podendo levar ao desperdício material pela reposição desnecessária de um equipamento ainda em bom estado de operação.

A manutenção baseada em condição, também conhecida por "manutenção preditiva" ou "monitoramento de condição", é uma abordagem preventiva não periódica, que combina processos e técnicas com base em dados de medições operacionais de sensores, com intuito de detectar, diagnosticar e prever possíveis falhas que possam colocar a operação em risco (SHIN; JUN, 2015). Essa estratégia tem sido extensivamente discutida na literatura nos últimos anos (JARDINE; LIN; BANJEVIC, 2006; AHMAD; KAMARUDDIN, 2012; SHIN; JUN, 2015) e trata sobre técnicas de monitoramento e avaliação de equipamentos de forma a preservar o uso do maquinário disponível, o que inclui o auxílio na tomada de decisão quanto ao tipo 
de ação a ser tomada por parte da equipe de manutenção, como, por exemplo, a necessidade de inspeção visual, ou a avaliação de custo-benefício entre reparo ou substituição de peças desgastadas (ALASWAD; XIANG, 2017).

Equipamentos defeituosos tendem a emitir medições discrepantes capturadas pelos sensores e apresentar taxas anormais de desgaste de seus componentes. A descoberta prematura de problemas, evita que esses equipamentos em falha continuem em uso, e suas partes tendem a ser preservadas. Essa característica promove não somente a economia e uso consciente sobre os ativos operados, mas também uma maior confiabilidade sobre o sistema (SHIN; JUN, 2015), já que equipamentos em situações previstas para falhar (ou seja, colocarem o sistema em risco) são tratadas antecipadamente, evitando indisponibilidades inesperadas.

Com o desenvolvimento e barateamento da tecnologia dos sensores que equipam a infraestrutura operacional, a aplicação da manutenção baseada na condição tornase viável, podendo trazer grande eficiência, dada a capacidade de prover uma visão antecipada de possíveis ameaças, e permitir um planejamento mais consciente sobre ações futuras nas atividades de manutenção, considerando redução de impactos na produtividade operacional, baseado nos sintomas avaliados sobre o estado de funcionamento do equipamento. Consequentemente, a manutenção baseada em condição possibilita promover maior eficiência e disponibilidade do serviço.

\subsubsection{Etapas do Processo de Manutenção baseada em Condição}

Inspirado em Isermann (2011) sobre gerenciamento de falhas, e Jardine (2006) sobre as principais etapas em uma estratégia baseada em condição, a Figura 16 ilustra um processo genérico contendo essas etapas: aquisição de medições de sensores (aquisição), tratamento e análise dos dados para a extração de parâmetros relevantes para as análises (processamento), a tomada de decisão para recomendar a política mais eficiente (tomada de decisão), com base em possíveis ações (ações). Tais etapas são detalhadas a seguir. 
FIGURA 16 - PROCESSO DE MANUTENÇÃO BASEADA EM CONDIÇÃO

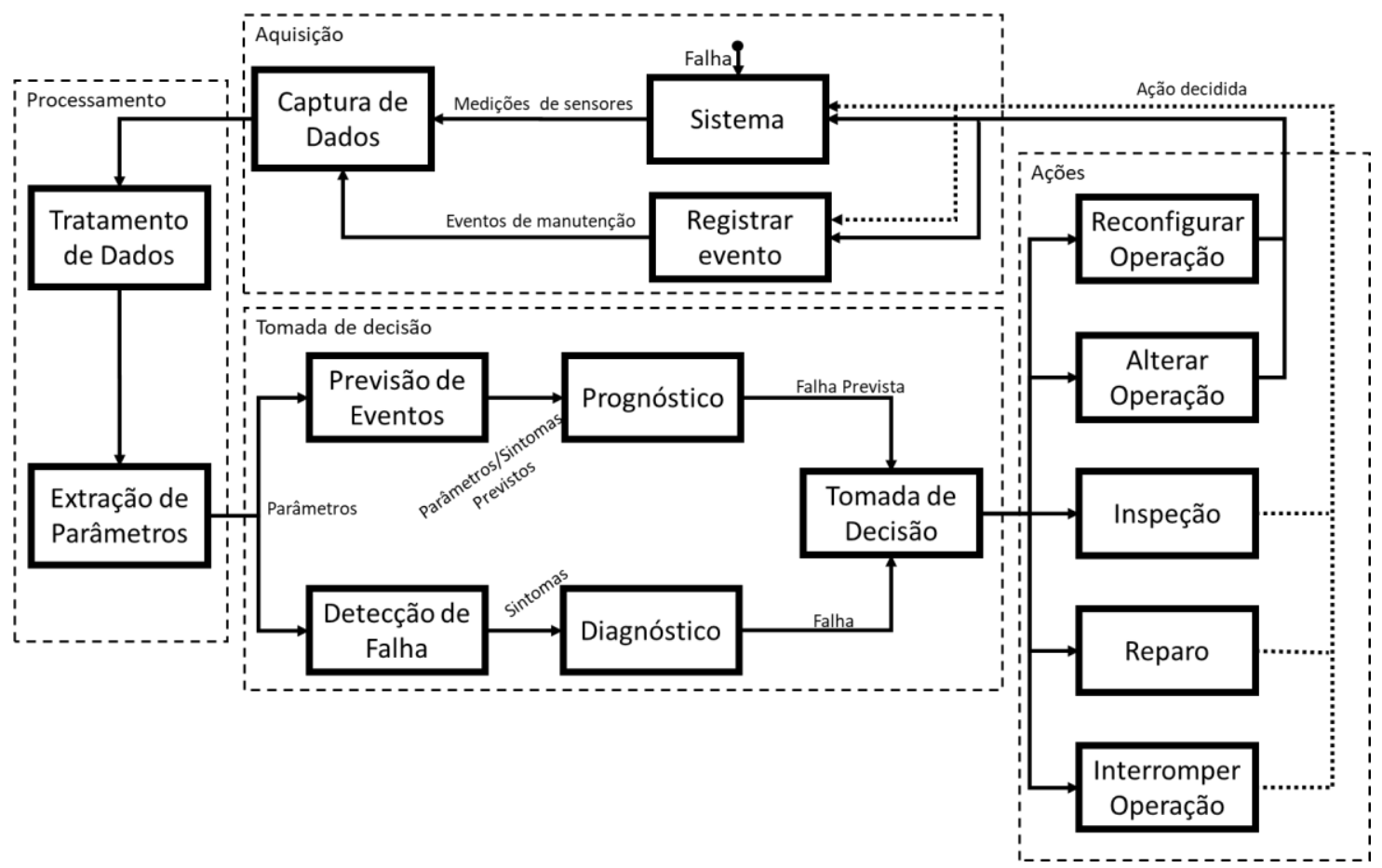

FONTE: AUTOR

1) Aquisição

A aquisição dos dados pode ser realizada a sobre histórico de eventos de manutenção ou pelo monitoramento de sensores (JARDINE; LIN; BANJEVIC, 2006). O histórico de eventos de manutenção engloba informações sobre ocorrências relacionadas aos ativos físicos, compreendendo o que ocorreu (inspeções, ocorrência de falhas ou de quebra de componentes) e o que foi feito (reparos, lubrificação, substituição de peças). Essa fonte de dados é comumente muito limitada, não estruturada e com muitos ruídos, já que é criada a partir de anotações manuais que podem não seguir padrões entre diferentes indivíduos. O monitoramento de sensores fornece medições brutas de instrumentos que equipam a infraestrutura operacional, e refletem grandezas relacionadas ao estado do equipamento em funcionamento.

Hashemian (2011) define que o monitoramento de condição pode ser feito a partir de três tipos de técnicas de sensoriamento: sensores do processo, sensores de teste e sinais de teste. Os sensores do processo englobam o uso de instrumentos nativos acoplados ao equipamento que medem características 
internas do sistema como pressão, temperatura e fluxo. Os sensores de testes, consideram o uso de sensores externos (normalmente sem fio) que capturam medições ambientais como vibração, ruídos acústicos, umidade ou temperatura do ambiente. Já os sinais de teste, que diferentemente dos dois tipos de técnicas reativas apresentados anteriormente, sugere a aplicação de sinais no sistema para detectar falhas no sistema, como, por exemplo, o uso de sensores ultrassônicos para encontrar rachaduras em peças.

2) Processamento

A etapa processamento dos dados refere-se ao tratamento e extração de parâmetros relevantes, sendo usado como entrada para posterior análise e tomada de decisões. O tratamento dos dados tem o objetivo de remover ruídos que venham a prejudicar os resultados das análises, como espaços em branco, valores nulos, correção de atributos, normalização de valores e remoção de parâmetros irrelevantes.

Os dados de entrada podem assumir três tipos de formatos: valores singulares, sinais (forma de onda) e multidimensionais (JARDINE; LIN; BANJEVIC, 2006). Os valores singulares são parâmetros que representam grandezas escalares como temperatura, umidade ou pressão. Sinais são valores capturados no tempo que têm comportamento oscilatório, como vibração e ruído acústico, e comumente precisam ser transformados do domínio do tempo para frequência, de modo que simplifique a análise e comportamento do parâmetro. Dados multidimensionais, são parâmetros que que possuem uma estrutura com múltiplos valores em uma mesma observação no tempo, como imagens e termografias infravermelhas.

A extração de parâmetros surge da necessidade de explicitar valores implícitos nos dados, como dados estatísticos e contextuais que possam contribuir efetivamente nas análises. Adicionalmente, as transformações de parâmetros fornecem uma visão mais apropriada no uso dos métodos preditivos, como as transformações de sinais (como Fourier, Hilbert e Wavelets) (FENG; LIANG; CHU, 2013), alterando os valores para o domínio da frequência, e as transformações dimensionais (como o Principal Component Analysis) (KHALID; 
KHALIL; NASREEN, 2014), promovendo a criação de novos parâmetros e tamanho dimensional reduzido, com perda ínfima de informação relevante. A redução dimensional de parâmetros favorece o treinamento de modelos em diversos aspectos, como melhoria nos resultados de predição, redução de sobre ajuste ("overfitting") pela eliminação de parâmetros irrelevantes, ruídos e dados redundantes (multicolinearidade) e treinamento mais veloz (menos dados a serem calculados) (PLASTRIA; DE BRUYNE; CARRIZOSA, 2008a).

O resultado dessas tarefas gera os dados tratados contendo o conjunto de parâmetros transformados para alimentar os métodos de análise de falhas.

3) Tomada de decisão

A tomada de decisão utiliza os dados tratados na fase de processamento, e por meio da aplicação de métodos para analisar e prever falhas, define-se a ação mais apropriada. A análise de falhas pode ser feita pela avaliação de eventos que já ocorreram (diagnóstico), ou pela previsão de eventos futuros baseado no estado atual do equipamento (prognóstico).

Dependendo da criticidade do problema encontrado, pode levar o sistema a ser interrompido ou mantido em operação para tratamento adequado quando for mais oportuno. De maneira geral, tomadas de decisão provenientes sobre prognósticos tendem a ser encaminhadas para inspeções no momento mais oportuno, dado que o problema ainda é incipiente. No caso de paradas planejadas baseadas em diagnósticos sobre o momento presente, as ações podem estar relacionadas a inspeções, reparos ou interrupções imediatas (no caso de risco eminente de acidentes), dependendo das evidências obtidas das análises.

4) Ações

Ações que mantenham o sistema em operação com alteração operacional, sugerem alteração na taxa operacional (como velocidade, vazão, pressão ou potência), para valores mais conservadores mitigando o risco da evolução da falha e acidentes naquela situação. No caso de sistemas tolerantes a falhas, 0 equipamento pode ser ajustado para usar seus recursos redundantes, de modo 
que mantenha o serviço ativo, podendo ter 0 desempenho reduzido (ISERMANN, 2011). Adicionalmente, Isermann (2011) sugere que ações tomadas relacionadas à inspeção e reparos, podem ser graduadas em diferentes níveis de criticidade, sendo a prevenção da falha sobre problemas incipientes ou de baixo risco, remoção da falha sobre problemas já manifestados e prevenção da falha através da redundância no caso de problemas manifestados que serão tratados através de componentes de contenção de sistemas tolerantes a falhas.

Ainda sobre a tomada de decisão sobre equipamentos que possam falhar de forma iminente, equipamentos em estado de funcionamento ótimo podem sofrer por eventos adversos da operação e apresentar comportamentos momentaneamente anômalos. Tais eventos podem ser imprevisíveis e surgem a partir da propagação de falhas por outros componentes que compõem o sistema ou mesmo em situações excepcionais de operação. Um prognóstico de falha robusta deve ser capaz de avaliar a criticidade em situações similares e diferir sobre falhas pontuais ou simples oscilações operacionais, que aparentemente fogem das faixas normais de operação, mas não necessariamente representam uma ameaça ao sistema (CHALAPATHY; CHAWLA, 2019), indicando assertivamente qual a melhor decisão a ser tomada.

A definição se um equipamento atingiu o limite da sua vida útil também pode ser subjetiva, dado que certas evidências não são capturadas pelos sensores, e podem requerer inspeção visual detalhada. Desconsiderando medições relacionadas a características físicas como dimensões e deformações, que são evidências explícitas de degradação, equipamentos que são monitorados por outros atributos como vibração ou emissões acústicas podem ser classificados de forma automática como em fim de vida sobre uma medição que indique ameaça iminente de falha ao comparar com faixas de seguranças operacionais definidas (medições ultrapassaram a faixa operacional limite), ou medições frequentes anormais, levando em conta a precisão e confiança dos sensores usados.

Uma opção complementar para apoiar tais questões é o uso de eventos históricos de manutenção combinados aos dados de monitoramento dos sensores (JARDINE; LIN; BANJEVIC, 2006). Os históricos de eventos podem 
ser associados a análises de sobrevivência (similar ao realizado na manutenção periódica), e são reforçados pelas medições dos sensores para realizar cálculo de ameaça. Essa abordagem é vantajosa ao combinar o risco de ocorrência de falhas em um tempo específico da sua vida útil (com base em uma curva de probabilidade) às suas condições atuais de degradação, sendo a distribuição Weibull comumente aplicada para modelar o risco de falha de equipamentos (JARDINE; LIN; BANJEVIC, 2006).

\subsubsection{Detecção de Falhas}

A detecção é a tarefa inicial em um processo de análise de falhas, sendo responsável por identificar comportamentos anômalos que podem perturbar o funcionamento do sistema. Diversos autores enquadram a detecção como parte do processo de diagnóstico (JARDINE; LIN; BANJEVIC, 2006; SHIN; JUN, 2015), já que as falhas detectadas são insumo para as análises mais detalhadas quanto a causa e criticidade. Entretanto, neste trabalho, os conceitos de detecção e diagnóstico são tratados à parte, de modo a designar claramente a fronteira funcional e tipos de técnicas adotadas.

A detecção de falhas tem sido tratada como uma aplicação de trabalhos direcionados à detecção de anomalias (SIELLY; COSTA, 2014; CHALAPATHY; CHAWLA, 2019), dada a natureza similar e conceitualmente aplicável de ambos os problemas tratados. Uma anomalia é definida como um evento raro e inesperado que se desvia do comportamento normal. Apesar da falha poder ser enquadrada como uma anomalia, uma anomalia não necessariamente é uma falha, pois pode se tratar de uma observação normal com padrão desviado e ainda não reconhecido, mas que não necessariamente comprometa o funcionamento do sistema (CHALAPATHY; CHAWLA, 2019). Esta pesquisa adota a adaptação conceitual de anomalias para o problema sobre detecção de falhas.

\subsubsection{Tipos de Anomalias}

A detecção de anomalias pode ser realizada em escopo pontual, coletivo e contextual, em relação aos conjuntos de dados de treinamento. A análise em nível pontual visa identificar observações destoantes em nível regional ou global da 
amostra, que aparentemente não sigam nenhum padrão. Nas anomalias coletivas, as disparidades são avaliadas por regiões específicas no espaço dimensional de parâmetros, ou por um padrão recorrente de observações. Anomalias contextuais se caracterizam como distorções em contextos específicos, e normalmente estão relacionadas a problemas encontrados em análise temporal ou espacial, ou seja, observações que aparentemente são normais em determinadas situações (visão pontual), podem se mostrar anômalas ao comparar com seu comportamento histórico.

A Figura 17 mostra exemplos dos três tipos de anomalia: no gráfico esquerdo, C1 pode ser considerado um cluster relativamente denso; A1 é uma anomalia pontual, devido ao seu distanciamento em relação aos demais pontos; C2 é um caso mais subjetivo, podendo ser considerado tanto um cluster de menor densidade ou um padrão de anomalia coletivo; A2 pode ser uma anomalia pontual regional (em relação a C2) ou uma anomalia global (em relação ao todo). O gráfico do lado direito mostra o exemplo de uma série temporal com comportamento senoidal, e apresentando uma anomalia contextual em D4, pois não houve medição discrepante, mas uma quebra da fase da onda.

FIGURA 17- TIPOS DE ANOMALIA
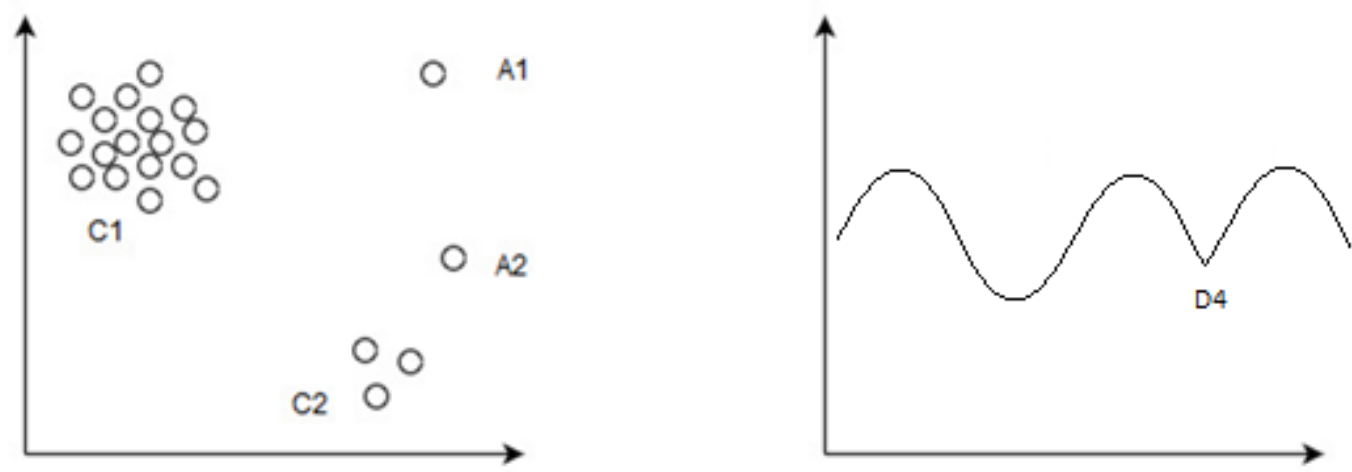

FONTE: AUTOR

\subsubsection{Critérios de Detecção}

A definição da fronteira entre os estados normal e falha é um problema inerente à tarefa de detecção. Entende-se que observações normais tendem a ser similares, consequentemente estando em zonas densas, com distâncias relativamente equilibradas do centroide, ou com alta qualidade de reconstrução. Dessa forma, esses 
modelos balizam o seu grau de discriminação de anomalias por um parâmetro de configuração de "contaminação", que determina o percentual de observações que apresentam maior grau de anomalia sobre os dados de treinamento.

Durante o treinamento, o modelo identifica o percentual das observações mais discrepantes da amostra, e define os limites de medida (no qual, a depender da técnica pode ser distância, densidade, reconstrução ou heurísticas específicas) conforme limites percentuais definidos como anomalia (contaminação). O modelo pode retornar diretamente uma resposta binária (normal ou falha), escores ou probabilidades (0\% sobre total certeza em ser normal, $100 \%$ sobre total certeza em ser falha, e consequentemente $50 \%$ sendo o nível máximo de incerteza sobre a resposta).

Como mostrado na figura 18, existem diferentes linhas de métodos de detecção não supervisionada sobre anomalias. Tradicionalmente, as implementações se baseiam em técnicas de agrupamento de dados (clustering), como Gaussian Mixture Model (GMM), K-Nearest Neighbor (KNN), K-means, e DBScan, que avaliam se uma observação é normal ou anômala através de um cálculo de similaridade, sendo pela densidade das observações (número de vizinhos próximos em um raio determinado), ou distância em relação aos centroides de agrupamentos de dados. 


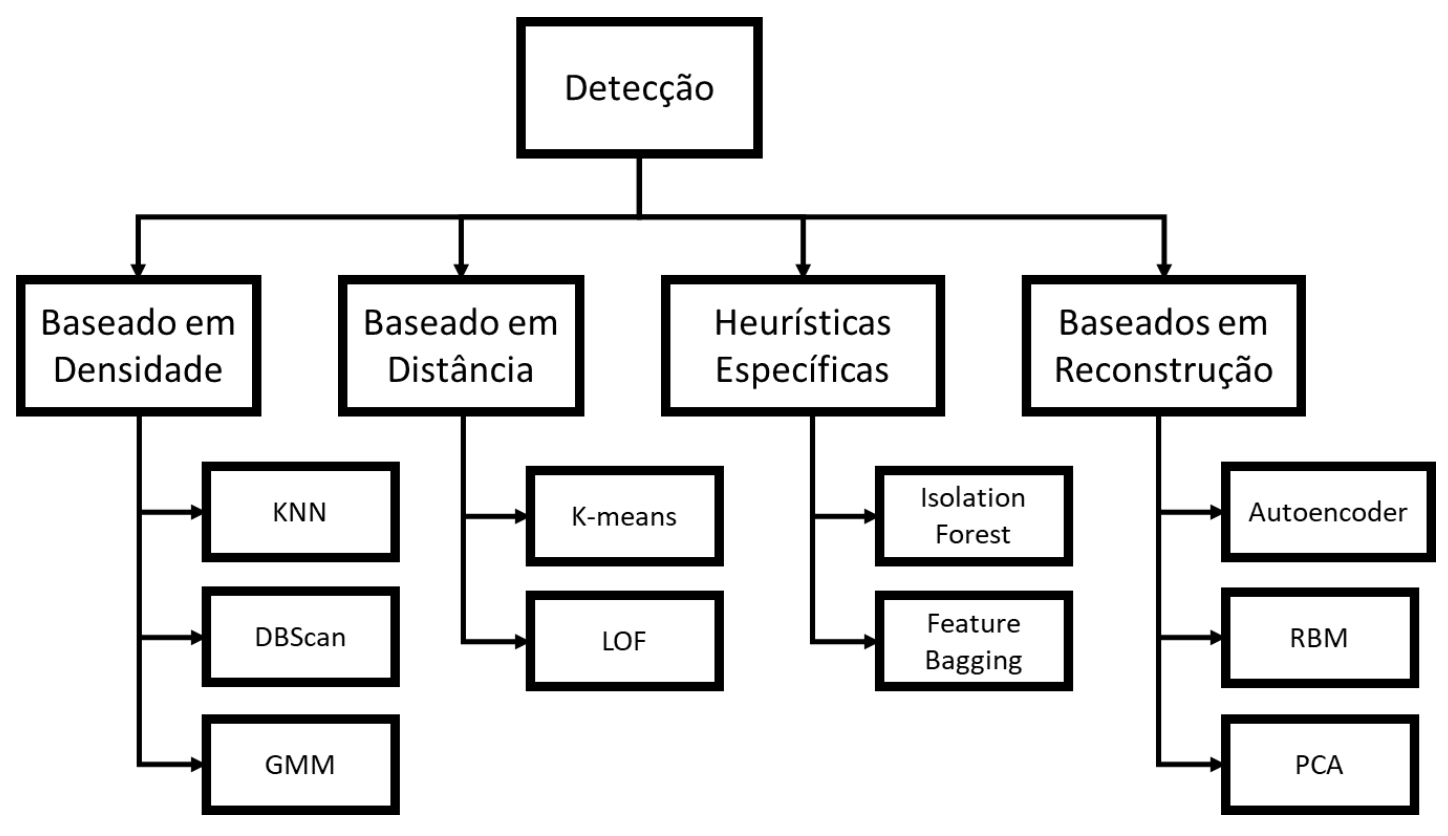

FONTE: AUTOR

As abordagens baseada em heurísticas específicas definem meios próprios de medidas para discriminação de anomalias, no qual podemos citar Feature Bagging (LAZAREVIC; KUMAR, 2005), Angle-based Outlier Detector (KRIEGEL; SCHUBERT; ZIMEK, 2008), e com destaque o Isolation Forest (LIU; TING; ZHOU, 2008), sendo considerado até um passado recente como estado-da-arte nesse tipo de aplicação.

O Isolation Forest é um modelo de ensemble (composição de vários modelos) de árvores de decisão (chamadas de árvores de isolamento), contendo uma heurística fundamentada na ideia que, ao realizar buscas por amostras em faixas de valores sobre parâmetros particulares, as anomalias são mais fáceis de serem isoladas, dado a seu aspecto naturalmente distorcido. Cada árvore de isolamento é treinada usando uma parcela do conjunto total de parâmetros e dos dados de treinamento, onde cada nó da árvore define regras de busca que visam encontrar amostras que estejam destoantes das outras. Desse modo, entende-se que amostras normais precisam percorrer mais nós nas árvores para serem isoladas de todo o resto, visto que elas se encontram normalmente concentradas em faixas mais limitadas do campo multidimensional de parâmetros. A figura 19 exemplifica uma tarefa de detecção feita com o Isolation Forest, na qual pode ser percebido que o ponto vermelho é facilmente isolável em 3 buscas (representadas pelos cortes sobre o plano dimensional). 0 
Isolation Forest é usado nesta pesquisa para comparação de desempenho sobre os experimentos de detecção de falhas.

FIGURA 19- EXEMPLO DE DETECÇÃO USANDO ISOLATION FOREST

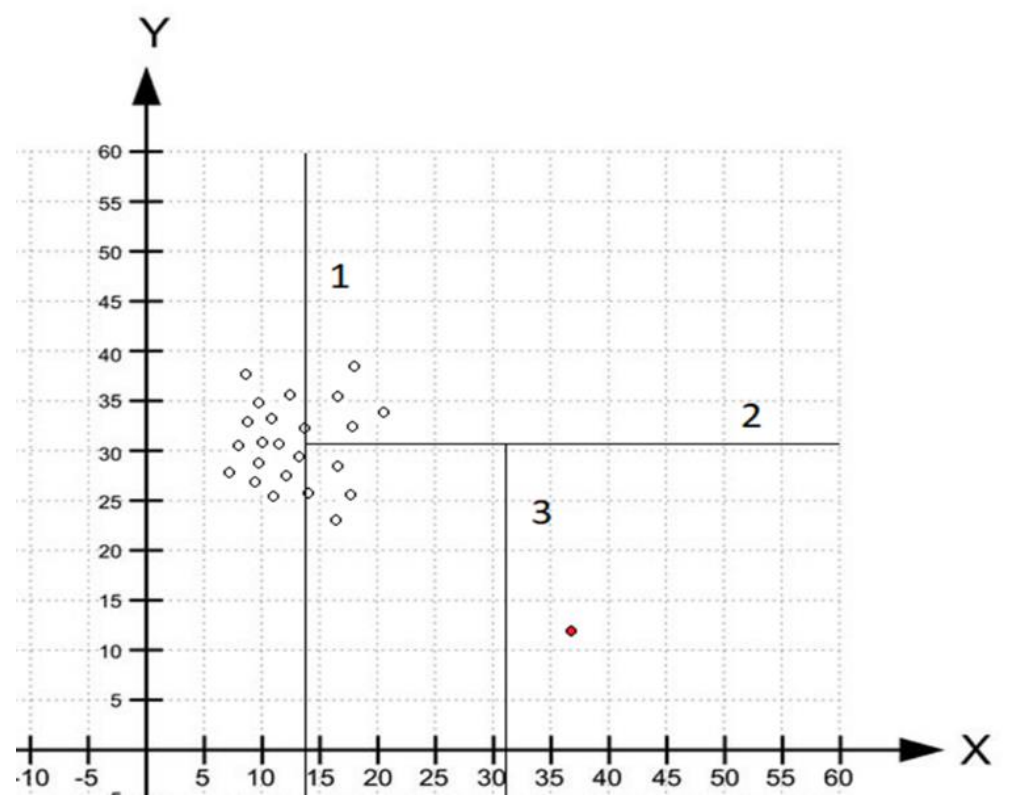

FONTE: AUTOR

Uma outra abordagem de métodos tem sido discutida extensivamente na literatura com foco na reconstrução e comparação com a respectiva entrada (CHALAPATHY; CHAWLA, 2019), com destaque para modelos como Autoencoders ( e suas variantes), Restricted Boltzmann Machines (RBM) e Principal Component Analysis (PCA). A ideia geral dessa abordagem é que o dado é transformado para uma dimensão (geralmente menor), e inversamente transformado para as dimensões originais. Como problemas de detecção de anomalias geralmente tratam bases de dados desbalanceadas (visto que anomalias são eventos raros), a filosofia de uso dos modelos baseados em reconstrução entende que os modelos são treinados para reproduzir observações normais com alto desempenho. Por outro lado, esses modelos tendem a falhar para reproduzir, com fidelidade, as anomalias. Desse modo, esses modelos discriminam as amostras pelo cálculo de erro residual entre normal (normalmente valores mais baixos) e falha (valores mais elevados).

A figura 20 representa o funcionamento genérico de um modelo baseado em reconstrução, na qual os dados de entrada $x$ são transformados em uma dimensão reduzida por uma função $f$, gerando os dados $z$. Os dados reduzidos $z$ são 
transformados para a dimensão original por uma função $g$, resultando na reconstrução $x^{\prime}$. O erro residual é calculado pela diferença entre a entrada e saída produzidas (erro residual) por uma função $h$, representada comumente pelo erro quadrático na forma $y=\left(x-x^{\prime}\right)^{2}$. E por fim, sobre esse erro residual, define-se uma faixa de tolerância entre normal e falha.

FIGURA 20 - MÉTODO GENÉRICO DE DETECÇÃO BASEADA RECONSTRUÇÃO

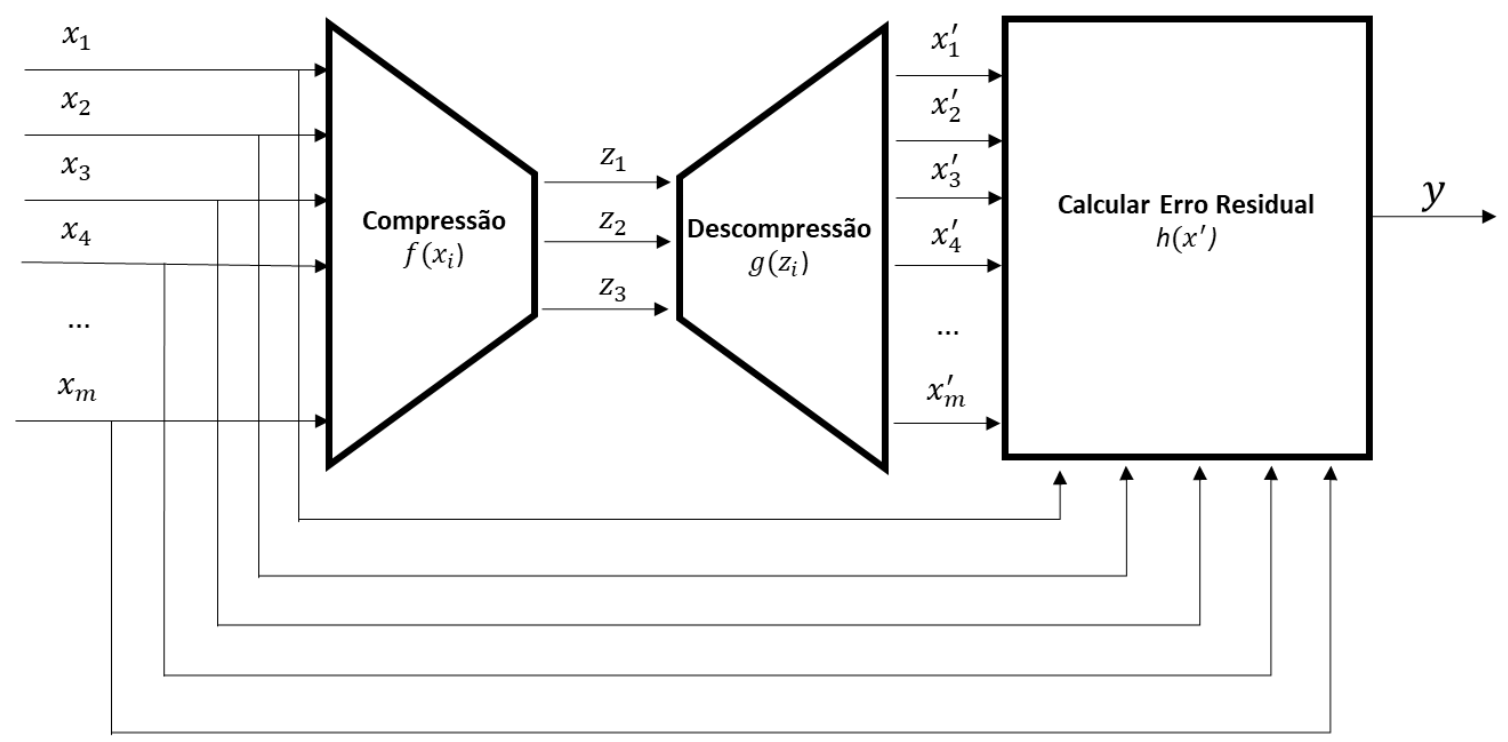

FONTE: AUTOR

\subsubsection{Métricas de Avaliação}

No contexto de métodos não supervisionados, diversas métricas estão disponíveis para avaliar a qualidade de geração de clusters sob diferentes aspectos (AMIGÓ, 2008), como homogeneidade, completude, isolamento de anomalias, e equilíbrio entre tamanho e quantidade de clusters. Tais métricas são apropriadas em problemas de geração de múltiplos clusters, sendo apropriadas na categorização multinominal sobre padrões de falha, parte importante da atividade de diagnóstico de falhas, que é discutido na próxima seção.

Por outro lado, assumindo-se que existam limites operacionais de segurança que discriminem objetivamente o comportamento normal e em falha, o problema de detecção pode ser encarado com uma classificação binária (normal ou falha), tornando o cenário de validação mais restrito e direto. Com base em especificações operacionais sobre faixas de segurança para funcionamento, ou apoio especialista na 
validação dos resultados classificados, os valores reais sobre os estados podem ser levantados, e consequentemente o uso de métricas tradicionais para métodos supervisionados podem ser satisfatórios.

Algumas das métricas mais comuns para classificadores podem ser melhor entendidas pela Figura 21, que retrata uma matriz de confusão, mostrando a composição de resultados entre a realidade e predição. A acurácia mede a capacidade de classificação geral do modelo. Como problemas de detecção normalmente utilizam bases de dados desbalanceadas (quantidade de valores normais é muito maior do que a quantidade de valores falhos), essa métrica não é adequada, pois a maioria das observações são normais, e mesmo modelos que não consigam captar tal característica, poderiam alcançar altas taxas de acurácia.

A precisão mede o grau de pureza sobre as observações classificadas como falha, ou seja, mede a capacidade do modelo não ser tendencioso a classificar observações normais como falhas. A sensibilidade é a capacidade do modelo detectar todas as falhas realmente existentes, ou seja, o quanto o modelo não ser tendencioso a deixar observações de falhas passarem despercebidas.

FIGURA 21 - MATRIX DE CONFUSÃO

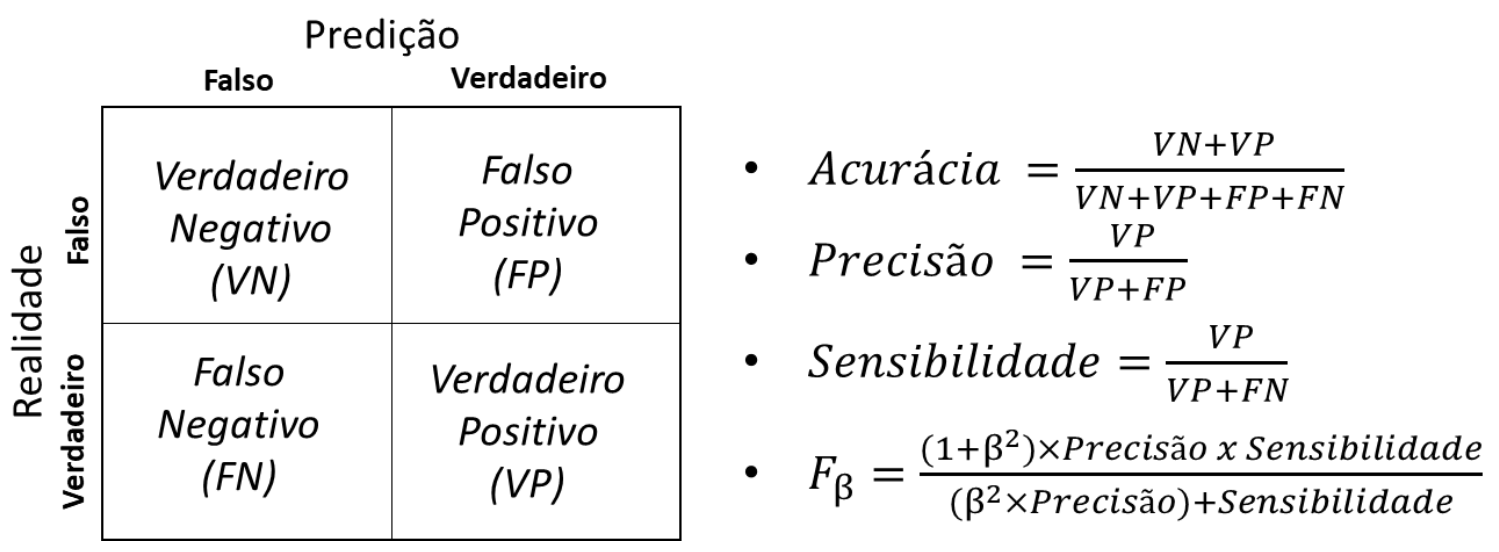

FONTE: AUTOR

A medida $\mathrm{F}_{\beta}$ ("F-measure") calcula uma métrica ponderada entre a precisão e a sensibilidade. Dependendo do requisito funcional, pode ser atribuído mais peso para a sensibilidade $(\beta>1)$ ou para precisão $(\beta<1)$. No caso mais trivial $(\beta=1)$, considerase como a média harmônica entre as duas métricas, no qual compartilham igual 
importância. Valores elevados da medida $F_{\beta}$ (assumindo um valor adequado de $\beta$ ) significa que o modelo é ótimo.

\subsubsection{Diagnóstico de Falhas}

No monitoramento de condição de sistemas, a capacidade de analisar falhas detectadas por meio do isolamento (localizar o componente que está em falha) e identificação (determinar a natureza da falha), pode ser chamado de diagnóstico (ISERMANN, 2011). Jardine (2006) define o diagnóstico de falhas, como o procedimento de se reconhecer padrões sobre informações obtidas no espaço de medições e parâmetros operacionais, e mapeá-los para o espaço de falhas.

\subsubsection{Abordagens de Diagnóstico}

Os métodos de diagnóstico de falhas podem ser classificados como (i.) baseados em modelos, (ii.) baseados em conhecimento e (iii.) baseados em dados (JAMIL et al., 2016). A Figura 22 descreve, de modo geral, as possíveis abordagens sobre diagnóstico de falhas e os tipos de técnicas associadas, dando-se destaque sobre a abordagem baseada em dados, visto que é o direcionamento integral desta pesquisa.

Os métodos baseados em modelos referem-se a equações matemáticas que descrevem o comportamento operacional do sistema ou componente, levando em consideração características físicas relacionadas ao desgaste natural causado pelo funcionamento. Essa abordagem é normalmente adequada para estruturas menores sob ambiente de funcionamento bem controlado. Por meio da comparação de resultados residuais entre os valores esperados com os valores medidos, 0 diagnóstico é levantado.

Em processos baseados em conhecimento, depende-se da avaliação qualitativa de especialistas do domínio do problema, o que pode ser subjetivo e impreciso do ponto de vista de eficiência, sendo pouco apropriado em operações de grande escala.

Os métodos baseados em dados são considerados como a opção mais capaz de se tratar problemas complexos, no que diz respeito à eficiência e escala (JAMIL et al., 2016). Esta abordagem faz uso de dados provenientes do monitoramento por sensores, e por meio de uma preparação adequada, diferentes métodos podem ser 
aplicados, como análises de sinais, métodos estatísticos e inteligência artificial. Independente da capacidade dos métodos, vale ressaltar que esse tipo de prática para diagnóstico pode continuar a depender do apoio de especialistas do domínio do problema, de modo a validar e nomear os padrões de falha encontrados.

FIGURA 22 - TIPOS DE DIAGNÓSTICO

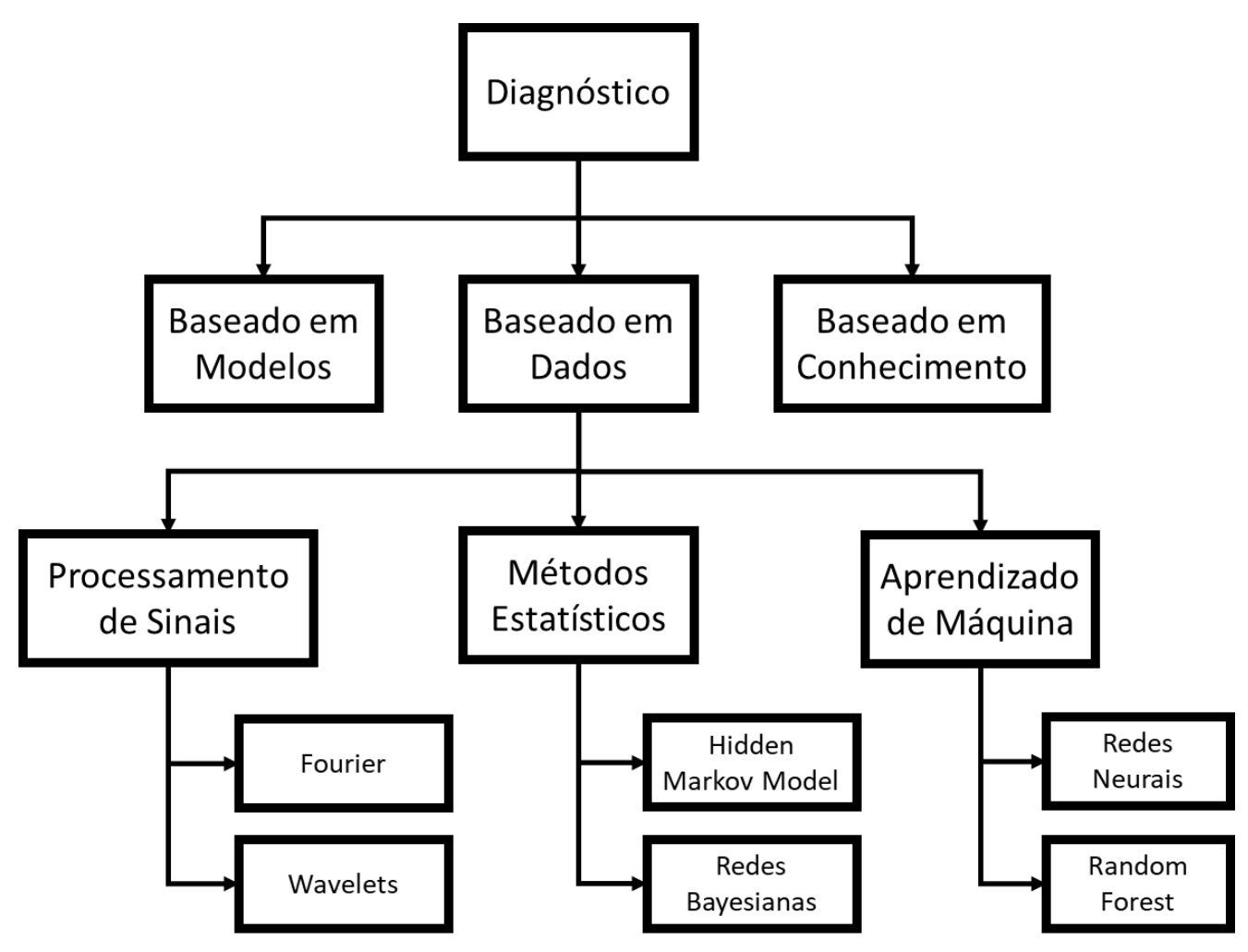

FONTE: AUTOR

As análises de sinais incluem verificação sobre padrões de assinatura de curvas e análises espectrais por meio de avaliações visuais por parte de especialistas ou ainda com uso de métodos de transformadas como Fourier e Wavelets. Como já exemplificado na Figura 16, por meio de um padrão de anomalia detectado na assinatura de uma onda, um modo de falha pode ser diagnosticado. Apesar da capacidade de identificar e localizar a fonte da falha com precisão, em determinados cenários, essa abordagem pode ser limitada a falhas incipientes, devido ao ruído sobre os sinais medidos, muitas vezes por perturbações do próprio ambiente (ZHANG et al., 2019).

Os métodos estatísticos sugerem a comparação de observações capturadas, e verifica padrões de desvios sobres propriedades, como a distribuição de probabilidade 
estimada em relação às observações presumidamente normais. Com o uso de técnicas, com destaque para a técnica de Mistura de Gaussianas, modelos de Markov ou redes Bayesianas, verifica-se se a composição de parâmetros das observações se enquadra apropriadamente em algum modo de falha previamente conhecido. As redes Bayesianas fornecem relações de dependência probabilística entre os parâmetros e a possível causa da falha, enquanto os modelos de Markov (com destaque para o HMM) têm sido comumente sugeridos como método de classificação de tipos e evolução da falha, ao se mapear a probabilidade entre o estado normal e os possíveis modos de falha, dado a condição atual.

O uso de técnicas de inteligência artificial promove um meio robusto para auxiliar na atividade de diagnóstico, permitindo, por meio do uso de métodos de otimização, que haja o aprendizado sobre relacionamentos complexos e não lineares entre parâmetros. Os métodos abrangem abordagens supervisionadas e não supervisionadas, dependendo da disponibilidade de descrições sobre a falha para uso no treinamento.

Em domínios de problemas bem controlados, no qual existem anotações sobre o diagnóstico constatado em relação às medições capturadas, os métodos supervisionados mais comumente aplicados são o SVM, Random Forest e arquiteturas de redes neurais supervisionadas. Visto que o custo e esforço operacional para capturar e manter essas anotações é alto, os métodos não supervisionados são uma saída viável, e sugerem um meio diferente para avaliar falhas. Esta pesquisa visa o aprofundamento e discussão sobre abordagens não supervisionadas.

\subsubsection{Diagnóstico Não Supervisionado}

A exploração de modos de falhas por meio de métodos não supervisionados é comumente realizada por de técnicas de clustering para reconhecimento de padrões (como K-means, DBScan e SOM). A ideia sugere que as observações que fogem de um comportamento supostamente normal, podem ser agrupadas e avaliadas pelo seu grau de similaridade (sendo as mais comuns a distância Euclidiana, Manhattan e Mahalanobis). A geração dos clusters deve ser avaliada (i.) no âmbito dos dados, por qualidade dos clusters formados por métricas intrínsecas dos dados, e (ii.) do ponto 
de vista prático e funcional (representatividade e abrangência dos grupos em relação aos modos de falhas conhecidos).

A avaliação de qualidade dos clusters formados pode ser feita por métricas para técnicas de clustering, que se baseiam em parâmetros como homogeneidade (capacidade de agrupar as observações alta similaridade na mesma categoria, favorecendo densidade), completude (capacidade de agrupar observações similares em um cluster concentrado, favorecendo volume), isolamento de anomalias em um grupo específico (também conhecido como "Rag bag", favorecendo a pureza dos clusters, visto que amostras que não se adequem a nenhum grupo, não serão forçadamente atribuídos a algum), e equilíbrio entre tamanho e quantidade de clusters (capacidade em balancear a criação de cluster maiores e menos densos, ou mais densos e em maior número) (AMIGÓ, 2008).

No que diz respeito à validação funcional, com o apoio de especialistas no domínio do problema, cada um dos grupos pode ser avaliado para identificar se a falha realmente existiu, e se a fonte da falha foi persistente dentro dos grupos. Para uma validação e categorização funcional com menos incerteza sobre os tipos de falhas identificados, é importante que a formação dos clusters sejam bem definidas.

Com o objetivo de melhorar a qualidade de geração dos clusters, a extração de parâmetros pode trazer resultados significativos sobre os resultados dos modelos. Por intermédio de técnicas de redução de dimensionalidade, com destaque para o PCA e autoencoder (e suas variantes), informações redundantes são descartadas, e os parâmetros são transformados em uma nova configuração reduzida e capaz de representar a configuração origem com baixa perda de informação. Essa prática promove um treinamento de modelos com melhores resultados, mais resistentes ao overfitting, e de modo mais rápido. Vale ressaltar que essa prática também favorece a qualidade de métodos supervisionadas (PLASTRIA; DE BRUYNE; CARRIZOSA, 2008b).

A Figura 23 exemplifica uma categorização via clustering, para identificar 3 modos de falha e o estado normal, sobre o mesmo conjunto de dados, porém com transformações dimensionais sobre formas diferentes: Principal Components Analysis (PCA), Stacked Autoenconder (SAE) e Stacked Denoising autoencoder (SDA). O 
exemplo mostra uma formação mais bem sucedida de clusters pelo SDA, ao conseguir clara separação entre os grupos (destacado por cores) com baixa sobreposição (pelo distanciamento mais claro das formações).

\section{Figura 23 - Formação de Clusters de FALHA}
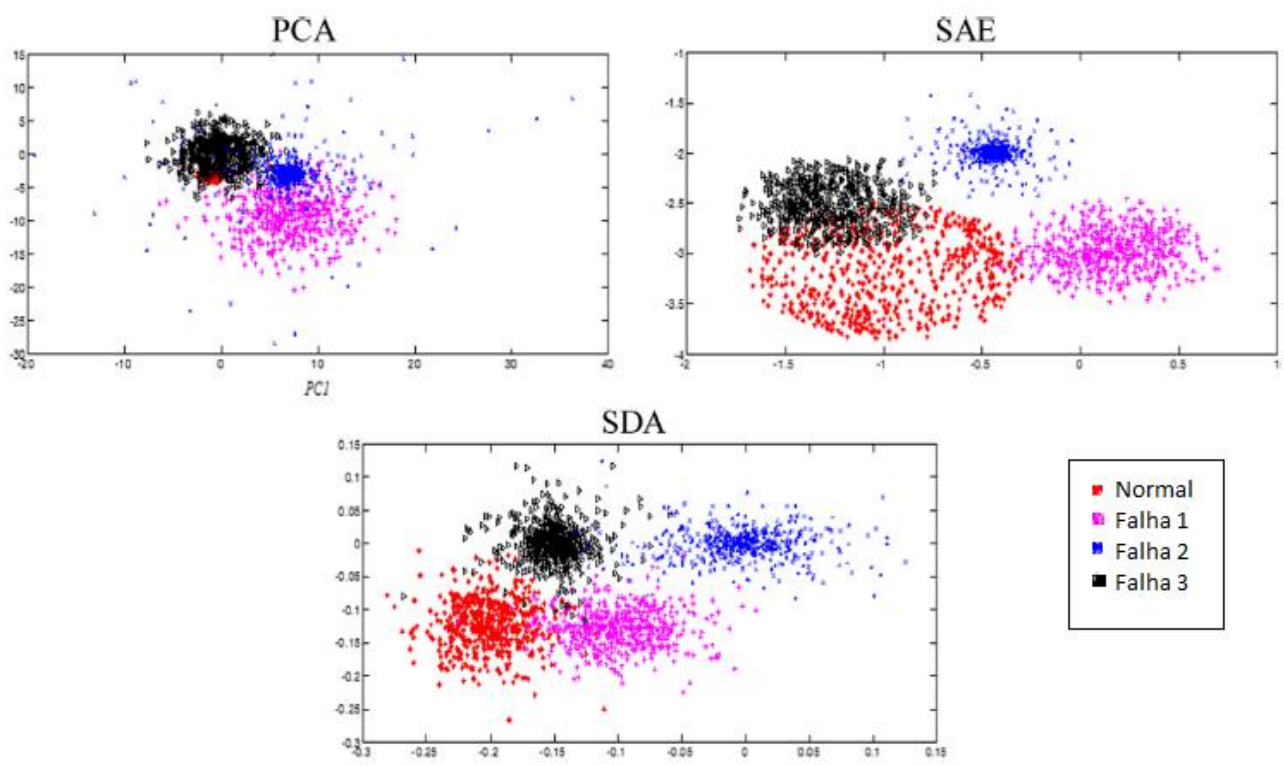

\subsubsection{Considerações sobre o Diagnóstico via Interpretabilidade de Modelos}

Como discutido durante esta seção, parte dos métodos são treinados em modo supervisionado, dependendo de informações operacionais (muitas vezes escassas), ou em casos não supervisionados, pelo uso de técnicas de reconhecimento de padrões, apoiado por especialistas para interpretar e validar os resultados, ou com base em regras sobre faixas de segurança operacionais, provendo lógicas simples fixas e pouco abrangentes em relação aos possíveis problemas do mundo real.

A abordagem de interpretabilidade de modelos é um conceito relativamente novo na literatura, obtendo grande destaque ao possibilitar que modelos complexos e mais robustos pudessem ser explicáveis. Em outros domínios de problema, principalmente na área de saúde, essa técnica tem sido sugerida sobre dois principais pretextos: (i.) prover confiança nos resultados do modelo e (ii.) prover meios que forneçam conhecimento sobre como o resultado foi obtido. 
Esta pesquisa identifica potencial no uso de tais técnicas para prover quais foram os parâmetros mais importantes para a classificação de uma observação como falha, mantendo o foco sobre técnicas de deep learning. Adicionalmente, padrões de ranqueamento de falhas são uma nova fonte de informação a ser explorada para identificação comportamental.

\subsubsection{Prognóstico de Falhas}

Denomina-se prognóstico à capacidade de prever falhas antes de sua manifestação e estimar o tempo de vida útil restante de um equipamento (KIM; CHOI; AN, 2016; LIU et al., 2019). O prognóstico engloba uma gama de disciplinas e ferramentas como tecnologias de sensoriamento, modelos físicos e estatísticos de degradação de peças e equipamentos, técnicas de inteligência artificial e conceitos de engenharia de confiabilidade (KIM; CHOI; AN, 2016).

Esta pesquisa adota o conceito de prognóstico considerando a capacidade de prever falhas e estimar a vida útil restante do equipamento, considerando uma faixa de visão futura determinada. Portanto, o prognóstico de falhas em casos de equipamentos que tendem a ter alta longevidade, e aparentemente estar em estado ótimo como no início da sua vida útil, poderia, por exemplo, concentrar-se em fazer a estimativa de que o equipamento não tenderia a falhar em um futuro visível. Consequente, entende-se que inferir algo além disso não seria confiável, podendo levar a resultados com baixa precisão.

Um método de prognóstico eficiente deve compreender o estado de funcionamento atual do equipamento e prever eventos em um tempo futuro determinado, ou seja, por meio do estado atual, antever um comportamento anormal, que possa levá-lo a uma situação de falha ou ao fim da sua vida útil. O prognóstico tende a ser muito mais eficiente que o diagnóstico, ao promover alto desempenho operacional pela redução de indisponibilidades do serviço (JARDINE; LIN; BANJEVIC, 2006). Entretanto, o diagnóstico continua sendo importante quando o prognóstico não for capaz de prever eventuais falhas. 


\subsubsection{Abordagens de Prognóstico}

O objetivo do prognóstico pode estar direcionado em dois pontos: (i.) estimar quando um equipamento tende a falhar ou qual o grau de risco de um equipamento vir a falhar, ou seja, operar fora dos padrões esperados, e que potencialmente levem a disfunções; (ii.) estimar o tempo de vida útil (RUL - Remaining Useful Lifetime), que é a estimativa de tempo para que um equipamento venha a sofrer um problema que interrompa parcialmente ou definitivamente o serviço provido (disfunção), tratando-se então de eventos potencialmente catastróficos que coloquem em risco a confiabilidade e segurança do sistema. Adicionalmente, a estimativa do RUL pode estar relacionada não somente a interrupções do serviço, mas também equipamentos com estado avançado de degradação que entrem em estado de falha com recorrência.

A estimativa de RUL e sobre possíveis falhas são sugeridas sob diversas formas na literatura. Similarmente à categorização descrita sobre diagnóstico de falhas, o prognóstico pode seguir abordagens (i.) baseadas em modelos, (ii.) baseadas em conhecimento e (iii.) baseadas em dados (JARDINE; LIN; BANJEVIC, 2006).

A abordagem tradicional baseada em conhecimento define regras prédeterminadas sobre o conhecimento empírico obtido (avaliações qualitativas), especificações do fornecedor que sugerem tempos fixos estimados (conforme discutido em Manutenção Periódica), ou pelo estabelecimento de faixas operacionais de segurança sobre medições de sensores baseados em históricos operacionais, combinados a modos conhecidos de falhas previamente mapeados.

A abordagem baseada em modelos faz uso de modelos mecânicos e matemáticos, adequados à arquitetura do equipamento, que reflete o tipo de desgaste natural sofrido sobre durante seu funcionamento, causado pela iteração das peças internas, ou sobre o funcionamento em taxas de operações diferentes e em condições ambientais adversas. À medida que a complexidade e incerteza sobre o funcionamento de sistema aumenta, a modelagem matemática que explicite os aspectos operacionais tende a ser muito dificultada (KHAN; YAIRI, 2018). Apesar da alta precisão, tal abordagem está comumente presente em sistemas menores ou sobre componentes específicos. A degradação de componentes e sistemas é frequentemente endereçada por modelos estocásticos que aproximam uma curva 
padrão aproximada em relação ao tempo, como feito nas técnicas Wiener, Gamma e Gamma Inverso (ASSAF; NEFTI-MEZIANI; SCARF, 2017).

As abordagens baseadas em dados trazem consigo questões quanto à definição sobre RUL. Um tipo de visão sobre RUL sugere a modelagem guiada por regras de faixas de segurança operacionais e por medições de sensores (similar a abordagem baseada em conhecimento), porém possibilitando a exploração sobre padrões de evolução de comportamentos de falha durante o tempo. A outra visão sugere a necessidade de conhecimento sobre as medições por sensores, e evidências relativas aos modos de falha e disfunções mapeados, permitindo a modelagem sobre tendências e propagação das falhas, com base nas distribuições dos parâmetros medidos. Ambas as visões podem ser endereçadas por meio de métodos estatísticos ou de inteligência artificial.

Entre os métodos estatísticos, para a predição de medições que permitam a predição de um equipamento sofrer falha baseados em dados históricos, bem como estimação de riscos (ou estados de falha e possíveis disfunção), podem ser citados: técnicas tradicionais de regressão linear; modelos auto regressivos com médias móveis (ARMA) e similares; modelos de espaço de estados como os filtros de Kalmann (para iteração e associação com múltiplos modelos com degradação linear e ruído gaussiano) e Filtro de Partículas (degradação não linear e ruído não gaussiano) (ASSAF; NEFTI-MEZIANI; SCARF, 2017); análises de sobrevivência; Modelos Ocultos de Markov (HMM); e Redes Bayesianas Dinâmicas.

Entretanto, a aplicação de métodos de aprendizado de máquina para prognóstico de falhas (assim como em diagnóstico) tem tido crescente adoção e foco de pesquisas encontradas na literatura nos últimos anos (KIM; CHOI; AN, 2016; KHAN; YAIRI, 2018). Diferentes abordagens para a realização de prognósticos, sugerindo o uso métodos supervisionados tradicionais (como Random Forest e SVM) e não supervisionados (para reconhecimento de padrões em dados sequenciais). Dentre essas técnicas, destacam-se as redes neurais, pela sua flexibilidade na modelagem e capacidade de predição, como as redes MLP, redes neurais convolucionais (ambas com entradas e saídas adaptadas), redes probabilísticas (como RBM e DBN), e principalmente as redes recorrentes, como a Gated Recurrent Unit (GRU) e a Long- 
Short Term Memory (LSTM), já preparadas para o processamento de séries temporais.

\subsubsection{Prognóstico Não Supervisionado}

O prognóstico não supervisionado adapta o uso das abordagens sugeridas para a detecção e diagnóstico não supervisionado, porém com foco em dados sequenciais para previsão de comportamentos futuros. Desse modo, enquanto as tarefas de detecção e diagnóstico visam avaliar o estado do equipamento no momento presente, no prognóstico, tem-se como objetivo estimar o comportamento futuro de um equipamento. Dessa forma, pretende-se estimar falhas pontuais antes da ocorrência, bem como estimar o RUL e identificar modos de falhas contextuais futuras, que representam desvios comportamentais no tempo, englobando o reconhecimento de padrões de propagação e evolução das falhas.

Assim como as abordagens de detecção/diagnóstico supervisionadas para tratar falhas existentes, o prognóstico supervisionado pode sofrer limitações para tratar anomalias que não seguem um padrão previamente conhecido (MALHOTRA et al., 2016). As pesquisas sobre predições de falhas não supervisionadas concentram-se em parte na aplicação de métodos de regressão associados a técnicas de clustering para identificar padrões anômalos (similar ao realizado sobre detecção de falhas). A partir da predição do comportamento futuro, o problema é reduzido ao desafio de detecção/diagnóstico, conforme apresentado nas seções 4.4 e 4.5. Entretanto, a tarefa de detecção/diagnóstico nesse caso é tratada sobre dados estimados, trazendo consigo uma maior propensão de imprecisão sobre o resultado pela propagação do erro residual obtida da predição comportamental.

Enquanto parte dos métodos tradicionais são limitados e adaptados para prever apenas o próximo passo, as redes recorrentes (como a LSTM) são nativamente preparadas para tratar séries longas temporais na entrada e saída, permitindo também de fato a análise das falhas contextuais em uma única predição. 


\subsubsection{Considerações sobre o Prognóstico via Interpretabilidade de Modelos}

Entende-se que as ponderações feitas sobre diagnóstico por meio de técnicas de interpretabilidade, podem ser aplicáveis ao prognóstico. Entretanto, algumas precauções devem ser tomadas nas verificações obtidas durante os experimentos, visto que a avaliação dos resultados sobre comportamentos futuros estimados traz maior incerteza e imprecisão sobre a análise de falhas.

Assim como na detecção, a tarefa de prognóstico treina o modelo preditivo sobre dados altamente desbalanceados. Técnicas de reamostragem ou ponderação de categorias podem ser aplicadas para reduzir os efeitos negativos dos dados desbalanceados sobre o treinamento do modelo, podendo levar a comportamentos instáveis em determinadas situações, quando os parâmetros ou objetivos de predição apresentam valores diferentes ou que extrapolam as faixas até então conhecidas durante a fase de treinamento.

Desse modo, mesmo que o modelo acerte sobre a predição em situação particular, a interpretabilidade do mesmo em algumas condições pode trazer explicações não razoáveis dentro do comportamento esperado, demonstrando que esse modelo pode ter acertado a predição ao acaso, e não ter aprendido adequadamente, significando que poderia vir a falhar em situações muitas vezes parecidas. 
Este capítulo apresenta alguns dos trabalhos relacionados mais relevantes encontrados durante a revisão de literatura. Foi constatado que a aplicação de técnicas de interpretabilidade tem sido majoritariamente aplicada no domínio da saúde, sobre análise do estado de saúde de pacientes e doenças. Relacionados às técnicas de deep learning, grande parte dos trabalhos estão relacionados a problemas supervisionados. Desse modo, esta pesquisa está direcionada à exploração de técnicas e métodos que foram pouco discutidos nessa combinação, e sobre um domínio de problema diferente. Nesta seção é apresentada uma seleção de trabalhos, que, de alguma forma, tem relacionamento com esta pesquisa, considerando aplicações não supervisionadas de deep learning, ou aplicações de técnicas interpretabilidade independentes de domínios de pesquisa.

Kraus (2019) sugere um método de estimação de RUL interpretável treinado via MLP, otimizado para encontrar parâmetros para um modelo inspirado na Taxa de Falhas Proporcionais de Cox, pela composição de 3 partes principais: (i.) um modelo não paramétrico em relação ao tempo para aproximação bruta da RUL (Weibull ou Log-normal), (ii.) combinação linear multivariada contendo parâmetros dos sensores sobre a toda sequência temporal (Lasso), (iii.) rede neural recorrente (LSTM) para aproximar variações não lineares não endereçada pelas outras 2 partes. Pela natureza "caixa-branca" da combinação linear (parte ii), é possível obter a relevância global e local (sobre uma observação particular) dos parâmetros sobre os resultados obtidos. Como base de comparação, regressores não lineares (como o Random Forest) e estatísticos (Weibull ou Log-normal) foram testados de modos combinado e separado. Mostrou-se que o modelo proposto contendo o regressor linear, associado ao modelo estatístico (Weibull) e a rede LSTM obteve resultados preditivos superiores, mantendo efetivamente a capacidade de interpretabilidade.

Kieu (2019) sugeriu a aplicação de dois tipos de ensemble de modelos (modelos que aglutinam um grupo de modelos para predição) compostos por sparse LSTM-AE para a detecção de anomalias, no qual uma configuração promove o treinamento independente de todos os modelos, enquanto o segundo sugere o treinamento de autoencoders direcionados a dados especializados. Esse tipo de rede tem como característica peculiar a remoção aleatória de conexões sobre as camadas 
escondidas. Os resultados apresentados mostram que ambas as configurações de ensembles obtiveram resultados superiores ao estado da arte sobre os conjuntos de dados testados, e sugerem que a configuração de ensemble contendo redes esparsas promovem grande redução de risco de overfitting pela variedade de ligações feitas entre as diferentes redes.

Lundberg (2018) sugere a aplicação de técnicas de interpretabilidade (SHAP) sobre a técnica Gradient Boosting Machines (GBM) para predição de ocorrência de hipoxemia (redução de oxigenação no sangue, podendo causar morte) em cirurgias, tendo por base dados históricos de cirurgias contendo diversos parâmetros relacionados às condições dos pacientes. Os resultados mostraram que as explicações do SHAP foram robustas e coerentes com a literatura médica em relação às classificações obtidas, proporcionando uma melhora de $15 \%$ para $30 \%$ sobre a capacidade de prever tais enfermidades durante os procedimentos cirúrgicos.

El Shawi (2019) realiza comparações de desempenhos sobre técnicas de interpretabilidade (LIME, SHAP e Anchors), e sugere atributos de avaliação de dessas técnicas, como identidade (observações idênticas devem ter explicações idênticas), estabilidade (observações pertencentes a uma mesma classe devem ter explicações comparáveis), separabilidade (observações não similares devem ter explicações não similares), similaridade (quanto mais similares as observações, mais similares suas explicações), tempo de execução (custo computacional para prover a explicação) e detecção de viés ( capacidade de detectar viés nos dados de treinamento). O estudo de caso foi realizado sobre 2 conjuntos de dados contendo dados reais sobre a saúde de pacientes, com objetivo de predição de risco de mortalidade e diabetes, respectivamente. Os resultados mostraram-se satisfatórios entre todos os métodos, mas nenhum destacou-se significativamente, mostrando comportamentos equilibrados entre todas as métricas definidas.

Jansen (2018) avalia o uso de uma técnica de interpretabilidade (DeepLift) sobre uma rede neural treinada para classificar e diagnosticar o estado fisiológico de pacientes que sofrem de apneia obstrutiva do sono. O resultado foi comparado com outros métodos como árvores de decisão e Random Forest. O diagnóstico pelo DeepLift obteve resultados robustos e coerentes em relação ao esperado, sendo 
estatisticamente superior em relação aos outros métodos, alcançando p-value inferior 0,001 em determinados casos avaliados.

Nóbrega (2019) sugeriu uma adaptação do LIME para suportar a interpretabilidade sobre sistemas de recomendação, chamado de LIME-RS. No estudo de caso, o LIME-RS foi testado para interpretar resultados sobre o modelo Factorization Machine, um conhecido algoritmo para sistemas de recomendação, treinado sobre um conjunto de dados com recomendações de filmes. Os resultados de recomendação do LIME-RS foram comparados com o EM-RS, um algoritmo com heurística dedicada a sistemas de recomendação. Os resultados mostram que o LIME-RS obteve resultados similares ao EM-RS, mostrando o potencial do LIME para interpretar outros cenários de problemas.

Grezmak (2019) apresenta um modelo caixa-preta para diagnóstico de falhas, baseado em uma rede neural convolucional (CNN), combinada com a técnica de interpretabilidade Layer-wise Relevance Propagation (LRP), acoplada em seu funcionamento. O estudo de caso avalia o modelo sobre um conjunto de dados para diagnosticar falhas sobre caixa de marcha, no qual o modelo foi treinado com dados brutos (sem processamento) e submetido a interpretar diferentes tipos e graus de falhas, obtendo resultados consistentes.

Kovalerchuk (2019) apresenta um novo algoritmo nominado Dominance Classifier and Predictor (DCP) para classificação multinominal e interpretabilidade de modelos caixa-preta, por meio avaliação de intervalos de valores sobre todos os parâmetros, e a quantificação da classe mais frequente (chamada de "classe dominante") na região avaliada. O autor sugere 5 heurísticas diferentes para votação, visando o ranqueamento dos parâmetros mais importantes sobre o resultado obtido, retornando regras de parâmetros em forma de árvores de decisão. O estudo de caso foi aplicado sobre dados médicos de pacientes com câncer de mama. Os resultados mostram que o DCP foi capaz de prover resultados robustos e consistentes com o conhecimento do domínio. Os autores sugerem que o modelo pode ser usado de modo independente como modelo preditivo, visto que a capacidade de interpretabilidade provida serve a nível global do conjunto de dados, no qual o desempenho é comparado com outros modelos como árvores de decisão, Naive Bayes, redes neurais e SVM. 
Qu (2018) propôs uma método de diagnóstico não supervisionado de falhas utilizando deep sparse autoencoders (SAE) para extração de parâmetros, combinando a técnicas de clustering (K-means) para classificação do estado do equipamento. $O$ estudo de caso foi realizado sobre uma máquina de testes, com amostras de operação contendo engrenagens em 5 diferentes estados de degradação. O método obteve resultados satisfatórios, alcançando 99\% de acurácia, enquanto outras técnicas de redução de dimensionalidade como PCA e Multidimensional Scaling (MDS), alcançaram resultados medianos aproximados de $69 \%$ e $57 \%$, respectivamente.

Shao (2018) apresenta um método de diagnóstico não supervisionado baseado em um ensemble de Denoising autoencoders (DAE) para classificação sobre o modo de falha, no qual cada um deles foi treinado utilizando funções de ativação diferentes. O erro residual é usado com entrada em uma rede feedforward específica para cada modelo, com treinamento supervisionado sobre o modo de falha (diagnóstico). No treinamento, cada uma das redes recebe um peso diferente, a depender da acurácia obtida, ou seja, as melhores redes têm maior peso durante a votação. O estudo de caso realizado sobre dados operacionais de rolamentos, no qual o método foi comparado com uma gama de modelos, como Random Forest, SVM, redes MLP, Deep Belief Networks (DBN), e redes neurais convolucionais (CNN). O método proposto obteve resultados consistentes e muito superiores em relação aos outros métodos testados. 


\section{MODELO DE DIAGNÓSTICO E PROGNÓSTICO NÃO SUPERVISIONADO UTILIZANDO MÉTODO RXP}

Neste capítulo detalha-se a proposta de trabalho desenvolvida nesta dissertação. Após as considerações iniciais destaca-se a proposta propriamente dita, composta pelas etapas de detecção, diagnóstico e prognóstico de falhas.

\subsection{CONSIDERAÇÕES INICIAIS}

Como já argumentado, em operações industriais e logísticas de grande porte, o estabelecimento de práticas de manutenção baseadas em condições, suportadas por métodos eficientes de diagnóstico e prognóstico de falhas, fornece meios para uma tomada de decisão mais inteligente sobre eventos que possam perturbar o provimento dos serviços, promovendo a redução de paradas inesperadas e um melhor uso dos ativos operacionais (SHIN; JUN, 2015).

O uso de técnicas de inteligência artificial oferece ferramentas para alcançar tais capacidades sob diferentes formas. Dentre elas, destacam-se as técnicas de deep learning, as quais já provaram ter grande potencial em problemas complexos (MARCUS, 2018). No que se refere à capacidade de um modelo refletir a realidade do problema em foco, tanto a precisão (capacidade de identificar falhas reais dentre as falhas classificadas), quanto a sensibilidade (dentre todas as situações de falha como, por exemplo, valor esperado, quantas estão corretas) são métricas importantes. Entende-se que para o domínio de detecção de falhas, a sensibilidade é fundamental do ponto de vista da confiabilidade do serviço, considerando a premissa que o modelo deve, ao menos, alcançar a capacidade de atender às especificações atualmente adotadas que reforcem a segurança da operação, tradicionalmente baseadas em regras fixas sobre medições de sensores. Considerando essas premissas, coloca-se a seguinte questão:

Questão 1: Os métodos de deep learning para detecção de falhas são capazes de atingir níveis ótimos de sensibilidade, e toleráveis de precisão, de modo que atendam, com impactos reduzidos, um processo de manutenção baseada em condição e guiado por regras sobre faixas de segurança operacionais? 
As técnicas de deep learning são consideradas estado-da-arte em aplicações sobre diferentes domínios de problemas (LECUN; BENGIO; HINTON, 2015). Por meio da escolha adequada de arquiteturas ajustadas e dados devidamente tratados, é possível obter resultados satisfatórios. Com o uso técnicas de interpretabilidade, criam-se meios alternativos para suprir a falta de clareza dos métodos de deep learning, provendo quais foram os atributos mais significativos sobre o resultado obtido (DOSHI-VELEZ; KIM, 2017).

Tal abordagem é sugerida pelo fato de que os métodos deep learning funcionam como "caixa-preta", ou seja, não provendo meios claros que expliquem os resultados obtidos. Em domínios de aplicação mais críticos, nos quais a interrupção do serviço pode levar a grandes perdas financeiras, ambientais e de vidas humanas, essa limitação causa desconfiança em seu uso, visto que não é sabido se modelo está fundamentando as suas respostas em parâmetros factíveis, e seu comportamento em situações adversas pode ser imprevisível.

A partir dessa viabilidade é colocada a segunda questão:

Questão 2: Os métodos de interpretabilidade são capazes de explicar se os métodos de deep learning conseguem resultados satisfatórios, baseando-se em conjuntos de parâmetros razoáveis com regularidade, mesmo em situações anormais?

Os métodos de interpretabilidade mostraram-se satisfatórios em aplicações em outros domínios de problemas, como na área médica, no apoio ao diagnóstico de doenças (ELSHAWI et al., 2019). Considerando que a área de manutenção visa endereçar principalmente as situações anormais que coloquem a operação em risco (no caso, é a ocorrência de falhas), será avaliada a viabilidade de sua aplicação.

Uma resposta positiva sobre a Questão 2, leva à constatação sobre a viabilidade de (i.) ganho de confiança pela constatação que o método funciona robustamente baseado em parâmetros razoáveis, e (ii.) ganho de conhecimento, ao fornecer dados as sobre as possíveis fonte da falha.

Considerando que o ajuste adequado para que um detector de falha obtenha resultados ótimos sobre a sensibilidade, naturalmente o desempenho da precisão é 
reduzido. Entretanto, levanta-se a hipótese que parte dos falso-positivos (observações suspostamente normais classificadas como falhas), com alto índice de incerteza sobre sua classificação, podem ser novos modos de falha que as especificações de segurança não consideram, por se tratar de um conjunto muito limitado de restrições de faixas de operação. Entende-se que a investigação sobre esses casos, e a exploração sobre padrões encontrados podem fomentar o ganho de conhecimento, o que leva à terceira pergunta:

\section{Questão 3: Os métodos investigados são aplicáveis, com as devidas} adaptações, para o prognóstico de falhas?

Por intermédio do uso de redes neurais recorrentes, que demonstraram-se eficientes tratar problemas com séries temporais e predição de eventos e comportamentos futuros (LECUN; BENGIO; HINTON, 2015), o prognóstico de falhas será realizado com uma filosofia similar àquela aplicada sobre o diagnóstico. Nesse caso, deve-se considerar um novo espectro ao analisar a falha contextualmente, ou seja, a transformação de uma falha incipiente até uma falha evidente considerando as faixas de segurança operacionais.

Inspirado no contexto e nas questões levantadas, esta pesquisa visa propor um método de prognóstico de falhas não supervisionado baseado em técnicas de deep learning, combinado a técnicas de interpretabilidade apropriadas a modelos complexos de aprendizado de máquina, considerados "caixa-preta", com objetivo diferencial de prover ganho de confiança ou (redução de incerteza) sobre seu funcionamento, e ganho de conhecimento.

\subsection{METODOLOGIA}

Esta seção descreve a metodologia adotada neste trabalho, a composição e assuntos tratados na pesquisa, relacionando-os com as contribuições específicas. A Figura 24 apresenta a estrutura geral da pesquisa, composta por 2 partes principais: (i.) Detecção/Diagnóstico, focado na análise de falhas presentes no sistema, e (ii.) Prognóstico, focado na previsão e análise de falhas futuras. Conforme explicado na subseção 2.3.3, esta pesquisa visa contribuir na tarefa de tomada de decisão em processos de manutenção baseada em condição (CBM). 


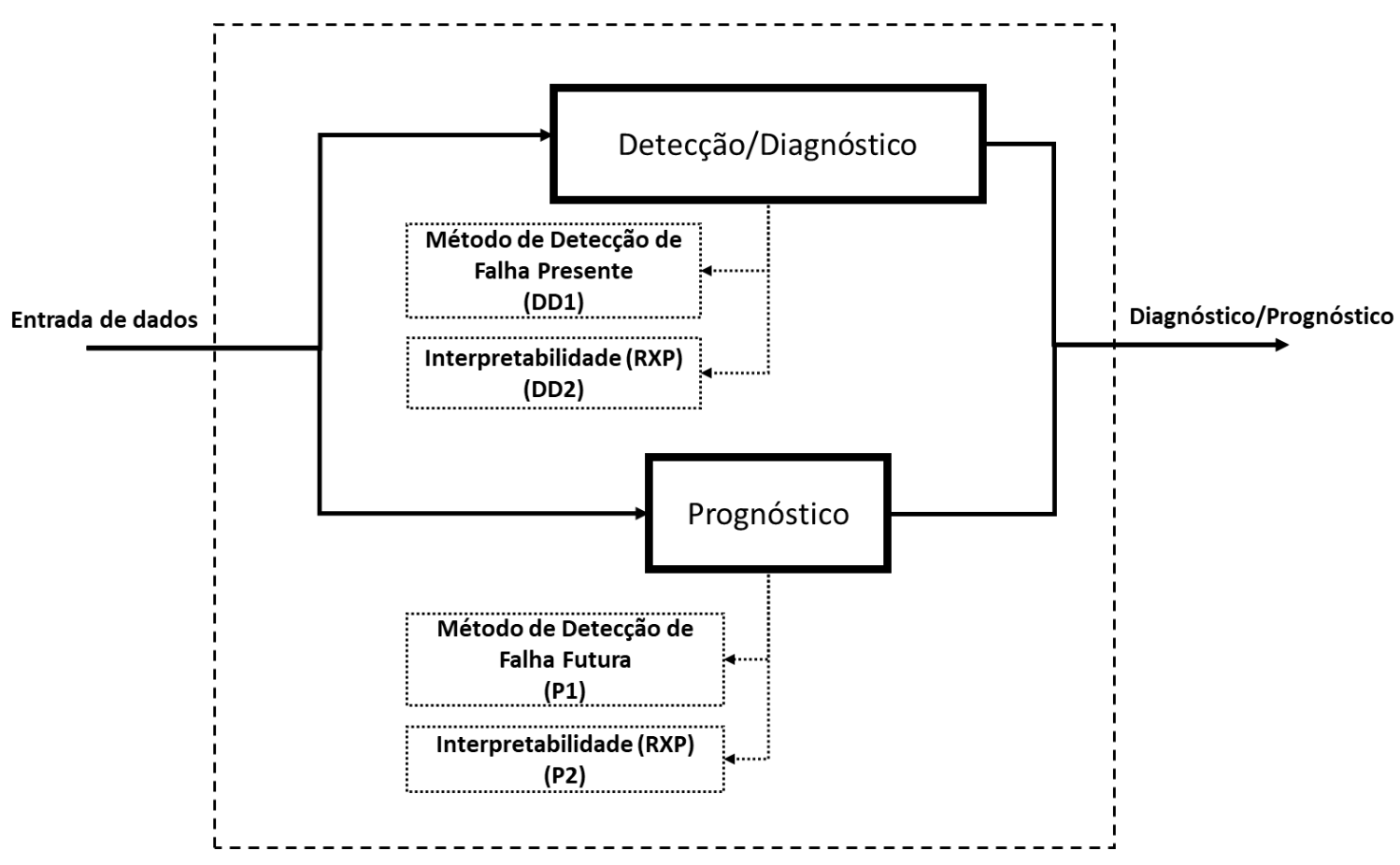

FONTE: AUTOR

Os retângulos com linhas sólidas no diagrama (detecção/diagnóstico e prognóstico) representam as características funcionais principais que compõem o método, e foram abordadas ao longo da pesquisa. Conforme descrito no capítulo 2 , a detecção e diagnóstico, representam a capacidade de análise de falhas sobre o momento presente da observação, enquanto o prognóstico representa o futuro, ou seja, a previsão e identificação de possíveis ameaças. Os retângulos com linhas pontilhadas apresentam as contribuições pontuais relacionadas a cada uma das características funcionais.

Apesar de a preparação dos dados não estar explícita no diagrama, e consequentemente não se constituir em uma contribuição científica por parte desta pesquisa, trata-se de uma tarefa fundamental e viabilizadora no processo experimental, para a obtenção de resultados relevantes e confiáveis. Como apresentado no estudo de caso (capítulo 6), diversos desafios devem ser tratados para compensar possíveis limitações e ruídos provenientes dos dados brutos. 


\subsubsection{Detecção/Diagnóstico de Falhas Presentes}

A Figura 24 apresenta a etapa de detecção aglutinada a etapa de diagnóstico utilizada neste trabalho. Embora as contribuições científicas deste trabalho estejam, majoritariamente, concentradas nos métodos de diagnóstico e prognóstico, a detecção é parte fundamental na abstração do sugerido para diagnóstico (interpretabilidade sobre métodos baseados em reconstrução), e a extensão da ideia que endereça a tarefa de prognóstico.

\subsubsection{Detecção}

A atividade sobre Métodos de Detecção de Falha Presente (DD1) avalia a capacidade de métodos não supervisionados de deep learning, com foco particular sobre a rede Autoencoder, dado que é o representante mais relevante para esse tipo de problema (CHALAPATHY; CHAWLA, 2019). A figura 25 exemplifica um Autoencoder adaptado para detecção de falhas, o cálculo residual usado (erro quadrático médio), a definição da fronteira de classificação, e as métricas apropriadas.

\section{FIGURA 25 - ETAPAS DE PREPARAÇÃO DOS DADOS}

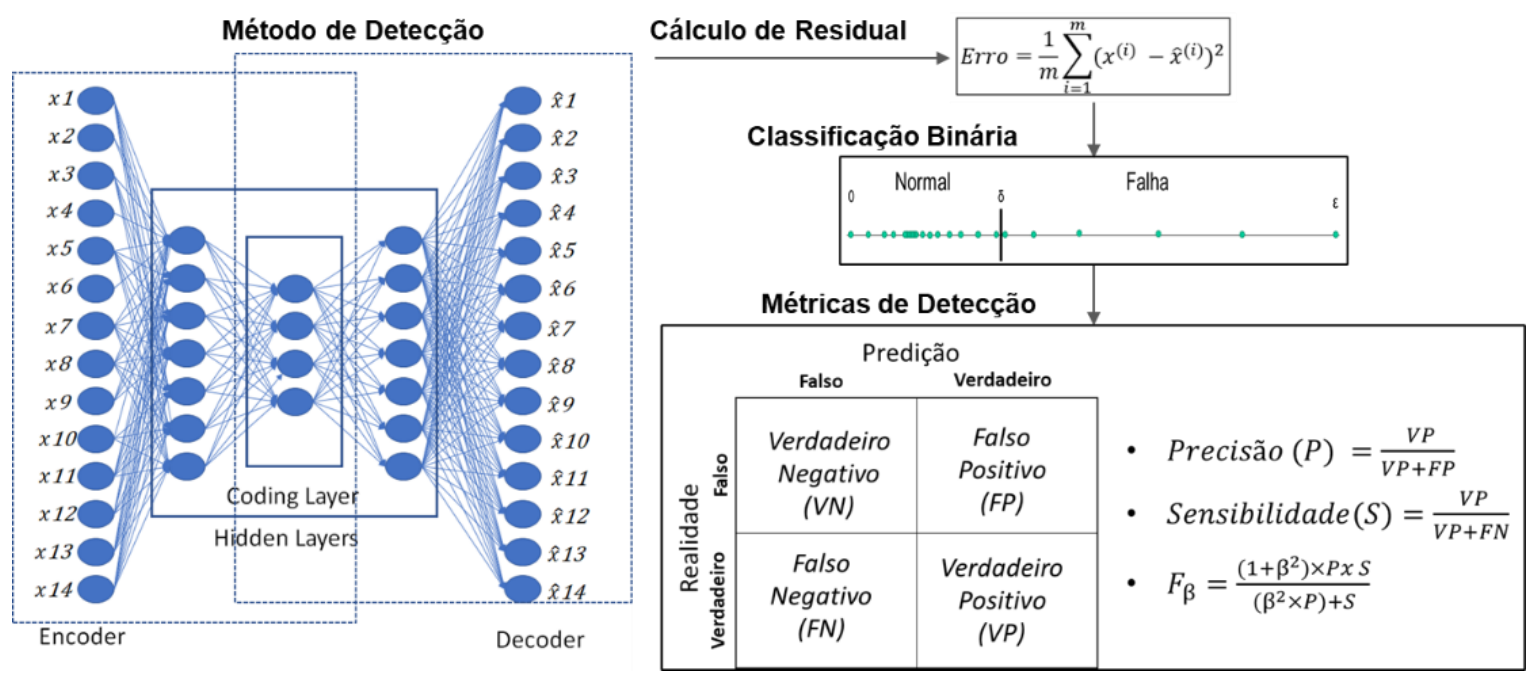

FONTE: AUTOR

Para validar a capacidade do método, definem-se as métricas apropriadas em relação à confiabilidade do sistema. Essa atividade fundamenta a validação dos resultados feita em comparação com especificações operacionais de segurança, que definem alarmes sobre medições capturadas pelos sensores, consequentemente 
tornando o problema de detecção como a validação de uma classificação binária comum, reduzindo a subjetividade de avaliação. Portanto, se algum parâmetro operacional estiver acima da faixa limite, será automaticamente assumido como falha, do ponto de vista de validação. A definição do critério de ajuste pode ser obtida pelo percentual de observações em falha sobre os dados de treinamento.

Entende-se que na aplicação de métodos de detecção que respeitem as especificações operacionais de segurança, a sensibilidade é a métrica mais adequada na perspectiva de confiabilidade de sistemas, pela percepção de que todas as falhas presumivelmente conhecidas e que venham a ocorrer, sejam detectáveis. Contudo, a precisão continuará sendo importante de modo que não cause distúrbios operacionais pela indicação excessiva de falhas em situações inadequadas. Portanto, a definição adequada quanto ao $\beta$ e o uso da medida $F$ são fundamentais.

Com isso, utilizam-se as métricas tradicionais como a precisão sensibilidade e medida $F\left(F_{\beta}\right)$. O objetivo é validar se o método é capaz aprender, de forma autônoma, as práticas de regras vigentes (sensibilidade), mantendo valores satisfatórios quanto à precisão. Para esse experimento, a definição da fronteira de decisão do classificador será definida a partir do percentual de falhas sobre os dados de treinamento. Pelo cálculo de erro residual sobre os dados de treinamento, é obtido o valor do erro sobre a última amostra dentre os maiores erros residuais dessa base. O resultado satisfatório deste trabalho, explica a resposta da Questão 1.

A Questão 2, que trata parcialmente sobre um requisito de detecção (confiança no modelo), é tratada durante os experimentos sobre diagnóstico.

\subsubsection{Diagnóstico - Método RXP}

O Diagnóstico (representado pelo bloco DD2 da figura 24) apresenta a contribuição sobre um novo método de interpretabilidade para modelos de detecção de anomalia não supervisionada, aqui denominado RXP ("Residual exPlainer"). O racional que fundamenta o RXP é inspirado na abordagem baseada em reconstrução para detecção de anomalias. Como já detalhado anteriormente, nessa abordagem o aspecto crucial que induz uma observação a ser classificada como anômala é o grau elevado de erro obtido entre a reconstrução e a entrada original. Desse modo, o RXP 
compara os erros residuais obtidos pelos parâmetros, e retorna um escore de pesos sobre quais os parâmetros tiveram mais relevância sobre uma classificação particular. O escore de pesos reflete uma contribuição relativa (percentual) atribuído a cada um dos parâmetros, independente da classificação obtida, visto que a fronteira de decisão é definida e tratada na tarefa de detecção.

Conforme a figura 26, considere um sistema composto por um modelo de detecção de falhas $(D 1)$ não supervisionado baseado em reconstrução, e um componente de diagnóstico (D2). A operacionalização desse sistema é realizada por uma fase prévia de treinamento do modelo $D 1$, e captura de dados estatísticos.

\section{FIGURA 26 - DIAGRAMA DE SISTEMA GENÉRICO DE DETECÇÃO DE FALHAS EQUIPADO COM RXP}

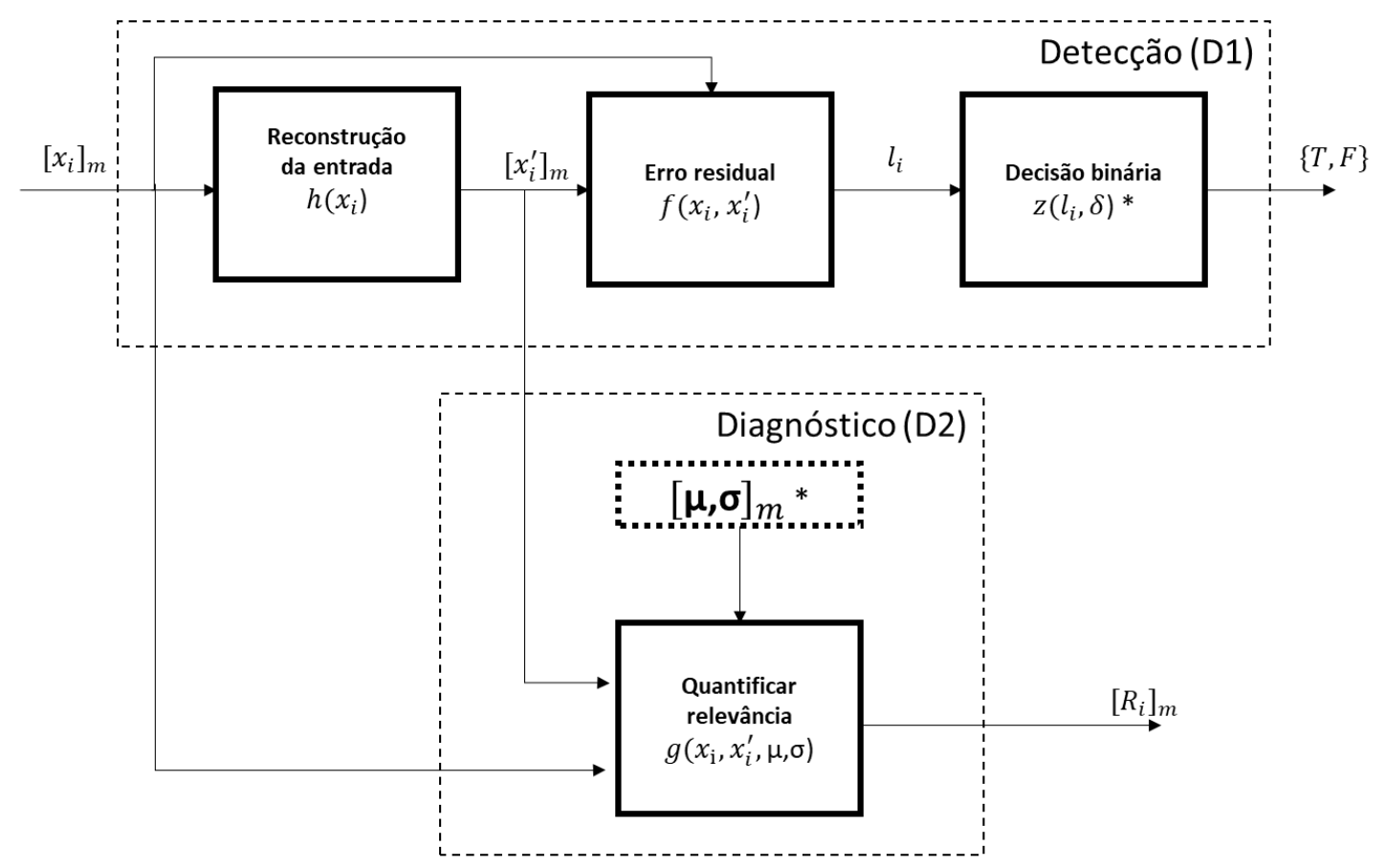

* $\delta, \mu, \sigma$ obtidos durante o treinamento do modelo de detecção

\section{FONTE: AUTOR}

Dado o conjunto de dados $T \in \mathbb{R}^{N x M}$ com $N$ instâncias e $M$ parâmetros, são coletadas a média e desvio-padrão dos residuais reconstruídos pelo modelo sobre cada um dos parâmetros para serem posteriormente utilizados no diagnóstico de falhas. Esses dados estatísticos são utilizados para calcular o escore Z de uma amostra (instância) avaliada durante a operação do sistema, definido pela equação 1 : 


$$
z_{i m}=\frac{x_{i m}-u_{m}}{\sigma_{m}}
$$

em que, $z_{i m}$ é o escore de desvio para um parâmetro $m$ pertencente à instância (amostra) $i, x_{i m}$ é o valor de entrada (original) do parâmetro $m$ da instância $i, u_{m}$ é a média e $\sigma_{m}$ é o desvio padrão dos residuais reconstruídos durante a fase de treinamento sobre o parâmetro $m$.

Durante a operação do sistema, uma entrada (amostra) específica $i$ (vetor $x_{i} \in$ $\mathbb{R}^{M}$ ) é classificada por $D 1$ como normal ou falha. Para essa mesma entrada específica $i\left(x_{i}\right)$, D2 quantifica a relevância $R_{i m}$ de cada parâmetro $m \in M$ de $x_{i}$ utilizando a equação 2 :

$$
R_{i m}=\frac{\log \left(1+\left|z_{i m}\right|\right)\left(x_{i m}-x_{i m}^{\prime}\right)^{2}}{\sum_{k=1}^{M} \log \left(1+\left|z_{i k}\right|\right)\left(x_{i k}-x_{i k}^{\prime}\right)^{2}}
$$

em que o numerador é a função de custo residual, sendo o erro quadrático entre o $x_{i m}$, valor de entrada do parâmetro $m$ da amostra $i$, e $x_{i m}^{\prime}$ o valor de $x_{i m}$ reconstruído pelo modelo do detector de anomalia, ponderada pelo módulo do escore $Z\left(z_{i m}\right)$ entre a característica entre a entrada original e seu valor médio de treinamento (equação 1). O denominador atua como fator de normalização em todas as dimensões de parâmetros. Após quantificar a relevância de todos os M parâmetros de $x_{i}$, obtêmse o vetor $R_{i}$. Quanto mais alto for o valor de um atributo contido em $R_{i}$, maior a relevância daquele o atributo para a classificação de falha tomada para a instância $i$ em relação aos seus demais atributos.

Dado que $R_{\text {im }}$ é normalizado em relação ao vetor de relevância sobre todos os parâmetros da instância $i$, o valor de $R_{\text {im }}$ entrega o impacto percentual do respectivo parâmetro $m$ para que a entrada tenha sido detectada como anomalia (falha). Do ponto de vista prático, entende-se dessa forma que é possível realizar um diagnóstico da falha automatizado previamente, pelo ranqueamento (ordenados de forma decrescente) do vetor $R_{i}$, resultando na lista ordenada de parâmetros relevantes.

Note que a equação 2 adota o erro quadrático como cálculo da reconstrução entre a entrada e a saída, representado pelas expressões $\left(x_{i m}-x_{i m}^{\prime}\right)^{2}$ (sobre um parâmetro em particular), e $\left(x_{i k}-x_{i k}^{\prime}\right)^{2}$ (sobre cada um dos parâmetros para 
normalização). Desse modo, no caso em que outras funções de erro fossem adotadas na tarefa de detecção, entende-se que essa mesma função poderia substituir o erro quadrático sem impacto negativo para o cálculo de $R_{i m}$. Independente da função de erro aplicada, a inspiração para concepção do RXP vem da ponderação obtida sobre o erro residual de cada parâmetro em relação ao erro residual global sobre todos os parâmetros (representado pelo somatório no denominador).

Durante o desenvolvimento do conceito, foi percebido que a inclusão do escore $Z$ (e posteriormente o logaritmo de $1+\left|z_{i m}\right|$ ) trouxeram resultados mais equilibrados em diferentes situações. Com esses novos componentes, o RXP leva em consideração não apenas os desvios na reconstrução, mas também os dados desviados em relação ao um padrão comum (evidenciados escore $Z$ ). Portanto, mesmo nos casos em que a rede consegue reconstruir com qualidade (ou seja, com uma taxa de erro reduzida) uma observação anômala, o escore $Z$ tende a penalizar entradas desviadas em relação aos dados de treinamento.

Sobre os resultados de interpretação obtidos, levanta-se a hipótese de avaliar o RXP como uma ferramenta para automatização da análise dos resultados de detecção, e possivelmente como recurso para complementar e ajustar de modo mais balanceado a decisão entre normal e falha pelo detector. A automatização da reclassificação das amostras é feita sem qualquer apoio sobre o real estado do equipamento (ou seja, não supervisionado), e pondera os resultados do RXP por critérios conservadores de modo que não prejudiquem o desempenho previamente atingindo pelo detector. O grau de desbalanceamento de relevância entre os parâmetros pode ser obtido pelo cálculo de variância sobre cada amostra, seguindo as regras gerais:

- Definição de falsos positivos: Amostras classificadas como falhas e que o resultado de interpretação atribua a maior relevância para parâmetros auxiliares serão reclassificados como normal. Os parâmetros auxiliares são aqueles não seriam intuitivamente apontados como fonte de uma falha detectada, como por exemplo velocidade, inclinação da vida, entre outros. Essa determinação deve ser feita por especialistas no domínio da aplicação, onde entende-se que é um passo não autônomo dentro da proposta. 
- Definição de falsos negativos: Amostras classificadas como normais e que o resultado de interpretação atribua um peso de muito desequilibrado sobre o primeiro parâmetro (que não seja auxiliar) serão reclassificados com falha.

\subsubsection{Prognóstico de Falhas Futuras}

Conforme a figura 24, o Prognóstico contribui com a previsão de falha futura (P1) e identificação (interpretabilidade) da causa (P2), com base nas estimativas do comportamento históricos dos componentes monitorados. Esse recurso promove ganho de conhecimento e confiança sobre o sistema ao alarmar as falhas ainda em estágios incipientes, permitindo uma tomada de decisão assertiva e planejada, e assim mitigando que evolua para situações graves que possam levar a disfunções e acidentes.

Visto que a abordagem adotada pela pesquisa segue um foco não supervisionado, assume-se que não existem informações sobre níveis de degradação de componentes que indiquem sobre o fim de vida útil do equipamento (ou histórico de manutenção que posterguem o mesmo). Portanto, o objetivo de prognóstico é prover visão se o equipamento tende a falhar em um horizonte futuro definido (sem presunção se é apenas uma falha pontual ou que tenha alcançado o fim da vida útil).

A seguir é detalhado o processo de treinamento e detecção de falhas futuras, bem como o processo de identificação de fonte da falha, também utilizando o método RXP.

\subsubsection{Previsão de Falhas Futuras}

A tarefa de prognóstico apresenta um cenário mais desafiador em relação a detecção de falhas presentes, visto que aqui a detecção e identificação das fontes das falhas acontecem sobre estimativas de comportamentos futuros. Dado que o objetivo de predição é voltado a estimar eventos de falhas (geralmente com baixíssima recorrência), e que fujam de um padrão normal de comportamento, podendo tratar-se de uma extrapolação de aprendizado, já que o aprendizado para predição do comportamento é feita por meio supervisionado, e as falhas podem se manifestar de formas ainda desconhecidas. Com isso, o modelo treinado tende a não aprender 
adequadamente quando tais situações ocorrem, resultando em uma aproximação (geralmente grosseira) para um comportamento sempre aproximado do normal.

Desse modo, a filosofia adotada para endereçar a previsão de falhas futuras é similar a feita sobre detecção de falhas existentes (subseção 4.2.1.1), porém com um passo adicional anterior para treinamento apropriado e previsão do comportamento futuro do equipamento, no qual é feito pelo uso de uso de redes LSTM-AE. Inspirado no processo de detecção não supervisionado baseado em reconstrução, a detecção é realizada pelo autoencoder treinado sobre as estimativas comportamentais do equipamento.

Para o funcionamento adequado do modelo, o treinamento deve seguir os seguintes passos, conforme a figura 27 :

FIGURA 27- PASSOS PARA TREINAR REDE LSTM-AE PARA PREVISÃO DE FALHAS FUTURAS

Balanceamento dos dados

(Oversampling)
Treinamento da rede

LSTM-AE
Definir Fronteira de Decisão $(\varepsilon)$

\section{FONTE: AUTOR}

a) Balanceamento dos Dados

Considerando que em problemas triviais de predição, os dados de treinamento desbalanceados podem causar enviesamento do modelo (JIANG et al., 2019). No contexto de predição de anomalias, esse problema torna o modelo insensível predição de anomalias, já que os resultados tenderão a convergir para dados aproximadamente normais, tornado o modelo incapaz de prever adequadamente qualquer evento raro. Para se reduzir o efeito de enviesamento, técnicas de balanceamento de dados podem ser aplicadas como undersampling (remoção de amostras da classe majoritária, que no problema em questão são os dados "normais") e oversampling (geração de amostras da classe minoritária, ou seja, as "anomalias") (KOTSIANTIS; KANELLOPOULOS; PINTELAS, 2006; BEKKAR; ALITOUCHE, 2013), sendo o SMOTE (e suas variantes) um das técnicas mais notáveis de upsampling. 
No caso de bases de séries temporais desbalanceadas, apesar de haver uma gama de proposições que sugerem soluções de oversampling para esse problema (CAO et al., 2013; LIANG, 2013; ZHU; LIN; LIU, 2019), não há consenso e aplicação de algum desses métodos que seja largamente difundido como o SMOTE. Com objetivo de evitar subjetividades adicionais de implementação desses métodos, a proposta adota uma abordagem simplificada pela repetição das amostras em falha. Por avaliações empíricas durante os experimentos desta pesquisa, foi percebido que o balanceamento da quantidade de anomalias entre $2 \%$ e $15 \%$ do conjunto de dados foi satisfatório para treinamento da rede.

b) Treinamento da Rede LSTM

Considere uma rede LSTM-AE treinada com uma base de dados $T$ de entrada $\in \mathbb{R}^{N x I x M} \operatorname{com} N$ instâncias e $I$ lapsos parâmetros e $M$ parâmetros, e saída $\in \mathbb{R}^{N x O x P}$, no qual $O$ e $P$ indicam respectivamente que o número de lapsos temporais e parâmetros preditos podem ser diferentes da entrada.

A flexibilidade do conjunto de parâmetros da saída poder ser diferente da entrada, permite que apenas os parâmetros críticos de segurança sejam considerados (como por exemplo sobreaquecimento e vibração), enquanto os auxiliares sejam descartados (como velocidade ou dados topográficos), o que reduz a carga de treinamento da rede (menos parâmetros), e evita erros quanto a tarefa de detecção/diagnóstico (por atribuir equivocadamente alta importância sobre parâmetros claramente irrelevantes).

c) Definir fronteira de Decisão $(\varepsilon)$

Após o treinamento de pesos da rede LSTM-AE, a base de dados $T$ é os residuais obtidos sobre cada um dos $P$ parâmetros e cada amostras. Conforme a equação 3, esses valores são usados para calcular a diferença em relação as predições sobre todos os parâmetros e todos os lapsos temporais e sua respectiva reconstrução feita pelo autoencoder, pelo erro quadrático sob a fórmula 


$$
e_{k}=\frac{1}{O P} \sum_{o=1}^{O} \sum_{p=1}^{P}\left(x_{k o p}-\hat{x}_{k o p}\right)^{2}
$$

no qual $\hat{x}_{k o p}$ corresponde à reconstrução do comportamento pelo autoencoder sobre uma amostra $k$ sobre o parâmetro $p \in P$, no lapso temporal $o \in O$, e $x_{k o p}$ a respectiva predição de comportamento feita pela LSTM-AE.

De modo a reduzir subjetividade e otimizar o resultado da classificação, sugere-se que a fronteira de decisão deve ser definida sobre o cálculo de erro residual $E$ sobre os dados de treinamento. Ao se obter $e_{k}$, aplica-se o cálculo de curva Precisão/Sensibilidade, que retorna todos os valores de precisão e sensibilidade considerando cada valor do vetor de erros como a fronteira de resposta. Para se obter o resultado mais equilibrado sobre as 2 métricas, calcula-se o vetor da medida $\mathrm{F}_{\beta}$ (figura 23), no qual a partir do maior resultado obtido, define-se a fronteira a ser adotada.

\subsubsection{Interpretabilidade de Falhas Futuras}

Como mostrado na subseção anterior, o processo de previsão de falhas futuras segue uma abordagem baseada em reconstrução. Com isso, o método RXP, inicialmente apresentado para contribuir com método de detecção de falha presente (também baseados em reconstrução), pode ser estendido e completar a tarefa de prognóstico pela interpretação das possíveis fontes das falhas futuras.

Nesse caso, a interpretabilidade feito pelo método RXP é feita sobre estimativas de comportamento futuro, comparado ao residual em relação à mediana das estimativas. Dada a capacidade das redes LSTM-AE de produzirem múltiplos lapsos temporais de predições, o método RXP pode ser aplicado sobre cada lapso individualmente, ou pela aglutinação de todos os lapsos em uma única dimensão, entregando a relevância de pesos sobre toda a série temporal predita em uma única resposta. Assim como realizado sobre o diagnóstico, pela avaliação da variância e desbalanceamento da relevância sobre os parâmetros, é possível obter ganhos de desempenho ao reclassificar falsos-positivos e falsos-negativos em situações particulares. 
Este capítulo apresenta detalhes sobre a operação ferroviária, equipamentos e dados que são considerados nos experimentos realizados nesta pesquisa.

\subsection{CONSIDERAÇÕES INICIAIS}

Em sistemas ferroviárias modernos, o material rodante (locomotiva e vagões) e via férrea são equipadas com sensores que capturam diversas características, com o intuito de prover meios de avaliar o estado dos equipamentos e agir com prontidão de forma a evitar eventos inesperados. A instrumentação da operação pode ser feita por meio de sensores acoplados ao material rodante (onboard) ou instaladas em pontos específicos da via (waysides), realizando a captura das medições, pontualmente, dos carros que atravessarem a região. O paradigma onboard permite a captura contínua dos dados, facilitando a aplicação de métodos para séries temporais. Em contrapartida, os sensores wayside capturam dados de forma esparsa, nos quais a leitura é feita pontualmente, quando o carro passar pela região específica. A identificação do vagão normalmente é feita por meio de leitores RFID (WANT, 2006) sobre os carros em movimento.

Infraestruturas onboard são consideravelmente mais robustas em comparação com os waysides, visto que no primeiro caso existe um fluxo contínuo de medições (escala de décimos ou milésimos de segundo), e no segundo, a captura de medições é feita de modo pontual, com frequência muito baixa (escala de minutos ou horas), consequentemente podendo fazer com que qualquer anomalia ou falha que ocorra não seja percebida até o próximo ponto ou instante de medição (LI et al., 2017).

Entretanto, o custo de implantação dos instrumentos no modelo onboard pode atingir valores consideravelmente maiores. Para cada vagão existente, um grupo de sensores deve ser instalado para medir peças específicas. No caso dos waysides, um grupo de instrumentos será responsável por monitorar todo o maquinário em operação. Uma forma sugerida de equilibrar a capacidade de monitoramento, considerando custos aceitáveis é a instalação de um número suficiente de waysides para capturar dados sobre o material rodante (rodas, eixos e rolamentos) e a 
instrumentação de alguns vagões para monitoramento da via (BERNAL; SPIRYAGIN; COLE, 2019).

O estudo de caso desta pesquisa faz uso de dados de sensores, compartilhados pela empresa VALE S/A, sobre a operação de ferrovia Estrada de Ferro Vitória à Minas (EFVM) durante o ano de 2018. Os dados foram obtidos por meio de múltiplos sensores de via (waysides), que amostram parâmetros de rodas e rolamentos de vagões para transporte de minério de ferro. Como pode ser visto na Figura 28, a EFVM liga diversas cidades, estações e minas no estado de Minas Gerais até o porto de Tubarão (Espírito Santo), possuindo 905 quilômetros de extensão, e estando sob concessão da VALE S/A desde o ano de 1997.

A EFVM é considerada umas das vias férreas de tráfego mais intenso do Brasil e com um dos maiores índices de produtividade a nível mundial, chegando a transportar aproximadamente 124 milhões de toneladas de carga por ano, correspondendo a 40\% do tráfego ferroviário nacional (ANTT, 2019). Essa ferrovia atende também ao transporte de pessoas. Seu transporte de carga é composto, majoritariamente, pelo escoamento materiais industriais, carvão, aço, produtos agrícolas, e principalmente minério de ferro, correspondendo a aproximadamente $90 \%$ da carga total transportada nessa via (ANTT, 2019).

Figura 28 - Estrada de FERRo Vitória À Minas (EFVM)

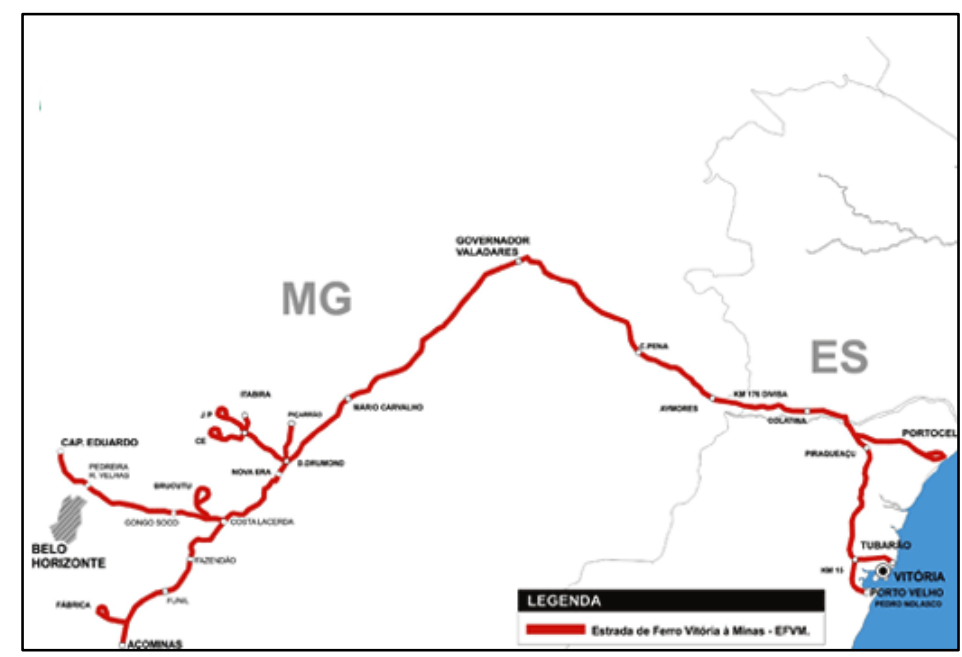

FONTE: ADAPTADO DE (ANTT, 2019) 
A operação ferroviária da nessa via é monitorada e gerenciada pelo Centro de Controle Operacional (CCO), com equipe dedicada a avaliar todos os aspectos que impactem na operação dos trens, tais como sinalização, sistema de intertravamento (e equipamentos relacionados), circuito da via, controle de velocidade, e monitoramento dos sensores. A Figura 29 mostra o painel de monitoramento de toda a via.

Figura 29 - PAinel de CONTROLE do CCO - EFVM

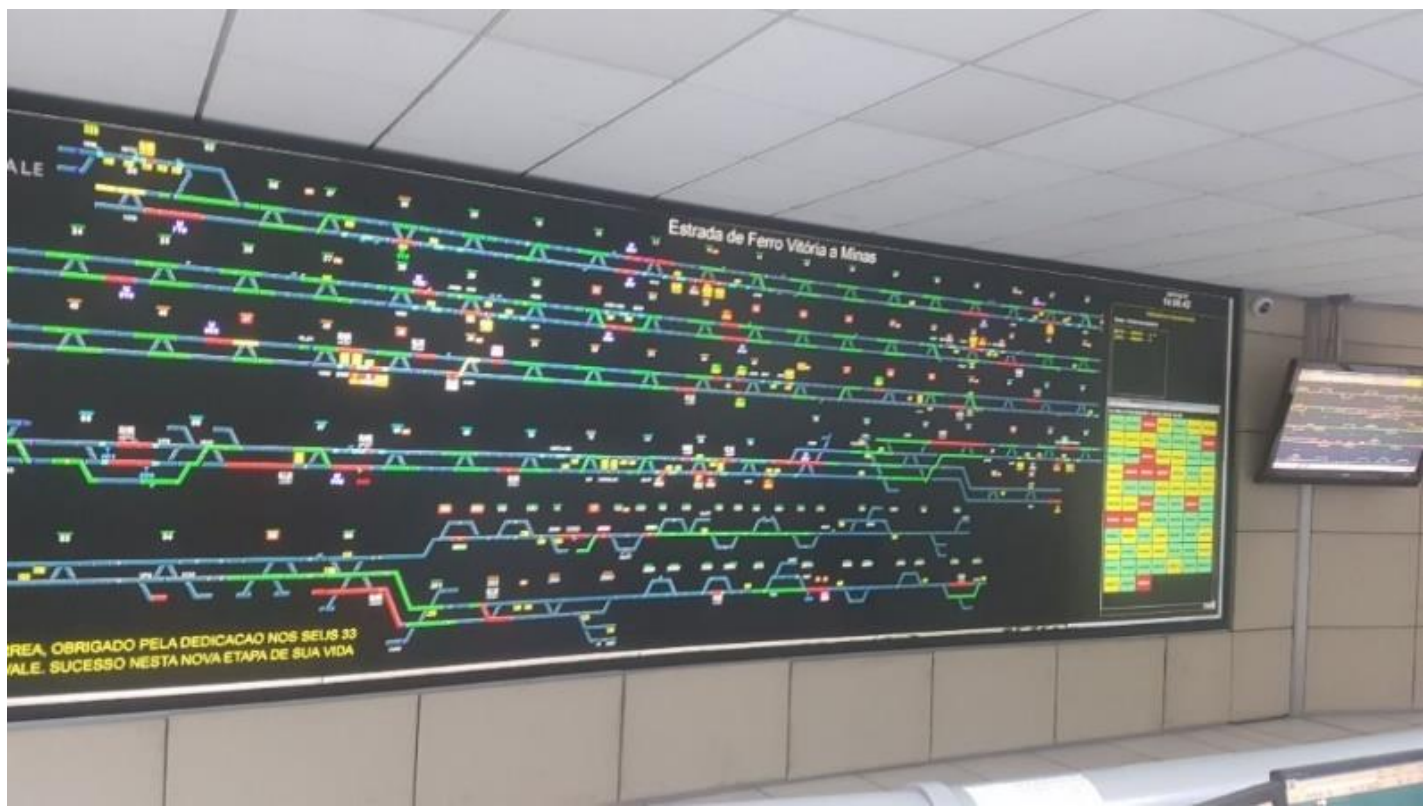

FONTE: AUTOR

\section{$5.2 \quad$ FONTES DE DADOS}

A EFVM é equipada com um grupo de sensores de via (waysides) que estão instalados ao longo de pontos específicos dessa via, capturando dados de temperatura (sensores HBW), vibração (sensores WILD), ruído (sensores RB) e geometria do rodeiro (sensores WSP) de todo material rodante que transita na região instrumentada.

Enquanto os sensores HBW encontram-se instalados em diversas regiões da via, os outros sensores estão concentrados apenas em um ponto específico. Dado que diversas falhas são manifestadas por meio de sobreaquecimento, causado pelo atrito anormal, deformações físicas e condições avançadas de deterioração do material, e ao número maior de sensores HBW (15 ao longo da via), o CCO baseia o seu 
monitoramento integralmente sobre esses sensores. Pequenos silos de trabalho se dedicam à análise de outros sensores, mas sem integração e análise conjunta entre todos os instrumentos.

Para o estudo de caso, a Vale forneceu dados de medições referentes ao período entre janeiro e novembro de 2018 sobre os sensores supracitados. A Tabela 1 lista os tipos de sensores, os tipos de medições capturadas, quantidade, localização na via, e parâmetros para retenção dos vagões para manutenção, referindo-se a medições de características sobre rodas e rolamento de vagões de transporte de carga. Como os dados são provenientes de silos de dados distintos, e em diferentes formatos, alguns tratamentos são necessários, de modo que adequem esses dados para a modelagem e processamento.

Os valores adotados sobre os parâmetros para retenção dos vagões são representados por diferentes variáveis para cada sensor e aspecto medido, sendo: (i) $h$ referente ao sensor HBW; (ii) $w$ referente ao sensor WILD; (iii) $r$ referente ao sensor RB; (iv) e o sensor WSP referenciado por 4 medições distintas, onde $p$ representa 0 perfil do friso, $a$ representa o altura do friso, $b$ p representa a bandagem e c representa a cava. Cada variável está em uma escala de medição diferente da outra, e as diferentes exemplificações de valores de uma mesma variável representam pontos diferentes de medição, que generalizam o entendimento das faixas de valores normais, pré-alarme e alarme. Portanto, usando o sensor HBW como exemplo, entende-se que $h^{\prime}<h^{\prime \prime}<h^{\prime \prime \prime}<h^{\prime v}$. Note que no caso do WSP, a deterioração da roda leva a redução de algumas dimensões (perfil do frio, altura do friso e bandagem), e diferentemente dos outros sensores, leva a uma verificação de valores reduzidos para atingir as faixas de alarme e pré-alarme. 
TABELA 1 - SENSORES DE VIA DA EFVM

\begin{tabular}{|c|c|c|c|c|c|c|}
\hline Sensor & $\begin{array}{l}\text { Região } \\
\text { (RH) }\end{array}$ & $\begin{array}{l}\text { Nível de } \\
\text { Medição }\end{array}$ & $\begin{array}{l}\text { Peça } \\
\text { Monitorada }\end{array}$ & $\begin{array}{l}\text { Medições } \\
\text { Realizadas }\end{array}$ & Unidade & $\begin{array}{l}\text { Parâmetros Para Retenção } \\
\text { De Vagões }\end{array}$ \\
\hline $\begin{array}{l}\text { Aquecimento } \\
\text { (HBW) }\end{array}$ & $\begin{array}{l}50,56,13, \\
13 i, 20,60, \\
130,43,27, \\
68,82,37, \\
540,90 \text { e } \\
204\end{array}$ & Eixo & $\begin{array}{l}\text { Roda, } \\
\text { Rolamento }\end{array}$ & $\begin{array}{l}\text { Aquecimento } \\
\text { das rodas } \\
\text { direita e } \\
\text { esquerda, } \\
\text { rolamentos } \\
\text { direito } \\
\text { esquerdo e }\end{array}$ & $\begin{array}{l}\text { Graus } \\
\text { Celsius }\end{array}$ & $\begin{array}{l}\text { - Normal: }<h^{\prime} \\
\text { - Pré-Alarme: Entre } h^{\prime \prime} \text { e } h^{\prime \prime \prime} \\
\text { - Alarme: }>h^{\prime v}\end{array}$ \\
\hline $\begin{array}{l}\text { Vibração } \\
\text { (WILD) }\end{array}$ & 7 & Eixo & $\begin{array}{l}\text { Roda, } \\
\text { Rolamento }\end{array}$ & $\begin{array}{ll}\text { Vibração } & \mathrm{e} \\
\text { roda direita } & \mathrm{e} \\
\text { esquerda, } & \\
\text { rolamento } & \\
\text { direito } & \mathrm{e} \\
\text { esquerdo } & \end{array}$ & $\begin{array}{l}\text { Quilo } \\
\text { newton } \\
\text { (kn) }\end{array}$ & $\begin{array}{l}\text { - Normal: < } w^{\prime} \\
\text { - Pré-Alarme: Entre } w^{\prime \prime} \text { e } w^{\prime \prime \prime} \\
\text { - Alarme: }>w^{\prime v}\end{array}$ \\
\hline $\begin{array}{l}\text { Acústico } \\
\text { (RB) }\end{array}$ & 7 & Eixo & $\begin{array}{l}\text { Roda, } \\
\text { Rolamento }\end{array}$ & $\begin{array}{l}\text { Falhas e } \\
\text { sintomas } \\
\text { categorizados } \\
\text { sobre rodas e } \\
\text { rolamentos }\end{array}$ & $\begin{array}{l}\text { Categórico } \\
\text { e Ordinal }\end{array}$ & $\begin{array}{l}\text { - Normal: }<r^{\prime} \\
\text { - Pré-Alarme: Entre } r^{\prime \prime} \text { e } r^{\prime \prime \prime} \\
\text { - Alarme: }>r^{\prime v}\end{array}$ \\
\hline \begin{tabular}{l}
\multicolumn{3}{l}{ Geometria } \\
do $\quad$ Perfil \\
(WSP)
\end{tabular} & 7 & Eixo & Roda & $\begin{array}{l}\text { Perfil do friso, } \\
\text { Altura do friso, } \\
\text { cava, } \\
\text { bandagem da } \\
\text { roda }\end{array}$ & $\begin{array}{l}\text { Milímetros } \\
(\mathrm{mm})\end{array}$ & $\begin{array}{l}\text { - Normal: } \\
\circ \quad \text { Perfil do friso: }>p^{\prime v} \\
\circ \quad \text { Altura do Friso: }>a^{\prime v} \\
\circ \quad \text { Bandagem: }>b^{\prime v} \\
\circ \quad \text { Cava: }<c^{\prime} \\
\text { - Pré-Alarme: } \\
\quad \text { Perfil do friso: Entre } \\
\quad p^{\prime \prime} \text { e } p^{\prime \prime \prime} \\
\quad \text { Altura do Friso: Entre } \\
a^{\prime \prime} \text { e } a^{\prime \prime \prime} \\
\quad \text { Bandagem: Entre } b^{\prime \prime} \\
\quad \text { e } b^{\prime \prime \prime} \\
\circ \quad \text { Cava: Entre } c^{\prime \prime} \text { e } c^{\prime \prime \prime} \\
\text { Alarme: } \\
\circ \quad \text { Perfil do friso: }<p^{\prime} \\
\circ \quad \text { Altura do Friso: }<a^{\prime} \\
\circ \quad \text { Bandagem: }<b^{\prime} \\
\circ \quad \text { Cava: }>c^{\prime v}\end{array}$ \\
\hline
\end{tabular}

FONTE: AUTOR

\subsection{PARÂMETROS PARA RETENÇÃO DOS VAGÕES}

Entre as informações da Tabela 1, destacam-se os parâmetros para retenção dos vagões, que definem faixas de valores fixas para reger, de maneira mais objetiva, a tomada de decisão, por parte da equipe de manutenção sobre o procedimento a ser seguido, como por exemplo a inspeção de campo, encaminhar para a oficina ou reduzir velocidade do trem.

Os parâmetros para retenção dos vagões são definidas pelas faixas "normal", "pré-alarme" e "alarme". Medições capturadas que estejam na faixa de alarme, levam à parada imediata, ou redução da velocidade até um ponto de inspeção mais próximo ou encaminhamento para a oficina. Medições em situação de pré-alarme, são 
verificadas e dependendo da recorrência de medições nesse estágio, planeja-se o encaminhamento para oficina.

Devido à incerteza sobre as medições capturadas e o real estado de degradação do equipamento, algumas práticas adicionais são realizadas, como o isolamento do vagão em caso de medições fora do padrão, mas que não necessariamente estejam em situação de alarme, por exemplo, a captura de medições recorrentes pelo sensor HBW, que indiquem que a temperatura da roda esteja consideravelmente acima da temperatura ambiente, mas ainda menor que a faixa de pré-alarme (ou seja, um valor entre $h^{\prime}$ e $\left.h^{\prime \prime}\right)$. A diferença de temperatura entendida como faixa de pré-alarme é definida quando a diferença de temperatura da roda esteja $h^{\prime \prime}$ graus acima da temperatura ambiente. Consequentemente, essa prática acontece pela recorrência sobre medições persistentes fora do comum são o meio que a equipe de operação adotou para mitigar o isolamento de vagões desnecessariamente, e ao mesmo tempo equilibrar o risco por uma atuação preventiva.

Dentre as medições representadas, o sensor WSP possui a mais alta dispersão, por tratar de capturas de dados em alta precisão (milímetros), e frequentemente apresentar resultados que extrapolam todas as faixas. Devido a essa alta imprecisão, para esse sensor, a equipe de manutenção verifica se os desvios ocorrem com uma recorrência mais elevada que nos outros dispositivos, de modo que mitigue falsospositivos.

Adicional aos dados dos sensores, a Vale possui um controle operacional das inspeções de campo realizadas pela equipe de manutenção, sendo preenchidas manualmente. Esse controle contém o histórico de inspeções realizadas em campo, catalogando algumas intercorrências acontecidas durante a operação, descrevendo o evento ocorrido, sintomas, diagnóstico e ação tomada.

\subsection{CARACTERÍSTICAS DO VAGÃO, RODA E ROLAMENTO}

A Figura 30 mostra um exemplo de par de vagão do modelo GDE (a), e a estrutura básica descrevendo alguns dos componentes mais importantes do carro (b). Dentre os componentes mostrados, destacam-se o rolamento e a roda, os quais são foco experimental desta pesquisa, visto que as medições pelos sensores waysides 
implantados referem-se a eles. Ambos os componentes sofrem por desgaste proveniente do atrito com outros componentes em movimento relativo diferente, no caso da roda com o trilho, e o rolamento com o eixo.

\section{FIGURA 30 - ESTRUTURA DE UM VAGÃo}

(a) Vagão GDE

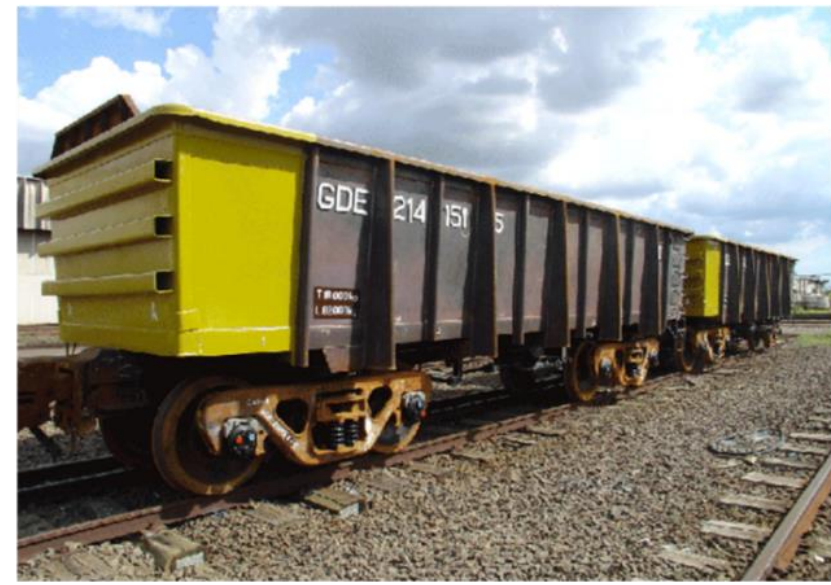

(b) Componentes

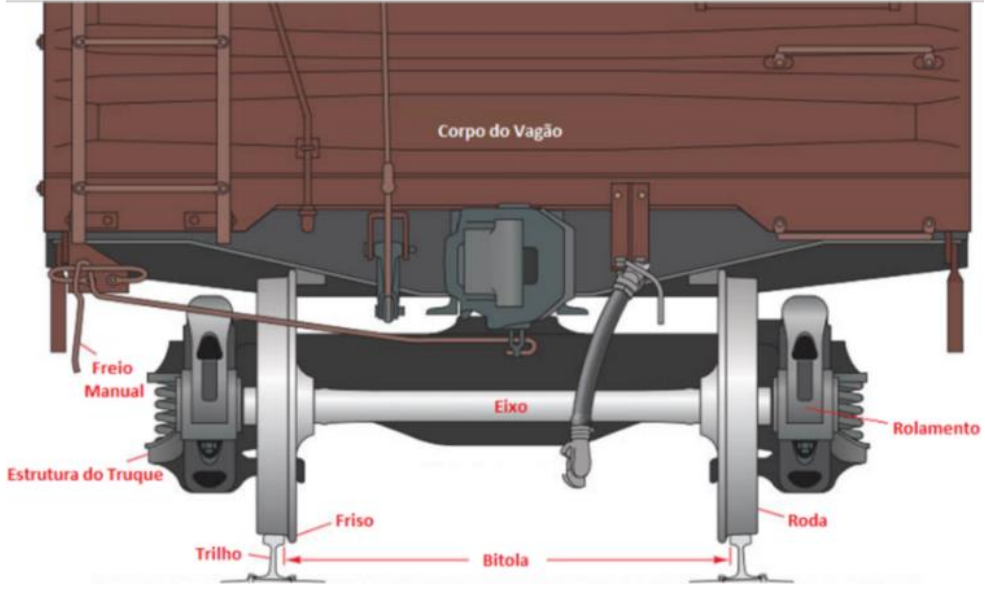

FONTE: (A) ACESSADO EM (GBMX, 2019); (B) ADAPTADO DE (SCHNEIDER, 2006)

Os vagões utilizados pela Vale considerados nesta pesquisa são do tipo gôndola modelo GDE (ABNT, 2015), no qual a carga é transportada em um caixote aberto em sua parte superior, produzido para o foco específico em transporte de minério de ferro. Conforme as especificações (ABNT, 2015), esse vagão pesa 16,5 toneladas, com capacidade máxima de aproximadamente 93,5 toneladas de carga (ou seja, peso máximo carregado de 110 toneladas), volume de até $30 \mathrm{~m}^{3}$ de carga, distribuído sobre 2 truques com 2 eixos em cada carro (totalizando 4 eixos por carro, e portanto com carga máxima 23,37 toneladas por eixo), e estrutura vinculada de freio manual sobre pares de vagões. 
Nas subseções seguintes são apresentadas algumas especificações e falhas conhecidas sobre rolamento e roda.

\subsubsection{Rolamento}

Os rolamentos estão presentes em equipamentos que necessitem o suporte de cargas entre peças com movimento relativo, ou seja, possibilitar a ação rotativa de um componente no sistema (ou mancal rolante), sendo aplicado em diferentes domínios, como máquinas industriais, motores, trens, entre outros. A deteç̧ão, diagnóstico e prognóstico de falhas sobre rolamentos têm sido foco de pesquisas nos últimos anos (ZHANG et al., 2019), por se tratar de um componente crítico e altamente vulnerável à degradação, causada por condições ambientais e operacionais de funcionamento, levando ao atrito anormal e deterioração acelerada.

Por se tratar de um componente que liga outros componentes ou subsistemas em movimento relativo, o bom funcionamento do rolamento está relacionado à operação em condições em que o atrito seja reduzido, ou seja: estar adequadamente lubrificado; corretamente instalado (alinhado com outros componentes e devidamente vedado); não possuir deformações mecânicas; e trabalhar dentro das especificações esperadas (no que diz respeito sobre carga operacional).

A Vale utiliza rolamentos com roletes cônicos da classe K do tipo 6 1/2" $\times 9$ ", capazes de suportar grandes cargas radiais (verticais) e axiais (laterais). Tal capacidade é importante não somente para suportar o peso vertical da carga transportada, mas também forças laterais provenientes de curvas e instabilidades ao longo da via.

A Figura 31 mostra um exemplo de um rolamento com roletes cônicos e nominação de cada uma de suas partes. Dentre elas, destacam-se o rolete, cone (anel interno) e capa (anel externo), sendo apontados pelo sensor RB (acústico), como possíveis fontes de falhas. Além das emissões de ruídos acústicos, as falhas em rolamentos são comumente percebidas por sobreaquecimento, porém sem indicar qual a causa, levando à instrução de redução de velocidade ou parada imediata, em situações extremas. 
A equipe de operação verifica se, além do sobreaquecimento, algo é percebido no sensor acústico. Um fenômeno comum na operação é quando uma roda permanece em faixas superiores de temperatura (ainda dentro da faixa normal) por longos períodos, levando a propagação para as outras peças, indicando falsopositivos de falhas no rolamento (que trabalha em faixas inferiores de aquecimento).

\section{FIGURA 31 - ROLAMENTO COM ROLETE CÔNICO}

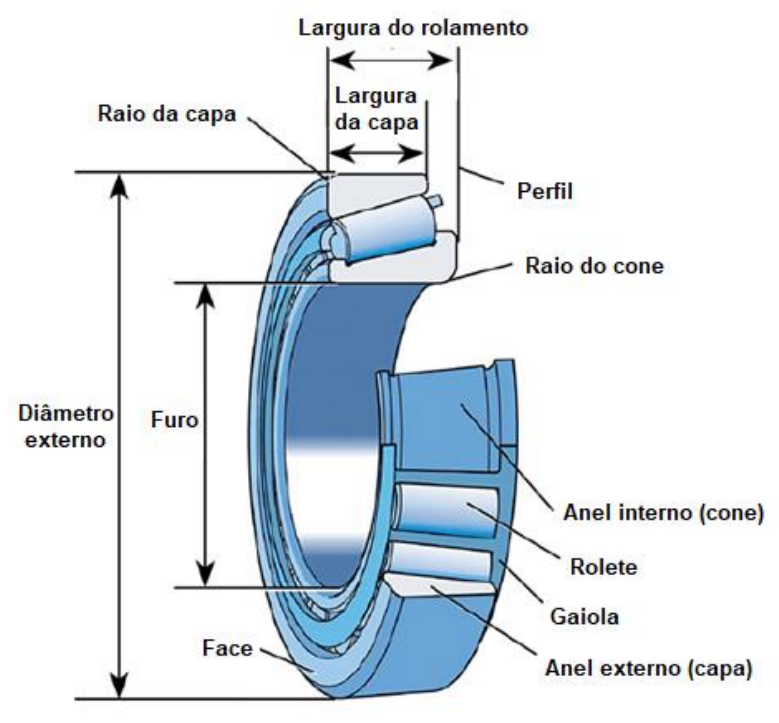

FONTE: ADAPTADO DE (GONZALEZ, 2015)

Em conformidade com os relatos efetuados pela equipe de manutenção, Kharche (2014) define que os problemas mais comuns sobre rolamentos estão relacionados a: (i.) fadiga, pela formação de rachaduras abaixo da superfície do rolamento, criando folgas e contato abrasivo em determinadas regiões, pelo desgaste natural ou sobrecarga; (ii.) desgaste por contaminação, pela penetração de partículas externas como poeira, alterando as propriedades do lubrificante, permitindo contato abrasivo sobre os componentes internos; (iii.) deformação plástica (ou brinelamento), causado por impacto excessivo pela sobrecarga ou perturbações abruptas que gerem vibrações acima do tolerável; (iv.) corrosão, pela água da chuva ou contaminação por gotejamento de água com partículas de minério vindas da carga, alterando as propriedades de lubrificação; (v.) lubrificação, pela insuficiência de material lubrificante distribuído adequadamente em partes importantes do rolamento como a interface gaiola-rolete, rolete-pista (interna e externa) e gaiola-pista (interna e externa). 


\subsubsection{Roda}

O estudo sobre o desgaste de rodas e os efeitos causados pelo contato com o trilho são comuns no domínio da engenharia ferroviária, baseando-se tradicionalmente tanto em modelos físicos-matemáticos, quanto em simulações computacionais, como análise de elementos finitos (SÁBITZ; KOLONITS, 2014).

O bom funcionamento dessa peça está diretamente relacionado às condições da superfície de contato (roda e trilho) e condições operacionais de funcionamento. Sakharov (2005) descreve que os principais modos de falhas em rodas de vagões são rachaduras, fissuras e deformações da peça, sendo causadas por sobreaquecimento excessivo (causadas por frenagens bruscas, ajuste inapropriado da sapata e sistema freios, ou deformações existentes na superfícies), e excesso de curvas.

A Figura 32 ilustra a geometria de uma roda e quais são as medições capturadas pelo sensor WSP. A superfície da roda é formada por uma região de contato ("wheel thread"), e o friso lateral interno ("flange"), podendo ser visto como um elemento de segurança que evita o descarrilamento. Spiroiu (2018) define que as características e propriedades geométricas da roda é um fator importante para a estabilidade do carros em movimento, e devem ser igualmente considerados como fontes de falhas em comparação com as deteriorações de superfície (rachaduras, fraturas e deformações).

FIGURA 32 - GEOMETRIA DO PERFIL DE UMA RODA DE VAGÃO

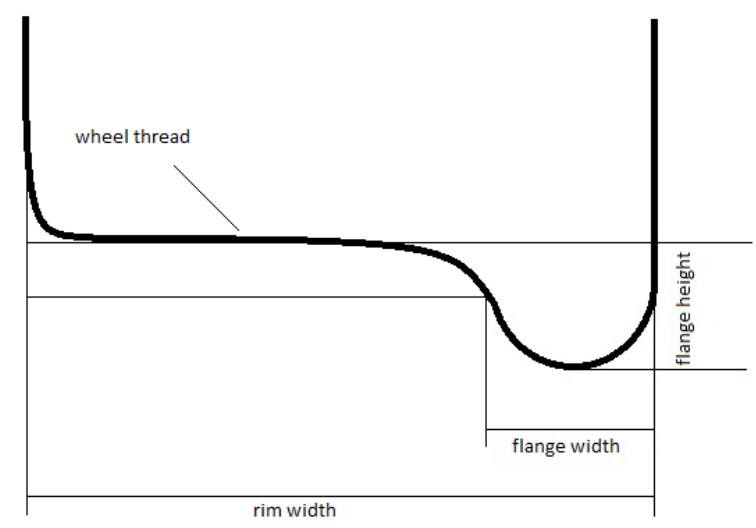

FONTE: AUTOR

Devido à alta dispersão sobre as medições do sensor WSP, as características da geometria da roda são pouco consideradas na tomada de decisão pelas equipes de 
manutenção da Vale. Portanto, a análise e detecção de falhas sobre rodas têm sido feitas, majoritariamente, pelas medições de sobreaquecimento (sensor HBW).

Diferentemente do rolamento, a roda de vagões ferroviários trata o contato com o trilho com o volume expressivamente menor de lubrificação, permitindo um contato mais direto e potencialmente mais abrasivo entre as duas superfícies rígidas que possuam alguma imperfeição. Consequentemente, essa peça é projetava para tolerar faixas de temperatura superiores às do rolamento, sem comprometer a sua vida útil. À medida que a superfície dessas peças se desvia das especificações originais, o contato tende a criar atrito (e consequentemente desgaste) anormal, comumente se manifestando pelo sobreaquecimento do material.

Em situações extremas de frenagem, uma roda pode ultrapassar 700 graus Celsius, seguido pelo resfriamento rápido sobre as regiões posteriores do trilho, causando o fenômeno conhecido por têmpera. Esse fenômeno leva a uma degradação termomecânica por transformações das propriedades metalúrgicas sobre as regiões afetadas peça, através da formação de martensita, que tem como característica ser mais rígido e quebradiço, levando a fraturas e degradação precoce da peça, consequentemente podendo alterar o padrão de medições obtidas pelos sensores. 
Este capítulo detalha todos os cenários experimentais que abrangem os tópicos levantados na proposta da pesquisa, bem como detalhes sobre preparação dos dados, tecnologias e configurações utilizadas, resultados e discussões.

\subsection{INFRAESTRUTURA E TECNOLOGIAS UTILIZADAS}

Seguem abaixo os detalhes das ferramentas e tecnologias usadas:

- Infraestrutura computacional:

- Laptop Dell Inspiron $\mathbf{7 4 6 0}$

- Processador: Intel Core 177500 (4 CPU's de 2.7 Giga hertz)

- Memória: 32 Gigabytes de RAM DDR4 (2133 Giga hertz)

- Armazenamento: HD SSD 256 Gigabytes (sistema operacional) e HD de 1 Terabyte 7200 rpm (armazenamento dos códigos desenvolvidos e dados experimentais)

- Sistema Operacional: Windows 10

- Ambiente experimental e tecnologias:

- Linguagem: Python 3.6 (desenvolvimento de todos componentes e experimentos utilizados na pesquisa)

- Ambientes de Desenvolvimento:

- PyCharm 2019 (classes e API's)

- Jupyter Notebook (execução de experimentos)

- API's utilizadas:

- Pandas: Manipulações e tratamentos de bases de dados

- Numpy: Manipulações e cálculos matemáticos sobre matrizes e manipulações gerais sobre séries temporais

- Sklearn: Biblioteca de apoio e treinamento de modelos de aprendizado de máquina (cálculo de métricas, recursos de embaralhamento e separações de dados para treinamento/teste, entre outros)

- TensorFlow 2: Desenvolvimento e treinamento de modelos de deep learning 


\subsection{PREPARAÇÃO DOS DADOS}

A preparação adequada dos dados possibilita a execução de experimentos com resultados mais confiáveis possibilitando alcançar melhor desempenho. $O$ tratamento proposto visa suprir os problemas encontrados, e transformar a visão dos dados de uma maneira mais apropriada para a aplicação dos métodos propostos neste texto.

A Figura 33 descreve os passos gerais de preparação dos dados para os experimentos. Durante as entrevistas com especialistas de campo da Vale, foi constatado que o nível de imprecisão das medições dos sensores de perfil de rodeiro (WSP) é extremamente elevado, e desse modo foi decidido não as utilizar na modelagem.

FIGURA 33 - ETAPAS DE PREPARAÇÃO DOS DADOS

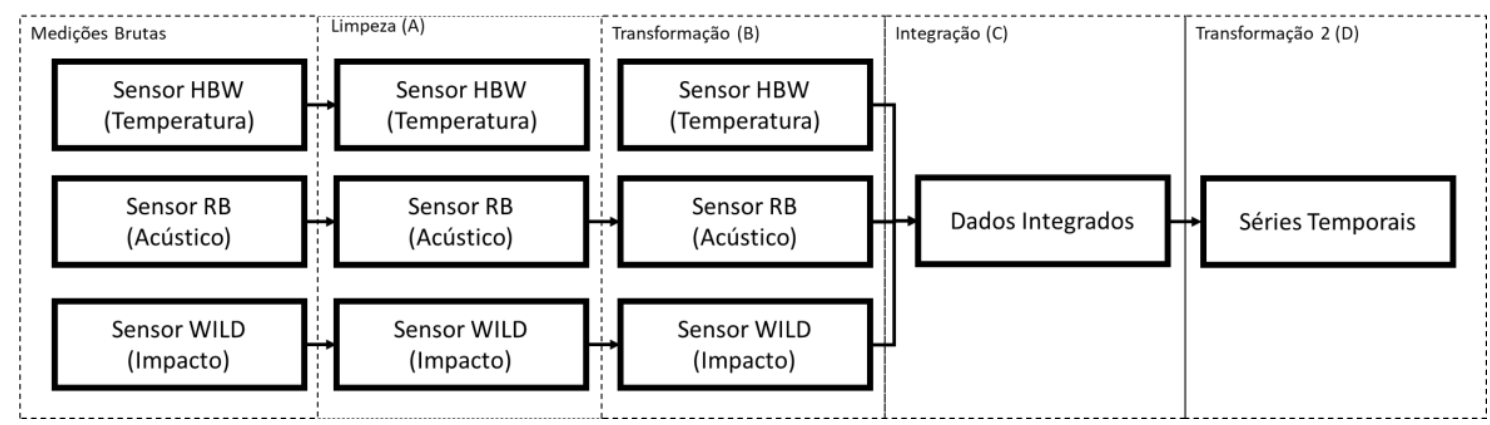

FONTE: AUTOR

Após a captura das medições brutas compartilhadas pela Vale (via arquivo texto), a tarefa de Limpeza $(A)$ engloba o tratamento e remoção de quaisquer ruídos e inconsistências que perturbem a integridade dos dados, como espaços em branco, registros nulos, caracteres especiais ou problemas de codificação.

A etapa de Transformação (B) envolve: (i.) a transformação da visão original das observações (sobre nível de eixo) para nível de vagão, unindo as diferentes observações sobre o mesmo vagão em um único registro, provendo uma visão geral do equipamento em um único registro; (ii.) a geração de atributos contextuais que reforcem os resultados dos algoritmos (como por exemplo a diferença de temperatura de um vagão em relação a todos os vagões em uma determinada viagem); (iii.) a transformação de valores para viabilizar o uso da informação sobre os modelos propostos (como mostrado no exemplo da Figura 34, no qual dados categóricos são 
transformados em colunas numéricas, tendo sido gerado o significativo conjunto de 200 novos parâmetros, sobre um total final de aproximadamente 257 parâmetros); (iv.) a geração de colunas sobre o estado da observação em relação aos parâmetros de retenção dos vagões provenientes de todos os sensores, como mecanismo de validação sobre os resultados em técnicas de detecção e predição ("0" se for normal e "1" se for falha).

\section{FIGURA 34 - EXEMPLO DE CODIFICAÇÃO DE DADOS CATEGÓRICOS PARA CAMPOS NUMÉRICOS}

\begin{tabular}{|l|l|l|l|l|}
\hline ID & Severidade & ID & RS & WHFLT \\
\hline 235 & RS_1; WHFLT_2 & 235 & 1 & 2 \\
\hline 250 & RS_3;WHFLT_1 & 250 & 3 & 1 \\
\hline
\end{tabular}

FONTE: AUTOR

A etapa de Integração $(C)$ envolve a fusão dos dados tratados e transformados dos sensores em um único conjunto, provendo uma visão integrada, sendo usado nos experimentos de detecção e diagnóstico de falhas presentes. Conforme explicado no estudo de caso, o número de equipamentos do sensor de aquecimento (HBW) instalados na via é superior aos outros sensores, sendo 15 sensores HBW e 1 sensor acústico (ABD) e 1 sensor de impacto (WILD). De modo a aproveitar todas as informações disponíveis, a integração dos dados foi feita pela ligação do equipamento (instância particular de vagão) e a combinação da data de medição mais próxima e sentido da viagem (sentido "mina" ou "porto") compatíveis entre os sensores. Como resultado, as informações de cada registro do ABD e WILD foram replicadas para cada medição do HBW, resultando em registros completamente preenchidos.

A etapa de Transformação $2(D)$ gera as séries temporais para serem usadas nos experimentos sobre o prognóstico de falhas. As amostras são inicialmente agrupadas por equipamento (vagão) em conjuntos de dados específicos. Visto que as informações que as informações do sensor ABD e WILD são altamente repetidas (para viabilizar a junção dos sensores) e extensas (90\% dos parâmetros são provenientes do sensor $A B D$ ), no caso do prognóstico, as informações desses sensores foram reduzidas a um campo singular para cada sensor, de modo que 
reduza o peso relativo desses sensores em relação ao conjunto de registros, e reflita adequadamente o cenário real da predição. Uma transformação logarítmica foi aplicada sobre os dados com o objetivo de reduzir a disparidade das entre as falhas e as amostras normais.

Após isso, esses conjuntos são processados em lote, e transformados em séries temporais (matrizes tridimensionais em que cada amostra possui um número determinado de parâmetros em cada período da sequência temporal). Devido ao grande volume de dados gerados e as limitações computacionais existentes, 0 número de parâmetros é reduzido para 20 e as séries temporais foram criadas com tamanho definido em 25 lapsos temporais, definido a partir de experimentos preliminares que determinaram esse valor como um tamanho suficiente para possibilitar resultados experimentais satisfatórios. As séries temporais são salvas em formato “.npy" (formato binário nativo da API Numpy para armazenamento dos dados), e contém um número determinado de amostras de equipamento.

Ainda durante a geração das séries temporais, dois tipos de escalas de transformações foram também avaliados: (i.) a escala comum (mais granular), guardando a medição sobre cada ponto da via, no qual 1 viagem contém até 15 pontos de medição); (ii.) agrupamento de medições por viagem (menos granular), no qual a série temporal guarda uma sequência de viagens. Do ponto de viagem funcional, a segunda abordagem é mais interessante por possibilitar que o modelo aprenda a prever comportamentos anômalos de forma mais antecipada, permitindo que o time de operação tenha mais tempo para se planejar sobre eventuais anormalidades estimadas. Os experimentos preliminares determinaram que a segunda abordagem (por viagem) permitiu que os modelos alcançassem desempenhos superiores, sendo assim adotado para os experimentos do prognóstico.

\subsection{EXPERIMENTOS}

Os cenários experimentais foram divididos de modo a atender a organização proposta na metodologia, destacando as respectivas contribuições, sendo a subseção 6.3.1 relacionada a detecção de falhas, 6.3.2 sobre diagnóstico de falhas e 6.3.3 sobre prognóstico de falhas. 


\subsubsection{Detecção de Falhas: Avaliação de Capacidade de Detecção de Falhas Presentes}

Esse experimento avalia a capacidade preditiva do autoencoder (descrito na seção 2.2.2) sob diversos aspectos e combinações de hiperparâmetros (parâmetros de configuração, que definem aspectos sobre o treinamento e comportamento do modelo gerado), de modo a confirmar quais arranjos mais adequados para preparação do modo para os experimentos de diagnóstico. Em alguns cenários particulares, 0 autoencoder é usado também como estratégia de redução de dimensionalidade para os outros modelos, de modo que se obtenha resultados ainda mais otimizados como base de comparação.

O autoenconder é comparado com outras abordagens de métodos reconhecidamente eficientes para problemas de detecção de anomalia, sendo eles o Isolation Forest (detalhado na seção 2.3.5.2) e redes $M L P$ supervisionadas (detalhado na seção 2.1.2), tendo sido selecionados para comparação pelos os seguintes motivos:

- O Isolation Forest é um método baseado em ensemble de árvores de decisão, com uma heurística projetada para problemas de detecção de anomalias, alcançando resultados superiores, chegando a ser considerado estado-da-arte até um passado recente (DOMINGUES et al., 2018; GARCHERY; GRANITZER, 2018).

- A rede $M L P$ é colocada como base de comparação da capacidade dos métodos supervisionados em relação aos não supervisionados. Visto que essa rede é treinada de forma supervisionada (o método de otimização converge para um resultado conhecido), a MLP supostamente deve alcançar os melhores resultados.

De modo a testar a efetividade dos métodos não supervisionados em discriminar falhas de forma autônoma, o autoencoder e o Isolation Forest receberam apenas um parâmetro constante a respeito do percentual de falhas baseado nos dados de treinamento (5,6\%), permitindo obter o escore de anomalias das amostras e definir a faixa de decisão entre normal e falha. Foram utilizados aproximadamente 2 milhões 
de registros de medição para treinamento, correspondendo ao período de operação entre janeiro e fevereiro, e 440 mil para teste sobre o mês de março.

Conforme a tabela 2, cada um dos métodos é avaliado sob diversas combinações de hiperparâmetros e arquiteturas do modelo (no caso das redes), de modo a obter resultados mais consistentes e intuições quanto à construção dos modelos, destacando-se (em negrito) as melhores configurações de acordo com os resultados experimentais. $\mathrm{O}$ autoencoder é testado em 3 configurações diferentes de arquitetura, no qual varia-se o número de camadas e taxa de compressão (transformação feita pelo encoder que resulta na dimensão do dado): (i.) rede profunda (cenário A1) com 28 camadas e alta compressão (96\%, ou 10 dimensões); (ii.) rede profunda (cenário A2) com 14 camadas e compressão moderada (75\%, ou 63 dimensões); (iii.) rede pequena (cenário A3) com 4 camadas e compressão reduzida (64\%, ou 95 dimensões).

TABELA 2-HIPERPARÂMETROS AVALIADOS

\begin{tabular}{|c|c|c|}
\hline Modelo & Tipo & Hiperparâmetros \\
\hline Autoencoder & $\begin{array}{l}\text { Não supervisionada (baseada } \\
\text { em reconstrução) }\end{array}$ & $\begin{array}{l}\text { - Número de camadas (e compressão): } 4 \text { (compressão de } \mathbf{6 4 \% ) , 1 6} \\
\text { (compressão de } 75 \% \text { ), } 28 \text { (compressão de } 96 \% \text { ) } \\
\text { - Dropout: } 0 \%, 20 \% \\
\text { - Funções de ativação (camadas escondidas): Sigmoide, Tangente } \\
\text { - Fiperbólica, ReLU } \\
\text { hunçes de ativação (camada de saída): Sigmoide, Tangente } \\
\text { - Função de erro da rede: Erro quadrático médio, entropia cruzada } \\
\text { binária } \\
\text { - Cálculo de residual da reconstrução: Erro quadrático médio, } \\
\text { entropia cruzada binária, Erro logarítmico quadrado } \\
\text { - Épocas: } \mathbf{1 , 3} \\
\text { - Porcentagem de Anomalias: } 5,6 \%\end{array}$ \\
\hline Isolation Forest & $\begin{array}{l}\text { Não supervisionada (baseada } \\
\text { em heurística específica) }\end{array}$ & $\begin{array}{l}\text { - Número de árvores: } 100,200,300 \\
\text { - Amostragem com reposição: sim, não } \\
\text { - Tamanho da amostra por árvore: } 100 \%, 50 \%, 10 \% \\
\text { - Porcentagem de Anomalias: } 5.6 \% \\
\text { - Dimensão Reduzida: } 4 \text { (compressão de } 64 \% \text { ), } 8 \text { (compressão de } \\
\text { 75\%), } 28 \text { (compressão de } 96 \% \text { ) provenientes do autoencoder e PCA }\end{array}$ \\
\hline MLP & Supervisionada & $\begin{array}{l}\text { - Número de camadas: } 8 \\
\text { - Dropout: } 0 \%, 20 \% \\
\text { - Funções de ativação (camadas escondidas): Sigmoide, Tangente } \\
\text { hiperbólica, ReLU } \\
\text { - Funções de ativação (camada de saída): Sigmoide, Tangente } \\
\text { hiperbólica, ReLU } \\
\text { - Função de erro da rede: Erro quadrático médio, entropia cruzada } \\
\text { binária } \\
\text { - Épocas: } 1,3 \\
\text { - Dimensão Reduzida: } 4 \text { (compressão de } 64 \% \text { ), } 8 \text { (compressão de } \\
75 \% \text { ), } 28 \text { (compressão de } 96 \% \text { ) proveniente do autoencoder e PCA }\end{array}$ \\
\hline
\end{tabular}

Foram definidas 5 configurações de modelos para os experimentos Isolation Forest (IF1, IF2, IF3, IF4 e IF5) e para a rede MLP (MLP1, MLP2, MLP3, MLP4 e 
MLP5), no qual a diferença entre cada um desses está apenas sobre o dado usado no treinamento. Os encoders de cada uma das configurações detalhadas acima (A1, A2 e A3) são usados como mecanismo redução de dimensionalidade sobre os dados para, respectivamente para 3 cenários do Isolation Forest (IF1,IF2 e IF3) e a MLP (MLP1, MLP2 e MLP3). Isso significa que os modelo IF1 e MLP1 usam a saída do encoder de AE1 (que geram dados comprimidos em 10 dimensões), IF2 e MLP2 usam a saída do encoder AE2 (63 dimensões), e IF3 e MLP3 usam a saída do encoder AE3 (95 dimensões).

As configurações IF4 e MLP4 usam o Principal Component Analysis (PCA) como entrada, definido para gerar uma saída de 95 dimensões. Sobre os cenários IF4 e MLP4, a taxa de compressão aplicada foi configurada para se reter 95\% da variância contida nos dados, ou seja, a informação é majoritariamente preservada. Note que o cenário AE3 (e consequentemente também IF3 e MLP3) aplica a mesma taxa de compressão dos cenários do PCA, porém realizando transformações não lineares, o que permite melhor desempenho e capacidade de codificação do dado. As configurações sobre IF5 e MLP5 usam os dados brutos como entrada, assim como em todos as configurações sobre o autoencoder. Como mostrado na tabela 2, cada um dos modelos é avaliado exaustivamente com um extenso conjunto de combinações de configurações. De modo a reduzir o tempo computacional de processamento, cada um dos modelos foi treinado em um número muito reduzido de épocas (o número de vezes que o conjunto de dados é colocado para processamento durante o treinamento, que no caso em questão foi testado em até 3 épocas sobre autoencoder e MLP, visto que cada época custa até 15 minutos sobre o pior cenário). Para mitigar o enviesamento dos modelos ("bias", que significa tendência do modelo em obter respostas direcionadas a uma categoria, que no caso pode ser normal ou falha), os dados foram embaralhados (shuffling) e aplicada uma validação cruzada em 3 grupos de dados ( 3 fold cross-validation).

A tabela 3 mostra o impacto individual causado pelos parâmetros sobre 0 treinamento dos modelos (pela alteração somente do valor, e mantendo os demais constantes). Note que as redes neurais são fortemente afetadas por diferentes configurações. Por outro lado, o Isolation Forest não demonstrou melhorias significativas ao alterar as configurações controladas. 
Além das combinações destacadas na tabela 3, os modelos também foram treinados com dados em diferentes transformações (normal, logarítmica e potência). A transformação de potência (na base 2) é usada como base sobre os resultados apresentados posteriormente, visto que avaliações preliminares mostraram que o autoencoder obteve ganhos expressivos de desempenho sobre a precisão, enquanto nos outros não apresentaram uma diferença aparente.

TABELA 3 - SUMÁRIO DOS IMPACTOS DOS HIPERPARÂMETROS

\begin{tabular}{|c|c|c|c|c|}
\hline $\begin{array}{l}\text { Tipo de Modelo } \\
\text { Impactado }\end{array}$ & Configuração & Precisão & Sensibilidade & Impacto \\
\hline $\begin{array}{l}\text { Autoencoder/ } \\
\text { MLP/ } \\
\text { Isolation Forest }\end{array}$ & $\begin{array}{l}\text { Seleção dos dados de } \\
\text { treinamento filtrando } \\
\text { apenas os casos } \\
\text { normais }\end{array}$ & & - & $\begin{array}{l}\text {-30\% sobre precisão ao treinar apenas com os dados } \\
\text { normais para o autoencoder } \\
\text { MLP foi testada apenas com todos os dados } \\
\text { Isolation Forest não impactado }\end{array}$ \\
\hline Autoencoder & $\begin{array}{l}\text { Treinamento sem } \\
\text { dados transformados } \\
\text { em potência }\end{array}$ & & & $\begin{array}{l}+30 \% \text { sobre precisão ao treinar com dados transformados } \\
\text { em potência (não foi notada melhoria ao aumentar a } \\
\text { escala entre } 2 \text { e } 4 \text { ) para o autoencoder } \\
\text { Isolation Forest não impactado }\end{array}$ \\
\hline Autoencoder & $\begin{array}{l}\text { Aumento do número } \\
\text { de camadas }\end{array}$ & & & $\begin{array}{l}\text { Ganho global de desempenho pelo aumento de número } \\
\text { de camadas }\end{array}$ \\
\hline Autoencoder & $\begin{array}{l}\text { Aumento da taxa de } \\
\text { compressão }\end{array}$ & & & $\begin{array}{l}\text { Ganho global de desempenho (principalmente } \\
\text { sensibilidade) pelo aumento da taxa de compressão (até } \\
\text { certo ponto) }\end{array}$ \\
\hline $\begin{array}{l}\text { Autoencoder/ } \\
\text { MLP }\end{array}$ & Inclusão de Dropout & & & $\begin{array}{l}-1.5 \% \text { sobre precisão e sensibilidade sobre autoencoder } \\
+1 \% \text { sobre precisão e sensibilidade sobre MLP }\end{array}$ \\
\hline $\begin{array}{l}\text { Autoencoder/ } \\
\text { MLP }\end{array}$ & $\begin{array}{l}\text { Usar sigmóide como } \\
\text { função de ativação na } \\
\text { saída }\end{array}$ & & & $\begin{array}{l}\text { +4\% sobre precisão e sensibilidade (com sigmoide na } \\
\text { camada da saída) }\end{array}$ \\
\hline $\begin{array}{l}\text { Autoencoder/ } \\
\text { MLP }\end{array}$ & $\begin{array}{l}\text { Usar tangente } \\
\text { hiperbólica como } \\
\text { função de ativação } \\
\text { nas camadas latentes }\end{array}$ & & & $\begin{array}{l}\text { +1\% sobre precisão e sensibilidade (com sigmoide na } \\
\text { camada da saída) }\end{array}$ \\
\hline Autoencoder & $\begin{array}{l}\text { Aumentar número de } \\
\text { épocas }\end{array}$ & - & & -3\% sobre sensibilidade, acima de 15 épocas \\
\hline $\begin{array}{l}\text { Autoencoder/ } \\
\text { MLP }\end{array}$ & $\begin{array}{l}\text { Erro quadrático ou } \\
\text { entropia cruzada } \\
\text { como função de erro } \\
\text { da rede }\end{array}$ & - & & $\begin{array}{l}\text { Erro quadrático médio e entropia cruzada obtiveram } \\
\text { resultados similares }\end{array}$ \\
\hline Autoencoder & $\begin{array}{l}\text { Cálculo de residual da } \\
\text { reconstrução usando } \\
\text { erro quadrático } \\
\text { médio }\end{array}$ & & & $\begin{array}{l}-2 \% \text { sobre precisão e }+6 \% \text { sobre sensibilidade ao aplicar o } \\
\text { erro quadrático médio comparado à entropia cruzada }\end{array}$ \\
\hline Isolation Forest & $\begin{array}{l}\text { Aumentar número de } \\
\text { árvores }\end{array}$ & - & & $\begin{array}{l}+5 \% \text { sobre sensibilidade ao aumentar o número de } \\
\text { árvores }\end{array}$ \\
\hline Isolation Forest & $\begin{array}{l}\text { Incluir amostragem } \\
\text { com reposição }\end{array}$ & - & - & Não foi notada diferença sobre os resultados \\
\hline Isolation Forest & $\begin{array}{l}\text { Aumentar tamanho } \\
\text { da amostra por } \\
\text { árovore }\end{array}$ & - & - & Não foi notada diferença sobre os resultados \\
\hline
\end{tabular}

FONTE: AUTOR

Outro ponto adicionalmente avaliado foi o treinamento utilizando todo o conjunto de dados, ou apenas utilizando os dados normais (o que torna o modelo mais sensível a distorções nos dados). Durante o treinamento, percebeu-se que em todos os 
modelos e cenários, o uso de todo o conjunto de dados foi mais apropriado para alcançar resultados melhores no quesito precisão.

Devido ao alto conjunto de combinações de hiperparâmetros avaliados, apenas o conjunto com os melhores resultados foi selecionado para apresentação sobre cada um dos cenários mostrados acima. A tabela 4 mostra os resultados obtidos considerando o melhor conjunto de hiperparâmetros por tipo de modelo e dimensão dos dados de treinamento (no caso do Isolation Forest e MLP). Como esperado, as redes MLP obtiveram os melhores resultados globais: a configuração de modelo MLP3 alcançou o melhor resultado de precisão com $99,36 \%$ e a medida $F$ (balanço entre precisão e acurácia) com 96,69\%; a configuração MLP5 obteve o melhor resultado de sensibilidade obteve o melhor resultado de sensibilidade com 97,41\%; as configurações MLP1 e MLP2 retornaram resultados insatisfatórios, possivelmente causados pela distorção causada na alta compressão pelos encoders AE1 e AE2.

TABELA 4-RESULTADOS

\begin{tabular}{|c|c|c|c|c|c|c|}
\hline Configurações & Tipo de Modelo & $\begin{array}{l}\text { Modelo de } \\
\text { Entrada }\end{array}$ & Dimensão da Entrada & Precisão & Sensibilidade & Medida F1 \\
\hline AE1 & Autoencoder & - & 257 (entrada original) & $82.98 \%$ & $98.84 \%$ & $90.20 \%$ \\
\hline AE2 & Autoencoder & - & 257 (entrada original) & $83.36 \%$ & $98.78 \%$ & $90.42 \%$ \\
\hline AE3 & Autoencoder & - & 257 (entrada original) & $7.29 \%$ & $95.47 \%$ & $13.55 \%$ \\
\hline IF1 & Isolation Forest & $\mathrm{AE} 1$ & 10 & $0 \%$ & $0 \%$ & - \\
\hline IF2 & Isolation Forest & $\mathrm{AE2}$ & 63 & $19.19 \%$ & $13.48 \%$ & $15.84 \%$ \\
\hline IF3 & Isolation Forest & AE3 & 95 & $19.80 \%$ & $91.51 \%$ & $32.56 \%$ \\
\hline IF4 & Isolation Forest & PCA & 95 & $9.69 \%$ & $98.93 \%$ & $17.66 \%$ \\
\hline IF5 & Isolation Forest & - & 257 (entrada original) & $8.76 \%$ & $96.72 \%$ & $16.08 \%$ \\
\hline MLP1 & MLP & $\mathrm{AE} 1$ & 10 & $0 \%$ & $0 \%$ & $0 \%$ \\
\hline MLP2 & MLP & $\mathrm{AE} 2$ & 63 & $0 \%$ & $0 \%$ & $0 \%$ \\
\hline MLP3 & MLP & $\mathrm{AE3}$ & 95 & $97.51 \%$ & $95.88 \%$ & $96.69 \%$ \\
\hline MLP4 & MLP & PCA & 95 & $91.58 \%$ & $94.53 \%$ & $93.03 \%$ \\
\hline MLP5 & MLP & - & 257 (entrada original) & $90.65 \%$ & $99.36 \%$ & $94.81 \%$ \\
\hline
\end{tabular}

FONTE: AUTOR

Dentre os métodos não supervisionados, destacam-se as configurações AE1 alcançando a melhor sensibilidade (98.84\%), e AE2 conseguindo o resultado de precisão (83.36\%) e da medida F1 (90.42\%). AE3, similar as configurações IF3, IF4 e IF5 se mostraram altamente enviesados a classificar as amostras como falhas, significando, onde alcançaram níveis elevados de sensibilidade ao custo de atingir taxas altas de falsos positivos. As configurações IF1 e IF2 obtiveram os piores resultados gerais ( $0 \%$ e $15.8 \%$ de medida $\mathrm{F} 1$, respectivamente). 
Ao considerar a aplicação em um sistema crítico real, as configurações AE1 e AE2 apresentaram resultados promissores, visto que os respectivos modelos aprenderam a classificar falhas com alto desempenho unicamente pelos dados, sem qualquer conhecimento sobre os parâmetros adotados para retenção dos vagões. Assumindo que o problema de detecção é aplicado em um sistema crítico, no qual as falhas não podem passar despercebidas (ou seja, mitigar os falso-negativos), AE1 e AE2 atingiram níveis elevados de desempenho, com diferença inferior a $0.6 \%$ em relação ao melhor resultado dos modelos supervisionados.

Embora os níveis de precisão tenham sido consideravelmente menor em relação a MLP (83\% contra 97\% no melhores resultados), os autoencoders possibilitam que os erros residuais obtidos pela reconstrução sejam usados como fonte de análise para indicar níveis sutis de desvio comportamental, que podem indicar estados incipientes de falha, ou equipamentos que estão simplesmente fora da faixa de tolerância aceitável em uma situação particular, mas que não necessariamente esteja em um estado de falha (falsos positivos). Em abordagens não supervisionadas, a definição da fronteira entre normal e falha não está bem definida, pelo alto nível de subjetividade envolvido, o que pode necessitar do veredito de especialistas para confirmarem o real estado do equipamento.

Conforme a figura 35, ao visualizar a distribuição dos residuais obtidos sobre a amostra de teste, percebe-se que a grande maioria está concentrada na região próxima a zero, visto que a maioria das amostras segue um padrão normal. Embora a cauda longa da distribuição (as amostras com valores mais elevados) possa indicar as situações com estágios mais avançados de degradação (visto que o desvio é mais evidente), a maioria expressiva das falhas estão muito próximas da região da fronteira da decisão (conforme apresentado e discutidos sobre as figuras 36 e 37). Essas amostras podem indicar equipamentos em estágios iniciais ou moderados de falhas, tornando a classificação subjetiva em alguns casos particulares, podendo ser facilmente confundidos com equipamentos normais com comportamentos excepcionalmente desviados por fatores externos (condições ambientais ou da taxa de operação forçada sobre o equipamento). 
FIGURA 35 - HISTOGRAMA DOS ERROS RESIDUAIS SOBRE AMOSTRA DE TESTE

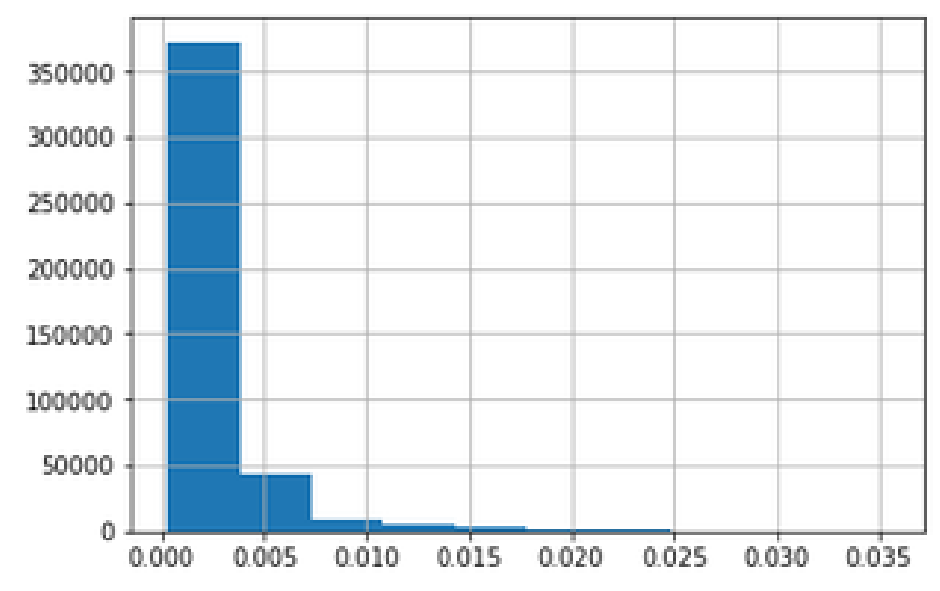

FONTE: AUTOR

A figura 36 exemplifica uma amostra estratificada de amostras de residuais obtidos dos dados de teste contendo verdadeiros positivos (falhas classificadas corretamente), verdadeiro negativos (amostras normais classificadas corretamente), falsos positivos (amostras normais classificadas como falha) e falso negativos (falhas não identificadas). Para facilitar a visualização dos grupos diferentes dos verdadeiros negativos (que são a grande maioria dos dados), as proporções da amostra foram balanceadas.

Quanto maior o erro residual, será supostamente menor a incerteza sobre a confirmação que o equipamento realmente está em falha. Por outro lado, equipamentos que estejam funcionando próximos à fronteira da falha (dentro ou fora da faixa normal) são passíveis de serem classificados indevidamente, sendo falsopositivos ou falso-negativos. Pela figura 36, percebe-se que o modelo é altamente sensível a desvios comportamentais, nos quais equipamentos que estejam operando de forma anormal (faixa de pré-falha, indicando pela região laranja) aparecem dentro da fronteira do estado normal e próximo do limite tolerável. Do mesmo modo, nota-se que os falso positivos (indicados pela região vermelha), também aparecem próximos da fronteira de decisão. Essa situação pode ser fruto de análises posteriores para verificar se tal comportamento é recorrente, se segue algum padrão, ou se está ligado a alguma tendência de evolução de falha que possa acontecer futuramente. 


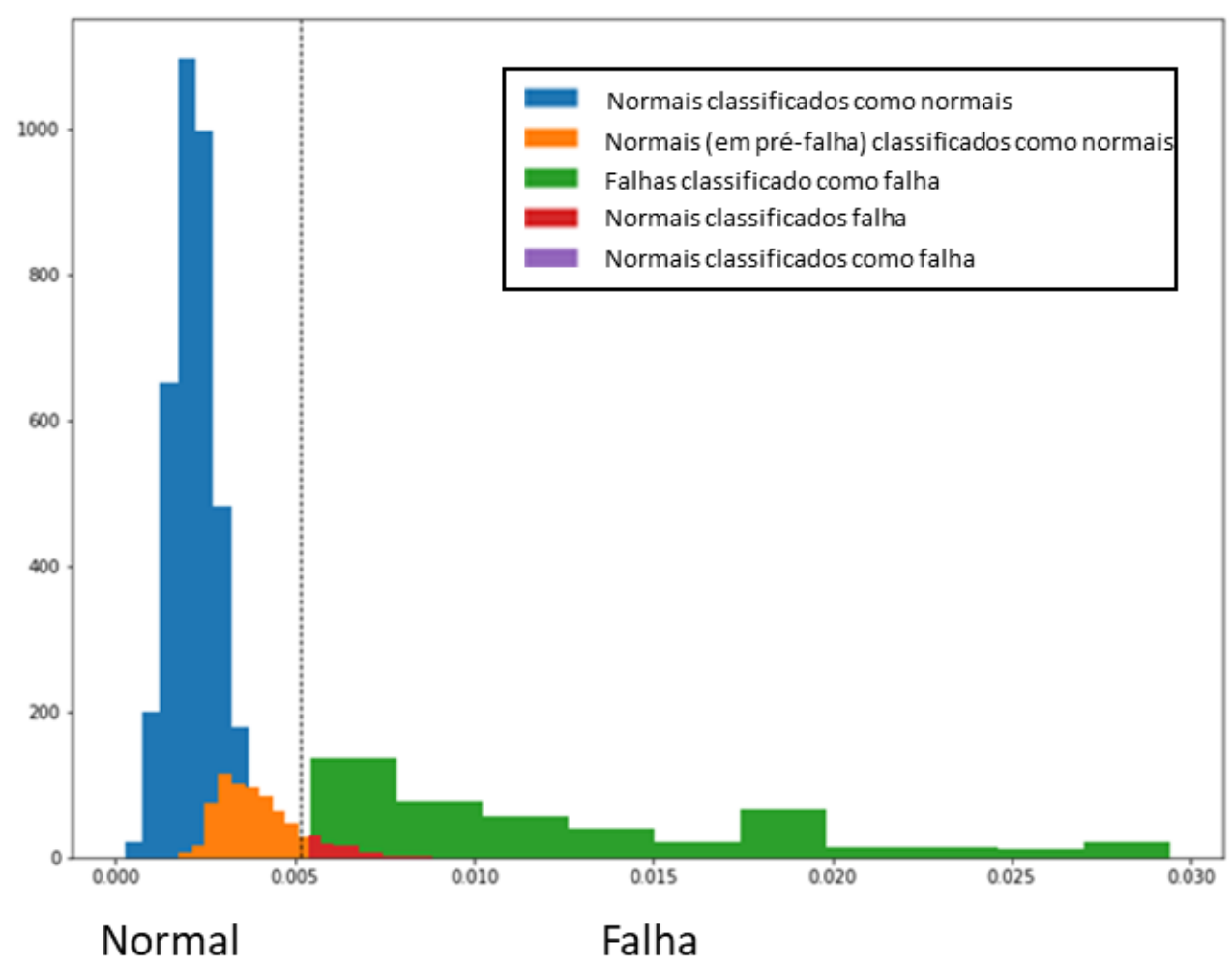

FONTE: AUTOR

Vale destacar que a alta compressão associada às transformações ao longo de redes profundas nos modelos $A E 1$ e $A E 2$, resultou em uma capacidade preditiva poderosa, considerando que o modelo convergiu para um classificador que endereça grande parte das falhas conhecidas baseadas nos parâmetros de retenção dos vagões, de forma autônoma, o que se entende possa ser aplicado em outros problemas reais com uma necessidade reduzida de um especialista ou anotações históricas de eventos de falha. Por outro lado, essa alta taxa de compressão foi insatisfatória quando usada como mecanismo de redução de dimensionalidade para outros modelos.

Entende-se que não há relevância sobre qualidade da reconstrução obtida pelos autoencoders aplicados em detecção de anomalias. Busca-se apenas que o comportamento da reconstrução realce distorções em relação a entrada original. Ao forçar o dado em uma taxa de compressão muito elevada, há uma tendência maior que a reconstrução seja mais distorcida, já que parte da informação é perdida durante as transformações em dimensões menores. 
Isso pode ser melhor entendido pela figura 37, que representa uma plotagem dos dados de teste gerados por um encoder com saída de 2 dimensões, treinado sob um conjunto de configurações similares ao $\mathrm{AE} 1$ (com a única diferença de forçar uma taxa de compressão ainda maior, com 2 dimensões na camada comprimida, em vez de 10 como no $\mathrm{AE} 1$ ). Percebe-se que o conjunto de dados normais (azul) estão concentrados em um cluster centralizado, enquanto os falsos positivos (verde) aparecem distribuídos na região periférica do cluster azul, e as falhas (laranja) estão altamente dispersas. Mesmo com uma perda de dados acentuada causada pela compressão mais agressiva aplicada sobre o dado (99,8\% de compressão), o modelo foi capaz de identificar com alto desempenho as amostras em falha, atingindo aproximadamente $76 \%$ de precisão e $95 \%$ de sensibilidade. Desse modo, note que para alcançar melhores resultados (quanto à precisão e principalmente sensibilidade), a taxa de compressão deve ser elevada até certo ponto (avaliado empiricamente), de modo a aproximar a um nível ótimo de perda de informação suficiente que não afete negativamente a fronteira de decisão encontrada pelo modelo.

\section{FIGURA 37 - DADOS REDUZIDOS POR UM ENCODER COM SAÍDA DE 2 DIMENSÕES}

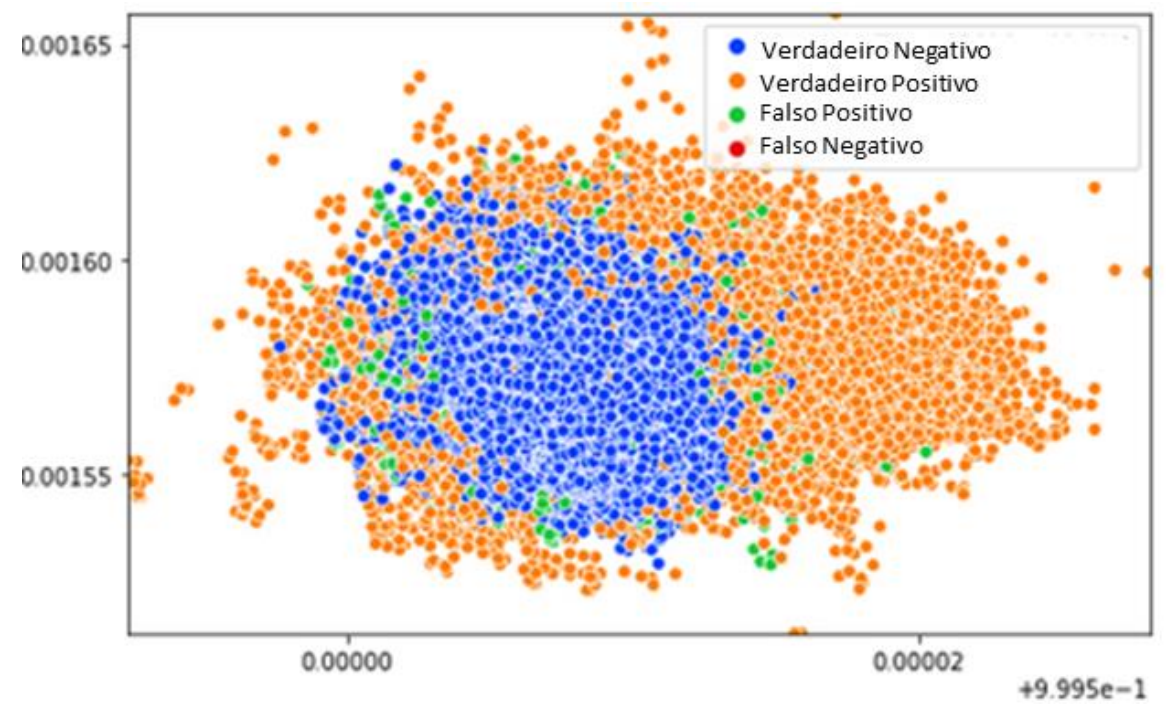

FONTE: AUTOR

Por outro lado, enquanto a redução de dimensionalidade pode contribuir para um treinamento melhor quando feita em níveis adequados (MLP3), note-se pelos resultados que o uso do dado excessivamente comprimido (IF1, MLP1 e MLP2) como entrada de um modelo, leva a um treinamento impróprio, pois grande parte da informação relevante do dado foi perdida no passo anterior da redução dimensional. 


\subsubsection{Diagnóstico: Avaliação de Capacidade do RXP}

Os experimentos de diagnóstico avaliam o uso de métodos de interpretabilidade aplicados ao diagnóstico, pela determinação do conjunto de atributos relevantes sobre amostra classificada como falha detectada (bem como qual é o comportamento quando a amostra é supostamente normal), sendo analisado em 3 perspectivas diferentes. No primeiro experimento, o desempenho do método proposto desenvolvido nesta pesquisa (RXP) é comparado com a SHAP em 3 diferentes configurações (SHAP1, SHAP2, SHAP3), onde cada uma das configurações ajusta o balanço sobre o custo computacional (velocidade das respostas) e regularidade dos resultados (redução de comportamento aleatório). O autoencoder é utilizado como base para a tarefa de detecção das falhas. No segundo experimento, avalia-se o uso do RXP como apoio para prover intuição (e consequentemente confiança) a respeito das respostas dos modelos de detecção.

No terceiro experimento, é avaliado o ganho de desempenho sobre a tarefa de detecção, fundamentado nas intuições discutidas sobre o experimento anterior. A avaliação é feita em duas configurações de modelos diferentes, onde, além da configuração base usada nos passos anteriores dos experimentos de diagnóstico, é treinado um outro autoencoder com menos camadas e uma menor taxa de compressão (consequentemente prejudicando a precisão e sensibilidade).

\subsubsection{Avaliação de Desempenho de Interpretabilidade}

Como comentado na seção 2.2.3, devido à alta subjetividade inerente à questão de interpretabilidade, não há consenso claro e bem definido sobre métricas (DOSHIVELEZ; KIM, 2017; MURDOCH et al., 2019). Inspirado em Doshi-Velez (2017), esta pesquisa adapta o cenário de avaliação para uma abordagem Funcional (figura 12, localizado na seção 2.2.3), na qual o problema avaliado é supostamente de baixa complexidade, provendo meios para uma avaliação automatizada e com baixa subjetividade. Isso pode ser feito por meio da métrica Mean Average Precision (MAP), comumente usada em problemas de ranking. O MAP pode ser representado pela seguinte equação (3):

$$
M A P=\sum_{k}\left(R_{k}-R_{k-1}\right) P_{k}
$$


em que $S_{k}$ é o recall (sensibilidade) e $P_{k}$ é a precisão do limite nas $K$ principais características relevantes. Note que, enquanto a sensibilidade é acumulativa, no caso da precisão, quanto mais resultados irrelevantes classificados próximos do topo, mais a precisão é penalizada no resultado geral.

Cada registro de interpretabilidade obtido (vetor relevância $R_{i} \in R^{M}$ ) é avaliado calculando-se um MAP baseado em um ranking sobre os principais parâmetros relevantes $\left(\left\{\left(i, R_{i i}\right),\left(j, R_{i j}\right), \ldots\right\}\right)$. Essa métrica aumenta recursivamente a precisão de cada ponto de classificação, começando do topo para o último, e captura a concentração dos resultados esperados no topo e penaliza qualquer ausência esperada.

Para reduzir aspectos subjetivos na avaliação dos resultados, com base nas respostas esperadas devido ao conhecimento especialista, os valores de relevância foram atribuídos como 0 (irrelevante) ou 1 (relevante), pelo mapeamento dos valores com respeito aos parâmetros de retenção dos vagões definidas pela VALE (seção 5.3). Isso significa que todos os parâmetros causadores possuem peso de impacto igual, e assim não há penalização sobre diferentes ordens de parâmetros relevantes que sejam subsequentes, apenas a punição sobre a ocorrência de parâmetros irrelevantes entre eles. Portanto, espera-se que todos os atributos tidos como os reais causadores de falhas estejam no topo do ranqueamento sem nenhum resultado irrelevante entre eles.

A figura 38 exemplifica o meio de avaliação sugerido pela interpretação realizada pelos 3 cenários do SHAP (SHAP1, SHAP2 e SHAP3) e o RXP sobre a amostra 295. Essa amostra contém 4 causas de falha relacionadas ao sensor ABD, onde o SHAP1, SHAP2 e o RXP foram capazes de identificar todos os parâmetros com grande importância de peso (compostos pelas barras maiores em cada plotagem), enquanto - SHAP3 falha na identificação de duas causas de falha, sendo parcialmente penalizado quanto à métrica.

Para a etapa de detecção de falhas, o autoencoder foi treinado usando cerca de 3,5 milhões de amostras em uma época, 32 amostras por lote, 25 camadas com compressão de até $98 \%$ entre a dimensão bruta (249) e a camada de codificação (5), no qual os outros detalhes de parametrização seguem as configurações realizadas 
nos experimentos da subseção 6.3.1. O autoencoder foi testado contra cerca de 379 mil registros contendo 3.867 amostras defeituosas (1\% do total de amostras), atingindo uma precisão de $82,5 \%$ e sensibilidade de $95,3 \%$. Durante os experimentos preliminares, outras configurações de hiperparâmetros foram também avaliadas, conseguindo resultados superiores. Porém essa configuração foi escolhida por prover uma capacidade preditiva razoável, e ao mesmo tempo resultar em uma quantidade interessante de amostras de falsos negativos ( 177 unidades) e de falsos positivos (774 amostras) que possibilite análises mais específicas.

FIGURA 38 - INTERPRETAÇÃO DE RESULTADOS SOBRE A AMOSTRA 295
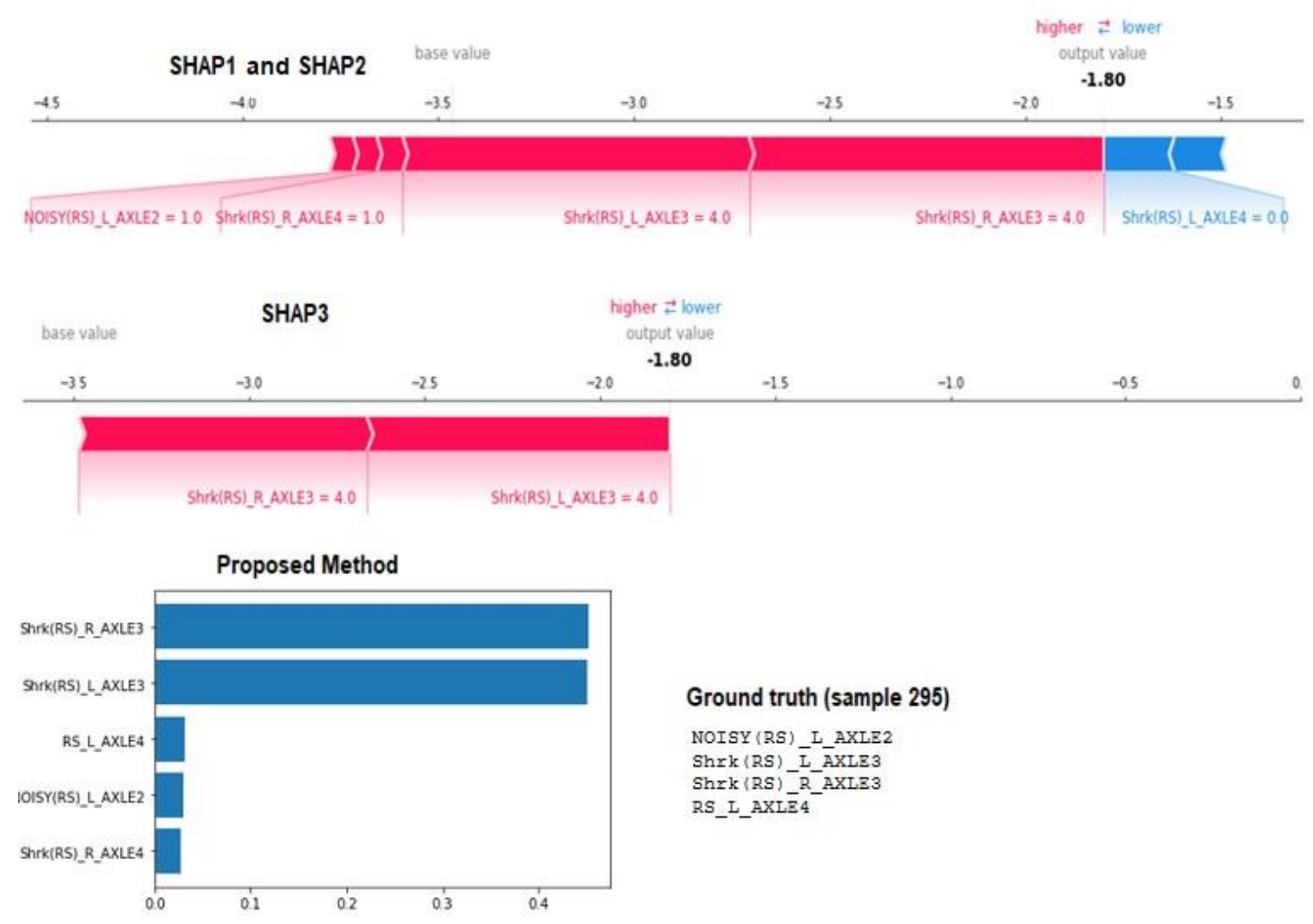

FONTE: AUTOR

Todas as falhas existentes (verdadeiro positivos e falsos negativos) e as falhas erroneamente identificadas (falsos positivos) foram selecionadas para avaliação, na qual foram realizados 30 testes com 200 amostras aleatórias diferentes (com substituição), a fim de reduzir qualquer erro aleatório. Note que a existência dos falsos positivos na avaliação força uma queda no desempenho calculado, visto que o resultado esperado nessas amostras seria um vetor populado por zeros (ou seja, 
nenhum parâmetro é relevante), mitigando enviesamento na seleção das amostras avaliadas.

Essas amostras foram interpretadas pelo método proposto (RXP) e pelo método SHAP, em três cenários diferentes (SHAP1, SHAP2 e SHAP3). O SHAP1 foi ajustado para retornar resultados mais precisos, porém ao custo de obter respostas mais lentas (cerca de 10 segundos por registro), sendo que o interpretador é treinado para geração de 800 amostras simuladas, usando 200 exemplos de treinamento da base de dados original. O SHAP2 foi ajustado para respostas mais rápidas (cerca de 5 segundos por registro), gerando 800 amostras simuladas usando 100 amostras da base de dados original. O SHAP3 foi ajustado para oferecer resultados muito rápidos (cerca de 150 milissegundos de gravação), gerando 80 amostras simuladas usando 10 exemplos da base de treinamento, mas apresentando resultados de interpretação mais instáveis.

Os resultados obtidos por este processo experimental são avaliados pela métrica Mean Average Precision (MAP), tempo médio de resposta (em milissegundos) e teste T emparelhado de resultados (RXP versus SHAP) e são apresentados tabela 5.

TABELA 5- RESULTADOS EXPERIMENTAIS (RXP, SHAP1, SHAP2 E SHAP3)

\begin{tabular}{|l|c|c|c|c|}
\hline \multicolumn{1}{|c|}{ Resultados Gerais } & SHAP1 & SHAP2 & SHAP3 & RXP \\
\hline MAP (Equação 3) & $80.47 \%$ & $80.61 \%$ & $79.54 \%$ & $81.38 \%$ \\
\hline $\begin{array}{l}\text { Tempo Médio de Resposta } \\
\text { (milissegundos) }\end{array}$ & 11,110 & 5,650 & 170 & 0.272 \\
\hline Teste Pareado T & $3.3 \times 10^{-10}$ & $6.5 \times 10^{-10}$ & $3.2 \times 10^{-12}$ & - \\
\hline
\end{tabular}

FONTE: AUTOR

Conforme mostrado nos experimentos sobre detecção, o valor residual obtido relativo a alguma amostra, pode indicar que a resposta tem um nível de incerteza crescente, à medida que o valor se aproxima da região da fronteira de decisão (entre normal e falha), visto que nessa região existe uma concentração alta de falsos positivos e negativos. Sobre os resultados obtidos, é avaliado como os modelos de interpretabilidade se comportam sobre amostras de diferentes regiões de residuais sobre as 774 amostras de verdadeiros positivos (ou seja, situações que o detector tenha identificado corretamente a falha) e 177 amostras de falsos negativos (situações que o detector falhou em identificar uma falha existe), assumindo que o nível de complexidade pode ser diferente, dado o nível de distorção entre os grupos. 
A figura 39 apresenta o histograma de residuais obtidos pelo autoencoder sobre os falsos negativos e verdadeiros positivos, onde se pode verificar que a distribuição é desbalanceada em ambos, havendo uma grande concentração de amostras próximas à região da fronteira de decisão (aproximadamente 0,002 ). As regiões de análise sobre os verdadeiro positivos foram divididas da seguinte forma : (i.) Região 1 (distante da fronteira de decisão) que abrange o fim da calda longa do histograma, englobando as 100 amostras com níveis mais elevados de residuais, onde entendese que os desvios sejam mais evidentes de serem interpretados (entre a faixa residual de 0,06 e 0,14); (ii.) Região 2 abrangendo as 100 amostras mais próximas da fronteira de decisão, apresentando níveis de desvios mais sutis (e supostamente mais difíceis de serem capturados adequadamente) ou com a grande maioria dos parâmetros se comportando de modo normal (e com apenas 1 ou poucos parâmetros desviados), apresentando faixas de residual de 0,000250 e 0,00175. No caso dos falsos negativos, todas as amostras são avaliadas, visto que trata de uma situação peculiar interessante, no qual é avalia-se o desempenho de interpretabilidade quando o detector não identificou a falha existente.

FIGURA 39 - REGIÕES DE ANÁLISE SOBRE FALSOS NEGATIVOS E VERDADEIROS POSITIVOS

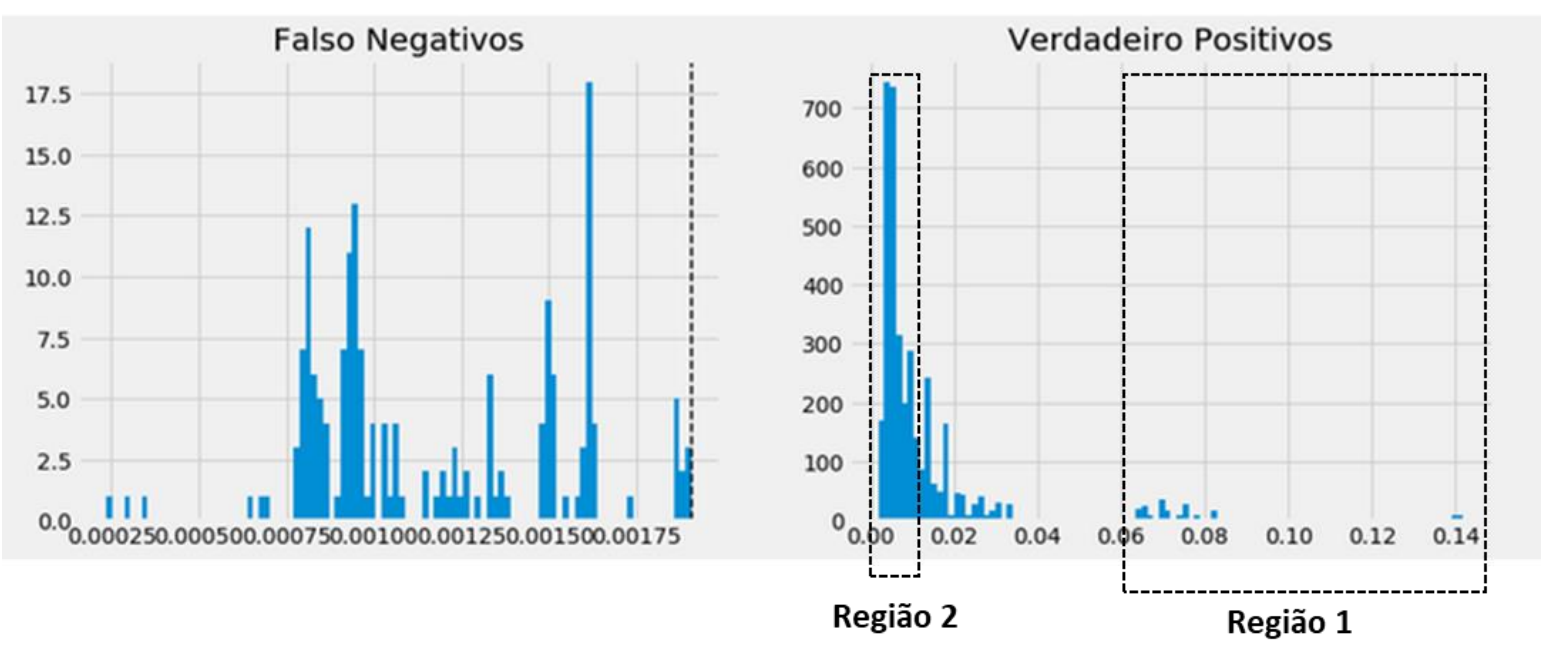

FONTE: AUTOR

A tabela 6 apresenta os resultados parciais sobre os grupos das amostras, onde se pode verificar que o RXP mantém a superioridade, alcançando o MAP de 100\% em todos os resultados. Enquanto que na região 1 engloba amostras com níveis elevados de residuais causados por desvios grosseiros sobre 1 ou vários parâmetros, na região 2 as possíveis falhas se manifestam de forma não aparente, no qual o residual obtido 
poderia ser facilmente confundido com amostras que ainda operam em situação normal, porem de forma desviada (gerando nesse caso os falsos positivos). Como pode ser constatado pela diferença de resultados entre a tabela 5 e 6 , ao retirar os falsos positivos, o resultado de todas as configurações de modelos treinadas alcançaram resultados muito elevados sobre o conjunto de dados avaliado.

Para fins práticos, o SHAP apresenta desempenho satisfatório em relação à métrica MAP, mas pode ser afetado pelo balanço entre entregar resultados consistentes (respostas corretas e mitigar o comportamento aleatório), ao custo de sofrer com explosões combinatórios em avaliações conjuntos de dados com número elevado de parâmetros.

TABELA 6 - DESEMPENHO SOBRE REGIÕES RESIDUAIS DIFERENTES EM EVENTOS DE FALHA

\begin{tabular}{|l|c|c|c|c|}
\hline \multicolumn{1}{|c|}{ Resultados (MAP) } & SHAP1 & SHAP2 & SHAP3 & RXP \\
\hline Verdadeiros Positivos (Região 2) & $100 \%$ & $100 \%$ & $100 \%$ & $100 \%$ \\
\hline Verdadeiros Positivos (Região 1) & $98.69 \%$ & $98.08 \%$ & $96.24 \%$ & $100 \%$ \\
\hline Falsos Negativos & $100 \%$ & $100 \%$ & $91.27 \%$ & $100 \%$ \\
\hline
\end{tabular}

FONTE: AUTOR

Como mostrado na tabela 6 , o RXP apresenta resultados superiores, associado à capacidade de oferecer respostas quase em tempo real. Embora a intuição sugerida indicar que a região 2 dos verdadeiros positivos é supostamente mais subjetiva de analisar (visto que os desvios são mais sutis), os resultados mostram que todas as configurações alcançaram $100 \%$ de desempenho, enquanto que na região 1 dos verdadeiros positivos alcançaram entre $96 \%$ e $99 \%$ pelas configurações do SHAP.

Apesar de não ser notada uma diferença significativa de desempenho entre o SHAP1 e SHAP2, parametrizações que favoreçam maiores velocidades nas respostas (como o SHAP3), correm riscos de instabilidade ao prover interpretações, e consequentemente ter o seu desempenho prejudicado, como fica evidente sobre as amostras dos falsos negativos e verdadeiros positivos na região 1. Outros cenários de testes devem ser executados com diferentes métodos de detecção (com desempenhos diferentes) de modo a confirmar a existência de padrões de como esses métodos de interpretabilidade se comportariam em outras situações.

Por meio do cálculo da medida $Z$ (equação 1), o RXP também se torna sensível a desvios, mesmo em instâncias sem desvio bruto em relação a nenhum parâmetro 
específico (mas ligeiramente perturbado em um conjunto deles). Neste trabalho, consideramos o cálculo residual global (dimensões gerais do erro ao quadrado) e o respectivo peso de cada parâmetro no valor. Portanto, outras experiências devem ser desenvolvidas para verificar o uso apropriado para cálculos de resíduos globais ou em relação ao parâmetro em outros cenários.

Além dos resultados quantitativos destacados como MAP e tempo de resposta, vale destacar que RXP apresenta a vantagem de ter um comportamento determinístico, ou seja, dada uma mesma entrada de dados sobre um mesmo modelo preditivo (assumindo que resultará em uma mesma reconstrução), a mesma interpretação será retornada. Essa característica é fundamental em aplicações sobre sistemas críticos, visto que uma resposta gerada com desvios aleatórios pode levar a tomadas de decisões equivocadas.

A figura 40 mostra como os métodos se comportam ao interpretar repetidas vezes cada registro da região 1 de verdadeiros positivos (150 amostras), no qual calcula-se a variância obtida em cada parâmetro sobre 30 testes, e somados a nível do registro. Os valores do SHAP3 foram normalizados para equalizar a escalar com RXP. Como esperado, devido a sua natureza determinística, RXP não sofreu perturbações sobre todos os testes, enquanto o SHAP3 demonstrou comportamentos aleatórios em determinadas amostras.

\section{FIGURA 40 - VARIÂNCIA DAS INTERPRETAÇÕES SOBRE TESTES REPETIDOS SOBRE A REGIÃO 1 DOS VERDADEIROS POSITIVOS}

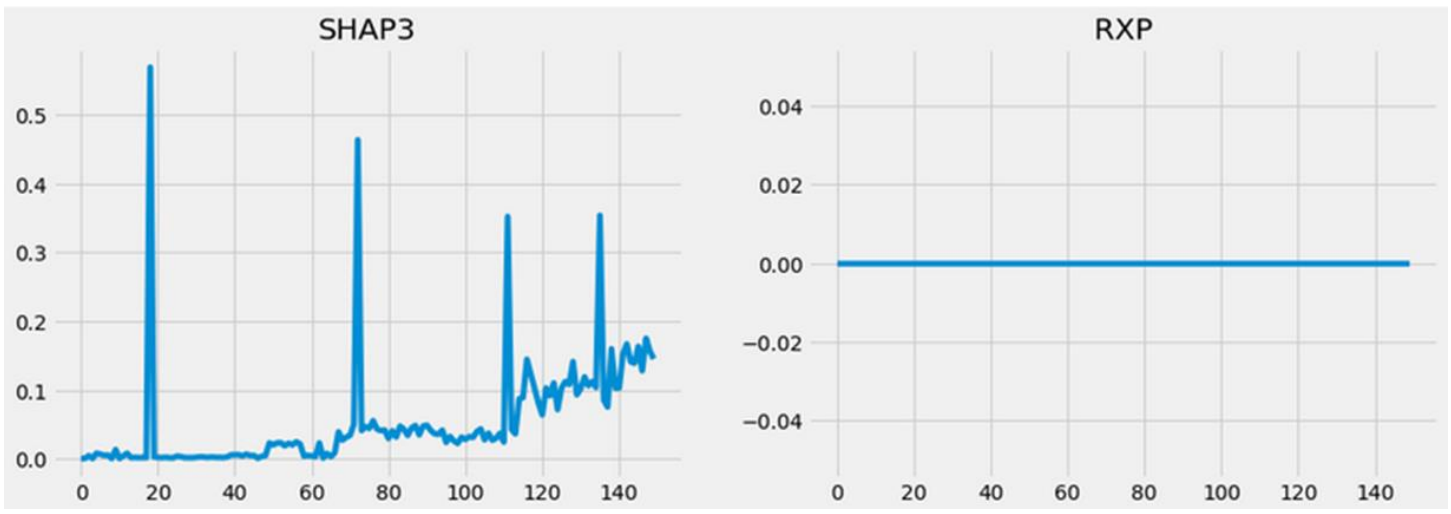

FONTE: AUTOR 
Análise das Interpretações

Como já mostrado no experimento anterior sobre desempenho, todos as configurações de métodos de interpretabilidade avaliadas alcançaram desempenhos muito satisfatórios sobre o conjunto de dados testados, mesmo sobre amostras que apresentam desvios próximos da fronteira de decisão entre normal e falha. Nesta seção, os métodos de interpretabilidade são analisados por uma outra perspectiva, considerando que em determinadas situações a tarefa de diagnóstico pode levar a avaliações mais subjetivas para constatação de estados incipientes de falhas.

Similar a divisão de amostras feitas sobre os verdadeiros positivos, a figura 41 apresenta uma extração de amostras sobre a região dos verdadeiros negativos, onde a região 1 englobam amostras distantes da fronteira de decisão (com níveis extremamente baixo de residuais da reconstrução), e a região 2 englobando amostras próxima à região da fronteira de decisão.

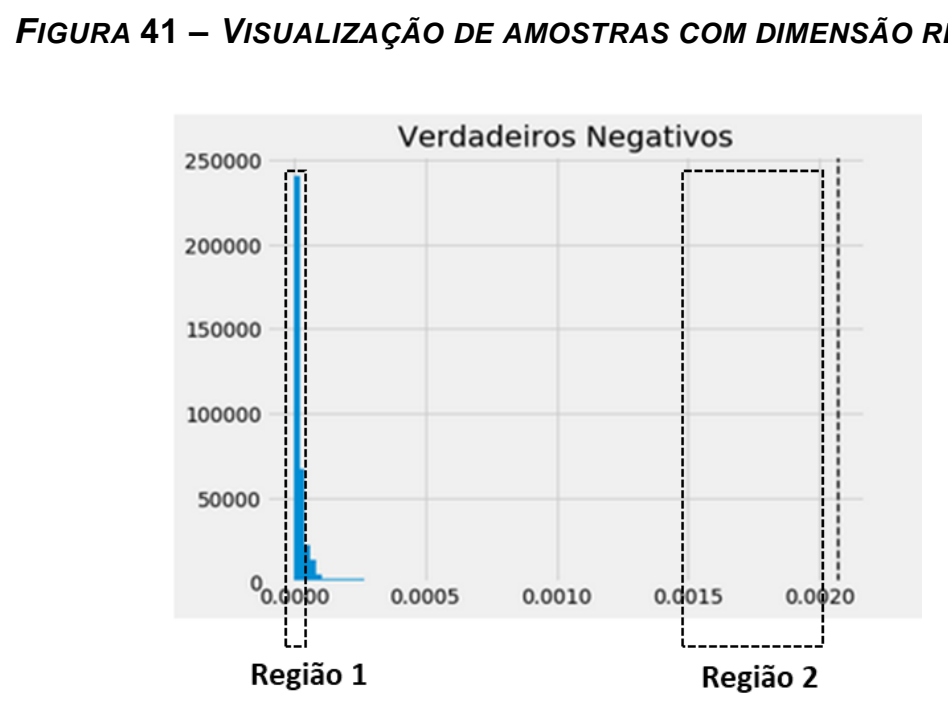

FONTE: AUTOR

A figura 42 apresenta um gráfico de dispersão sobre as relevâncias calculadas, e reduzidos em 3 dimensões utilizando PCA. As amostram englobam os falsos positivos, falsos negativos, verdadeiro positivos (região 1 e 2 , conforme a figura 39) e verdadeiro negativos (região 1 e 2, conforme a figura 41), sendo que devido ao grande volume de verdadeiros negativos, foi limitada 1000 amostras para cada região para evitar efeito de sobreposições na visualização. 
Observe que há uma formação de 2 clusters maiores, sendo que o da esquerda concentra os verdadeiros negativos mais "puros" (região 1), uma parcela da região 2 dos verdadeiros negativos e uma pequena fração sobre os outros grupos. Apesar do cluster da direita concentrar as amostras em situação duvidosa (e possivelmente que pode indicar uma falha), note que a grande maioria dos verdadeiros negativos está omitida (menos de $1 \%$ visível). Isso significa que há uma grande sobreposição entre vários grupos, e a separação entre amostras normais e falhas não é clara, o que limita a intuição de forma mais direta além desse ponto.

\section{FIGURA 42 - VISUALIZAÇÃO DE AMOSTRAS COM DIMENSÃO REDUZIDA}

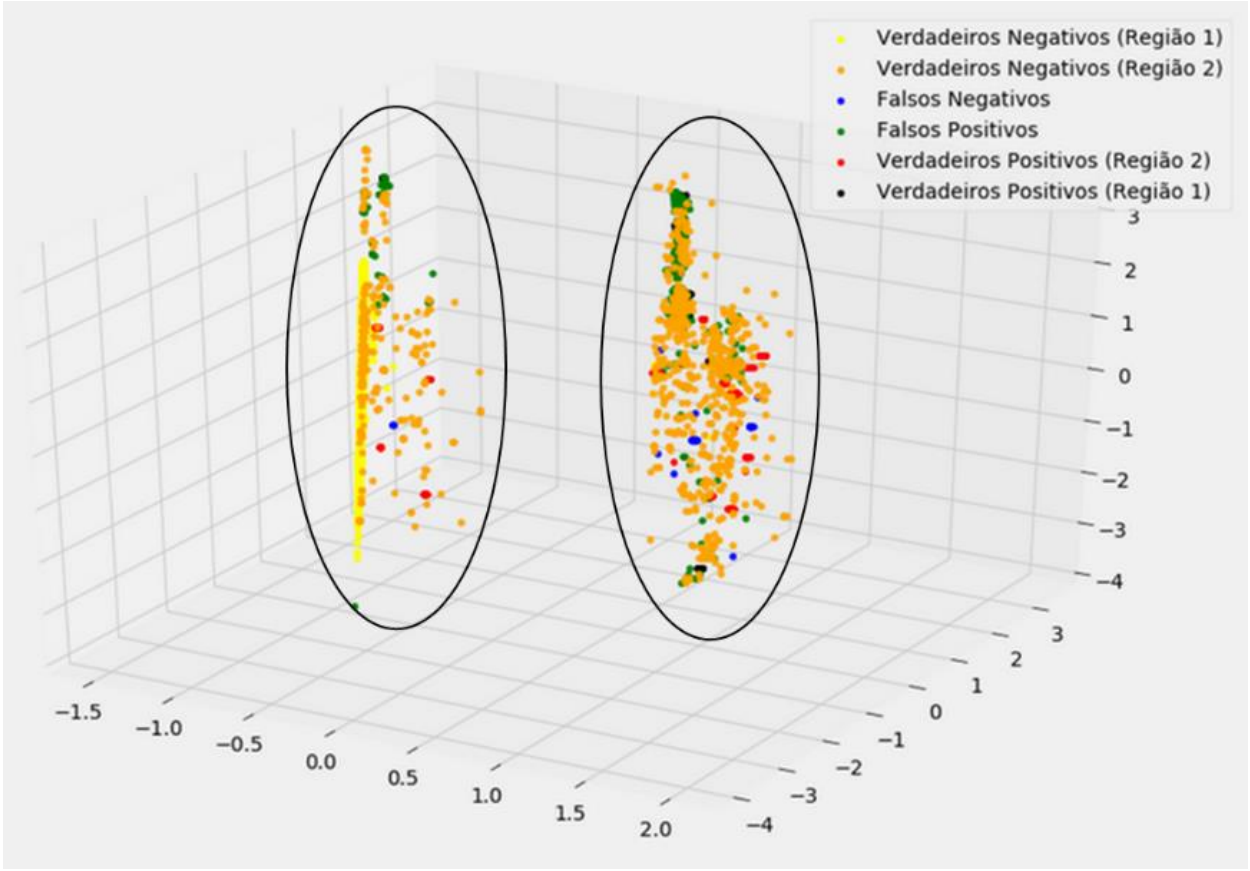

FONTE: AUTOR

Um outro meio para avaliar os resultados e compreender melhor padrões sobre as interpretações é pela distorção das relevâncias entre os parâmetros. A figura 43 apresenta gráficos de caixa (boxplots) sobre a variância obtida sobre a relevância dos parâmetros por amostra por grupos de dados (falsos positivos, falsos negativos, verdadeiros positivos sobre a região 1 e 2 ).

Visto que amostras normais tendem a possuir menos distorções sobre seus valores, os seus parâmetros tendem a receber um peso de relevância menos discrepantes em relação aos outros, ou seja, as relevâncias tendem a estar 
distribuídas de forma mais uniforme sobre o total de parâmetros (como no caso dos verdadeiros negativos e falsos positivos mostrado nos blocos abaixo).

Por outro lado, as amostras em falha (falsos negativos e verdadeiros positivos) tendem a apresentar relevâncias concentradas sobre os parâmetros que indicam a causa da detecção, o que eleva a variância sobre a calculada. Desse modo, nota-se que a região 1 dos verdadeiros positivos apresenta valores superiores de dispersão sobre as configurações de interpretabilidade testadas, visto que esse grupo de dados indica possivelmente estágios avançados de falha, identificado por distorções mais grosseiras.

\section{FIGURA 43 - VARIÂNCIA DAS INTERPRETAÇÕES SOBRE TESTES REPETIDOS EM DIFERENTES FAIXAS DE RESIDUAIS}
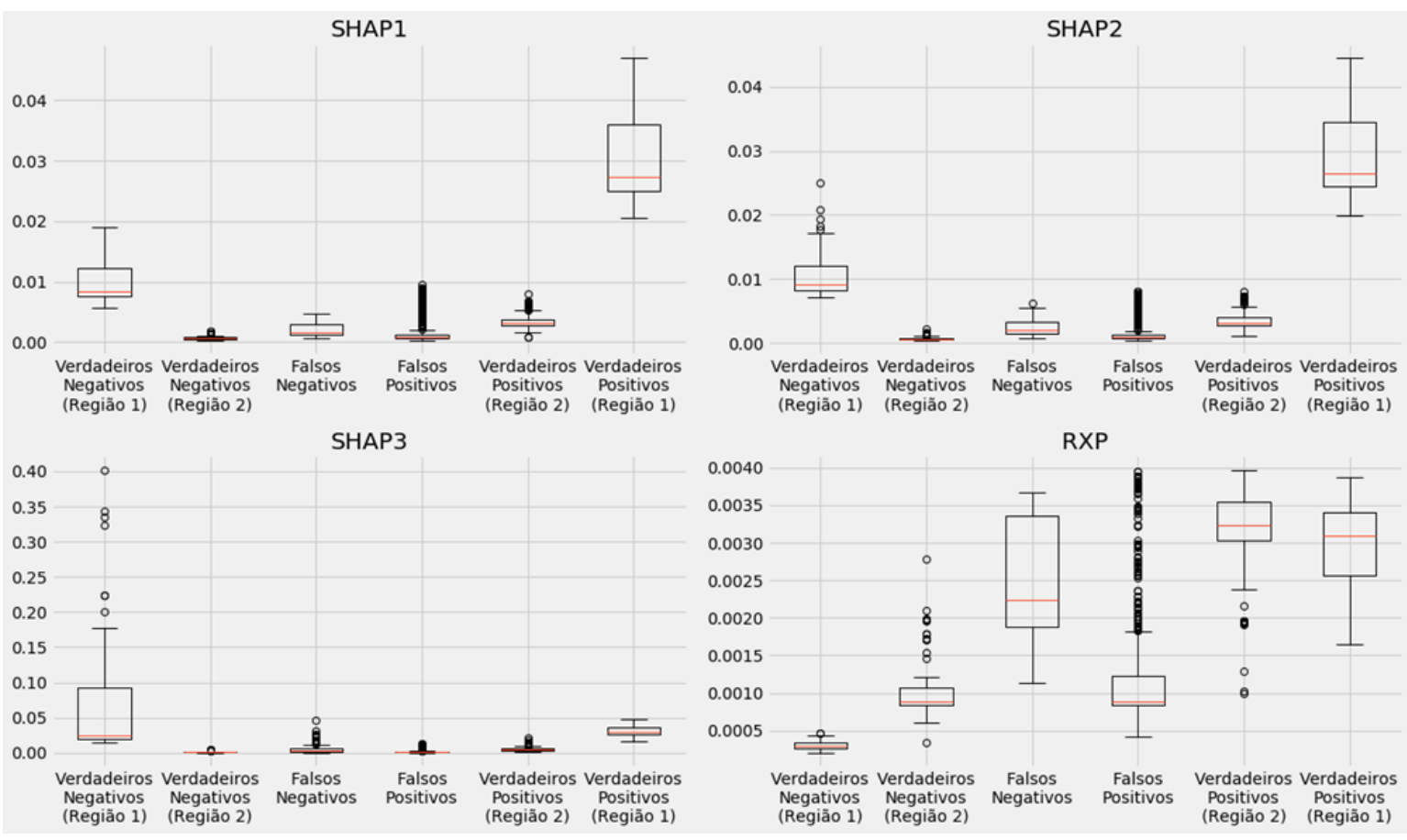

\section{FONTE: AUTOR}

Diferentemente das configurações do SHAP, observe que o RXP foi capaz reproduzir níveis mais elevados de variação das respostas sobre os falsos negativos e verdadeiro positivos da região 1 e 2 , separando todas as amostras das amostras normais ao manter os níveis mais reduzidos sobre os falsos positivos e verdadeiros negativos, ou seja, conseguindo obter um novo meio de distinguir as amostras como normais ou em falha, independente do detector ter falhado ou não em situações particulares. 
Esse fato é interessante, pois permitiria que a interpretabilidade fosse usada como apoio não somente para diagnosticar eventos que certamente são falhas, mas também como um indicador para reduzir a incerteza quanto a resposta obtida, e consequentemente melhorar o desempenho do sistema de detecção.

Embora os resultados do RXP sejam geralmente superiores no que diz respeito à separação sobre o estado real do equipamento sobre as amostras avaliadas, percebese que a distribuição das dispersão sobre as amostras na região da fronteira apresenta uma calda longa de valores discrepantes que podem induzir a erros de compreensão, como no caso dos verdadeiros negativos (da região 2 ) e falsos positivos com níveis altos de dispersão, ou falsos negativos e verdadeiros positivos (região 1) com níveis menores de dispersão. Essas situações são subjetivas, visto que os valores de residuais podem ser parecidos, embora os estados reais do equipamento sejam diferentes.

Desse modo, mesmo com o detector falhando sobre falsos positivos, o RXP seria capaz de indicar que uma amostra foi indevidamente classificada como falha pela verificação que há uma baixa variância sobre os pesos de relevância dos parâmetros, ou pela atribuição de relevância elevada sobre parâmetros auxiliares (como por exemplo velocidade ou peso do vagão). A figura 44 exemplifica essa situação por meio da interpretação de 4 amostras realizadas pelo RXP, onde as amostras 377 e 820 indicam alta relevância sobre parâmetros auxiliares relacionados a velocidade (train_speed_out e train_speed_in), sendo que na amostra 820 ainda mostra uma distribuição de relevâncias relativamente mais equilibradas (os parâmetros mais relevantes tem pesos inferiores a $30 \%$ ).

As amostras 1091 e 1150 são contraexemplos, onde a interpretação indicaria a necessidade de análise visual e mais detalhada do equipamento feita por especialistas, onde poderia ser avaliado possíveis estados incipientes de falhas se os desvios se tornarem recorrentes. No exemplo 1091 indica uma relevância de distorção sobre os rolamentos do lado esquerdo do vagão, sobre os eixos 4 respectivamente, onde o parâmetro mais importante alcança sozinho $80 \%$ da relevância (Shrk(RS)_L_AXLE4). No exemplo 1150, indica que a fonte do desvio de forma mais distribuída entre os 3 primeiros parâmetros mais relevantes indicando falhas em 
rolamentos nos eixos 3 (Shrk(RS)_L_AXLE3 e Shrk(RS)_R_AXLE3) e 4 ((Shrk(RS)_R_AXLE4) do vagão, com uma relevância de aproximadamente $85 \%$.

\section{FIGURA 44 - ANÁLISE DE RELEVÂNCIA DE PARÂMETROS SOBRE FALSOS POSITIVOS}

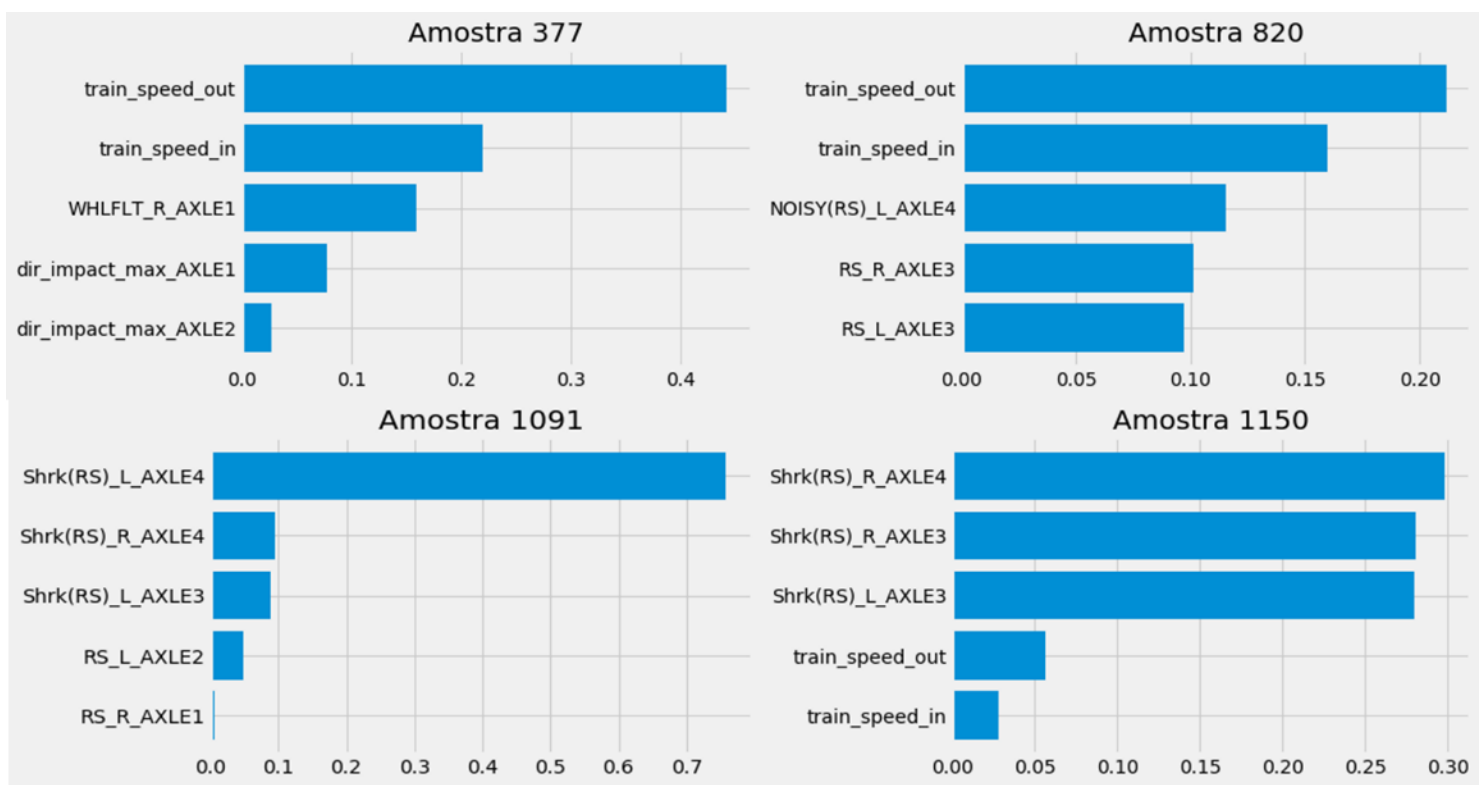

FONTE: AUTOR

Assumindo que exista conhecimento a respeito dos parâmetros do modelo (como no estudo de caso em questão), os resultados de detecção associados ao RXP possibilitariam a redução de falsos positivos (ou seja, aumento da precisão), ao prover intuição que o detector em algumas situações particulares classifica equivocadamente como falha com base em parâmetros que não são cabíveis de serem atribuídos como fonte de falhas.

A figura 45 mostra o percentual de amostras interpretadas que atribuíram a maior relevância a um parâmetro cabível dentro do conhecimento especialista sobre ser uma possível fonte de falha (como por exemplo medições de sobreaquecimento, vibração ou ruído). Portanto, parâmetros como velocidade, peso do vagão, grau de declive/aclive da via não seriam razões suficientes que para atribuir uma amostra como falha. Visto que que esse problema traria alta penalização em relação ao MAP, as amostras de verdadeiros positivos alcançaram $100 \%$ de abrangência das amostras contendo parâmetro mais relevante não sendo auxiliar, e consequentemente foram omitidas do gráfico abaixo. 
Figura 45 - PERCENTUAL de AMOStRAS COM PARÂMETRO MAIS RELEVANTE NÃO AUXILIAR

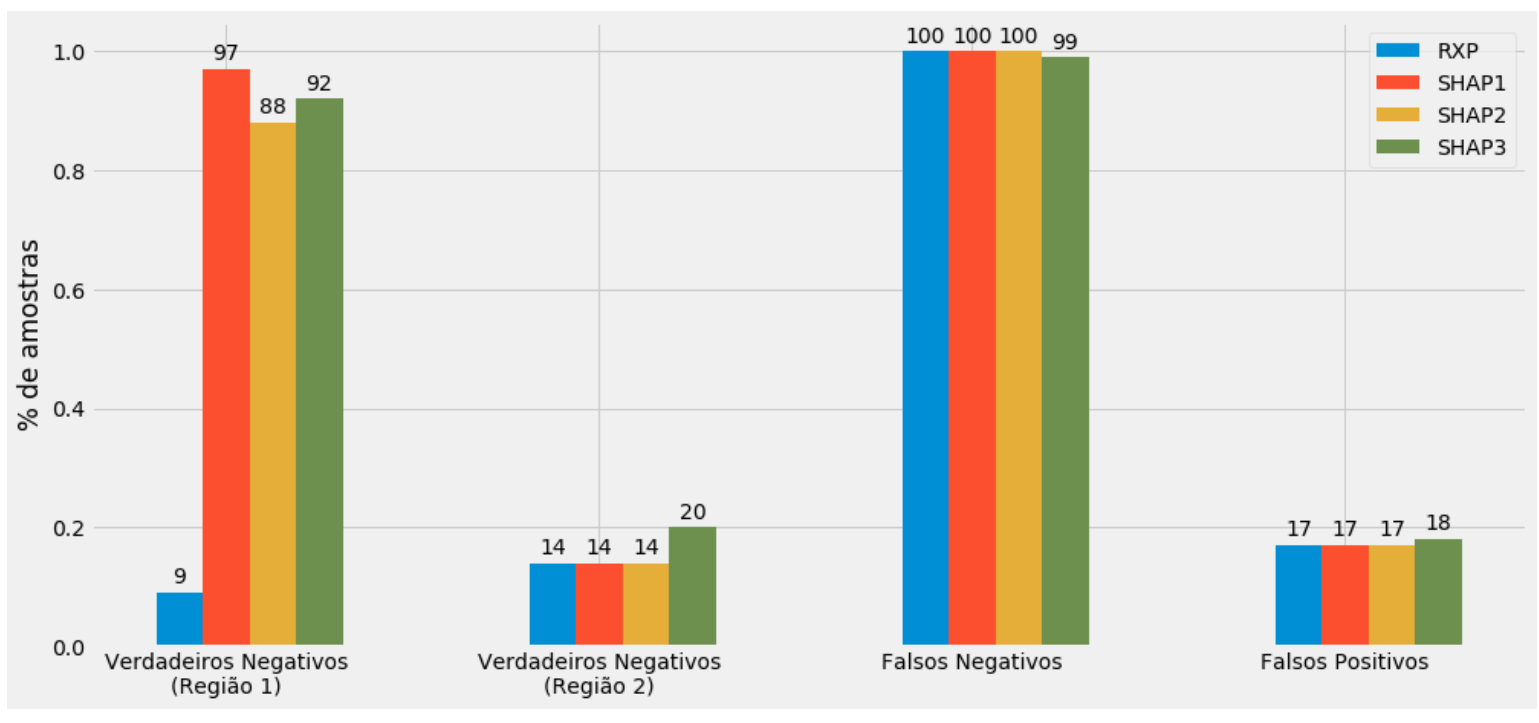

FONTE: AUTOR

Observe que por essa visão, o RXP também fornece uma visão que separa as amostras realmente normais e falhas, pela baixa ocorrência de amostras com parâmetros não auxiliares sobre (verdadeiros negativos e falsos positivos), e alta ocorrência sobre verdadeiros positivos e falsos negativos. O SHAP alcança resultados similares, com a diferença estando sobre os verdadeiros negativos da região 1, onde apenas RXP alcança um percentual de amostras de $9 \%$, e os cenários do SHAP acima de $92 \%$. Sobre parte das amostras normais na região da fronteira (verdadeiros positivos da região 2 e falsos positivos), entre 14\% e $20 \%$ das amostras, a interpretabilidade revelaria que o detector está atribuindo inadequado a maior relevância a um parâmetro não auxiliar.

A respeito dos falsos negativos, a figura 46 apresenta resultados de interpretações pelo RXP sobre 4 exemplos, onde as amostras 370 e 376 são diagnosticadas com problema de excesso de vibração (dir_impact_max_AXLE2) e (dir_impact_max_AXLE3) respectivamente, alcançando relevâncias acima $90 \%$ de relevância, sobre apenas o primeiro parâmetro em cada caso. 
Figura 46 - ANÁlise de RELEVÂNCIA de PARÂMETROS SOBRE falsos NEGATIVOS

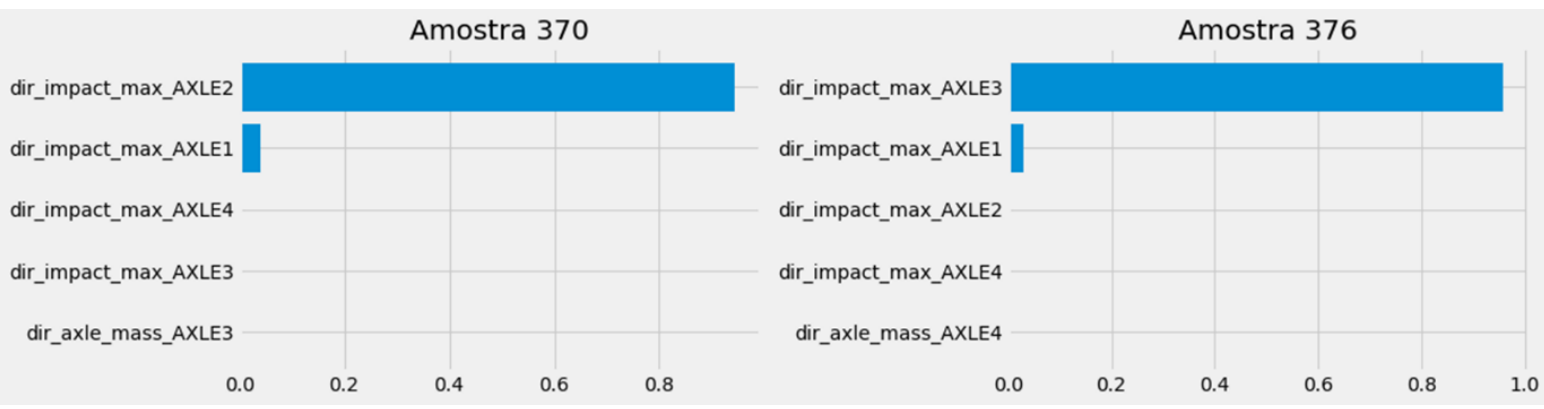

FONTE: AUTOR

Considerando os resultados obtidos sobre falsos negativos pela figura 45 e a distribuição de relevâncias mostradas na figura 46, as situações onde há uma grande concentração de relevância sobre um único parâmetro podem indicar situações de falhas mesmo quando o detector falhou. As amostras de falsos negativos mostrados são exemplos claros de medições que seguem um padrão normal na maioria quase absoluta dos parâmetros, ocorrendo desvio (que pode ser severo) em apenas um deles (como no caso das amostras 370 e 376 ).

Como o detector usa o erro quadrático médio para calcular o grau de distorção sobre a reconstrução, o desvio desse parâmetro indicador da falha é diluído na média global dos parâmetros, que é relativamente baixo. Como o RXP calcula medida Z por cada parâmetro (que em linhas gerais mede o grau de desvio em relação ao seu comportamento normal), ele é capaz de destacar o seu grau de desvio em relação a todos os outros.

A figura 47 mostra por uma outra visão a capacidade do RXP em capturar as discrepâncias singulares dos parâmetros desviados, onde o peso médio de relevância atribuído pelo RXP sobre o principal parâmetro para cada um dos grupos de controle, no qual fica evidente os eventos de falhas $(76 \%$ sobre falsos negativos $e$ aproximadamente $83 \%$ sobre verdadeiros positivos). Por outro lado, nota-se uma atribuição mais baixa sobre falsos positivos (39\%) e verdadeiros negativos (aproximadamente $16 \%$ sobre a região 1 e $34 \%$ sobre a região 2 ). 

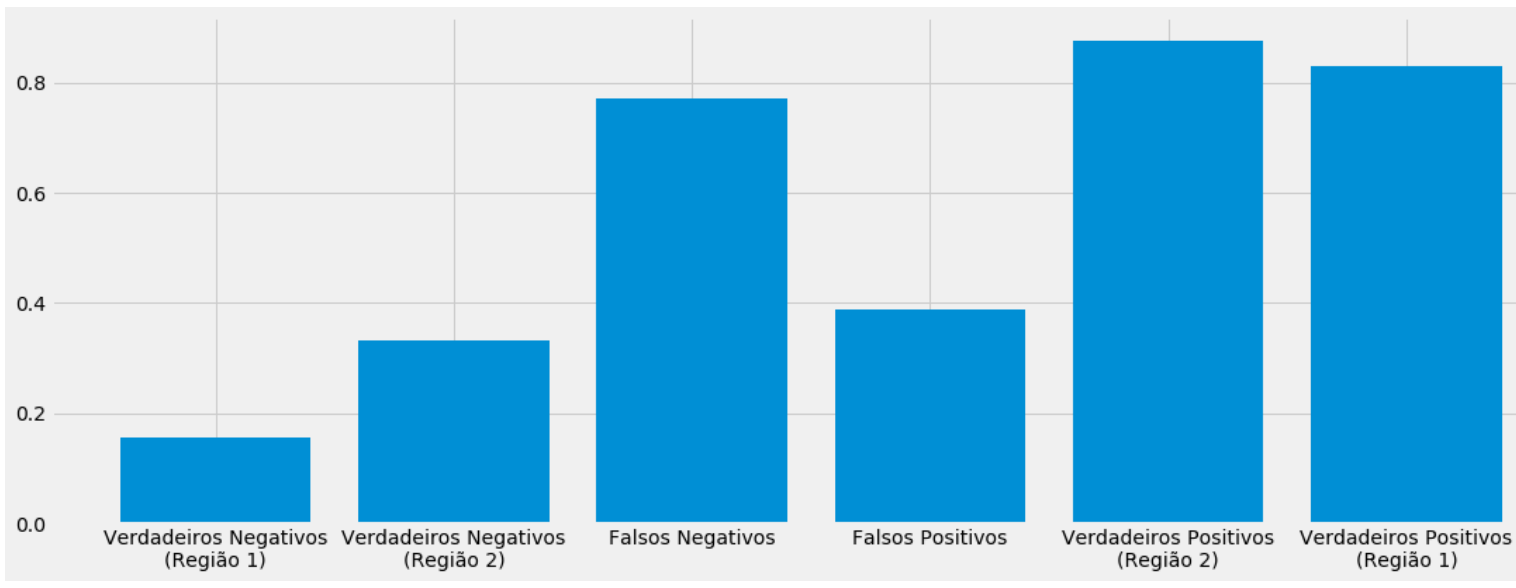

FONTE: AUTOR

A associação do RXP o detector na tomada de decisão possibilita a redução de falsos negativos (ou seja, aumento da sensibilidade), evitando que falhas existentes passem despercebidas. As intuições capturadas nesta seção são aplicadas de forma conservadora no experimento de seguinte, de modo a mensurar o ganho obtido ao associar o RXP com o detector.

\subsubsection{Avaliação de Ganho de Desempenho sobre Detecção usando Interpretabilidade}

Com base nas intuições levantadas no experimento anterior, 2 configurações de detector foram associadas ao RXP com o objetivo de avaliar o ganho de desempenho obtido. A tabela 7 sumariza as configurações gerais de cada um dos modelos avaliados nesse experimento, onde a configuração $A E 3$ reflete a mesma configuração realizada sobre os experimentos de detecção (seção 6.3.1). A configuração AE12 é a mesma utilizada nos experimentos e análise de diagnóstico (seções 6.3.2.1 e 6.3.2.2) mesclada com adaptações das configurações $A E 1$ (maior taxa de compressão) e AE2 (maior número de camadas). Cada modelo apresenta níveis diferentes de desempenho, onde o objetivo é avaliar o ganho alcançado pelo detector atuando com e sem o RXP. Todos os modelos foram treinados e testados sobre os mesmos conjuntos de dados dos experimentos referenciados na seção 6.3.2.1, onde a escolha da fronteira de decisão foi aproximada por meio do cálculo da curva de 
Precisão/Sensibilidade, pela escolha do melhor resultado sobre a medida $\mathrm{F}$ ( $\operatorname{com} \beta=$ 1 , indicando balanço entre precisão e sensibilidade) com a base de dados de treinamento.

TABELA 7- MODELOS DE DETECÇÃO USADOS PARA AVALIAR GANHO DE DESEMPENHO COM RXP

\begin{tabular}{|l|c|c|c|c|c|c|}
\hline Configuração & Tipo & $\begin{array}{c}\text { Número de } \\
\text { Camadas }\end{array}$ & Taxa de Compressão & Precisão & Sensibilidade & F-1 \\
\hline AE12 & Autoencoder & 14 & $97,99 \%$ (5 parâmetros) & $82.5 \%$ & $95.37 \%$ & $88.87 \%$ \\
\hline AE3 & Autoencoder & 4 & $74,69 \%$ (63 parâmetros) & $17.16 \%$ & $96.78 \%$ & $29.16 \%$ \\
\hline
\end{tabular}

Conforme já introduzido na metodologia, a automatização da reclassificação das amostras é feita de modo não supervisionado, levando em conta o grau desbalanceamento obtido com os resultados do RXP. Para esse experimento são definidos valores claros de limites para reclassificação:

- Definição de falsos positivos (FP1): Amostras classificadas como falhas e que o resultado de interpretação atribua a maior relevância para parâmetros auxiliares serão reclassificados como normal.

- Definição de falsos negativos (FN1, FN2 e FN3): Amostras classificadas como normais e que o resultado de interpretação atribua um peso de relevância igual ou acima das de 90\% (FN1), 95\% (FN2) e 100\% (FN3) sobre o primeiro parâmetro (que não seja auxiliar) serão reclassificados com falha.

A tabela 8 apresenta os resultados obtidos sobre cada um dos modelos avaliados com as combinações de ajustes de reclassificação, conforme as legendas indicadas. A combinação de configurações testadas promoveu ganhos expressivos de desempenho em ambos os modelos, sendo aproximadamente $6 \%$ de $\mathrm{F}-1$ (14\% de ganho de precisão e queda de $2 \%$ de sensibilidade) sobre AE12, e aproximadamente de $57 \%$ de $\mathrm{F}-1$ ( $59 \%$ de ganho de precisão e $1 \%$ sobre sensibilidade) sobre AE3. Embora o melhor resultado obtido no AE3 seja da combinação FP1 + FN1, pelas as combinações testadas, percebe-se que o ajuste para redução de falsos positivos (FP1) foi responsável pelo salto no desempenho global dos resultados. 
TABELA 8-GANHO DE DESEMPENHO EM DETECÇÃO USANDO RXP

\begin{tabular}{|l|c|c|c|c|c|c|}
\hline & \multicolumn{3}{|c|}{ AE12 } & \multicolumn{3}{c|}{ AE3 } \\
\hline Configuração & Precisão & Sensibilidade & F-1 & Precisão & Sensibilidade & F-1 \\
\hline Base & $82.50 \%$ & $95.37 \%$ & $88.87 \%$ & $17.16 \%$ & $96.78 \%$ & $29.16 \%$ \\
\hline FP1 & $\mathbf{9 6 . 3 7 \%}$ & $93.20 \%$ & $\mathbf{9 4 . 7 6 \%}$ & $76.69 \%$ & $95.81 \%$ & $85.19 \%$ \\
\hline FN1 & $44.91 \%$ & $\mathbf{9 6 . 9 1 \%}$ & $61.38 \%$ & $17.47 \%$ & $98.95 \%$ & $29.71 \%$ \\
\hline FN2 & $80.72 \%$ & $95.42 \%$ & $87.46 \%$ & $17.22 \%$ & $97.20 \%$ & $29.26 \%$ \\
\hline FN3 & $82.50 \%$ & $95.37 \%$ & $88.87 \%$ & $17.16 \%$ & $96.78 \%$ & $29.16 \%$ \\
\hline FP1 + FN1 & $48.13 \%$ & $94.74 \%$ & $63.83 \%$ & $\mathbf{7 7 . 0 1 \%}$ & $\mathbf{9 7 . 9 8 \%}$ & $\mathbf{8 6 . 2 4 \%}$ \\
\hline FP1 + FN2 & $93.89 \%$ & $93.25 \%$ & $93.57 \%$ & $76.76 \%$ & $96.23 \%$ & $85.40 \%$ \\
\hline FP1 + FN3 & $\mathbf{9 6 . 3 7 \%}$ & $93.20 \%$ & $\mathbf{9 4 . 7 6 \%}$ & $75.69 \%$ & $95.81 \%$ & $85.19 \%$ \\
\hline
\end{tabular}

FONTE: AUTOR

O uso do resultado da classificação e níveis de residuais obtidos pelo detector, associado à interpretação feita pelo RXP, promove meios para uma tomada de decisão mais assertiva. Ao prover o recurso de interpretabilidade, consequentemente possibilita obter ganho de confiança e ganho de conhecimento. O ganho de confiança refere-se ao uso sobre um meio para avaliar métodos de detecção baseados em modelos "caixa-preta", considerando se os resultados obtidos estão fundamentados em um conjunto de parâmetros que seja coerente. Essa validação promove o ganho de confiança por avaliar a regularidade das fundamentações dos resultados em observações com problemas gradualmente mais subjetivos (múltiplas fontes de falhas ou maior incerteza se o estado de falha), principalmente quando o resultado correto é supostamente sabido. Em casos mais subjetivos, a verificação por especialistas é fundamental para validar o desempenho da interpretações.

\subsubsection{Prognóstico: Avaliação de Capacidade sobre Falhas Futuras}

Como já discutido na seção 4.2.2, a tarefa de prognóstico envolve situações adicionais em comparação com a tarefa de detecção de falhas já existentes, visto que aqui a detecção e identificação das fontes das falhas acontecem sobre estimativas de comportamentos futuros, que podem se manifestar de modos até então desconhecidos. Dado que a frequência de ocorrência de falha é extremamente baixa $(0,8 \%)$, e que os modelos preditivos tendem a aproximar o padrão do dado que foi usado em treinamento, o aprendizado do modelo pode ser comprometido ao tentar aprender sobre esse tipo de situação. Para endereçar o aprendizado de eventos raros, técnicas de reamostragem (oversampling) devem ser aplicadas sobre o conjunto de treinamento para balanceamento entre as classes de amostras (normal ou falha), de 
modo o preditor sofra menos com problemas de enviesamento sobre os dados normais. Neste experimento, é adotado um método mais simples de oversampling, apenas pela replicação de amostras em falha já existentes.

Considerando que a vida útil das peças de um vagão está na faixa de anos (até 15 anos no caso dos rolamentos e 12 anos sobre as rodas), o período amostral disponível corresponde a uma fração muito pequena do seu histórico operacional. Ao mesmo tempo, existem milhares de vagões contendo peças em estágios diferentes de degradação, no qual não se tem qualquer informação disponível que indique o tempo operacional decorrido. Isso significa que uma falha pode evoluir de modo muito sutil durante um período muito de operação até que se manifeste de modo mais nocivo. Desse modo, mesmo que fosse usado o período integral das medições disponíveis (12 meses) para treinamento do modelo, corresponderia a uma pequena parte da vida útil das peças.

Nesses experimentos os dados são transformados para séries temporais sobre um conjunto total de 3,500 vagões, onde uma amostra representa um histórico de 25 lapsos de medições de um mesmo equipamento. Cada lapso temporal representa a agregação de todas as medições sobre uma mesma viagem, ou seja, o vagão partindo do porto em direção à mina ou da mina em direção ao porto. O número de vagões $\mathrm{e}$ tamanho da série foi determinado a partir das limitações computacionais (e consequentemente tempo de processamento) vista durante os experimentos preliminares, dado que o aumento da sequência determina uma carga maior sobre a memória durante os treinamentos dos modelos.

A partir da predição do comportamento do equipamento, é avaliada a capacidade de previsão de falhas futuras, bem como a capacidade de interpretação da fonte das falhas estimadas.

\subsubsection{Avaliação de Capacidade de Detecção}

Conforme mostrado na tabela 9, os experimentos de predição de falhas definem 4 cenários de testes com conjuntos de dados gerados e selecionados de formas distintas sobre históricos de 3,500 vagões. Assumindo que a seleção das amostras é feita randomicamente, o objetivo dos cenários é avaliar como os modelos se 
comportam sobre contextos diversos, onde impõem diferentes níveis de dificuldade preditiva, e consequentemente permitem análises sobre outras perspectivas.

TABELA 9-CONJUNTOS DE DADOS DE TREINAMENTOS PARA PREDIÇÃo DE FALHAS

\begin{tabular}{|c|c|c|}
\hline Cenário & Amostras de vagões específicas entre treino e teste & Corte Temporal (em 01/01/2018) \\
\hline T1 & Não & Não \\
\hline T2 & Sim & Não \\
\hline T3 & Não & Sim \\
\hline T4 & Sim & Sim \\
\hline
\end{tabular}

FONTE: AUTOR

No cenário $T 1$, as amostras são separadas aleatoriamente, onde dados de um mesmo vagão podem estar tanto em treino quanto em teste, sem qualquer controle sobre a região temporal cada amostra se encontra, ou seja, podem existem amostras de janeiro até dezembro em treinamento ou em teste. A ideia desse cenário é verificar se a modelo é capaz de capturar padrões de falhas independente do tempo de vida operacional decorrido ou restante, já que o equipamento monitorado possui uma vida útil muito longa, e o conjunto de dados contém peças com tempos diferentes de operação.

O cenário T2 é similar ao cenário $T 1$, porém havendo uma separação de amostras de equipamentos específicos para treinamento e para teste, onde o objetivo é avaliar a capacidade de generalização do modelo em capturar falhas em novos equipamentos, até então não vistos em treinamento. Esse cenário soma um nível de dificuldade maior, já que os modos de falhas (ou perturbações em estágios incipientes) podem se manifestar de modos diferentes, o que poderia necessitar uma capacidade de extrapolação do aprendizado além do que os dados de treinamento fornecem, nessas situações.

O cenário T3 é similar ao T1, com a diferença que os dados separados entre treinamento e teste consideram um corte temporal (também conhecido validação outof-time), onde o treinamento engloba os dados entre 01 janeiro de 2018 e 31 de junho de 2018. Esse cenário avalia se a partir de um histórico recente de meses, é possível prever um padrão de falha futura sobre o mesmo grupo de equipamentos.

O cenário T4 é uma junção do cenário T3 e T2, onde as amostras selecionadas em treinamento e teste vem de vagões diferentes, e ao mesmo tempo fazendo um 
corte no tempo. Esse cenário é supostamente o mais complexo, já que as amostras testadas são de equipamentos diferentes dos usados em treinamento, e ao mesmo tempo testados em uma época diferente do ano.

A tabela 10 apresenta os resultados obtidos pelos modelos treinados em cada um dos cenários de amostragem sobre a rede LSTM, contendo um neurônio treinado de modo supervisionado (ou seja, forçando uma resposta binária quanto a classificação de falha usada como base de comparação), e um grupo de parâmetros de saída processados pelo autoencoder para classificação não supervisionada. Nota-se que a saída supervisionada obteve resultados superiores em relação à saída não supervisionada, alcançando uma diferença aproximada de até 12\% (sobre os cenários T1 e T3) e 4\% sobre F-1 (sobre os cenários T2 e T4), onde a sensibilidade alcançada por ambas é similar (diferença de até 6\%) e a maior disparidade está sobre a precisão (diferença de até 18\% em T1 e 21\% em T3). Entretanto, considerando que a saída não supervisionada aprendeu autonomamente a discriminar as falhas em relação aos resultados normais, o autoencoder mostrou grande capacidade de aprender padrões mesmo sobre as estimativas do modelo.

TABELA 10 - RESULTADOS DE PREDIÇÕES DE FALHAS SOBRE OS DIFERENTES AMOSTRAGENS

\begin{tabular}{|c|c|c|c|c|c|c|}
\hline & \multicolumn{2}{|c|}{ Saída não supervisionada (autoencoder) } & \multicolumn{3}{c|}{ Saída supervisionada } \\
\hline Cenário & Precisão & Sensibilidade & F-1 & Precisão & Sensibilidade & F-1 \\
\hline T1 & $48.33 \%$ & $79.16 \%$ & $60.02 \%$ & $64.10 \%$ & $79.01 \%$ & $70.78 \%$ \\
\hline T2 & $5.68 \%$ & $6.30 \%$ & $5.97 \%$ & $15.21 \%$ & $7.03 \%$ & $9.61 \%$ \\
\hline T3 & $37.93 \%$ & $74.03 \%$ & $54.18 \%$ & $55.82 \%$ & $80.95 \%$ & $66.08 \%$ \\
\hline T4 & $6.59 \%$ & $8.75 \%$ & $7.52 \%$ & $8.31 \%$ & $8.52 \%$ & $8.42 \%$ \\
\hline
\end{tabular}

FONTE: AUTOR

Os cenários que contenham amostras de um mesmo equipamento distribuídas entre treino e teste (T1 e T3) alcançaram resultados consideravelmente superiores em relação aos cenários com separação entre equipamentos (T2 e T4). Esses resultados evidenciam que a manifestação das falhas pode acontecer de modos diferentes sobre instâncias particulares de vagões, e que o período amostral de 1 ano e o tamanho limitado das séries temporais ( 25 períodos) podem ser pouco representativos para percepção de uma evolução do estado de degradação do equipamento. Adicionalmente, observe que mesmo ao separar as amostras em períodos temporais distintos sobre treino e teste (T3 e T4) não foi percebida uma diferença considerável em relação aos respectivos cenários sem tal separação (T1 e T2). 
Isso significa, que durante todo o período avaliado as falhas já poderiam estar presentes, porém se manifestando de modo sutil e intermitente. Quando medições de um equipamento em particular são usadas no treinamento, o modelo supostamente consegue aprender o seu padrão comportamental, e consequentemente quando uma falha (já existente, porém em estado dormente) pode acontecer. Por outro lado, um equipamento não visto em treinamento pode ser comportar de modo parecido, porém com a manifestação da falha acontecendo em situações sutilmente diferentes, indicando que o modelo não conseguiu extrapolar sobre nesses casos.

O comportamento sutil sobre a manifestação da falha é evidenciado pela figura 48 , onde mostra um gráfico de caixas mostrando as medições obtidas sobre cada um dos lapsos da série temporal, em amostras que podem conter ou não falhas (tanto na própria série, quanto no futuro real). Devido à alta dispersão, não é possível notar uma diferença clara de desvio ou formação de tendência sobre quando uma falha irá ocorrer, onde a média e o desvio padrão permanecem praticamente constantes durante toda a série (média próxima de 15 e desvio padrão aproximado de 5). Adicionalmente, pelos os resultados mostrados na tabela 10 nota-se que a separação dos equipamentos entre treino e teste impacta de modo tão elevado, que ao aplicar o corte temporal desempenho obtido é muito pouco perturbado, nos quais os pares de resultados de T2 e T4 (bem como T1 e T3) alcançaram resultados com grandezas similares.

O foco desse experimento foi comparar a robustez e capacidade de detecção do método proposto, que segue uma abordagem livre de conhecimento especialista no domínio (não supervisionada), em relação a uma abordagem supervisionada. Verificou-se que apesar da superioridade da abordagem supervisionada, o meio não supervisionado via autoencoder apresentou resultados promissores, visto que 0 desempenho tem potencial de ser melhorado com o uso adequado de técnicas de interpretabilidade. Os experimentos da seção 6.3.3.2 exploram essa ideia com o RXP pela reclassificação de possíveis falsos positivos e falsos negativos.

O desempenho reduzido obtido nos cenários com a separação de equipamentos foi observado tanto na abordagem supervisionada, quanto a não supervisionada. Como já comentado acima, isso mostra que a limitação nesse caso não estaria relacionada ao método aplicado em si, mas ao fato de que o dado usado talvez seja 
pouco representativo, ou seja, a série temporal aplicada deveria ser mais longa, ou que o dado de treinamento deveria compreender períodos históricos acima de 1 ano. Devido às limitações computacionais existentes e a falta de mais dados, esta pesquisa se limita a explorar os resultados obtidos na tabela 10 sobre os resultados não supervisionados.

FIGURA 48 - PADRÕES DE MEDIÇÕES SOBRE A SÉRIE TEMPORAL EM DIFERENTES SITUAÇÕES
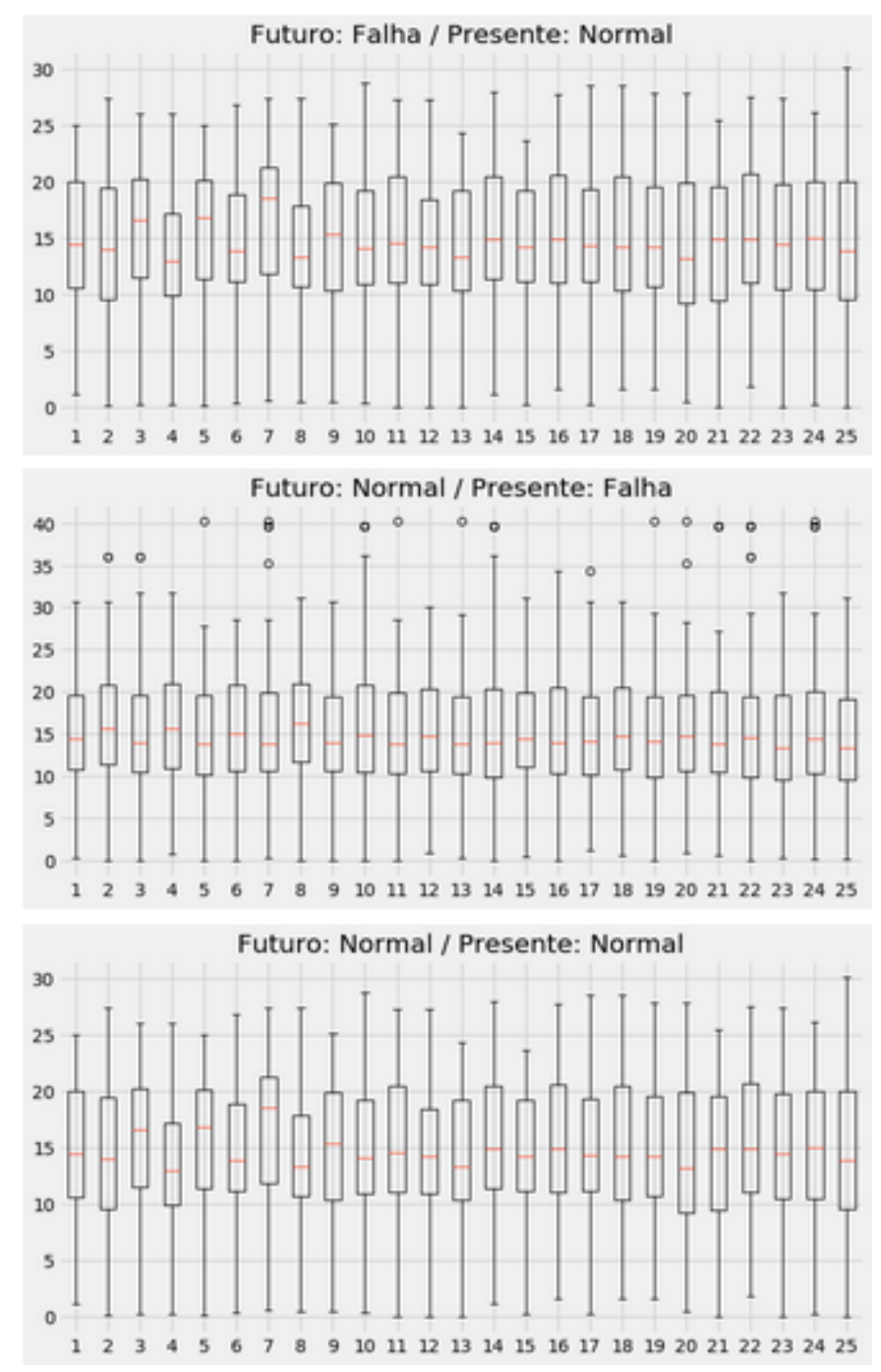

FONTE: AUTOR

\subsubsection{Análise das Interpretações e Ganho de Desempenho Preditivo}

Os experimentos com RXP para prognóstico contemplam a aplicação desse método sobre o conjunto de parâmetros da saída que estimam o comportamento futuro do equipamento. Como resultado, a interpretabilidade constrói uma lista ordenada de relevância sobre os parâmetros da saída (estimativas da rede LSTM e a 
sua respectiva reconstrução pelo autoencoder) e não sobre a entrada original (composta pelas séries temporais). Por outro lado, os métodos tradicionais de interpretabilidade como o SHAP processam a relevância dos resultados em relação a entrada original, assim não sendo possível comparar o desempenho entre as interpretabilidade, já que processam grupos de parâmetros diferentes.

A tabela 11 apresenta o desempenho a respeito do MAP obtido pelo RXP sobre todas as amostras que realmente são falhas (aproximadamente 1,300 amostras distribuídas entre falsos verdadeiros positivos e falsos negativos) classificados pelo autoencoder sobre as estimativas da rede LSTM. Os resultados mostram uma queda expressiva de desempenho do RXP em comparação com o desempenho obtido sobre o diagnóstico em falhas presentes. Independente do desempenho do modelo LSTM + autoencoder na identificação das falhas futuras, o RXP alcançou níveis similares sobre cada um dos cenários de amostras (T1, T2, T3 e T4).

TABELA 11 - RESULTADOS EXPERIMENTAIS RXP SOBRE AS PREDIÇÕES DE FALHAS

\begin{tabular}{|c|c|c|c|c|}
\hline Resultados Gerais & T1 & T2 & T3 & T4 \\
\hline MAP & $22.91 \%$ & $23.09 \%$ & $26.02 \%$ & $24.45 \%$ \\
\hline \multicolumn{5}{|c|}{ FONTE: AUTOR } \\
\end{tabular}

Assim como foi feito nos experimentos de diagnóstico, avaliou-se como o RXP se comporta sobre diferentes tipos de amostras preditas pelo o modelo. Para isso serão selecionadas 200 amostras de diferentes regiões de residuais, como os falsos positivos, falsos negativos, os verdadeiros positivos e negativos próximos da região da fronteira de decisão (região 1), e verdadeiros positivos e negativos com taxas mais elevadas de residuais (região 2) sobre cada um dos cenários de amostras do experimento anterior (T1, T2, T3 e T4).

A figura 49 apresenta o comportamento das variâncias obtidas por amostras e reunidas por cada grupo, conforme destacado acima, onde nota-se uma queda significativa na segregação dos grupos em relação aos resultados obtidos sobre o diagnóstico (figura 43), o que torna mais desafiador o uso do RXP como validação automatizada sobre o resultado da predição. Independente do desempenho preditivo do modelo, a variância das amostras em todas as situações segregação se torna ainda menor, mostrando que o modelo preditivo não consegue estimar com clareza os desvios iminentes do comportamento do equipamento. Isso significa, que a 
distribuição das relevâncias entre os parâmetros está mais homogênea e menos evidente para contestar o resultado obtido. Enquanto o comportamento percebido sobre a detecção de falhas presentes onde o modelo pode ser beneficiado pela calibração de suas respostas com o RXP, o uso similar para prognóstico é prejudicado, visto que a análise ocorre sobre estimativas dos comportamentos, e não sobre o comportamento que acontece de fato.

\section{FIGURA 49 - PADRÕES DE VARIÂNCIA DA RELEVÂNCIA OBTIDOS PELO RXP SOBRE AS ESTIMATIVAS}

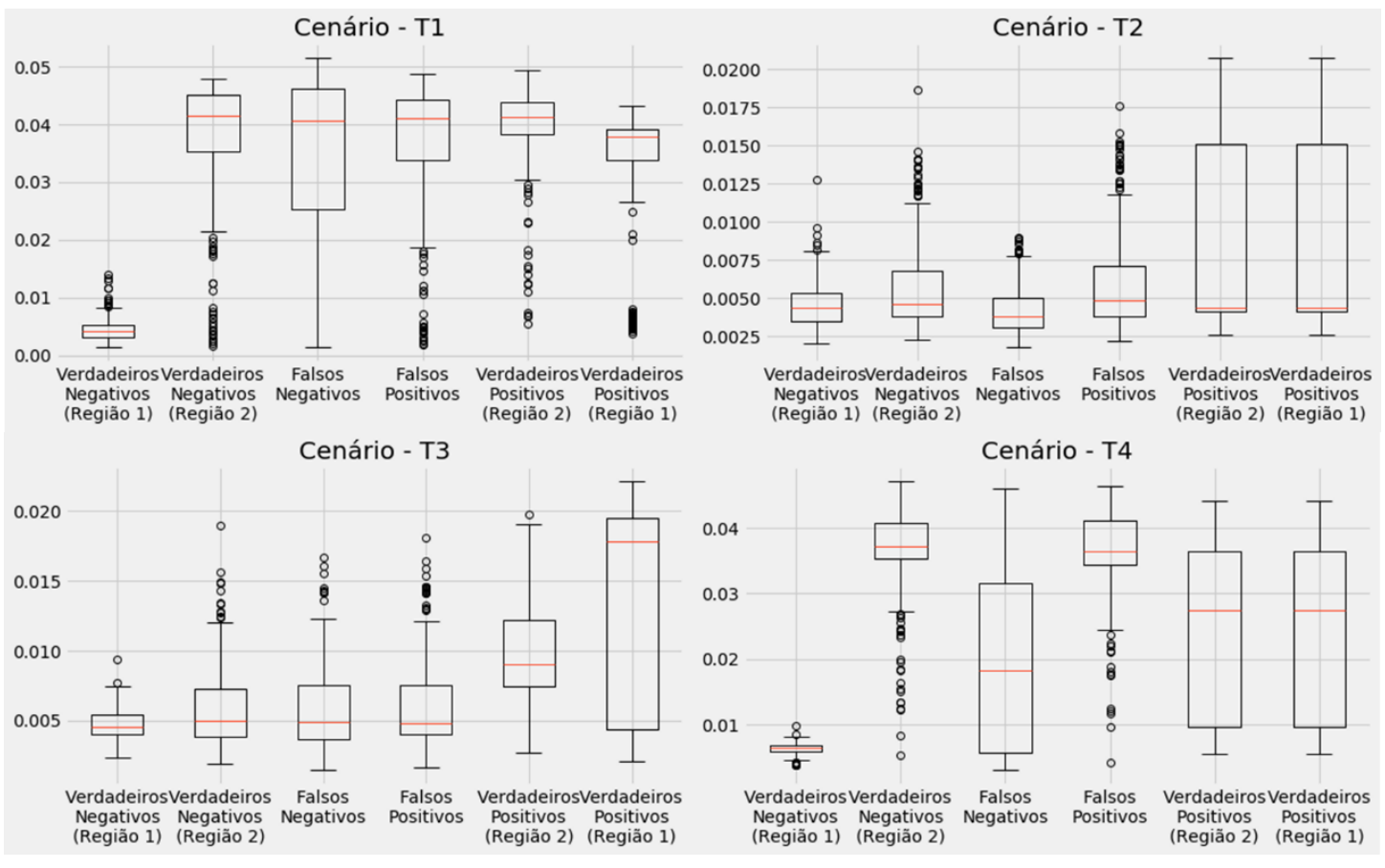

FONTE: AUTOR

Durante os experimentos de diagnóstico, foi percebido que um peso de atribuição muito elevado sobre os parâmetros mais relevantes é um indicador forte que a amostra em questão é falha, e poderia ser usado para complementar o resultado de classificação ao corrigir amostras falso negativas. Aproveitando dessas intuições obtidas sobre experimentos de diagnóstico, a figura 50 mostra qual o peso de atribuição sobre o parâmetro mais relevante dentre os grupos de controle sobre cada um dos cenários de amostras.

Como já constatado na figura 49, os experimentos de interpretação sobre as estimativas não trazem intuições entre os grupos de controle. Todos os cenários de amostras apresentam os parâmetros mais relevantes com pesos equilibrados entre os grupos de controle. A figura 50 apresenta a média de peso atribuída ao parâmetro 
mais relevante obtido pelo $\mathrm{RXP}$. No caso do cenário $\mathrm{T} 1$, apenas o grupo de verdadeiros negativos da região 1 (longe da fronteira de decisão) apresentou um peso aproximado de $20 \%$, enquanto todos os outros grupos apresentaram pesos aproximados de $80 \%$. No caso dos cenários T2 e T3, todos os grupos de controle apresentaram pesos muito similares dentro de seus cenários (aproximados entre 25\% e 30\%). O cenário T4 trouxe uma resposta contraditória ao atribuir pesos mais elevados sobre os falsos positivos e verdadeiros negativos da região 2 (próximos da fronteira de decisão), enquanto a região 1 dos verdadeiros negativos ficou próxima de $30 \%$, e os verdadeiros positivos próximos de $60 \%$.

\section{FIGURA 50 - MÉDIA DE PESO DO PARÂMETRO MAIS RELEVANTE OBTIDO PELO RXP SOBRE OS GRUPOS DE CONTROLE}

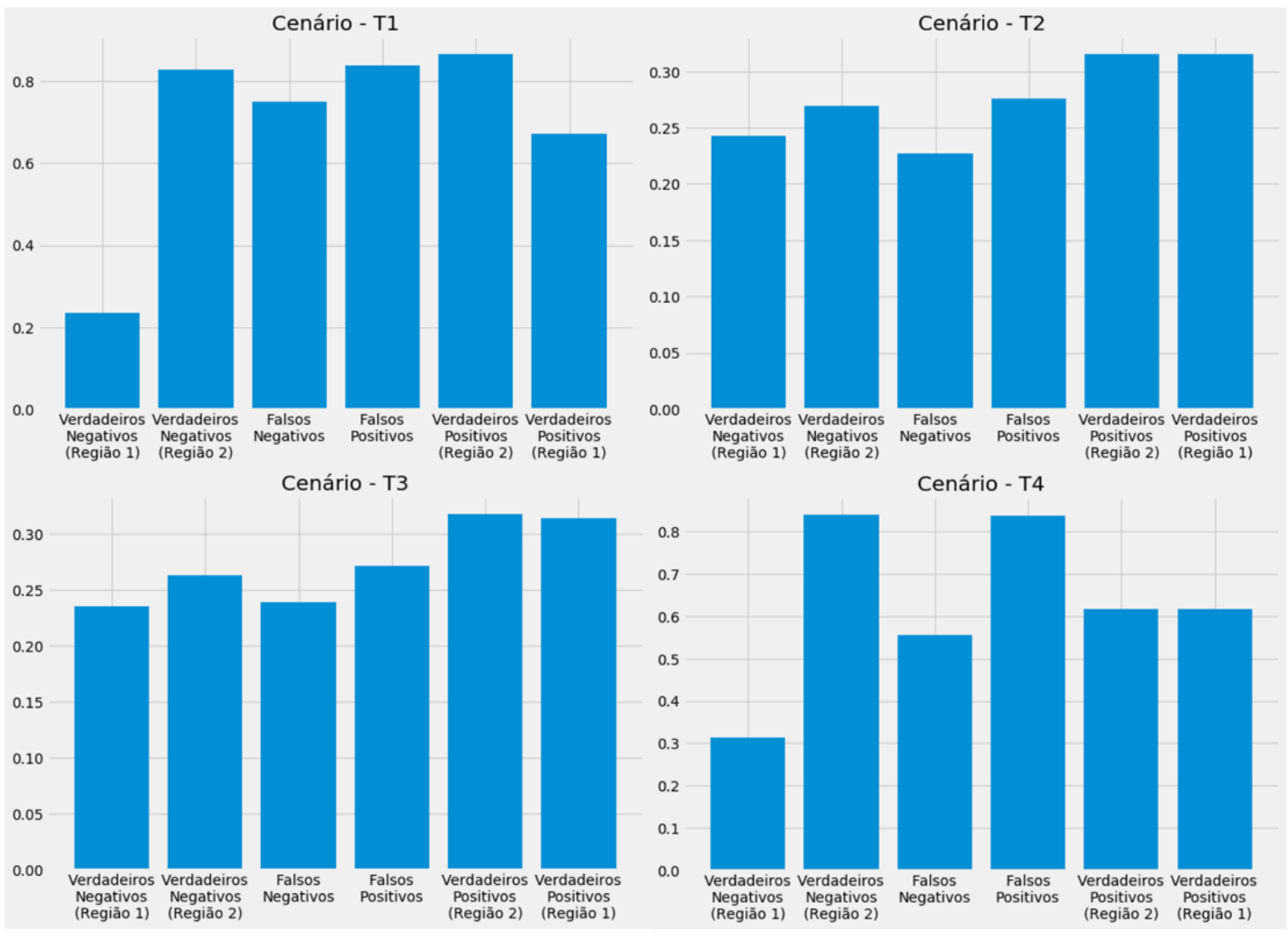

\section{FONTE: AUTOR}

Note que o resultado ótimo esperado seria uma alta disparidade relativa entre normais (verdadeiros negativos e falsos positivos) em relação as falhas (verdadeiros positivos e falsos negativos), como no caso dos experimentos de diagnóstico, sendo obtido com êxito. Desse modo, a atribuição de pesos baixa (como notada em T2 e T3) 
ou elevada (como em T1) é indiferente, sendo que o caracteriza a falta de transparência é a similaridade de pesos atribuídas entre os grupos de controle. 
Apesar da alta capacidade do deep learning para aprender e generalizar problemas complexos, a sua incapacidade em prover um meio que explique, de modo humanamente compreensível, como os resultados de suas predições foram obtidos, dificulta o seu uso em sistemas críticos. Entende-se que a falta de explicações afeta o conceito de dependabilidade a respeito de um serviço ser "justificadamente confiável" (AVIZIENIS et al., 2004).

O uso de técnicas de interpretabilidade acopladas a modelos de deep learning promove um formato de validação que permite conferir se os resultados de predição estão fundamentados em um conjunto factível de parâmetros. Nas áreas financeira e da saúde, o requisito de interpretabilidade é destacado como regulatório na aplicação de técnicas de aprendizado de máquina para automatização para análises e apoio à tomada de decisão. O conhecimento restrito quanto aos limites reais que um equipamento suporta leva à admissão de taxas conservadoras, de forma a mitigar falhas e acidentes, que, no entanto, não impedem a geração e evolução de novas falhas. O conhecimento sobre aspectos das possíveis falhas como modo, geração, evolução e impactos em um sistema é um assunto subjetivo e complexo, e envolve a compressão do inter-relacionamento entre componentes que integram sistema, questões ambientais e o modo de operação aplicado.

As técnicas não supervisionadas mostram-se vantajosas no diagnóstico e prognóstico de falhas, ao possibilitar uma generalização da análise, considerando que a manifestação de anomalias e falhas pode acontecer em novos formatos (CHALAPATHY; CHAWLA, 2019). Por meio do reconhecimento de padrões, situações potenciais de falha podem ser mapeadas antes de sua evolução e manifestação, permitindo a tomada de decisão antecipada, e favorecendo a preservação do material e a confiança sobre o serviço entregue. Os métodos de detecção de falhas não supervisionadas devem ser capazes de suprir o conhecimento vigente, ou seja, minimamente possui uma alta capacidade de capturar as falhas sobre medições que quebram as regras de segurança operacionais.

Abaixo será sumarizado as contribuições alcançadas neste trabalho, bem como algumas limitações e sugestões de trabalhos futuros. 


\subsection{CONTRIBUIÇÕES E LIMITAÇÕES}

As contribuições desta pesquisa estão relacionadas à viabilização de ganho de confiança e ganho de conhecimento, por um método genérico ao domínio do problema. O ganho de confiança refere-se ao provimento de transparência e à constatação de que as predições obtidas por métodos de aprendizado "caixa-preta" são razoáveis. $O$ ganho de conhecimento está relacionado à apresentação de método de exploração e descoberta de novos modos de falha, pela análise de padrões de problemas ainda incipientes no sistema e que não ferem as regras de limites operacionais. Adicionalmente é sugerido um meio de automatizar o uso do método de interpretabilidade como um fator de ajuste no processo de decisão sobre o método de detecção de falhas.

Essa pesquisa explorou o autoencoder como um método não supervisionado baseado na reconstrução, onde entende-se que o aprendizado foca em compreender como é o comportamento normal do equipamento, e tudo que se desvie (com uma certa taxa de tolerância) é considerado uma falha. Essa filosofia promove um ganho quanto a generalização do método, visto que a falha pode se manifestar de modos imprevisíveis.

Sobre os resultados de detecção obtidos, esse trabalho propõe o uso técnicas de interpretabilidade como uma abordagem para diagnosticar as falhas identificadas, visto que esse recurso traz alguma transparência que justifique sobre uma decisão obtida. Considerando um método de deteç̧ão baseado em reconstrução como referência para identificação das falhas, foi desenvolvido um método próprio para interpretação dos resultados obtidos (Residual eXPlainer - RXP), onde foi mostrado grande potencial para uso prático, obtendo ganhos expressivos em custo computacional (sendo milhares de vezes mais rápido que o SHAP), e ao mesmo tempo mantendo a superioridade descritiva sobre a recomendação dos parâmetros.

Foi percebido que ao calcular a variância sobre o conjunto de pesos de relevâncias entre os parâmetros, o RXP foi capaz de discriminar com grande qualidade as amostras entre normais e falhas. As amostras normais tenderam a apresentar uma distribuição de relevância de modo mais equilibrado, enquanto as falhas apresentavam um peso concentrado sobre o parâmetro mais relevante. Desse 
modo, foi visto que o RXP pode ser usado como um método automático para a ajustar o processo decisão de detectores, provendo ganhos expressivos de desempenho sobre métodos com a fronteira decisão inapropriada.

A subjetividade contida ao discriminar falhas em algumas situações pode ser mais bem explorada em trabalhos futuros, para identificar novos modos de falha em um estado incipiente, em casos que as regras operacionais (ou o conhecimento atualmente vigente) não leva em consideração. É colocada a hipótese que a aplicação do RXP associado a técnicas de clustering para reconhecimento de padrões, não somente sobre as observações, mas também sobre as explicações provenientes dos modelos de interpretabilidade, são uma rica fonte dados para investigação, e que podem gerar conhecimento de forma autônoma.

No que diz respeito ao prognóstico, a tarefa de identificar as falhas sobre estimativas comportamentais se mostrou desafiadora. A natureza da tarefa de identificação de anomalias e falhas envolve a análise sobre eventos raros, o que traz um desafio preditivo sobre alto desbalanceamento dos dados, além da própria aleatoriedade sobre o modo como esse tipo de evento pode ocorrer. A filosofia adotada em detecção sobre aprender o comportamento normal do equipamento, para então discriminar as falhas também foi adotada no prognóstico, porém com ganhos mais limitados devido a passo anterior de predição do comportamento do equipamento. As técnicas de reamostragem (oversampling) se mostraram fundamentais para o treinamento mais apropriado do modelo. Esse detalhe é importante, pois destaca o desafio ao tentar aplicar uma abordagem integralmente não supervisionada, visto que o oversampling deve replicar as amostras que supostamente são falhas, o que exige conhecimento especialista para a seleção dessas ocorrências.

A limitação preditiva é notável ao analisar resultados experimentais sobre a predição de falhas, onde foi testada sobre 4 cenários de amostragens, e assume-se níveis graduais de dificuldade sobre a modelagem. Os cenários combinam amostragens distintas sobre treinamento e teste, considerando a segregação (ou não) dos mesmos equipamentos e avaliação sobre períodos temporais diferentes (ou não). Enquanto a diferença no período temporal não causou grande impacto nos resultados, foi percebido uma queda expressiva no desempenho ao tentar prever falhas em 
equipamentos novos, mostrando a natureza das falhas de se manifestarem de modos completamente diferentes. Ao aplicar o RXP sobre as predições, nota-se também uma queda na transparência quanto a segregação em observações normais e em falha, e que se torna mais amplificada à medida que o resultado preditivo do modelo decai. Esses resultados mostram que a dificuldade do modelo preditivo em estimar com qualidade e clareza quando um equipamento tende a se desviar de fato. Novos métodos de análises devem ser pensados em desenvolvidos para contornar as limitações encontradas atualmente.

Sob a perspectiva de aplicar o método proposto em um problema real de operação, os resultados preditivos sobre os cenários sem a separação de equipamentos alcançaram resultados interessantes. Apesar do desempenho reduzido em relação ao diagnóstico de uma falha existente, esse recurso permite que a equipe de operação tenha algum indício (até então inexistente) antecipado e possa se planejar antecipadamente com assertividade razoável (considerando que a frequência de eventos inesperados é baixíssima, sendo inferior a 1\%). Mesmo com a queda do desempenho do RXP sobre as estimativas, esse método pode manter contribuição significativa para uma investigação mais direcionada acerca da fonte do problema, trazendo mais agilidade no processo de manutenção. A geração dos pesos de relevância sobre cada um dos parâmetros para cada amostra interpretada gera um conjunto de dados totalmente novo, com características diferentes da entrada nativa.

Do mesmo modo que esta pesquisa identificou um meio de usufrui do RXP para ajustar e melhor os resultados de detecção sobre falhas presentes, existe uma possibilidade que outros métodos possam ser desenvolvidos para extrair informações de valor quanto ao prognóstico.

\section{T.2 SUGESTÕES DE TRABALHOS FUTUROS}

Seguem abaixo algumas sugestões de trabalhos futuros que são entendidas como relevantes em relação ao progresso do resultado obtido por esta pesquisa.

1) Estimação de incerteza dos resultados em atividades de detecção, diagnóstico e prognóstico de falhas. 
Motivação: A pesquisa atual explorou o uso de técnicas de deep learning e de interpretabilidade para prover estimativas pontuais sobre as atividades de detecção, diagnóstico e prognóstico de falhas. Contudo, a mensuração do grau de incerteza dos resultados obtidos não foi escopo desta pesquisa. Por isso, entende-se que a inclusão de métodos bayesianos sobre a modelagem realizada nesta pesquisa possibilitaria estimar o grau de incerteza dos resultados obtidos, o que promoveria um ganho de confiança $e$, consequentemente, maior assertividade e eficiência na aplicação dos resultados em um cenário real de manutenção.

\section{2) Expansão do método proposto sobre a exploração para séries temporais}

Motivação: A pesquisa atual produziu um conjunto de modelos que, durante sua operação, é capaz de realizar a detecção e diagnóstico de falhas com base no status atual dos elementos avaliados. Ou seja, os modelos de detecção e diagnóstico utilizam apenas a leitura dos dados do elemento de campo avaliado em um determinado instante de tempo, não considerando os dados históricos daquele elemento. No caso do prognóstico, a predição utiliza sua sequência histórica de tamanho pré-definido, e apesar do método permitir a predições de múltiplos períodos futuros, os experimentos focaram na predição apenas lapso temporal seguinte (devido à alta propagação de erro ao ampliar o horizonte preditivo). Mesmo com as premissas limitantes colocadas, o método RXP não obteve resultados tão satisfatórios quanto os que foram alcançados sobre o diagnóstico de falhas presentes. Portanto, entende-se que existe um caminho a ser explorado para adaptação e evolução do método sobre séries temporais, que permitiriam a não somente a detecção, diagnóstico de falhas considerando fontes de anomalias identificadas entre os lapsos temporais, mas também uma evolução mais significativa sobre a identificação das fontes de falhas no prognóstico.

Observação: A forma de avaliação desse estudo pode ser subjetiva, visto que os achados encontrados seriam suposições de equipamentos que estariam em estado de falha que fogem das regras atualmente adotadas (que se baseiam em regras simples quando uma medição é aferida acima de um limite pré-definido). Portanto, os resultados obtidos deveriam ser comprovados por históricos de 
manutenções ou verificações com o time de oficina para constatar se a falha realmente existia. Adicionalmente, deve ser usada uma infraestrutura computacional adequada para flexibilizar os cenários experimentais pela ampliação dos lapsos temporais da entrada e da saída.

\section{3) Utilização das anotações operacionais (oficina e equipe de campo) para enriquecimento da modelagem dos modelos preditivos}

Motivação: As anotações feitas pelo time de manutenção são informações valiosas que fornecem contextos diferentes sobre as medições dos sensores. $O$ tratamento e integração adequados destas informações podem enriquecer os conjuntos de dados existentes, permitindo uma modelagem supervisionada mais ampla e fiel ao contexto real da operação. Do ponto de vista de pesquisa, é um problema desafiador, que pode envolver técnicas de processamento de linguagem natural (NLP) para tratar dados não estruturados provenientes das anotações em texto livre realizadas pelos profissionais de manutenção.

Observação: Os dados fornecidos atualmente são muito pouco representativos em relação a todos os eventos que acontecem na operação, o que pode trazer uma dificuldade sobre os experimentos.

\section{4) Monitoramento da operação feito em tempo real sobre grandes volumes de dados}

Motivação: Uma parte desafiadora dessa pesquisa foi a preparação dos dados para uma modelagem adequada. Vale notar que, na abordagem atual (adotada na presente pesquisa), o processo de tratamento completo do dado bruto (proveniente de múltiplos sensores) até a modelagem para o prognóstico consome aproximadamente 24 horas. Em um cenário real de aplicação, o uso de técnicas de Big Data se torna um requisito fundamental, permitindo a criação de um pipeline completo, desde a captura de um fluxos de dados de múltiplas fontes de sensores, processamento, até a modelagem tempo real considerando os dados recém processados, associados ao histórico massivo de medições tratadas previamente. 
Observação: Para comprovação sobre a efetividade da pesquisa, necessitaria de uma infraestrutura computacional adequada para os experimentos.

5) Método preditivo para possibilitar extrapolação do aprendizado sobre comportamentos anômalos.

Motivação: Conforme discutido e comentado ao longo desta pesquisa, apesar da grande capacidade preditiva provida pelos métodos de deep learning para aprender e generalizar (também conhecido como interpolação) problemas similares aos apresentados sobre os dados de treinamento, eles tendem a falhar em casos onde são apresentados valores de parâmetros e objetivos de predição que vão além do conhecido (extrapolação). A capacidade de extrapolação de modelos preditivos é um grande desafio científico do aprendizado de máquina, e quando relacionado a aplicação em sistemas críticos, poderia trazer um enorme ganho prático, ao prover maior confiança sobre os comportamentos desses modelos mesmo em eventos imprevisíveis, e com grande grau de risco. 


\section{REFERÊNCIAS}

AHMAD, R.; KAMARUDDIN, S. An overview of time-based and condition-based maintenance in industrial application. Computers and Industrial Engineering, v. 63, n. 1, p. 135-149, 2012. Disponível em: $<$ http://dx.doi.org/10.1016/j.cie.2012.02.002>. ALASWAD, S.; XIANG, Y. A review on condition-based maintenance optimization models for stochastically deteriorating system. Reliability Engineering \& System Safety, v. 157, p. 54-63, 1 jan. 2017. Disponível em:

$<$ https://www.sciencedirect.com/science/article/pii/S0951832016303714>. Acesso em: 13 ago. 2019.

AMIGÓ, E. A comparison of Extrinsic Clustering Evaluation Metrics based on Formal Constraints Technical Report. p. 1-32, 2008.

ANTT. Mapa da Malha da Estrada de Ferro Vitória a Minas. Disponível em: <http://appweb2.antt.gov.br/concessaofer/efvm/mapa_efvm.asp>. Acesso em: 16 jul. 2019.

ASSAF, R.; NEFTI-MEZIANI, S.; SCARF, P. Unsupervised learning for improving fault detection in complex systems. IEEE/ASME International Conference on Advanced Intelligent Mechatronics, AIM, p. 1058-1064, 2017.

AVIZIENIS, A. et al. Basic concepts and taxonomy of dependable and secure computing. IEEE Transactions on Dependable and Secure Computing, v. 1, n. 1, p. 11-33, jan. 2004. Disponível em: <http://ieeexplore.ieee.org/document/1335465/>. Acesso em: 25 ago. 2019.

BEKKAR, M.; ALITOUCHE, T. A. Imbalanced Data Learning Approaches Review. International Journal of Data Mining \& Knowledge Management Process, v. 3, n. 4, p. 15-33, 31 jul. 2013.

BÉLISLE, E. et al. Evaluation of machine learning interpolation techniques for prediction of physical properties. Computational Materials Science, v. 98, p. 170177, 15 fev. 2015.

BENGIO, Y.; SIMARD, P.; FRASCONI, P. Learning long-term dependencies with gradient descent is difficult. IEEE Transactions on Neural Networks, v. 5, n. 2, p. 157-166, mar. 1994. Disponível em: 
<https://ieeexplore.ieee.org/document/279181/>. Acesso em: 26 set. 2019.

BOX, G. E. P.; JENKINS, G. M.; REINSEL, G. C. Time Series Analysis:

Forecasting and Control. [s.l: s.n.]

$\mathrm{CAO}, \mathrm{H}$. et al. Integrated oversampling for imbalanced time series classification.

IEEE Transactions on Knowledge and Data Engineering, v. 25, n. 12, p. 28092822, 2013.

CHAKRABORTY, S. et al. Interpretability of deep learning models: A survey of results. In: 2017 IEEE SmartWorld, Ubiquitous Intelligence \& Computing, Advanced \& Trusted Computed, Scalable Computing \& Communications, Cloud \& Big Data Computing, Internet of People and Smart City Innovation

(SmartWorld/SCALCOM/UIC/ATC/CBDCom/IOP/SCI), Anais...IEEE, ago. 2017. Disponível em: <https://ieeexplore.ieee.org/document/8397411/>. Acesso em: 19 set. 2019.

CHALAPATHY, R.; CHAWLA, S. Deep Learning for Anomaly Detection: A Survey. p. 1-50, 2019. Disponível em: <http://arxiv.org/abs/1901.03407>.

CONNOR, P. Train Maintenance | The Railway Technical Website | PRC Rail

Consulting Ltd. Disponível em: <http://www.railway-technical.com/trains/trainmaintenance/>. Acesso em: 2 jul. 2019.

CYBENKO, G. Approximation by superpositions of a sigmoidal function.

Mathematics of Control, Signals, and Systems, v. 2, n. 4, p. 303-314, dez. 1989.

Disponível em: <http://link.springer.com/10.1007/BF02551274>. Acesso em: 24 set. 2019.

DOMINGOS, P. A few useful things to know about machine learning.

Communications of the ACM, v. 55, n. 10, p. 78, 1 out. 2012. Disponível em: <http://dl.acm.org/citation.cfm?doid=2347736.2347755>. Acesso em: 21 ago. 2019.

DOMINGUES, R. et al. A comparative evaluation of outlier detection algorithms:

Experiments and analyses. Pattern Recognition, v. 74, p. 406-421, 2018.

DOSHI-VELEZ, F.; KIM, B. Towards A Rigorous Science of Interpretable Machine Learning. n. Ml, p. 1-13, 2017. Disponível em: <http://arxiv.org/abs/1702.08608>.

DU, M.; LIU, N.; HU, X. Techniques for Interpretable Machine Learning. 2019.

EIM; EFRTC; CER. Report from the EIM-EFRTC-CER Working Group on Market 
Strategies for Track Maintenance \&amp; Renewal | CER:Home. Disponível em: $<$ http://www.cer.be/publications/brochures-studies-and-reports/report-eim-efrtc-cerworking-group-market-strategies>. Acesso em: 5 jul. 2019.

ELSHAWI, R. et al. Interpretability in HealthCare A Comparative Study of Local Machine Learning Interpretability Techniques. p. 275-280, 2019.

FENG, Z.; LIANG, M.; CHU, F. Recent advances in time-frequency analysis methods for machinery fault diagnosis: A review with application examples. Mechanical Systems and Signal Processing, v. 38, n. 1, p. 165-205, 2013. Disponível em: <http://dx.doi.org/10.1016/j.ymssp.2013.01.017>.

GARCHERY, M.; GRANITZER, M. On the influence of categorical features in ranking anomalies using mixed data. In: Procedia Computer Science, Anais...Elsevier B.V., 1 jan. 2018.

GBMX. Vagão Gôndola GDE - GBMX. Disponível em:

<http://gbmx.com.br/negocios/vagao-gondola-gde/>. Acesso em: 12 set. 2019.

GILPIN, L. H. et al. Explaining explanations: An overview of interpretability of machine learning. Proceedings - 2018 IEEE 5th International Conference on Data Science and Advanced Analytics, DSAA 2018, p. 80-89, 2019.

GOLDSTEIN, M.; UCHIDA, S. A Comparative Evaluation of Unsupervised Anomaly Detection Algorithms for Multivariate Data. PLOS ONE, v. 11, n. 4, p. e0152173, 19 abr. 2016. Disponível em: <https://dx.plos.org/10.1371/journal.pone.0152173>. Acesso em: 19 ago. 2019.

GONZALEZ, C. What's the Difference Between Bearings ? 2015.

GREFF, K. et al. LSTM: A Search Space Odyssey. IEEE Transactions on Neural Networks and Learning Systems, v. 28, n. 10, p. 2222-2232, 2017.

GREZMAK, J. et al. Explainable convolutional neural network for gearbox fault diagnosis. Procedia CIRP, v. 80, p. 476-481, 2019. Disponível em: $<$ https://doi.org/10.1016/j.procir.2018.12.008>. HASHEMIAN, H. M.; BEAN, W. C. State-of-the-Art Predictive Maintenance Techniques*. IEEE Transactions on Instrumentation and Measurement, v. 60, n. 10, p. 3480-3492, out. 2011. Disponível em: <http://ieeexplore.ieee.org/document/5754581/>. Acesso em: 23 jul. 2019. 
HOCHREITER, S.; SCHMIDHUBER, J. Long Short-Term Memory. Neural Computation, v. 9, n. 8, p. 1735-1780, 13 nov. 1997. Disponível em: <http://www.mitpressjournals.org/doi/10.1162/neco.1997.9.8.1735>. Acesso em: 26 set. 2019.

HORNIK, K.; STINCHCOMBE, M.; WHITE, H. Multilayer feedforward networks are universal approximators. Neural Networks, v. 2, n. 5, p. 359-366, 1 jan. 1989. Disponível em: <https://www.sciencedirect.com/science/article/pii/0893608089900208>. Acesso em: 24 set. 2019.

ISERMANN, R. Fault-Diagnosis Applications. Berlin, Heidelberg: Springer Berlin Heidelberg, 2011.

JAMIL, F. et al. Annals of Nuclear Energy Fault diagnosis of Pakistan Research Reactor-2 with data-driven techniques. Annals of Nuclear Energy, v. 90, p. 433440, 2016. Disponível em: <http://dx.doi.org/10.1016/j.anucene.2015.12.023>. JANSEN, C. et al. Feature relevance in physiological networks for classification of obstructive sleep apnea. Physiological Measurement, v. 39, n. 12, 2018.

JARDINE, A. K. S.; LIN, D.; BANJEVIC, D. A review on machinery diagnostics and prognostics implementing condition-based maintenance. Mechanical Systems and Signal Processing, v. 20, n. 7, p. 1483-1510, 1 out. 2006. Disponível em: <https://www.sciencedirect.com/science/article/pii/S0888327005001512>. Acesso em: 8 ago. 2019.

JIANG, W. et al. A Novel GAN-based Fault Diagnosis Approach for Imbalanced Industrial Time Series. p. 1-6, 2019. Disponível em:

<http://arxiv.org/abs/1904.00575>.

KAUWE, S. K. et al. Can machine learning find extraordinary materials?

Computational Materials Science, v. 174, p. 109498, 1 mar. 2020.

KHALID, S.; KHALIL, T.; NASREEN, S. A survey of feature selection and feature extraction techniques in machine learning. Proceedings of 2014 Science and Information Conference, SAI 2014, p. 372-378, 2014.

KHAN, S.; YAIRI, T. A review on the application of deep learning in system health management. Mechanical Systems and Signal Processing, v. 107, p. 241-265, 1 
jul. 2018. Disponível em:

$<$ https://www.sciencedirect.com/science/article/pii/S0888327017306064>. Acesso em: 29 set. 2019.

KHARCHE, P. P. Review of Fault Detection in Rolling Element Bearing. International Journal of Innovative Research in Advanced Engineering, v. 1, n. 5, p. 169-174, 2014.

KIEU, T. et al. Outlier Detection for Time Series with Recurrent Autoencoder Ensembles. p. 2725-2732, 2019.

$\mathrm{KIM}, \mathrm{N}$. H.; CHOI, J. H.; AN, D. Prognostics and health management of engineering systems: An introduction. [s.l: s.n.]

KINNISON, H. A.; SIDDIQUI, T. Aviation maintenance management. [s.I.] McGraw-Hill, 2013.

KOTSIANTIS, S.; KANELLOPOULOS, D.; PINTELAS, P. Handling imbalanced datasets : A review. Science, v. 30, n. 1, p. 25-36, 2006. Disponível em: $<$ http://citeseerx.ist.psu.edu/viewdoc/download?doi=10.1.1.96.9248\&amp;rep=rep1\& amp;type=pdf>.

KOVALERCHUK, B.; NEUHAUS, N. Toward Efficient Automation of Interpretable Machine Learning. Proceedings - 2018 IEEE International Conference on Big Data, Big Data 2018, p. 4940-4947, 2019.

KRAUS, M.; FEUERRIEGEL, S. Forecasting remaining useful life: Interpretable deep learning approach via variational Bayesian inferences. Decision Support Systems, v. 125, 2019.

KRIEGEL, H.-P.; SCHUBERT, M.; ZIMEK, A. Angle-Based Outlier Detection in High-dimensional Data. [s.l: s.n.]

LAZAREVIC, A.; KUMAR, V. Feature bagging for outlier detection. In: Proceedings of the ACM SIGKDD International Conference on Knowledge Discovery and Data Mining, Anais...2005.

LECUN, Y.; BENGIO, Y.; HINTON, G. Deep learning. Nature, v. 521, n. 7553, p. 436-444, 27 maio 2015. Disponível em:

<http://www.nature.com/articles/nature14539>. Acesso em: 5 jul. 2019.

LI F.; JOHNSON J.; YEUNG S. Recurrent Neural Networks. Disponível em: 
<http://cs231n.stanford.edu/slides/2017/cs231n_2017_lecture10.pdf>. Acesso em: 25 set. 2019.

LIANG, G. An effective method for imbalanced time series classification: Hybrid sampling. In: Lecture Notes in Computer Science (including subseries Lecture Notes in Artificial Intelligence and Lecture Notes in Bioinformatics), Anais...Springer, Cham, 2013. Disponível em: <https://link.springer.com/chapter/10.1007/978-3-319-036809_38>. Acesso em: 22 jul. 2020.

LIDÉN, T. Railway Infrastructure Maintenance - A Survey of Planning Problems and Conducted Research. Transportation Research Procedia, v. 10, p. 574-583, 1 jan. 2015. Disponível em:

<https://www.sciencedirect.com/science/article/pii/S2352146515001982>. Acesso em: 5 jul. 2019.

LIPTON, Z. C. The mythos of model interpretability. Communications of the ACM, v. 61 , n. 10 , p. $35-43,2018$.

LIU, F. T.; TING, K. M.; ZHOU, Z.-H. Isolation Forest. In: 2008 Eighth IEEE International Conference on Data Mining, Anais...IEEE, dez. 2008. Disponível em: <http://ieeexplore.ieee.org/document/4781136/>. Acesso em: 4 set. 2019.

LIU, Q. et al. Manufacturing system maintenance based on dynamic programming model with prognostics information. Journal of Intelligent Manufacturing, v. 30, n. 3, p. 1155-1173, 27 mar. 2019. Disponível em:

<http://link.springer.com/10.1007/s10845-017-1314-6>. Acesso em: 5 jul. 2019.

LU, C. et al. Fault diagnosis of rotary machinery components using a stacked denoising autoencoder-based health state identification. Signal Processing, v. 130, p. 377-388, 1 jan. 2017. Disponível em:

$<$ https://www.sciencedirect.com/science/article/pii/S0165168416301797>. Acesso em: 11 set. 2019.

LUNDBERG, S. M. et al. Explainable machine-learning predictions for the prevention of hypoxaemia during surgery. Nature Biomedical Engineering, v. 2, n. 10, p. 749760, 10 out. 2018. Disponível em: <http://www.nature.com/articles/s41551-018-0304$0>$.

LUNDBERG, S. M.; LEE, S. A Unified Approach to Interpreting Model Predictions. n. Section 2, p. 1-10, 2017. 
LÜTKEPOHL, H. New introduction to multiple time series analysis. [s.I.] New York, 2005.

MAKHZANI, A.; FREY, B.; GOODFELLOW, I. Adversarial Autoencoders. 2014.

MALHOTRA, P. et al. Multi-Sensor Prognostics using an Unsupervised Health Index based on LSTM Encoder-Decoder. 2016. Disponível em:

<http://arxiv.org/abs/1608.06154>.

MARCUS, G. Deep Learning: A Critical Appraisal. 2 jan. 2018. Disponível em: <http://arxiv.org/abs/1801.00631 >. Acesso em: 2 ago. 2019.

MICENKOVÁ, B.; MCWILLIAMS, B.; ASSENT, I. Learning Outlier Ensembles : The Best of Both Worlds - Supervised and Unsupervised. Proc. of the ACM SIGKDD Workshop on Outlier Detection and Description, ODD., p. 1-4, 2014. MOBLEY, R. K. An Introduction to Predictive Maintenance. [s.I.] ButterworthHeinemann, 2002.

MURDOCH, W. J. et al. Interpretable machine learning: definitions, methods, and applications. p. 1-11, 2019. Disponível em: <http://arxiv.org/abs/1901.04592>.

NÓBREGA, C.; MARINHO, L. Towards explaining recommendations through local surrogate models. Proceedings of the ACM Symposium on Applied Computing, v. Part F1477, p. 1671-1678, 2019.

OLAH, C. Understanding LSTM Networks. Disponível em: <http://colah.github.io/posts/2015-08-Understanding-LSTMs/>. Acesso em: 26 set. 2019.

PLASTRIA, F.; DE BRUYNE, S.; CARRIZOSA, E. Dimensionality reduction for classification, comparison of techniques and dimension choice. Lecture Notes in Computer Science (including subseries Lecture Notes in Artificial Intelligence and Lecture Notes in Bioinformatics), v. 5139 LNAI, n. September 2014, p. 411418, 2008a.

PLASTRIA, F.; DE BRUYNE, S.; CARRIZOSA, E. Dimensionality Reduction for Classification. In: [s.I.] Springer, Berlin, Heidelberg, 2008b. p. 411-418.

QU, Y. et al. Gear pitting fault diagnosis using disentangled features from unsupervised deep learning. I2MTC 2018 - 2018 IEEE International Instrumentation and Measurement Technology Conference: Discovering New 
Horizons in Instrumentation and Measurement, Proceedings, p. 1-6, 2018. RIBEIRO, M. T.; GUESTRIN, C. “Why Should I Trust You ?” Explaining the Predictions of Any Classifier. 2016.

RODRIGUES, D.; LAVORATO, P. Maintenance, Repair and Overhaul (MRO) Fundamentals and Strategies: An Aeronautical Industry Overview. International Journal of Computer Applications, v. 135, n. 12, p. 21-29, 2016.

SÁBITZ, L.; KOLONITS, F. Finite element and analytical computation of flash temperature. v. 3, p. 267-278, 2014.

SAED SAYAD. Multi-layer Perceptron. Disponível em:

<http://www.saedsayad.com/artificial_neural_network_bkp.htm>. Acesso em: 24 set. 2019.

SCHNEIDER, P. Freight car trucks and carbodies - Key components of a freight car. Disponível em: <http://trn.trains.com/railroads/abcs-ofrailroading/2006/05/freight-car-trucks-and-carbodies>. Acesso em: 11 set. 2019.

$\mathrm{SHAO}, \mathrm{H}$. et al. A novel method for intelligent fault diagnosis of rolling bearings using ensemble deep auto-encoders. Mechanical Systems and Signal Processing, v. 102, p. 278-297, 2018. Disponível em:

<https://doi.org/10.1016/j.ymssp.2017.09.026>.

SHAPLEY, L. S. A Value for n-Person Games. In: KUHN, H. W.; TUCKER, A. W. (Ed.). Contributions to the Theory of Games (AM-28), Volume II. Princeton: Princeton University Press, 1953. p. 307-318.

SHIN, J. H.; JUN, H. B. On condition based maintenance policy. Journal of Computational Design and Engineering, v. 2, n. 2, p. 119-127, 2015. Disponível em: <http://dx.doi.org/10.1016/j.jcde.2014.12.006>.

SHRIKUMAR, A.; GREENSIDE, P.; KUNDAJE, A. Learning Important Features Through Propagating Activation Differences. 9 abr. 2017. Disponível em: <http://arxiv.org/abs/1704.02685>. Acesso em: 23 set. 2019.

SIELLY, B.; COSTA, J. Fully unsupervised fault detection and identification based on recursive density estimation and self-evolving cloud-based classifier Fully Unsupervised Fault Detection and Identification Based on Recursive Density Estimation and Self-evolving Cloud-based . n. October, 2014. 
SMITH, D. J. (David J. Reliability, maintainability, and risk : practical methods for engineers. [s.I.] Butterworth-Heinemann/Elsevier, 2011.

SPIROIU, M.; NICOLESCU, M. Failure modes analysis of railway wheel. v. 06005, p. 1-6, 2018.

STERN, S. et al. The Rail Sector's Changing Maintenance Game. McKinsey Study, p. 22, 2017. Disponível em:

$<$ https://www.mckinsey.com/ /media/mckinsey/industries/travel transport and logistics/our insights/the rail sectors changing maintenance game/the-rail-sectorschanging-maintenance-game.ash $x>$.

TAM, A. S. B.; CHAN, W. M.; PRICE, J. W. H. Optimal maintenance intervals for a multi-component system. Production Planning \& Control, v. 17, n. 8, p. 769-779, 21 dez. 2006. Disponível em:

<https://www.tandfonline.com/doi/full/10.1080/09537280600834452>. Acesso em: 1 ago. 2019.

TROGER, P.; FEINBUBE, L.; WERNER, M. WAP: What activates a bug? A refinement of the Laprie terminology model. In: 2015 IEEE 26th International Symposium on Software Reliability Engineering (ISSRE), Anais...IEEE, nov. 2015. Disponível em: <http://ieeexplore.ieee.org/document/7381804/>. Acesso em: 3 set. 2019.

UIC. Statistics - International Union of Railways (UIC). Disponível em: <https://uic.org/statistics\#Rail-transport-in-the-world>. Acesso em: 2 jul. 2019.

USHER, J. S.; KAMAL, A. H.; SYED, W. H. Cost optimal preventive maintenance and replacement scheduling. IIE Transactions, v. 30, n. 12, p. 1121-1128, 1998.

Disponível em: <http://link.springer.com/10.1023/A:1007524100829>. Acesso em: 1 ago. 2019.

ZAKHAROV, S. M.; GORYACHEVA, I. G. Rolling contact fatigue defects in freight car wheels. v. 258, p. 1142-1147, 2005.

ZHANG, S. et al. Machine Learning and Deep Learning Algorithms for Bearing Fault Diagnostics - A Comprehensive Review. [s.I: s.n.].

ZHU, T.; LIN, Y.; LIU, Y. Oversampling for Imbalanced Time Series Data. 2019. Disponível em: <https://doi.org/10.1145/nnnnnnn.nnnnnnn>. 
